

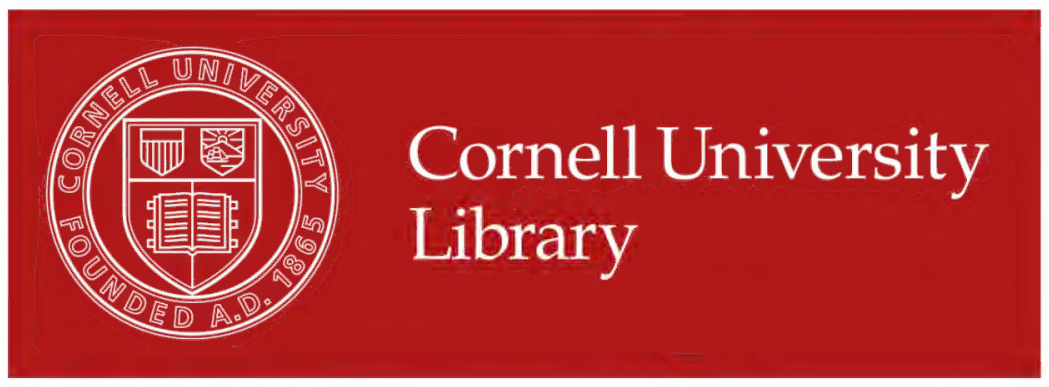

\section{The original of this book is in the Cornell University Library.}

There are no known copyright restrictions in the United States on the use of the text. 


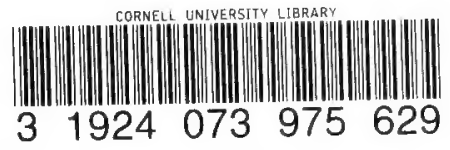







\section{Production Note}

Cornell University Library produced this volume to replace the irreparably deteriorated original. It was scanned at 600 dots per inch resolution and compressed prior to storage using CCITT/ITU Group 4 compression. The digital data were used to create Cornell's replacement volume on paper that meets the ANSI Standard Z39.481992. The production of this volume was supported by the United States Department of Education, Higher Education Act, Title II-C.

Scanned as part of the A. R. Mann Library project to preserve and enhance access to the Core Historical Literature of the Agricultural Sciences. Titles included in this collection are listed in the volumes published by the Cornell University Press in the series The Literature of the Agricultural Sciences, 1991-1996, Wallace C. Olsen, series editor. 



\section{MANAGEMENT OF DAIRY PLANTS}




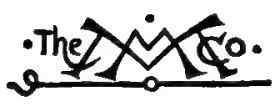

THE MACMILLAN COMPANY

NEW YORK - BOSTON - CHICAGO - DALLAS aTLANTa - SAN PRANCISCO

MACMILLAN \& CO., Limited

LONDON - BOMBAY - CALCUTTA

MELBOURNE

THE MACMILLAN CO. OF CANADA, LtD.

TORONTO 


\title{
MANAGEMENT OF DAIRY PLANTS
}

\author{
BY \\ M. MORTENSEN \\ PROFESSOR OF DAIRYING AT IOWA STATE COLIEGE
}

Sirm Hark

THE MACMILLAN COMPANY.

1921

All rights reserved 
Copyright, I92I

BY THE MACMILLAN COMPANY

Set up and electrotyped. Published January, Igar. 


\section{PREFACE}

THE larger portion of the material presented in this book has been collected by the author during the fourteen years while he was engaged in commercial dairy work. Much has also been obtained from the experience of others. The author has during the past ten years taught the subject of creamery management to students, and the material presented in this book has been given to the students in the form of lectures.

Acknowledgment is due to Professor F. W. Beckman of the Department of Agricultural Journalism of Iowa State College for his valuable assistance, particularly with the chapter on Advertising, which was largely written by him, also to Professors B. W. Hammer, A. W. Rudnick, and M. R. Tolstrup, who have all assisted in this work.

The author is indebted to the following parties for the use of electrotypes and illustrations: Creamery Package Manufacturing Company, Chicago, Illinois; J. G. Cherry Company, Cedar Rapids, Iowa; York Manufacturing Company, York, Pa.; Vilter Manufacturing Company, Milwaukee, Wisconsin; Madison Cooper Company, Calcium, N. Y.; National Dairy Council, Chicago, Illinois; The Wisconsin Experiment Station, Madison, Wisconsin; Kansas Experiment Station, Manhattan, Kansas; and the Dairy Division, Department of Agriculture, Washington, D. C.

Iowa State College,

M. MORTENSEN.

December, I920. 



\section{CONTENTS}

Chapter $\quad$ Page

I. Preliminary Survey of Conditions................. I

II. Form of Organization...................... II

Copartnership........................ II

Corporation.......................... I4

Mutual Coöperative Creamery Association........... I8

Joint-stock Company.... . . . . . . . . . . . . 2I

IIJ. Creamery Construction. .. . . . . . . . . . . . . 24

Floor Plan......... . . ............ 24

Foundations, Walls and Brickwork............. 30

Roofs............................. . ${ }_{36}$

Painting............................ 37

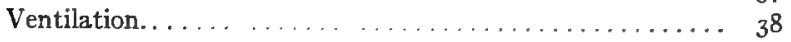

IV. Sewage Disposal. ...................... 40

Sewer System. . . . . . . . . . . . . . . . . . . 40

Cesspool........................... . 43

Septic Tank. . . . . . . . . . . . . . . . . . . 44

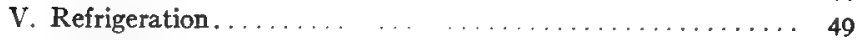

Insulation......................... 49

Systems of Refrigeration. . . . . . . . . . . . . ${ }_{58}^{8}$

Natural Refrigeration....... . . . . . . . . . . 58

VI. Mechanical Refrigeration.................... 68

General Discussion......... . . . . . . . . . . 68

Compression System. . . . . . . . . . . . . . . 69

Absorption System..................... 8ז

VII. Labor........................... $8_{4}$

Organizing a Strong Workinf Force... . ........... 84

Paying for Labor........... . . . . . . . . . . 92

VIII. Purchase of Milk and Cream.................. I00

System of Dealing with Patrons................. 100

Systems of Milk and Cream Purchase and Delivery....... I08

IX. Purchasing Equipment and Supplies.. . . . . . . . . . I 23

The Buyer...................... I $\ldots \ldots \ldots$

How to Buy......................... 125

Records...................... 126 
viii

CONTENTS

Chapter $\quad$ Page

X. Cost of Power....................... r

Steam Power..................... r 3 r

Gasoline for Power....................... r40

Kerosene for Power..................... I4I

Electric Power.......................... I4I

XI. Pasteurization . . . . . . . . . . . . . . . . . . . $\mathbf{I 4 3}$

A. Cost of Pasteurization.................... I43

B. The Economic Efficiency of Pasteurizing Machinery... I50

XII. Cost of Water......................... ${ }_{158}$

A. Power Required for Pumping Water........... 158

B. Water Pumps. . . . . . . . . . . . . . . . . 160

C. Economy in Pumping Water at the Creamery . . . . . 162

XIII. Rent, Depreciation, Interest, and Insurance........ . . 163

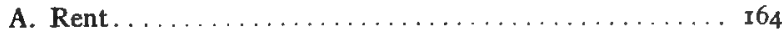

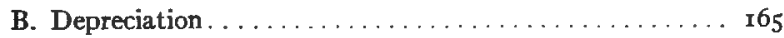

C. Interest. . . . . . . . . . . . . . . . . . 165

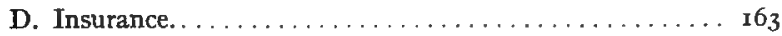

XIV. The Butter Overrun and the Relation between Chemical Composition of Butter and Overrun............... I68

The Butter Overrun. . . . . . . . . . . . . . . . I68

Relation between Chemical Composition of Butter and Overrun........................ 170

XV. Mechanical Losses and Their Influence on Butter Overrun.... 18I

Losses that Occur during the Manufacturing Process. .... . 18I

Losses Due to Inaccuracy in Weighing and Testing. . . . . . 188

Per Cent Overrun which may be Legally Obtained. . . . . . 195

XVI. Cost of Manufacturing Butter.................. 198

XVII. Profits Obtained from the Manufacture of Ice Cream. . . . . 203

A. Cost of Material. . . . . . . . . . . . . . . . . . . 203

B. Yield of Ice Cream...................... 218

C. General Expenses in Manufacturing Ice Cream...... 22I

XVIII. Marketing of Dairy Products. . . . . . . . . . . . . 226

A. Salesmanship........................ 226

B. Methods of Marketing................... $23 \mathrm{I}$

C. Office Records........................ ${ }_{237}$

XIX. Cost of Marketing Dairy Products. , . . . . . . . . . 245

A. Cost of Marketing Butter. . . . . . . . . . . 245

B. Cost of Marketing Cheese.................. 253

C. Cost of Marketing Ice Cream................ 254

D. Cost of Marketing Milk and Cream............. 258 
XX. Preparing the Butter for Market................ 272

A. Butter Packages... . . . . . . . . . . . . . . . 272

B. Packing the Butter.................... 277

XXI. Advertising Dairy Produrts. . . . . . . . . . . . . $28 \mathrm{I}$

The Purposes of Advertising..... . . . . . . . 282

Essentials in Creamery Advertising. . . . . . . . . . . 287

Mediums for Creamery Advertising.................. 294

Planning and Writing the Advertisement. . . . . . . . . 299

XXII. Business Correspondence................... . . 309

A. The Appearance of Letter ..................... 309

B. Parts of a Letter.... . . . . . . . . . . . . . . . 312

C. The Form Letter................... 317

D. Filing of Correspondence. $\ldots \ldots \ldots \ldots \ldots \ldots \ldots$

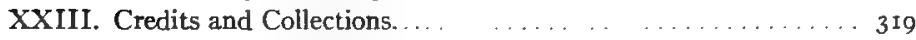

A. The Credit Man ...................... 319

B. Fact upon which the Credit Man Bases his Judgment. . 320

C. Office Records of Credit Information............. 323

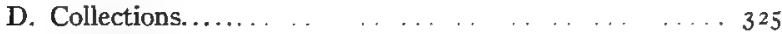

XXIV. Creamery Bookkeeping..................... 332

A. Definition and General Information . . . . . . . . 332

B. Record of Purchases..................... 335

C. Record of Sales...................... $34 \mathrm{I}$

D. Record of Inventory . . . . . . . . . . . . 342

E. Profit and Loss........................ 345 


\section{LIST OF ILLUSTRATIONS}

FIG. I,-Large windows in front expose the interior of the factory to the view of passers-by .................... 25

FIG. 2.-The arrangement of the creamery is influenced by the location of the railroad track . . . . . . . . . . . . . . 27

FIG. 3-A well-arranged floor plan for a small creamery ......... 29

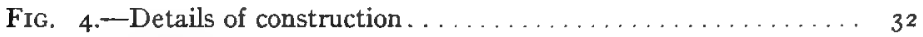

FIG. 5.-A sewer system that is readily cleaned............ ${ }_{40}$

Fig. 6.-Bell trap............................ . . 4 I

FIG. 7. Siphon trap $\ldots \ldots \ldots \ldots \ldots \ldots \ldots \ldots \ldots \ldots \ldots \ldots \ldots, 4^{2}$

FIG. 8.-Catch basin ......................... 43

FIG. 9.- Sections showing the construction of a septic tank..... 47

Fig. Io.-Sections of insulated walls by Ruddick............. 55

FIG. I I.-Section showing construction of floor and wall insulated with cork or lith.......................... 57

FIG. 12.-Section showing perfect air circulation in an ice bunker refrigerator.............................. . . . . . . .

FrG. 13.-Insulated ice house ................. . . 6I

Fic. 14.-The Cooper gravity brine system and chloride of calcium process............................. . 63

Fig. 15-Method of connecting refrigerating systems, ...... . 7 I

FIG. I6.-York single-acting ammonia compressor......... . 74

Fig. 17.-Vilter double-acting ammonia compressor . . . . . . . 75

Fig. 18. - An atmospheric ammonia condenser. . . . . . . . . . . . 77

Fig. 19.-A double-pipe ammonia condenser. . . . . . . . . . . . . . 79

FIG. 20,-System for artificial ice making. . . . . . . . . . 82

FIG. 2I.-Map of the territory .................... I05

FIG. 22.-Midget vest pocket press.................. III

FIG. 23.-Plant equipped with water-heating apparatus......... I 39

Fig. 24. - Pasteurizer with the Danish Experiment Station Improvements.............................. 154

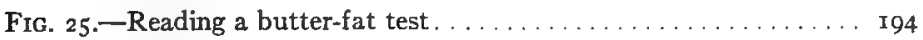

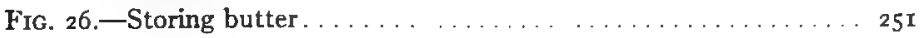

FrG. 27.-Public weigh-house, Alkmar, Holland............ 252 
xii

FIG. 28.-Wisconsin cheddar cheese production, I9I I . . . . . 255

FIG. 29.-Cheddar cheese shipments from Wise, $191 \mathrm{r} \ldots \ldots \ldots \ldots \ldots 255$

FIG. 30.-Total expense of milk distribution per quart.......... 263

FIG. 3I.-Percentages of total costs per quart by size of total business. . 263

Fig. 32.-A refrigerator butter carrier................... 273

Fig. 33.-A butter tub paraffiner..................... 273

FiG. 34.-Advertising the food value of dairy products......... 285

FIG. 35.-Advertising the food value of dairy products......... 285

Fic. $36,-A$ well-designed trade-mark. . . . . . . . . . . . . 290 


\section{LIST OF FORMS}

FoRm I.-Application for Position as Buttermaker....... 85

Form II.-Information Blank................. 86

Form III.-Creamery Productive Labor Cost Record. . . . . . . 95

Form IV.-Creamery Proportioned Yearly Labor Recor.d..... 99

Form $\quad$ V.-Creamery Field Record................ Io6

Fovm VI.-Monthly Record of Patrons................ 107

Form VII.-Receiving Clerk's Can Record............ II

Form VIII.-Daily Cream Receiving Record ............. II3

FORM $\quad$ IX.-Driver's Report..................... II8

Form X.-Route-Checking Record.............. I19

Form XI.-Station Report.................. 12I

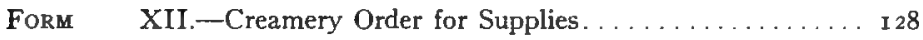

FoRM XIII.-Inventory of Supplies................. I29

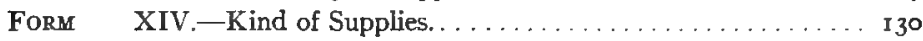

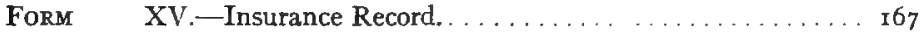

ForM XVI.-Churn Record................... 189

Form XVII.--Daily Cost Record and Manufacturing Report.... 202

Form XVIII.-Ice Cream Manufacturing Report Showing Cost of Material Used Per Gallon of Ice Cream Manufactured 222

Form XIX.-Ice Cream Shipping Tag............... 225

Form XX.-Report Card on Prospective Customers........ 238

Form XXI.-Sales Ticket....................... 239

FORM XXII.-Invoice..................... 240

ForM XXIII.-Statement.... . . . . . . . . . . . . . 24I

ForM XXIV.-Patrons' Sales Ticket................ 242

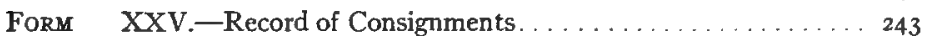

ForM XXVI.-Route Sheet...................... 244

ForM XXVIa.-Daily Balance Sheet................. 270

Form XXVII.-The Order Clerk's Credit Card ............ 325

Form XXVIIa.-A Bank Draft..................... 330

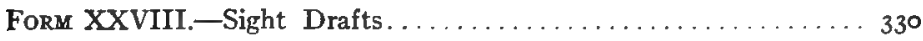

Form XXIX.-A Time Draft....................

Form XXX.-Debit Ledger....................... 333 


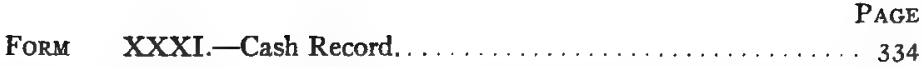

ForM XXXII.-Check Register................... 336

Form XXXIII._Patrons' Statement and Check ........... 337

Form XXXIV.-Itemized Record of Purchases............ 338

FORM XXXV.-Purchase Record.................. 340

Form XXXVI.-Sales Record . . . . . . . . . . . . . . . . 343

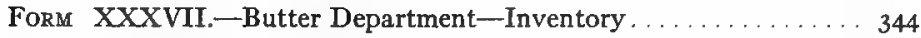

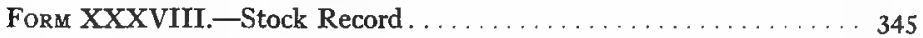

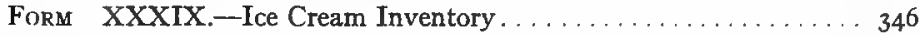

FoRM XL.-Manufacturing and Inventory Record ....... 347

Form XLI.-Statement of Profit and Loss for May........ 348

ForM XLII. -Ice Cream . . . . . . . . . . . . . . . 349

Form XLIII.-Financial Statement.................. 350 


\section{LIST OF TABLES}

TABle I-Transmission of Heat Through Various Insulating Structures....................... 52

TABle II.-Table of High Test Chloride Calcium Solutions... . 73

TABLE III.-Composition of Fuels................. I32

TABLE IV.-Quantity of Fuel Saved by Heating Feed Water. . . I 36

TABle V.-Cost of Power...................... I37

TABLE VI.-Densities and Specific Volumes of Water........ I45

TABLE VII.-Table for Determining Friction Loss........... I60

TABLE VIII.-Table Giving Value of Overrun per Pound of Butter and per Pound of Butter Fat.............. I 7 I

TABle IX.-Table Giving Value of Overrun per Pound of Butter and per pound of Butter Fat............ I 72

TABLE X.-Table Illustrating How the Fat Content of the Resulting Butter Iufluences the Reduction in per cent of Overrun ......................... I 84

TABLE XI.-Table Illustrating How the Fat Content of the Whole Milk Influences the Reduction in Overrun......... I84

TABLE XII.-Table Illustrating How the Fat Content of Resulting Cream Influences the Reduction in Overrun...... 185

Table XIII.-Table Illustrating How the Fat Content of Resulting Butter Influences the Reduction in Overrun.... 187

TABLE XIV.-Table Illustrating How the Fat Content of Cream Influences the Reduction in Overrun............ 187

TABLE XV.-Illustration of the Financial Loss Sustained by a Creamery Taking Composite Samples. . . . . . . . 192

TABLE XVI.-Influence of Temperature on Reading of Test...... 193

TABLE XVII.-Who Gets the Money? ................. I99

TABLE XVIII.-What it Costs to Make and Market Kansas Creamery Butter.......................... 200

TABLE XIX.-Comparison of the Official Creamery Butter Grades of Different Wholesale Trade Organizations.........246

TABle XX.-A Comparison of Prices at Which Different Grades of Butter and Butter Substitutes Were Sold in New York, Philadelphia, Chicago, St. Paul, and Minneapolis.... . 
TABLE XXI.-Comparison of Quality (Average Score) and Average Retail Price of Branded and Unbranded Butter...... $25^{\circ}$

TABle XXII.-Labor Cost For Filling and Capping Milk Bottles.... 259

TABLE XXIII.-Table Showing Time Required for Filling and Capping. 260

TABLE XXIV.-Percentages of Total Cost per Quart of Wholesale and Retail Milk (Eighty Plants), by Size of Character of Business........................... 264

TABLE XXV.-Table Showing Cost of Handling Milk in American Cities............................. 265 


\section{MANAGEMENT OF DAIRY PLANTS}





\section{MANAGEMENT OF DAIRY PLAN'TS}

\section{CHAPTER I \\ PRELIMINARY SURVEY OF CONDITIONS}

A CREAMERY may be owned and controlled by an individual, a closed stock company, or it may be controlled by the people of the entire community; but regardless of its prospective form of organization, certain factors which will largely determine the success or failure of the enterprise should be considered in its undertaking. These are:

I. Nature of business.

2. Raw material available.

3. Competition.

4. Amount of money required.

5. Banking facilities.

6. Amount of rural business handled by the town.

7. Attitude of the community toward the undertaking.

8. Railroad facilities.

9. Suitability of site and building.

Io. Competence in the manager.

Nature of Business. - Formerly the creamery business was confined strictly to butter making, but now several side lines are often included, such as ice cream making and cheese making. A creamery receiving milk, either exclusively or in part, may find it advantageous to manufacture cheese from all or from a portion of it. Some creameries handle eggs at a profit. It is even claimed that a laundry may be operated profitably in connection with a creamery. It may be operated at a profit; but, for sanitary reasons, a laundry seems hardly proper as a side 
line as a coördinate feature of the creamery. If operated by common power, the laundry should be separated from the creamery by a solid wall and the workers in one place should take no part in the operations of the other place.

The market facilities will naturally play a big part in determining the nature of the business. If a creamery is located in a thriving town or in a city, ice cream making would naturally fit in with butter making. Special demands may be created for soft cheese. A retail business may be started to advantage. In a number of cities, creameries are selling, at retail, all the products they manufacture.

Although some or perhaps all of such side lines should be taken up gradually only after the business has been established, yet there should be a fair survey of such opportunities at the outset, as these will often largely determine the advisability of starting a creamery.

Raw Material Available. - Considering Iowa conditions, a creamery located in the country or in a small town and not depending on local markets for the sale of its products, nor placing any dependence on side lines, should receive cream or milk from not less than 600 cows. ${ }^{1}$ If working with less, the operating expenses are too great and such a creamery is unable to compete with a strong rival. Farrington and Benkendorf ${ }^{2}$ estimate for Wisconsin that there should be at least 400 cows for a creamery and 200 cows for a cheese factory, with a good prospect of increasing this number in the near future.

As an illustration, consider two creameries, one receiving the raw material from 400 cows, the other receiving the raw material from 800 cows. Assume that these creameries are handling only gathered cream, that the entire amount of butter fat produced by the cows is sold to the creamery, and that each cow produces I4O pounds of butter fat annually. Also take for granted that the price paid by each creamery for butter fat delivered at its plant is not less than the New York quotation for extras, and that the butter is sold on commission at one cent per pound in excess of the price paid for butter fat. The

${ }^{1}$ Bul. 139, Ia. Agr. Expt. Sta., 1913. ${ }^{2}$ Bul. 244, Wis. Agr. Expt. Sta., I915. 
average yearly selling price of the butter is estimated at $\mathbf{2 7}$ cents per pound. The overrun is figured at 20 per cent.

Dally Statement of Creamery No. ${ }^{1}$

400 cows produce yearly 56,000 lbs. butter fat.

400 cows produce daily $155.5 \mathrm{lbs}$. butter fat.

I $55.5 \mathrm{lbs}$. butter fat produce $186.6 \mathrm{lbs}$. butter.

\section{Disbursements}

I 55.5 lbs. butter fat at 26 cents............. $\$ 40.43$

Butter maker's salary at $\$$ Ioo per month.......... 3.33

Tubs, salt, color, etc..................... I.20

Ioo lbs. skim milk for starter................ $\quad .50$

Coal and ice............................. 1.00

Drayage................................ ${ }^{.25}$

Miscellaneous expenses................... $\quad{ }_{50}$

8 per cent interest on a $\$ 4,000$ investment.......... $\quad .89$

Annual depreciation of ro per cent ............ I.I I

Freight on 186 lbs. butter at I cent per lb.......... $\quad$ I. 86

Commission of 5 per cent on 186.6 lbs. butter at 27 cents.. $\quad 2.52$

\section{Credits}

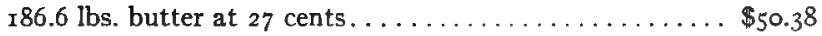

$500 \mathrm{lbs}$. buttermilk at Io cents per cwt ........... $\quad{ }_{5} 0$

Daily Loss.................... \$ $\$ 2.7 \mathrm{I}$

Daily Statement of Creamery No. 2

800 cows produce yearly ir 2,000 lbs. butter fat.

800 cows produce daily 3 II.I lbs. butter fat.

3 II.I lbs. butter fat produce $373.3 \mathrm{lbs}$. butter.

\section{Disbursements}

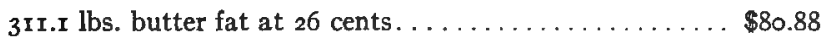

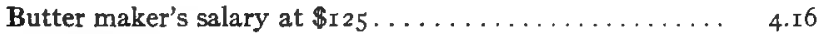

Tubs, salt, color, etc..................... $\quad 2.40$

200 lbs. skim milk for starter................. I.

Coal and ice................................ I.20

Drayage................................ ${ }^{25}$

1 Estimates made under pre-war conditions. 
Miscellaneous expenses..................... $\quad .50$

8 per cent interest on a $\$ 4, \infty \infty$ investment. . . . . . . . . $\quad .89$

Annual depreciation of Io per cent .............. I.II

Freight on $373.3 \mathrm{lbs}$. butter at I cent per lb........ 3.73

Commission of 5 per cent on $373.3 \mathrm{lbs}$. butter at 27 cents... 5.04

\$IOI.I6

Credits

$373.3 \mathrm{lbs}$. butter at 27 cents. . . . . . . . . . \$100.79

I,000 lbs. buttermilk at 10 cents per cwt.......... I.00 \$101.79

Total Profit................... 0.63

From the above it is evident that a creamery receiving the cream from only 400 cows will not be able to pay for butter fat within one cent of the price received for its butter. When meeting competition from a larger plant, its strength will be reduced. It also appears as if Creamery No. 2 should be able to pay for butter fat within a fraction of a cent of the price it receives for butter.

In using the above tables, however, it should be considered that a certain amount of milk and cream will be used on the farm. In reality, therefore, if the stockholders sign up for 800 cows, we should not depend on receiving the cream from more than 600 cows.

Competition. - Competition should be considered in the purchase of raw material as well as in the sale of finished product. In the matter of purchase, study the character of the competition, the methods adopted by competitors, the nature of their business, their costs for collecting raw material and for producing finished output, and their facilities for marketing. If the competitor is a man of clean habits and of sound business principles, then he will have the best people of the community working with him. If he is less honest in his dealings, his competition may be disagreeable for a time but will eventually lose out against a strong rival. A proprietary plant cannot prosper in the same town where a successful coöperative creamery is in 
operation. The cream-receiving station is usually operated at such an expense and the cream collected there is of such poor quality that its competition seldom wins great strength against a local coöperative plant. But it should always be considered that a competing firm, regardless of its nature, will, while it lasts, receive at least a share of the business.

A coöperative creamery may be organized and operated in any community if the stockholders represent enough cows. A proprietary plant should seldom, if ever, be established in a territory surrounded by strong competitors, for under otherwise equal conditions the younger firm is at a disadvantage.

It is rather unusual for a smaller plant to establish a local market for its butter; but if it does, it should know about its competitors who sell goods on the same market, their selling prices, quality of goods, cost of delivery, credit systems, and special concessions offered to their dealers.

Amount of Money Required. - The money needed to start and carry on a creamery business includes the amounts necessary for building, equipment, and working capital.

The building may be rented. This is the mode frequently adopted when starting in cities, especially by people who have only limited means, and while the business is yet in its experimental stage. A storeroom is often fitted up at small cost and the principal investment consists of such machinery as may be readily converted into cash in case of failure. A new creamery building large enough to make 1,000 pounds of butter daily when only cream is received may be built and equipped for from $\$ 4, \infty 00$ to $\$ 5, \infty 00$, while a creamery with a capacity of 2,000 pounds of butter daily, including a six-ton compressor, can be built and equipped for from $\$ 8,000$ to $\$$ I0, $\infty$. $^{1}$

In addition to the building and equipment, a working capital is required. By working capital is understood the margin of quick assets over current liabilities. Quick assets are those which can readily be turned into cash, such as good accounts, good receivable bills, marketable notes, and securities. Furthermore, in the creamery business we can include under this head 
inventories of raw material as well as of finished product; also, such supplies as tubs, salt, butter color, etc. However, butter wrappers, cartons, or other articles marked with a particular trade-mark and which could, therefore, not be sold readily to other factories should not be considered under the head of quick assets.

The amount of money required for working capital depends mainly on the amount of business, method of paying for cream, time of credit on supplies, amount of supplies carried on hand, terms of credit to customers, and promptness in collecting outstanding accounts, and, finally, on the amount of stock kept on hand either in the form of finished products or as products in process of manufacture.

Where the raw material is bought on time and the finished product is sold for cash or on a commission basis, only a small working capital is required. Some coöperative creameries conduct their business on this basis, paying monthly or semimonthly for the raw material and selling their butter on consignment. In such cases the company often makes out a sight draft, with bill of lading, for two thirds the value of the butter shipped. This draft is then sent through the bank, and the company's account there is generally credited with the amount at the time of deposit. If, however, a system is adopted by which the raw material is bought on cash basis and the finished product sold on two weeks' time, then the company will need sufficient capital to pay in advance for the month's supply of cream and supplies needed. This is because the butter fat remains unsold in the creamery for several days in the form of cream or butter. Moreover some of the outstanding credit accounts will not be collected even within three or four weeks after sale of butter.

Banking Facilities. - Due consideration should be given both to the financial responsibility and to the authorized capital stock of the bank from which the creamery enterprise must make loans. National banks by law are required to limit their loans to one concern to 20 per cent of the bank's authorized capital and surplus. A creamery transacting a big business and buying its raw material for cash may often during the 
summer months need to borrow more money than the smaller banks are able to furnish.

Amount of Rural Business Transacted in the Town. - To a local proprietary creamery it is of importance that the farmers from the surrounding territory do their trading in the town in which the creamery is located. The greater the territory the town draws trade from, the better patronage the creamery will receive, as farmers usually sell their cream where they do their buying. It has also the advantage of enabling the creamery man to meet more of his patrons and thereby to come in closer touch with them.

For the coöperative and the central creamery this factor is - of less importance. In the former case, farmers deliver their cream where they are financially interested. In the latter case, the central plant generally prefers to locate in some city where other opportunities of greater importance are afforded. Such concerns do not cater particularly to local producers, but depend on raw material being shipped to them from long distances.

Attitude of the Community Toward the Undertaking. Unless both the producers and the people of the town manifest a reasonable amount of interest in the creamery undertaking it will be more or less of an experiment as to outcome. A cooperative creamery may be successful without the support of the people of the town, but a proprietary plant should have the support of both country and town people.

If the people do not manifest any interest or if they show unwillingness to support the local creamery, such indifference or even unfriendliness may usually be traced to one or more of the following causes: First, the people have had unpleasant experiences with former local creameries; or, second, they consider the men at the head of the undertaking as undesirable persons with whom to do business; or, third, the community as a whole is rather pessimistic and lacking in coöperative spirit. Any one of these factors is well worth considering. Although a manager may win out eventually in spite of it all, yet the business will have proved more expensive by the time it is put 
on a profitable working basis than in the case of the creamery which receives the support of its local people in starting.

A community of townspeople and farmers may often indicate its good will toward such a project by offering a bonus to the promoter. This usually consists of a building site or even offer to pay part of the building costs. Such an offer is of much value as an evidence of local friendliness; but as the bonus is, of course, always in lieu of certain specified conditions, to accept it may hamper future success more than the bonus will compensate. The creamery company as a rule will do better to buy its own site and erect its own building, thereby keeping greater independence and increasing its prestige in the community.

Railroad Facilities. - A central plant should be located in a city with more than one railroad. The more railroads leading to the city, the larger the region to draw from and the more thoroughly the immediately surrounding territory is made available to the creamery. A large plant also markets its own products, and it is therefore an advantage to be directly connected with a larger number of towns and cities. This factor should not be disregarded by the smaller plants, for many of them might advantageously dispose of their products to near-by dealers.

Suitability of Site and Building. - In determining the location and housing of a creamery give thorough consideration to sanitation, convenience, and business advantages.

I. Location with Reference to Sanitation. - The surroundings of a creamery should be sanitary. Good facilities for drainage are essential. A creamery should never be located close to barns or places where offensive odors are prevalent, or to places which are natural breeding grounds for flies. It is advisable to provide room for a septic tank large enough to handle the sewage from the creamery. A sufficient supply of good water should be available.

If a building formerly utilized for other purposes is secured, it should be so located and constructed that it can readily be put into a suitable and sanitary condition without too great 
expense. The floors will usually have to be replaced with cement floors; the walls should be smooth, preferably cemented with smooth, hard, cement plaster, or at any rate they should be thoroughly renovated and painted or whitewashed. There should be plenty of windows, and the building should permit of easy ventilation.

2. Location with Reference to Convenience. - If the creamery is in a city, it should be so located that at least one side and one end of the building face a street or an alley. If located in the center of a block it will be inconvenient for shipping and the amount of sunlight available will be insufficient. A creamery should not be located in the principal retail portion of the city, as those streets are crowded with people and the sidewalks cannot be used for shipping so readily as in districts less crowded. In smaller towns this factor will not deserve so much consideration.

A location adjoining a railroad track is of advantage to a creamery doing a large business, but for the smaller plant in a small town the railroad track is of less value. It may even be a disadvantage, inasmuch as patrons delivering their own milk or cream will consider the trains a source of danger. Where farmers deliver their products to the creamery, the location is most convenient if near the center of town. But if, for other reasons, the creamery must be located inconveniently for these deliveries, patronage will often be secured by establishing creamreceiving stations near the trading centers. ${ }^{1}$

3. Location with Reference to Business Advantage. - Creamreceiving stations are located at business centers, not merely for the sake of convenience, but also for advertising advantages which are perhaps of equal importance. The creamery itself, if located in the main portion of a town, is thus better advertised. In such a building the front windows should be large enough for the passer-by to obtain a fair view of the entire plant. In larger cities, small creameries are at times located in the retail districts, but they should be so placed that shipping will

1 This is to be recommended only for such places where other creameries collect through stations. 
be taken care of from the back part of the creamery through the alley.

Competence of the Manager. - Managers competent to operate a large creamery are scarce. The successful manager should have had general business experience, and preference should be given to one who has also had practical creamery experience. A company should thoroughly investigate the past record of the man under consideration for this position.

The manager should be honest and broad-minded. He should be fair in his dealings with everybody. The manager should be clean in habits. One who is addicted to liquor cannot be trusted at all times nor can he render his employers the best service.

The creamery manager should have a discerning mind. $\mathrm{He}$ must be able to judge the men with whom he has business dealings and also the men he employs. He should recognize the limitations as well as the possibilities of his employees.

He should be an organizer. He must be able not only to establish a superior working system in factory, field, and office, but along with this he must also organize a working force which can carry out his ideas without friction, each member becoming a useful link in the entire chain of the organization. He should be a good executive. As such he must be a man of punctuality and perseverance, able to gain the confidence of his employees, and at the same time obtain efficient and economic service from them.

He should have had at least a fair technical training in the manufacture of those products which his factory is to handle.

He should be a money-maker. The success of a business enterprise is largely measured by its financial success. A man that can be expected to make money for the company is supposed to be able to save for himself. Nevertheless, some men do make money for their employers while spending their own earnings as soon as received. The ability of a man to save is; however, a good guide when engaging a creamery manager. 


\section{CHAPTER II}

\section{FORM OF ORGANIZATION}

THE simplest and oldest form of business ownership is that by the individual. As long as one person owns and operates a business, its organization is very simple. All business transactions with this individually owned concern will be directly with the owner or his agent. Should this person, however, take one or more partners, then an organization known as a copartnership is formed.

\section{COPARTNERSHIP}

A partnership is an association founded upon a contract between two or more competent persons for joining their money, goods, labor, and skill, or any or all of these, for the purpose of carrying on a legal trade or business, with the understanding that there shall be a communion of profit among such partners.

Partnerships are of two kinds - general and limited. A general partnership is the most common form and is an association of two or more parties who agree to enter into a specified business without fixing limitations. A limited partnership is an association of parties for some of whom liability is limited. This latter form of partnership is allowed in some states, but is rarely organized, and is now largely supplanted by the corporation. A limited partnership is usually required to file in some public office a certificate showing its membership, the purpose for which organized, its total capital, its assets, and the number of shares held by special partners.

How a Partnership is Formed. - A partnership may be formed by a written agreement. Such an agreement should specify the names and duties of each partner, the purpose for which the partnership is created, the amount of money invested by each, how the partners will share in profits and losses, form 
of bookkeeping records, duration of the company, and other special provisions.

A verbal agreement is sufficient for creating a partnership, but in the absence of a written agreement the law assumes that partners share profits and losses equally.

Who May Be Partners. - All legally competent persons may enter into a partnership. Insanity, idiocy, or habitual drunkenness disqualifies persons from becoming partners.

A minor may enter into a partnership, but contracts by him are voidable and he cannot be held for partnership liability. The minor, when he comes of age, or before, has the further privilege of renouncing his connection with the company and of disaffirming past transactions if he chooses. If, however, he remains connected with the company a reasonable length of time after coming of age, the law assumes that he is a legal partner.

Classes of Partners. - According to their responsibilities, partners may be designated as:

I. Ostensible Partner, the real partner; that is, the one known to the world as a partner.

2. Dormant Partner, the silent partner; that is, not known to the world as a partner but partaking of profits. He can sever his connection with the company without giving public notice of the same and is not liable for debts contracted after his retirement.

3. Nominal Partner, appearing to the world as partner without having any interest in the firm's business. He is liable to a third party to the same degree as the ostensible partner.

4. Special Partner, one who supplies a certain amount of capital. If complying with the statutory requirements, he is liable only in proportion to his interest in the firm.

Liabilities of the Firm. - A partnership has the privilege of doing business in the firm name and may sue or be sued like an individual. Debts contracted by any member of the firm for purchases made on the firm account shall be paid by the partnership. In case of the partnership being dissolved, the partners, in accordance with agreement, will divide the 
property which remains after all firm indebtedness has been paid.

Liabilities of Individual Partners. - The liabilities of partners to each other are regulated by written agreement; in its absence, the law assumes that partners share alike in profits and losses. If a partner withdraws before his partnership contract expires, he is liable to the remaining member or members of the firm for damages due to his withdrawal.

The partners are individually responsible to a third party for indebtedness contracted by the copartnership.

But creditors of each partner as an individual, if any, must first be satisfied before that partner's personal property can be attached for his partnership liabilities.

A new partner is not responsible for debts contracted before he was admitted as a partner.

Dissolution of Partnership. - A partnership is dissolved by

I. Expiration of predetermined time.

2. Mutual agreement.

3. Death of a partner.

4. Change of membership.

5. Bankruptcy of a member or of the partnership itself.

6. Court action, as in case of dishonesty, habitual drunkenness, etc.

No partner can sell out his interest in a copartnership and in that way avoid liability for debts contracted.

When a copartnership is dissolved, a notice thereof should be sent in writing to all firms or individuals with whom the company is dealing or with whom it had former dealings. Such announcements should also be made through the newspapers.

If a partnership is dissolved by the death of one member, the surviving members settle the partnership accounts, but they are not authorized to carry on the business for other purposes. When the affairs of the partnership have been settled and when the amount belonging to the deceased has been paid to his rightful heirs, the surviving partners may then resume business. 


\section{CORPORATION}

A corporation has been defined as an association of individuals forming a body which the law regards as an individual. The members of such a body may change successively without affecting its status as a legal unit.

We may distinguish between business corporations organized for pecuniary profits and corporations established for other than pecuniary purposes, such as churches, fraternal organizations, etc. The business corporation is gradually supplanting the more risky form of copartnership. This body organized for pecuniary profit is the one most commonly known by the name of "Corporation" or "Business Corporation," being an organization of persons for the purpose of conducting some commercial enterprise.

Advantages of the Corporation. - Parties investing money in business find that the corporation has several advantages over the older form of organization. Such advantages are: First, the permanency of the organization regardless of death, insolvency, or change of its members; second, the limited liabilities; third, the ease with which any person's interest in the corporation may be disposed of or transferred to other parties.

Creation of a Corporation. - A copartnership is created by contract between two or more competent persons with the purpose of carrying on some legal business. A corporation is not created merely by agreement of the members, but must receive permission from certain government officials to act as a corporate being. Usually the secretary of state grants the applicant a charter permitting the members to do business under a corporate name and particularizing the rights and privileges granted to such a body. The number of members required for creating a corporation varies in the different states, the minimum number in most states being from three to five.

Before commencing any business except their own organization, the members must adopt articles of incorporation which must be signed and acknowledged by the incorporators. For a corporation consisting of a number of members it is not neces- 
sary that all act as incorporators, the number required being designated by law. The articles, when properly signed, are submitted to the secretary of state for his acceptance.

It is advisable to consult an attorney when formulating the articles of incorporation, as the required form is controlled by statute. The following may serve as an illustration of points which are usually considered in such articles.

I. The name of the corporation and its principal place of business.

2. The general nature of the business to be transacted.

3. The amount of capital stock authorized, the number of shares into which it is to be divided, and the time and conditions on which it is to be paid.

4. The time of commencement and termination for the corporation.

5. The names of the officers or persons by whom its affairs are to be conducted and the time and manner in which they will be elected.

6. The highest amount of indebtedness to which it is at any time to subject itself.

7. Whether private property is to be exempt from corporate debts.

Powers of the Corporation. - A corporation is considered by law as being a legal or artificial person. It cannot carry on business except to the extent permitted by its articles of incorporation. If the organization decides to engage in business not permitted by its charter, an amendment to its articles of incorporation must first be made. The ordinary powers of a corporation are as follows:

I. Perpetual Succession. - By this it is not understood that a corporation can continue forever, for in most states the duration of the corporation is determined by the articles of incorporation. But if the organization is operated in compliance with law, the corporation may be renewed successively and thus continue indefinitely.

The change of membership in a corporation does not affect the life thereof. The holding of stock in a corporation is evi- 
denced by a certificate of stock which is transferable. A corporation may, therefore, consist of members who were not its original stockholders, yet the corporation is the same and possesses the same rights and privileges as under its original incorporators.

2. Electing Officers and Filling Vacancies. - The directors constitute the managing officers of the corporation. They are elected by the stockholders from their own membership. The directors again usually elect from the stockholders, or more often from their own members, a president, a vice president, treasurer, and a secretary. The president, vice president, and treasurer, if elected from stockholders not already directors, become members of the directing board upon their election to office. A majority of the directors usually constitutes a quorum for the transactions of business. The board is limited in power by the articles of incorporation and by the by-laws of the organization. The individual members of the board of directors cannot transact business for the corporation; they must act as a body. The board, however, has power to appoint some agent whom it can authorize to transact the business of the corporation.

In case of vacancy in an office due to death, withdrawal, or any other cause, the board of directors is vested with power to elect a successor who will hold office until the first regular meeting for election of officers.

3. Right to Sue and be Sued. - The corporation may sue and be sued as an individual, but its individual members cannot sue or be sued on the corporation's account.

4. Right to Purchase and Hold Property and Real Estate.

5. Right to Use a Common Seal.

6. Right to Make By-Laws. - The by-laws are the rules and regulations by which a corporation governs itself. They should be passed by the stockholders of the corporation and must be consistent with the articles of incorporation and with the general law.

The by-laws contain special provisions in reference to stock and stockholders. They define the duties of directors and offi- 
cers, contain the rules governing finances and dividends, and regulations as to meetings, amendments, and special provisions.

Rights and Liabilities of Individual Stockholders. - The powers of individual stockholders are vested in the board of directors, but each individual has the right to attend stockholders' meetings and to cast one vote for each share of stock he holds. He can participate in dividends in proportion to his holdings in the corporation. In case of dissolution of the corporation he has a right to share, proportionately to his holdings, in whatever amount is left after the liabilities of the company have been paid.

The stockholder of a creamery corporation, in case of insolvency, is liable to the full amount for which he has subscribed and in some states assessments may be made against the stock.

Capital Stock. - The capital stock of a corporation is the aggregate amount of stock which the company is allowed by its charter to issue. This capital stock is divided into shares. The size of these shares is left to the discretion of stockholders, but is usually one hundred dollars each. The definition of kinds of stock is frequently controlled by statute but may usually be considered as follows:

I. Common Stock. - This is the general stock of the corporation - the stock which, without special provisions, shares in profits. If no special stock is issued by the company, all of its stock is common stock. The holder of common stock participates in profits. He has the right to attend all meetings of the company, can vote on his stock, and shares in the assets of the company in proportion to the shares of stock he holds.

2. Preferred Stock. - This is stock which has been sold under a guaranty that it will net a definite per cent dividend if the same is earned by the company. If less is earned, the entire earnings will then be divided among the holders of preferred stock. The dividend on the common stock is declared after the holders of preferred stock have all been satisfied. If the corporation becomes insolvent, the preferred stock is redeemed after the debts have been paid and before any of the common stock has been redeemed. 
3. Treasury Stock. - Issued stock which has become the property of the corporation by purchase, gift, etc., is known as "treasury stock." As such it is inactive, since it does not share in profits and has no power to vote. It is considered as an asset of the company and may be sold or held by the company at the discretion of the directors.

4. Watered Stock. - This is stock that represents more than the full value of money which has been paid into the treasury of the company. Stock is watered by the unscrupulous corporation either for the purpose of making a big profit on the sale of stock or for the purpose of deceiving people as to the real earnings being made. Consider, for example, an electriclight company. It has invested $\$ 1 \infty, \infty \infty$ in the enterprise. The stockholders realize 25 per cent on their investment. In order to comply with certain state laws as well as to conceal from the public the enormous rate of dividend, the corporation issues stock up to $\$ 200,000$ without correspondingly increasing any tangible values on which that additional stock rests. On such an inflated capital this annual dividend then becomes $121 / 2$ per cent instead of 25 per cent.

Certificate of Stock. - A certificate of stock is evidence of ownership. It is transferable when properly indorsed by the owner and made payable to the purchaser. It is then to be transferred on the books of the company.

Dissolution of a Corporation. - A corporation may be dissolved (I) at the expiration of the predetermined time, (2) by the voluntary act of the stockholders, (3) by law - as in case of fraud or dishonesty in the conduct of business by the directing board or the managing officers, (4) by insolvency.

When a corporation is dissolved, the debts of the company are first to be paid. The balance of the assets will then be divided among the stockholders in proportion to their holdings in the company.

\section{MUTUAL COÖPERATIVE CREAMERY ASSOCIATION}

This form of creamery organization was originated in Denmark in 1882 by Stilling Anderson of Copenhagen. The asso- 
ciation was organized in the small country town of Hjedding not far from Esbjerg in Jutland. Coöperative associations along other lines were started in Denmark as early as I866 by $\mathrm{Mr}$. Sonne of Tisted, Jutland. Mr. Sonne's idea for such associations was originally borrowed from Great Britain.

A mutual coöperative creamery association is an organization of dairymen for the purpose of jointly converting the raw materials, milk and cream, into finished products such as butter, cheese, ice cream, etc., the business being conducted on a purely mutual and coöperative plan.

Such an organization may or may not be incorporated. If incorporated, its business, like that of any other corporation, is governed by articles of incorporation and by-laws. Its affairs are likewise conducted by a board of directors, and officers are elected either by vote of the members of the organization or by its directors. The directors usually select an agent who is responsible to the board of directors for his management of the business.

Capital Stock and Dividends. - In some states the coöperative association is organized with capital stock, but no dividends are declared on such stock. In other states the coöperative association is organized without capital stock, thereby indicating that dividends cannot be declared.

The coöperative creamery, like the church, is of common benefit to a community and should be the common property of its people. The money required for establishing such a creamery should be subscribed by the producers in proportion to the amount of butter fat produced by each. In Denmark, a person joining a coöperative creamery association must guarantee to furnish the milk from all of his cows for a definite period extending over several years. This system, however well adapted to Denmark, has not been incorporated in the by-laws of associations in the United States. It is more difficult in this country to have the amount subscribed correspond to the amount of butter fat delivered to the creamery.

One of the more satisfactory methods of securing money for the establishment of a coöperative creamery is through a loan 
secured by the association. This loan may be made by a bank or by individual members of the association. If the money is borrowed from a bank or a loan association, such an institution will naturally demand security. This is given by the members of the creamery association in the form of individual notes or joint notes which are held by the bank as collateral. The interest on this loan and part of its capital are paid annually from a sinking fund which is created by reserving one cent or a fraction of a cent per pound, from the price of the butter fat delivered by each patron, or by assessing each patron a definite per cent on the money he receives for butter fat delivered. The amount or per cent to be paid varies in proportion to the amount of indebtedness, to the total amount of butter fat received by the association, and to the number of years required to pay the entire indebtedness.

A sinking fund should always be created by the coöperative creamery association, whether the plant has been paid for or not. It is needed to keep the plant and equipment in repair and to buy new equipment. The amount accumulated for that purpose should measure up to 20 per cent of the cost of building and equipment and should be kept as a special account in the bank.

All money received by the association from the sale of its goods belongs to the patrons of the creamery. After all operating expenses have been paid and the necessary amount deducted for a sinking fund, the remaining sum should be divided among the patrons in proportion to the amount of butter fat delivered by each.

Membership and Its Rights. - Only patrons of the creamery may become members of a mutual coöperative association. Each patron has one vote on all matters pertaining to the business. The fact that a person becomes a patron of the creamery should make him a member of the association as, in paying his share of the sinking fund, he is paying toward the maintenance of the plant.

Dissolution. - In case of the dissolution of a coöperative creamery association, each patron or former patron has the right 
to share in whatever amount is left after the liabilities of the association have been paid, such share being in proportion to the amount of business he has transacted through the association.

Advantages. - The coöperative creamery is usually successful in communities where a sufficient amount of milk is produced and where the people understand how to work together in harmony. In such communities the advantages of the mutual coöperative creamery association over one owned by an individual or a company are, primarily:

I. Increased Value of Raw Product. - This is due to elimination of dividends on capital stock and also to decreased expense in securing raw material through assurance of its more definite supply. Furthermore, this greater profit to members on their raw product stimulates them to secure increased production from their herds.

2. Better Quality of Raw Product. - The patrons of a coöperative creamery realize more keenly the importance of better care for milk and cream on their own farms, knowing that neglect along such lines results in direct loss to them. In a coöperative organization the producers pay closer attention to the quality of goods delivered by their fellow members and the one who delivers raw products of inferior quality is liable to severe criticism.

\section{JOINT-STOCK COMPANY}

The joint-stock company as a creamery company is an organization of persons who join together for the purpose of converting raw materials into finished products as well as for the purpose of marketing the same. This organization has a capital stock on which dividends are declared. The joint-stock company proves to be most successful in certain places, mainly those localities where the townpeople have come to a full realization of the advantages of home industry and organization, and where they exert some influence over the farming population. Many such creamery companies have been organized entirely by the efforts of the townspeople. They are commonly known as coöperative creameries but are not strictly coöperative in principle. Some of them approach coöperative methods closely 
while others are operated on much the same plan as a business corporation.

Capital and Dividends. - The joint-stock company differs from the coöperative organization in that it declares dividends on capital stock and that stock is frequently held by people who are not producers. Some creameries operated under this form declare a large dividend on capital stock, but such dividend should not at any time exceed the current rate of interest on money loans. Some of these associations, when properly controlled by the producers, stipulate in their articles of incorporation what per cent of dividend may be declared. Some do not designate such returns as dividends but as interest. They are thus making the coöperative feature more prominent and are also guarding against the possibility of any stockholder obtaining an unfair dividend, as the maximum rate of interest is defined by law.

Price Paid for Raw Material. - Some creameries draw a distinct line between patrons who are stockholders and patrons owning no stock. They often pay a non-stockholder from one to two cents less per pound for butter fat delivered to the creamery; at the same time they deduct from his check a regular membership assessment for running expenses and for the sinking fund from which dividends and cost of repairs are paid.

To illustrate, suppose a creamery thus organized and conducted received an average of 400 pounds of butter fat daily or $144, \infty 00$ pounds annually. If its capital stock was $\$ 5, \infty 00$ and one cent per pound were deducted for fat received, the dividend declared in that way would amount to $\$ 1,440$ annually, or 28.8 per cent of the capital stock. At the same time patrons might be required to contribute to the sinking fund from which the regular dividend on capital stock is to be declared to stockholders.

Obviously, the price paid for butter fat should be the same for all, whether stockholders or not. 'When non-stockholders assist in creating a sinking fund from which dividends and cost of repairs are paid, no more can rightfully be asked of them; nor is it fair to the patrons of such a creamery to create a sinking 
fund much in excess of what is actually needed for declaring a fair dividend and for upkeep of the plant.

Who May Become Stockholders. - Others than patrons of the creamery may own stock in the organization. But the patrons should at all times own its major portion. If the controlling interest is held by non-producers, the coopperative features of the organization are likely to be less marked, and the producers are more likely to lose enthusiasm. A creamery that has been organized as a joint-stock company may eventually be changed into a coöperative creamery by gradually buying up the stock with the money in the sinking fund, if agreeable to the stockholders. It often appeals to a stockholder to know that he may subscribe to stock with the understanding that a definite dividend, say 8 per cent, will be paid annually together with a definite per cent of the capital. He feels more keenly that money thus subscribed is not lost.

Rights of Stockholders. - Only stockholders of the organization can vote on matters pertaining to the business. Some creameries are so organized that the stockholder has one vote for each share of stock, others come closer to the mutual cooperative association in allowing each member only one vote regardless of the amount of stock he holds. In most creameries of this kind the number of shares that can be held by one individual is limited.

This form of creamery organization, if conducted as near as possible on the coöperative plan, has the same advantages as the coöperative association; and in places where the townspeople are more aggressive than the farming population, this form is even preferred. This type of creamery association should not be confused with some of the big corporations that provide for a certain amount of stock to be sold to producers in different sections of the country. The latter form is not coöperative in any way except in name. The organization is under the absolute control of comparatively few individuals as, even if more than half of the stock were sold to producers, such stockholders are usually scattered so widely that no united action could be carried through by them. 


\title{
CHAPTER III \\ CREAMERY CONSTRUCTION
}

\author{
FLOOR PLAN
}

Size of Floor. - The amount of floor space needed depends on the character and volume of business to be conducted and the methods of manufacture. The amount of room required in a plant handling whole milk is somewhat greater than that required for a plant manufacturing the same amount of butter from gathered cream. If cheese or ice cream is to be manufactured in connection with butter making, the problem becomes more complex. There is no definite rule by which to figure the amount of space required for manufacturing a definite amount of finished product, as it depends so largely on the method of manufacturing. As an illustration: In the manufacture of butter, one plant prefers to pasteurize the cream, another will churn the cream raw. The latter requires less space than the former for doing the same amount of work. Then, again, the kind of machinery installed often makes a noticeable difference, one pasteurizer occupying perhaps twice as much floor space as another of the same capacity.

It is considered that a floor space 26 feet by 50 feet is sufficient for a gathered-cream factory manufacturing up to 500 pounds of butter daily, and a floor space 30 feet by 60 feet for manufacturing from 500 pounds to I, 500 pounds daily. A floor space of 40 feet by 60 feet should be sufficient for manufacturing from $I, 000$ pounds to $I, 500$ pounds of butter and from $5 \circ$ gallons to roo gallons of ice cream daily.

Arrangement. - The chief factors in determining a successful plan of arrangement are:

I. Local Conditions. - Arrangement of floor space will be influenced by location with respect to street, alley, or railroad 


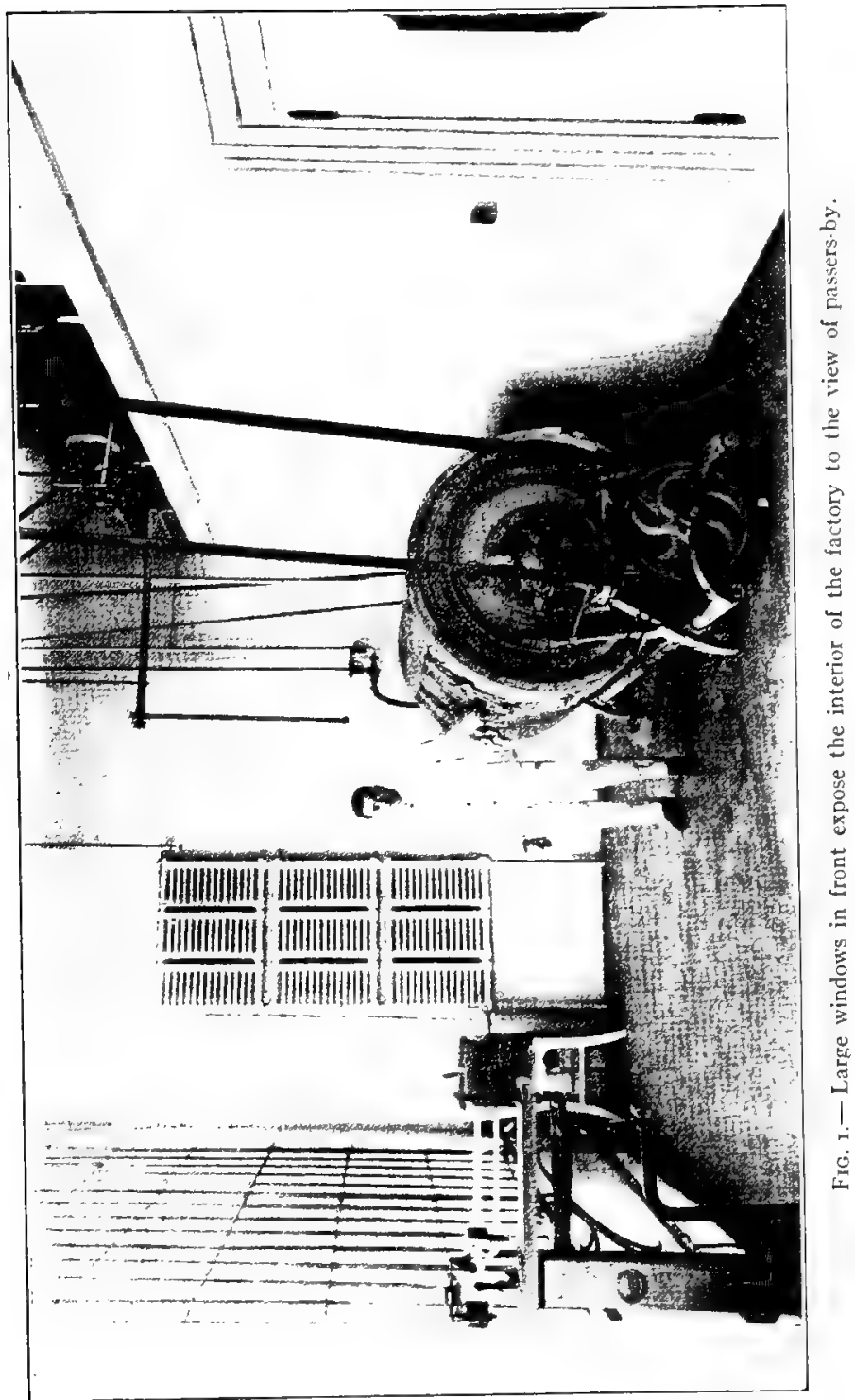


track. Weather conditions might determine the place for cream intake. Retail business in connection with the factory might change the whole plan of arrangement. Advertising possibilities might well bring certain portions of the factory to the front so that some of its manufacturing operations are in plain sight of people passing by. This point is well illustrated by Fig. I, in which is shown a butter and ice cream factory located on the main street. Large windows in front expose the interior of the factory to the view of passers-by. The floor plan in Fig. 2 illustrates some influences a railroad track may have on the arrangement of a creamery. This building had to be so planned that coal, ice, and supplies could be unloaded from the cars on the creamery track and butter loaded into cars similarly placed.

2. Convenience in Operation - The greatest economy of labor and power is obtained by having the product move through its successive factory operations on a straight line. At one end of that line the factory receives its raw material, as cream or milk; at the other end it puts out that raw material as finished product in the form of butter, cheese, ice cream, etc. It is obvious that those parts of a factory whose work is closely related should be near together. It would be very inconvenient, for example, to have the receiving room close to the churn and more distant from the cream ripeners. The natural and most logical arrangement is that with the cream-receiving room or platform first, the vat next, and then the churn. Testing is so closely connected with the receiving of cream and milk that it should be done close by or in the receiving room. Office work is also closely connected with the work in the receiving and testing rooms and should be near to both.

Referring again to the floor plan in Fig. 2: In order that ice, coal, and supplies might be most conveniently unloaded direct from the car, it was necessary to locate the boiler toward the center of the building. This made it very inconvenient in removing ashes, and the supply room was not conveniently located. Later, when it was decided to install a refrigerating plant, the former inconvenience was readily overcome by remov- 


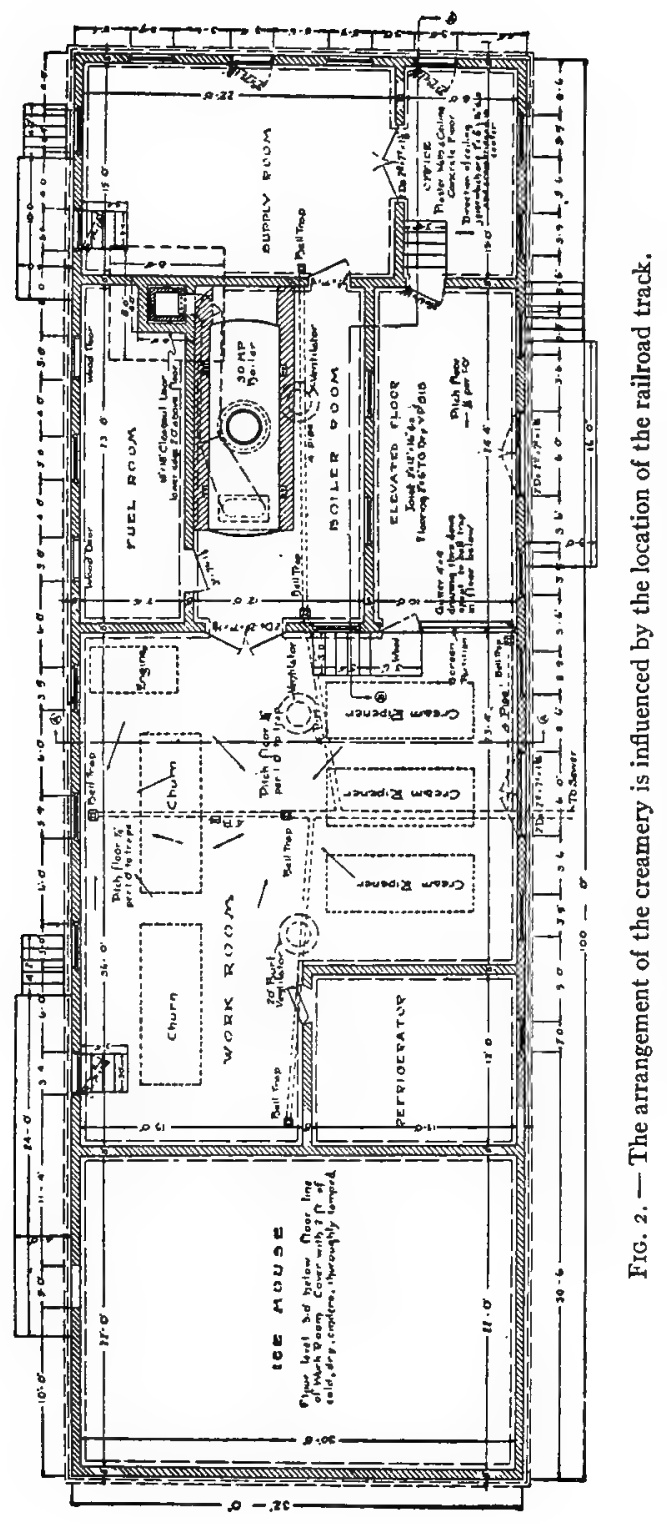


ing the coal room, boiler room, and receiving room to the other end of the building. The refrigerator could then be located against the supply storage room.

Slope of Floor. - The floor in a creamery should have a slope of about one inch in four feet. In the churn room this slope should gradually increase toward the drain.

Floor Materials. - Cement floors are perhaps the most serviceable as well as the most economical for creameries, but sawed stone and tile are also used to a limited extent.

I. Cement. - The cement floor consists of a concrete base from four inches to six inches in thickness, with a surfacing one half inch in thickness. The base should be placed on a well settled and packed soil.

The concrete base may be made of one part best Portland cement, two parts clean, coarse, sharp sand, and three parts mixed gravel or finely broken stone or tile, all thoroughly mixed and lightly tamped in place. Before the concrete has set, there should be applied to it a half-inch finish or surfacing consisting of equal parts of Portland cement and sharp sand, and this should then be troweled smooth.

A cement floor may be laid in the second or third story of a creamery building; but unless the entire floor is constructed from reënforced concrete, such cement should be laid on top of a heavy plank floor properly supported to prevent jarring. Such an upper-story floor should be constructed practically the same as the main floor described above, except that between the concrete base and the plank floor there should be laid a covering of waterproof prepared material similar to prepared roofing. The sheets of this material should be properly cemented before the cement floor is laid. This waterproofing answers the double purpose of preventing the floor from leaking and of preserving it from cracks due to uneven contraction and expansion in the cement and wood. If the different parts of the floor are subjected to extreme differences in temperature, then the surfacing should be divided off into squares or rectangles about thirty inches wide. The crevices may be filled with hot asphalt. 


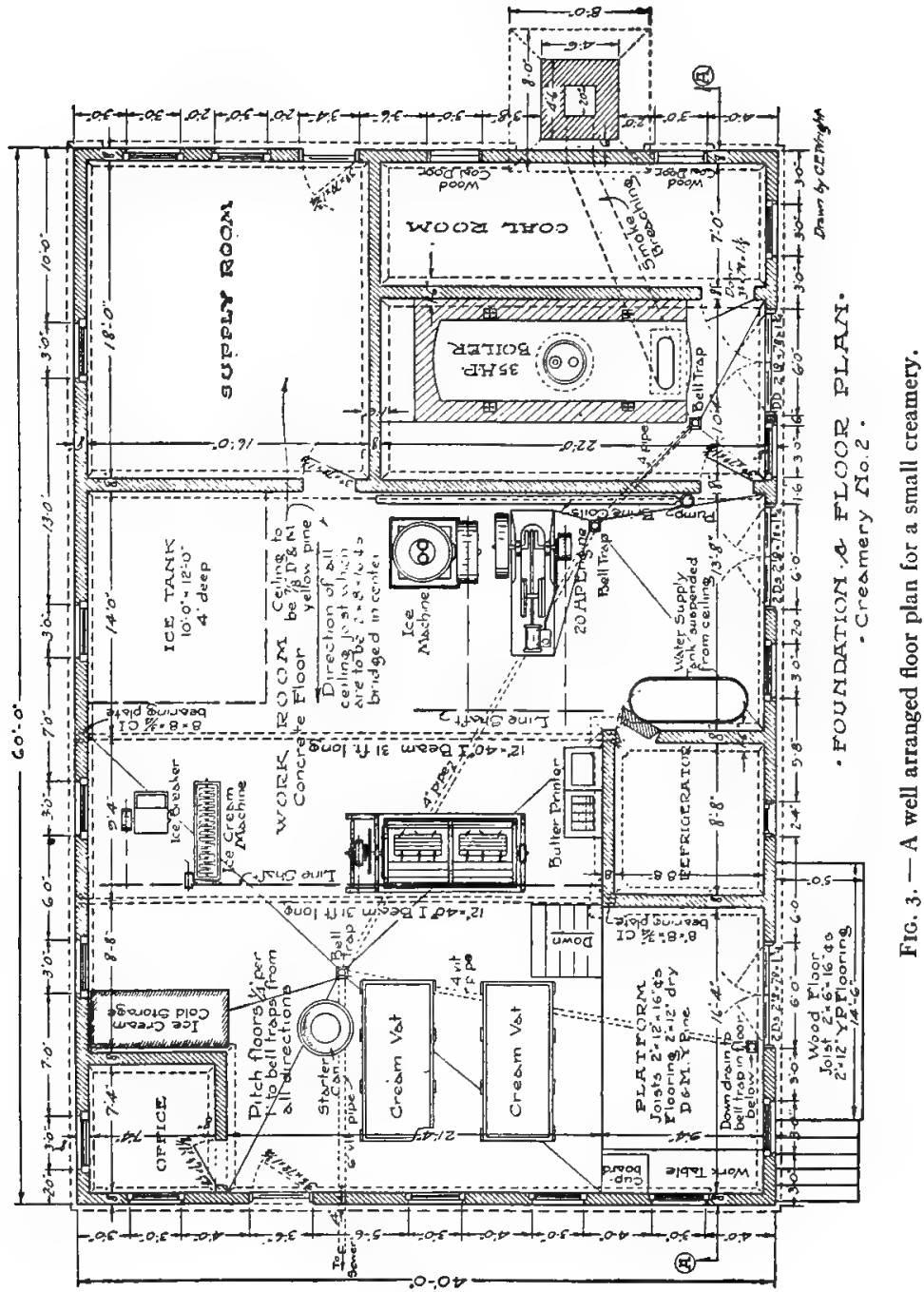


2. Stone and Tile. - If sawed stone or tile is used for the floor, either one should be laid in cement on a concrete base similar to the base constructed for cement floors.

3. Asphalt. - This has been used for creamery floors to some extent as a surface coating usually of about one and one half inches in thickness. It is laid on a concrete base as in the case of floors previously described. As asphalt floor has the advantage of being comparatively soft and hence less tiring to workmen than the harder floors. Furthermore, it is considered waterproof, and is comparatively easy to repair. However, as it gradually dissolves under hot water, it proves less desirable for floor covering in a creamery.

4. Plank. - The plank floor was formerly used more extensively than any other kind. As it is unsanitary and lacking in durability, it cannot be considered very serviceable.

\section{FOUNDATIONS, WALLS, AND BRICKWORK}

Mortar. - Kidder ${ }^{1}$ recommends for brickwork a mortar made from one part of Portland cement and three parts of sand. "One barrel of Portland cement and three barrels of sand thoroughly and properly mixed will make $3 \mathrm{r} / 3$ barrels, or I2 cubic feet, of good strong mortar . . . sufficient to lay . . . 750 bricks, with $1 / 4$ to $3 / 8$-inch joints."

Hoeppner maintains that a mortar made from cement and sand alone should not be used for hollow tile, as such mortar is too "short" and will roll off the tile and hence does not insure a full joint.

Cement. - Cement used for building construction should meet the following requirements of the American Society for Testing Materials:

The specific gravity of the cement, thoroughly dried at $100^{\circ}$ C., shall not be less than 3.I0.

It shall leave by weight a residue of not more than 8 per cent on a No. Ioo, and not more than 25 per cent on a No. 200 sieve.

It shall develop initial set in not less than thirty minutes,

' Architects' and Builders' Pocketbook, by Kidder, r912, pp. 199-200. 
but must develop hard set in not less than one hour, nor more than ten hours. ${ }^{1}$

Cement mortar is injured to a great extent if frozen before it is set. Kidder ${ }^{2}$ maintains that it is not safe to allow a slowsetting cement mortar to freeze in less than four days after it has been placed, while a very quick-setting cement mortar may freeze in twelve hours without injury provided the mortar is kept frozen until set. Portland cement mortar is injured more when it alternately freezes and thaws than when it remains frozen before it has set hard.

Foundation. - This is most satisfactorily constructed from concrete. The thickness of the foundation at its top is equal to that of the wall, but gradually increases in thickness toward the bottom (Fig. 4). The depth of the foundation varies in accordance with the character of the ground and the size of the building. A foundation from 4 feet to 6 feet deep is usually sufficient for a building one story to two stories in height.

The concrete for the foundation may be made of one part Portland cement, three parts clean, coarse, sharp sand, and five parts tile or stone broken in pieces of not more than 2 inches dimension. The cement and sand are first to be thoroughly mixed in the dry state, then mixed with water, and the broken tile or stone added, after which the concrete is turned over three times in the mixing box and immediately deposited in the trenches and tamped lightly until the water rises to the surface. The concrete walls above ground should be finished smooth and even.

Walls. - The kind of material from which the walls of a creamery may be constructed depends largely on the cost and efficiency of material available in the particular locality. The most common materials used in the construction of creamery walls are brick, hollow tile, brick and hollow tile, and cement blocks. A frame building is not to be recommended, as the fire risk is greater and the structure is lacking in sanitation, durability, and appearance. The walls of workrooms should be at least 16 feet from floor to ceiling.

1 Kidder, Igr 2, p. 853.

2 Kidder, p. I99. 


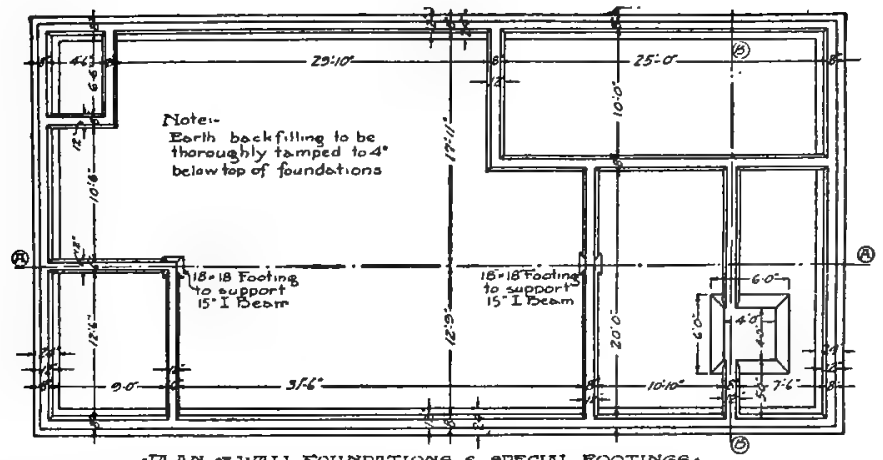

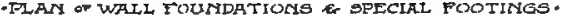
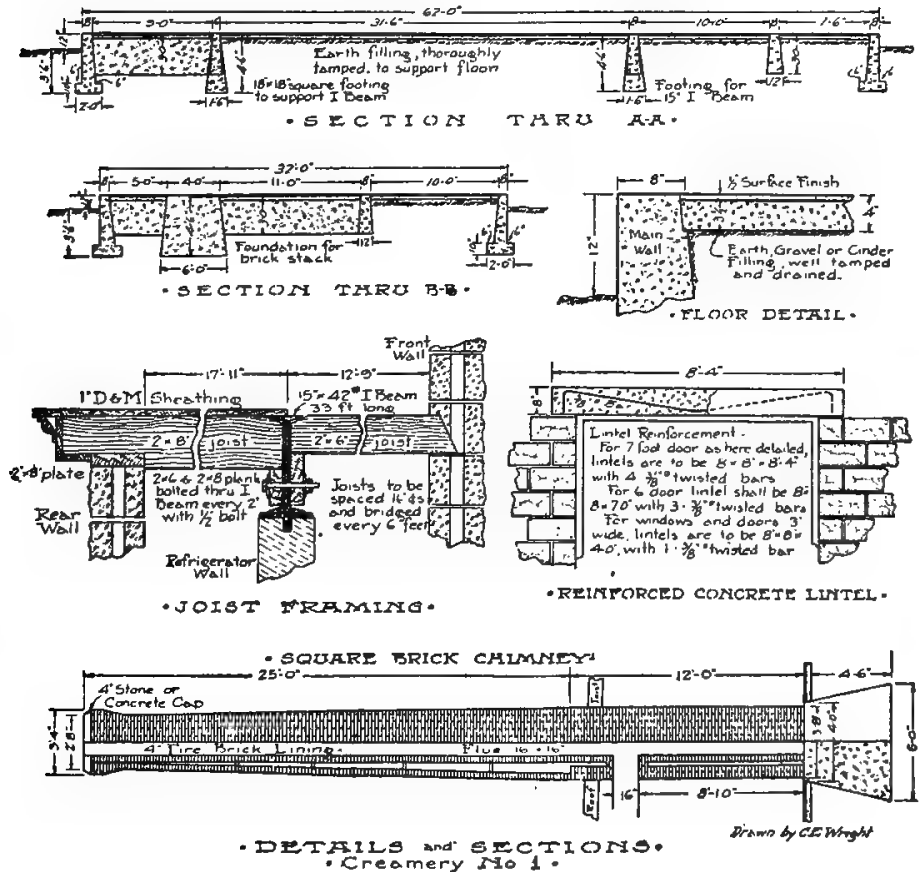

Fig. 4. - Details of construction. 
I. Brick. - Brick is perhaps the most satisfactory material from which to construct a creamery wall, but it is also the most expensive. The standard size of brick is 2 inches by 4 inches by 8 inches. The brick should be uniform in composition and free from lime spots. A hard-burned brick is most durable; but for a building located in the city, pressed brick is more satisfactory for facing. A brick should be tested for its power to absorb moisture. This may readily be done by the following method: Place a brick in the furnace or in the oven of a kitchen range; leave it there for 24 hours or until the weight of the brick remains constant; then submerge in water for 24 hours; afterward, wipe it dry with a cloth and weigh. A brick absorbing moisture to exceed 8 per cent of its own weight should be rejected. Such a brick will disintegrate during the winter season when the moisture in it freezes.

A one-story or two-story creamery building constructed from brick should have a wall not less than ro inches thick, allowing 2 inches for air space. The bricks should be laid with wellfilled, full-bedded joints $3 / 8$ inches wide. The walls should be plumb and straight, using a line on both sides of the wall throughout its entire height. They should be securely bonded with headers, and should be reënforced above all openings. All exposed joints in walls should be neatly smoothed with the trowel.

2. Hollow Tile. - Hollow tile has been used quite extensively during recent years in the construction of creameries. The standard sizes of hollow tile are 4 inches by 8 inches by 12 inches and 5 inches by 8 inches by $\mathrm{I} 2$ inches. The former is used more frequently. What has been stated concerning the quality of brick applies also to tile. It is tested in a similar manner, and any tile absorbing moisture to exceed 5 per cent of its own weight should be discarded.

Hollow tile may be laid in two different ways - either on edge or down flat. If on edge and with a tile 4 inches thick, the wall should be constructed Io inches thick with a 2-inch air space allowed. The principal objection to this wall, unless cemented on both sides, is its unattractive appearance. If the tiles are laid flat, a single layer will make a wall 8 inches thick. 
Such a wall is suitable for a one-story creamery, and is practically as attractive as one made of brick.

Particular care should be taken that joints are well filled with properly prepared mortar. If not, rain dashed by heavy wind will beat through the wall. Special attention should also be given to assure that ends of blocks are properly joined with mortar. Owing to their construction, this becomes the most difficult task in laying tile.

The principal advantages of hollow tile are its comparative cheapness and low cost of laying. Air spaces in blocks serve as insulation if the walls are absolutely tight in construction. If any particular objection can be made, it is primarily that a hollow-tile wall may be more readily damaged, as by a wagon backing up against it. If a hole is made, the hollow tile affords an excellent hiding place for mice and rats. It is also more difficult to make an air-tight wall from hollow tile.

3. Combination of Brick and Hollow Tile. - This is becoming the more popular material for wall construction. It usually consists of a 4-inch brick for the outside wall, then a 2-inch air space, and finally a 4-inch hollow tile, making a ro-inch wall. The brick and hollow tile should be securely bonded with headers. This combined material has advantages over hollow tile in that it gives the building an outward appearance of solid brick, and the latter can be laid more easily to form a tight wall. It has the advantage of a solid brick wall in being less expensive and at the same time just as durable, since the inside wall is covered with cement plaster. Inside partitions are usually built from hollow tile exclusively.

4. Cement Blocks. - The cement blocks used for creamery construction are either 8 inches by 8 inches by 24 inches or else 8 inches by 8 inches by 16 inches in size. These blocks should be double, with two or four wire headers between halves. Those used for outside walls are usually made rock-faced for the sake of appearance; those for inside partitions are smoothfaced. The blocks'should show good workmanship in construction, be made of good material, and show a sustaining strength, under test, of at least $I, \infty 00$ pounds per square inch after they 
have reached an age of 28 days. The blocks should be imbedded in cement mortar, with joints not exceeding $3 / 4$ inch. The greatest objection to the cement-block wall is its tendency to absorb moisture. This, however, is largely overcome by using the particular blocks described above.

5. Sills and Lintels. - These are made most satisfactorily from concrete. The exterior window sills, if thus made, should be reënforced and set in place. The lintels should be reënforced, and the concrete used should be of a strong mixture containing one or more parts of cement, two parts of clean sand, and four parts of coarse gravel or broken stone.

6. Plastering. - The walls of all rooms except the coal room should be covered with two or three coats of a good, hard wall plaster. The last coat is to be composed of hard cement wall plaster, finished with a steel trowel, and brought to a true, even surface free from cracks.

All plastering should be carried to the floor and connected with the surfacing from the floor. It is often advisable to carry the floor surfacing up on the wall for about one foot. Instead of the wall meeting the floor on a right angle, the juncture may be slightly rounded, thus making it easier to clean. A wall finished as above may be scrubbed and can, therefore, be kept in a sanitary condition.

Chimney. - In planning the foundation for a chimney, it is advisable to consult an architect or at least some experienced person. If the soil is loose or wet, it may be necessary to drive piles on which to build the foundation. Fig. 4 illustrates a foundation and chimney built on firm soil for a 37 -foot brick chimney.

The chimney proper or stack should be built from shale brick. The core of the chimney upward from the bottom of the smokebridging opening should be built of fire brick laid in fre clay and securely bonded to the outer wall with galvanized iron bonds of such length and strength as to insure stability. Due provision should be made in the stack for attaching the smoke bridging or flue from the boiler, and for placing an iron cleanout door in the bottom of the stack. A door I8 inches by I8 inches is most satisfactory for the ordinary sized stack. 
Engine and Boiler Foundations. - These should be built in accordance with details and specifications furnished by the manufacturer, and should be made from concrete composed of one part Portland cement, two and one-half parts clean sand, and five parts coarse gravel, broken stone, or tile. The foundation bolts should be placed in gas piping $1 / 2$ inch greater in diameter, and should extend to within 3 inches of the bottom of the foundation.

\section{ROOFS}

The size and number of timbers required to support the roof should be carefully figured by an architect. It is considered that timbers should not span over more than 24 feet. If the building is of such construction that longer timbers are required, it may be advisable to use one or more steel beams, thereby shortening the timbers required as well as increasing the strength of the building.

There are two general types of roofs - the flat and the pitched.

Flat Roof. - The flat roof is constructed in much the same manner as a floor except that it has a slight pitch. The most common materials used on this type of roof are gravel, tin, and special prepared roofing such as asbestos, etc.

I. Gravel Roof. - The gravel roof should have a pitch of from $5 / 8$ inch to $\mathrm{I}$ inch in the foot. It is supposed to protect a wooden roof better than tin, its life being from ro to 5 years. Its cost will amount to about $\$ 7$ per square, ${ }^{1}$ a square being roo square feet.

2. Tin Roof. - A tin roof, if properly laid and kept painted, will last from 20 to 30 years. Its cost will vary from $\$ 8$ to $\$$ r I per square. ${ }^{1}$

3. Prepared Roofing. - Such roofs are constructed in accordance with specifications furnished by the manufacturer. The cost of constructing a four-ply asbestos roof at Hartley, Iowa, was $\$ 7.29$ per square. ${ }^{2}$

1 Figured at pre-war cost of material and labor.

2 Bul. 139, Ia. Agr. Expt. Sta., I9r3, 
Pitched Roof. - Materials recommended as fireproof for a pitched roof are asbestos shingles, clay tiles, metal tiles, and slate.

The pitch of the roof is obtained by dividing the height by the span; thus we speak of its being one-half, one-third, and one-fourth pitched.

\section{PAINTING}

Paint consists of a liquid carrier with which is mixed a solid substance called pigment which gives the color desired. For ordinary painting, this liquid consists of linseed oil; but for enamel paints, varnish is used. White pigments consist of white lead, white zinc, or zinc lead. ${ }^{1}$ Yellow is commonly chromate of lead, or chrome yellow. Green is chrome green - a mixture of chrome yellow and Prussian blue. Blue is ultramarine, or sometimes Prussian blue. Brilliant red is usually a coal-tar color, while dull reds and browns are oxides of iron. Others are dull yellow. Black paints are made from carbons such as boneblack, lampblack, or graphite.

Paints should never be applied to wet or damp surfaces. A plastered wall should first be washed thoroughly with a solution of soap and next with a solution of alum. After it is entirely dry, a coat of oil should be applied, and then the paint. If applied directly, the paint will be attacked by the lime in the plaster.

Knots, sap, and defects in the woodwork should be thoroughly covered with one coat of shellac reduced to the proper consistency in pure grain alcohol. All joints, nail holes, and similar defects should be filled level with white-lead putty after the priming coat has been applied.

Priming Coat. - The priming coat is the first paint applied, and usually consists of ordinary paint and raw linseed oil mixed in equal proportions. A gallon of priming coat will cover about 300 square feet. All exterior woodwork that is to be painted should be primed immediately upon its delivery to the premises.

${ }^{1}$ Kidder, Architects' and Builders' Pocketbook, I912, p. 1403. 
Painting Proper. - After the priming coat is properly dried, two or more coats of ordinary paint should be applied. A gallon of paint will cover about 600 square feet. White paints are frequently used in our most modern creameries, often with a darker wainscoting. A very attractive effect is produced by applying two or three coats of common white paint followed with two coats of white enamel paint. If the proper enamel is secured, woodwork or cement walls thus painted may be washed with soap and water.

Painting Steel and Iron. - In painting structural steel or galvanized iron, it should first be thoroughly scrubbed and dried, then painted. The first coat should consist of pure red lead and pure linseed oil mixed in the proportion of twenty-five pounds of lead to one gallon of oil. The next two coats should consist of white lead and linseed oil, mixed with coloring matter as desired.

\section{VENTILATION}

A creamery or dairy establishment should be well equipped with windows, and these should be kept open as much as possible. But ventilation obtained in this way is far from sufficient. If the chimney is of good capacity, it can be made to serve as a most excellent means of ventilation. Mr. J. Sorenson ${ }^{1}$ recommends the placing of two registers in the chimney, each to be from 6 to ro inches square. One is to be located about 6 inches from the floor and the other near the ceiling, the lower being used during cold weather and the upper during summer months.

One type of simple ventilator is in the form of a flue extending from the ceiling through the roof and properly protected with a hood. This type is fairly satisfactory during the summer season, but during the winter too much heat escapes through the flue. A type similar to the King system of ventilation will prove more satisfactory. This should consist of large openings near the floor from which flues extend through the roof of the building. The foul air is drawn up and discharged through these flues, and the fresh air is admitted through a series of

1 Bul. 4I, Minnesota Dairy and Food Dept., rg12. 
small openings placed midway in the wall on the opposite side of the room.

A hood connected with a flue extending through the roof should be installed over wash sinks and pasteurizers so that steam from such places may be conducted away from the room. 


\section{CHAPTER IV \\ SEWAGE DISPOSAL}

\section{SEWER SYSTEM}

ALL rooms in the creamery, except the coal room and the refrigerator, should be connected with the sewer. Water from wash sinks should be conducted through a pipe directly into the sewer, a trap being placed under the sink. Some creameries have an open drain or gutter in the workroom, with the floor

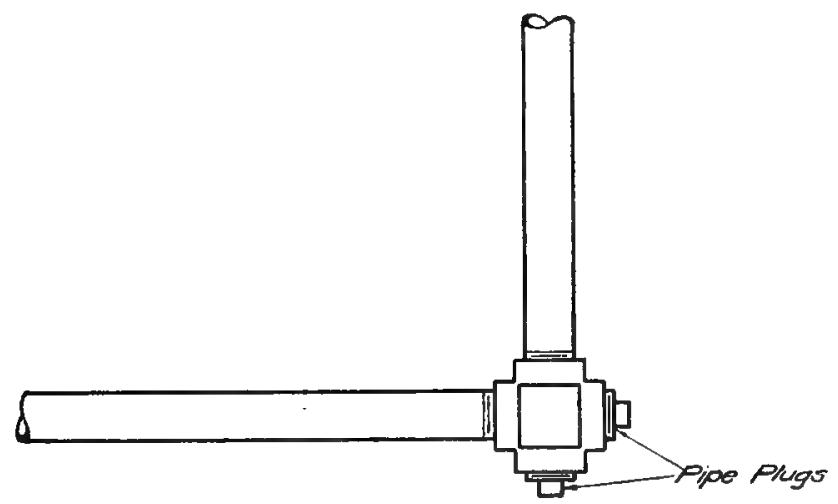

Frg. 5. - A sewer system that is readily cleaned.

sloping gently toward a trap through which the water runs into a closed tile or sewer system.

If tile is used in constructing the drainage system, it should be glazed. The tile should have a diameter of from 6 to 8 inches, and should be so laid that it may be cleaned with a wire or iron rod, if necessary. The sewer system in a large building should be constructed to clean readily by sections without requiring 
pipes to be cut. This may be accomplished by using Ts or double Ts instead of Ls, closing them with plugs.

Sewer Traps. - A sewer trap is a contrivance holding water, to be placed in local drainpipes wherever there is danger of air from a sewer getting into the interior of a building. The water acts as a seal against passage of gas in either direction, but permits free passage of liquid in the direction of the main sewer. The principal kinds of traps used in a creamery are the bell trap, the siphon trap, and the $S$ trap.

I. Bell Trap. - This is the one most commonly used in smaller creameries. In large creameries, the bell trap is often
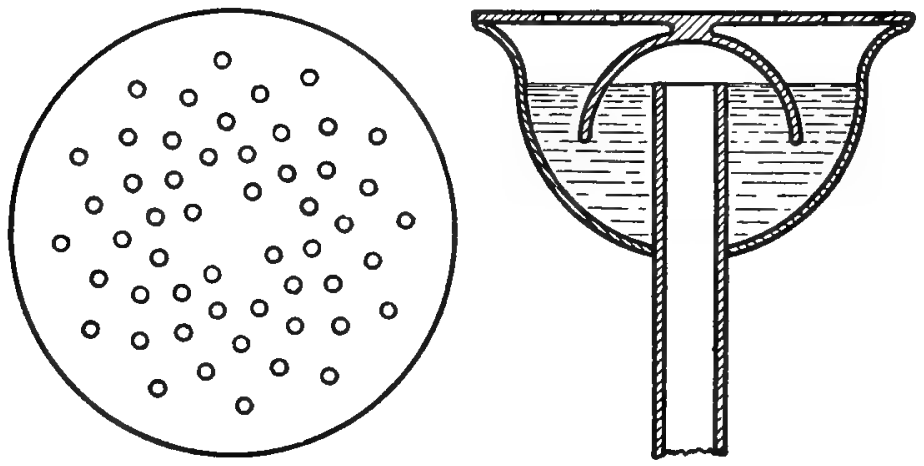

Fig. 6. - Bell trap.

used as a floor trap, while one of the other forms may be added to the sewer system. The bell trap alone usually affords sufficient protection in small plants when a comparatively large amount of water is passing through at short intervals and where the creamery sewer is not connected with some larger sewer system as in cities. A bell trap cannot be ventilated; therefore, whenever that is found necessary, another style of trap should be installed.

The principal reasons of insufficiency in a non-ventilated trap are:

I. An increased pressure of gas within the sewer may displace 
the water seal enough to permit passage of gas. When this does occur, the gas usually passes in the form of bubbles and can be detected in that way.

2. Excessive suction may draw so much water out of the trap that the remainder fails to act as a seal.

3. By evaporation, the water seal may be so lowered that gas is allowed to pass.

4. By absorption, the water may take up gas on the sewer side and liberate it on the house side.

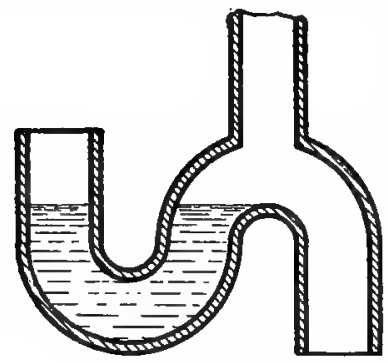

Fre. 7. - Siphon Trap.

2. Siphon Trap. - This is perhaps the most satisfactory of traps to be ventilated. The ventilator should be the same size as the pipe composing the drain. It is placed in the second curvature of the siphon. It is most satisfactory to place the ventilated trap in a local sewer before that enters the main sewer. Bell traps will then usually suffice for the floor traps.

3. S-Shaped Trap. - This type, which can be ventilated, is used frequently under sinks and to some extent, also, in the main sewer system.

Catch Basin. - It is well to have the large drain that leads out of a creamery connect with a catch basin a short distance from the building. This basin should be round, about 3 feet in diameter, and from 5 to 7 feet deep, depending on the slope of the ground. It may be built from either concrete or brick as happens to be most convenient. Its use is to catch all heavy materials, such as sand, nails, etc.; for this purpose, the bottom of the basin should be from 2 to 4 feet lower than the tile that carries the drainage away from it. This catch basin may be covered with plank and about a foot of dirt, thus preventing any odors from escaping. It should be inspected once or twice a year to make sure that it is in good working order. If filled up to any extent, it should be cleaned - the work of only a few minutes. 


\section{CESSPOOL}

In many places, the creamery will be required to purify its sewage before allowing it to enter the town sewer or before discharging it into public streams. For that purpose a cesspool or a septic tank is used.

The cesspool may be utilized if the subsoil is of a loose, sandy, or gravelly nature. The cesspool consists of a hole dug in such

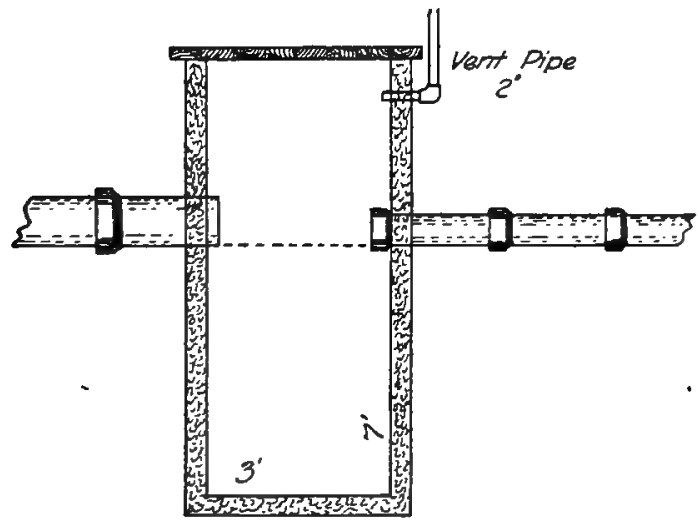

FIG. 8. - Catch Basin. ${ }^{1}$

soil of a size sufficient to hold several days' sewage. It should be walled up with stones not too closely fitted together and the top covered tight with planks and earth. The sewage water will seep away between the stones into the surrounding loose subsoil and thence gradually disappear. As this subsoil becomes clogged with suspended particles from the sewage, it gradually decreases in efficiency as a filter. Then a second cesspool is often dug, the sewage being conducted from one to the other through a tile placed some distance from the bottom of each pit.

The cesspool is hardly to be recommended, as it has too many possibilities for danger through contamination of well water. But if used, it should be located at least 400 or 500 feet from the well.

Bulletin 46, Minn. Dairy and Food Dep. 


\section{SEPTIC TANK}

In sewage purification, the septic tank proves of greater service and of less danger than the cesspool. In the latter, sewage is purified by filtration. In the former, it is cleansed mainly by a process of fermentation. This process involves the following principles which in turn influence the size and form of construction of the septic tank:

I. Solid matter in the sewage which is subject to fermentation must be given time to be decomposed by bacterial action. This calls for a tank large enough to hold several days' drainage.

2. The bacteria are anaerobic and work best where sewage is quiet and covered with air-excluding scum. To accomplish this, the tank is divided into compartments which will automatically retard the flow of sewage between intake and outlet and keep fresh sewage separate from the older, thus hastening decomposition in the latter.

It is maintained by some that the septic tank alone will be sufficient for the purification of sewage from the creamery. But it is safer to connect the septic tank with a filter bed over which the fermented sewage is discharged from the tank, either directly or through an intervening dosing chamber. By this method the purification of sewage is accomplished in two stages and with greater certainty of result.1

I. The reduction process, which takes place in the tank and under conditions of air exclusion. Here the solid matter held in suspension in the sewage is decomposed by fermentation into an easily burned substance.

2. The oxidation process, occurring in the filter bed and with greatest possible exposure to air. Here the products of reduction are spread over the surfaces of numerous soil particles and thus purified through oxidation.

Size of Tank. - The tank must be so large that it will hold sewage accumulations long enough for complete decomposition to take place. In creamery sewage, the solid matter is largely milk remnants in which decomposition is confined mainly to

1 Wisconsin Exp. Sta. Bulletin 245, rgr5, p. 54. 
liquefaction of protein, breaking up of milk sugars, and emulsification of fats. This generally necessitates a larger tank than for a like amount of ordinary sewage.

The size necessary to take care of this daily flow can be estimated in various ways, one being to assume that the amount of sewage will be from I to $I / 2$ gallons for every pound of butter manufactured. In general, a septic tank for creamery use should be large enough to hold the sewage which would accumulate for about six days in the summer season. As fermentation will be slower during winter, the sewage must be left longer in the tank in order to decompose; but this is offset by the smaller quantity of water used during winter months. Hence, one size will usually prove satisfactory the year round.

But before a septic tank is installed, the sewer from the building should be so connected that water which does not need purification may be conducted away from the creamery without passing through the septic tank, and only such drainage as needs purification should be admitted to the tank; otherwise, the sewage in the tank becomes too dilute and a much larger tank will be required. Chemicals, such as strong acids or alkalies, should be eliminated from sewage for the tank.

Construction of Tank. - The septic tank should be so located that its inlet is at least somewhat below the outlet from the factory. The most satisfactory material for construction is concrete. To facilitate decomposition, as explained above, the tank should be divided into three compartments of equal size. The outside walls and bottom should be about $\mathrm{I} 2$ inches thick; the partitions may be reduced to 6 or 8 inches in thickness.

Siphons connect the first compartment with the second and the second with the third. They prevent the scum from being carried away and thus destroying the putrefactive bacteria. They also prevent the drainage from running across the surface of the tank without remaining to be decomposed. These two siphons, together with the inlet and outlet pipes, may be constructed from 4-inch pipe.

The inlet pipe discharging sewage from the factory into the tank and the outlet pipe at the opposite end should each have 
an elbow on the inside of the tank so that the drainage will be delivered and take its exit below the surface of sewage already in the tank, thus not disturbing the scum.

The partitions, the elbows at the two ends, and the siphon connections all operate to compel the liquid to run slowly through the tank as desired and to keep the scum undisturbed. As the drainage enters, the substances not in suspension - solid matter, sand, etc. - settle to the bottom, and leave the liquid portion to be at once attacked by the numerous decomposing ferments beneath the scum.

The cover of the tank may be constructed from planks or from concrete, the latter being the most satisfactory. It should be provided with manholes through which the sediment in the tank may be removed at least once a year.

Dosing Chamber. - Farrington and Davis ${ }^{1}$ recommend that a dosing chamber be provided between the septic tank and the filter bed, its purpose being to compel the liquid from the tank to discharge onto the filter bed intermittently instead of continuously and thus allow air to permeate the filter bed at intervals.

The dosing chamber should be large enough to contain effluent from the tank sufficient to flood the filter bed from one to three inches deep. The depth of the chamber should equal the discharging depth of some standard siphon.

Filter Bed. - This is constructed from about a foot of gravel on top of which is added three or four feet of coarse sand, tile being laid at the bottom of the gravel for carrying the water away. Farrington and Davis estimate that the area of the filter bed should be such that the rate of application of the settled wastes would not exceed 25,000 gallons per acre in 24 hours. Thus, $\frac{\text { gallons of waste } \times 43,560}{25,000}=$ area of filter needed, in square feet.

If the effluent has too strong an odor, they recommend that chloride of lime be added to it in the dosing chamber about an hour before its discharge onto the filter bed. The proportion

${ }^{1}$ Wisconsin Exp. Sta. Bulletin 245, 19r5, p. 13. 

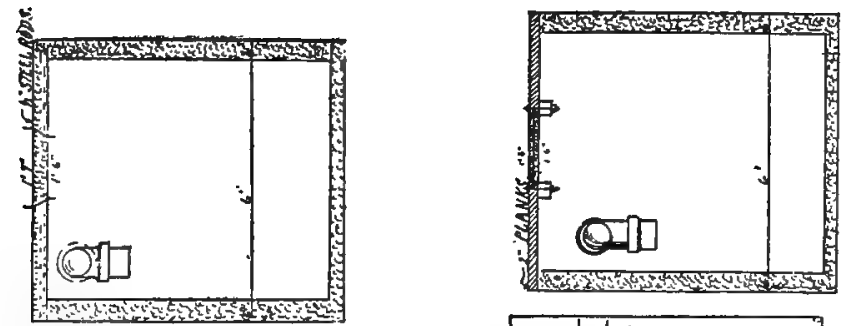

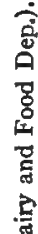
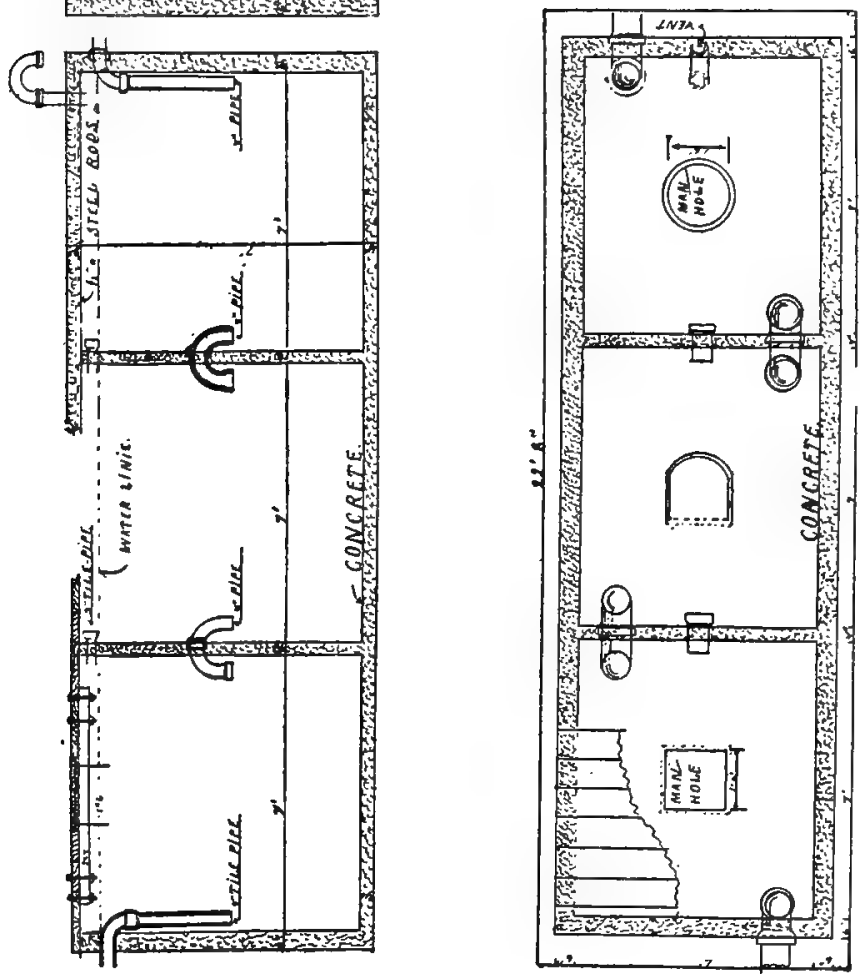

อ

.

올

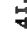

를

且

窇

.

范

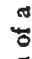

몽

운

.

8

곡

号 
of lime chloride thus added should be from I to 5 pounds to I,000 gallons of effluent.

Sewage for Irrigation. - Experiments have been carried on to some extent in Denmark and Ireland, using creamery sewage for irrigating purposes and flooding several small fields alternately by intermittent discharge. In the United States, this would be of little interest to city manufacturers and, for the present, of but small value to country operators. 


\section{CHAPTER V \\ REFRIGERATION}

ONE of the chief requirements in any creamery is adequate means for keeping the products it handles properly cooled. Refrigeration may be brought about either by a natural or by a mechanical system. In either case, however, it is essential that cooling rooms and cooling tanks are properly insulated.

\section{INSULATION}

A thermic insulator is anything which prevents or retards the transmission of heat. As applied to a creamery, insulation means the separation of its storage rooms from outside temperatures by non-heat-conducting walls, ceilings, floors, windows and doors. The insulator conserves refrigeration which has been created through natural or artificial means; hence, the slower its powers of heat transmission, the better the insulator will be. Any rules of guidance for effective insulation must, therefore, be based on the principles of heat transmission.

Transmission of Heat. - Heat may be transmitted in three ways:

I. By Radiation. - Heat is transferred from one body to another where the temperature of the intervening medium remains unaltered. This form of transmission is of less importance in considering the subject of insulation.

2. By Convection. - Heat is transferred by convection when it is carried from one point or object to another by means of some outside agent as air, water, or any gas or fluid; thus heat may be removed from a cold-storage room by the brine method of refrigeration. In the case of a refrigerator wall with large air space, the face next to the outer air is warmer than the face next to the cold room. In the air space, the air against the 
outer wall becomes heated and rises, its place being taken by the cold air against the inside wall. As this in turn becomes warm, it forces its way upward; the other air, having gradually cooled, drops to the bottom; thus a continuous circulation is set up inside the air space itself and heat is constantly transported by convection.

3. By Conduction. - This mode of transmission is accomplished by the transfer of heat from one molecule to another. It is the mode oftenest to be reckoned with in problems of insulation. The heat conductivity of dense substances, such as metals.whose molecules are heavy and close together, is high; the conductivity of lighter material, such as wood, is less; while that of the gases is extremely low. An absolute vacuum would be an absolute insulator, but that is practically impossible on a large scale. Material containing the greatest amount of air divided in the smallest air spaces forms the best insulating material.

Formula for Estimating Heat Conduction. - Of course, there is no building material or form of construction which gives perfect insulation. The total amount of heat which any given insulation will transmit in 24 hours is the measure of the refrigeration lost through imperfect insulation in that time, and hence of the refrigeration that must be applied every 24 hours to offset that loss and keep the storage room at a given degree of temperature. For calculating this loss and consequently needed offset, the following formula may be used:

$$
R=f n\left(t-t^{\prime}\right) \text { British thermal units } 1
$$

In the foregoing formula, $f$ represents the total square feet of insulating surface surrounding a given storage room - walls, floor, ceiling, windows, and doors; $n$ is the number of B. T. U. of heat transmitted through such surface every 24 hours for each square foot, for each degree Fahrenheit of difference in temperature between inside and outside of wall; $t$ is the average temperature outside the wall, and $t^{\prime}$ is the temperature to be

${ }^{1}$ A B.T. U. is the amount of heat required to raise the temperature of $I$ pound of water $\mathbf{r}^{\circ} \mathrm{F}$, at its greatest density. 
maintained inside. $R$ represents the number of units of refrigeration lost through these walls every 24 hours, and hence of refrigeration that must be supplied every 24 hours to offset that loss.

In other words, $R$ is the measure of ice meltage in 24 hours, expressed in British thermal units. This, translated into tons ${ }^{1}$ of ice which can support that meltage, gives the following formula:

$$
R=\frac{f n\left(t-t^{\prime}\right)}{284,000} \text { tons }
$$

Factors Governing Insulation of Storage Rooms. - The selection and use of insulating materials are to be guided by the following factors:

I. Insulating Powers of Materials, Structures, and Walls. The insulating power of any material, structure, or wall is really the same as its heat-conducting power applied inversely, and is measured by the value of $n$ as given in the formulas above.

A. Insulating Materials. - For different materials, Siebel \& gives the following values for $n$ :

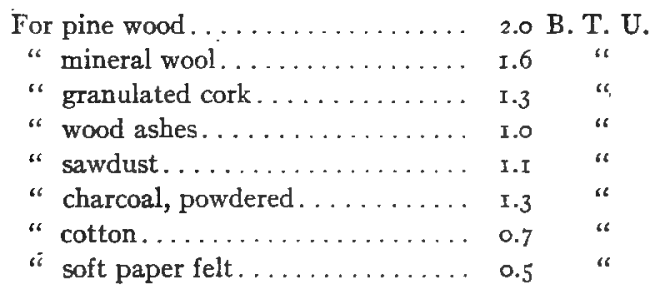

B. Insulating Structures. - In the following table by Starr, ${ }^{3}$ the value of $n$ for different structures is shown in column $I$. Column II shows the meltage of ice in pounds per 24 hours, where the difference in temperatures is $40^{\circ} \mathrm{F}$. and the transmitting surface is roo square feet.

1 To convert I pound of ice at $32^{\circ} \mathrm{F}$. into water at $32^{\circ} \mathrm{F}$. requires an amount of heat equal to $1_{42}$ B. T. U. - known as the "latent heat of fusion" for ice.

${ }^{2}$ Siebel's Compend. of Mechanical Refrigeration and Engineering, IgI , p. I17.

${ }^{3}$ Ibid, p. $\left.38 \mathrm{I}.\right\rfloor$ 


\section{TABLE I}

Transmission of Heat through Various Insutating Structures

\begin{tabular}{|c|c|c|}
\hline Structures & $I$ & $I I$ \\
\hline $\begin{array}{l}\text { 5/8-in. oak - paper, I in. lampblack, } 7 / 8 \text {-in. pine. (This is } \\
\text { the ordinary small stock family refrigerator.). . . . . . . }\end{array}$ & 5.7 & 160.7 \\
\hline One $7 / 8$-in. board, 1 -in. pitch, I $7 / 8$-in. board. . . . . . . & 4.90 & 138. \\
\hline $\begin{array}{l}\text { Four } 7 / 8 \text {-in. spruce boards, two papers, solid, no air space } \\
\text { Two double boards and paper (four } 7 / 8 \text {-in. boards), and one }\end{array}$ & 4.28 & 120. \\
\hline 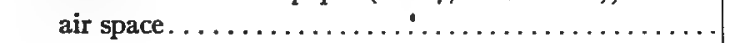 & $3.7 I$ & 105. \\
\hline One $7 / 8$-in. board, 2 -in. pitch, one $7 / 8$-in. board. . . . . . & 4.25 & IIg.7 \\
\hline $\begin{array}{l}\text { One } 7 / 8 \text {-in. board, } 21 / 2 \text {-in. mineral wool, paper, one } 7 / 8 \text {-in. } \\
\text { board } \ldots \ldots \ldots \ldots \ldots \ldots \ldots \ldots \ldots \ldots \ldots \ldots \ldots \ldots \ldots \ldots \ldots \ldots \ldots \ldots\end{array}$ & 3.62 & IOI.9 \\
\hline Two $7 / 8$-in. double boards and two papers, I-in. hair felt & $3 \cdot 318$ & $93 \cdot 4$ \\
\hline $\begin{array}{l}\text { Two } 7 / 8 \text {-in. boards and paper, r-in. sheet cork, two } 7 / 8 \text {-in. } \\
\text { boards and paper. . } \ldots \ldots \ldots \ldots \ldots \ldots \ldots \ldots \ldots \ldots \ldots \ldots \ldots \ldots\end{array}$ & $3 \cdot 30$ & 92.9 \\
\hline $\begin{array}{r}\text { One } 7 / 8 \text {-in. board, paper, } 2 \text {-in. calcined pumice, paper and } \\
7 / 8 \text {-in. board } \ldots \ldots \ldots \ldots \ldots \ldots \ldots \ldots \ldots \ldots \ldots \ldots \ldots \ldots \ldots \ldots\end{array}$ & $3 \cdot 3^{8}$ & 95.2 \\
\hline 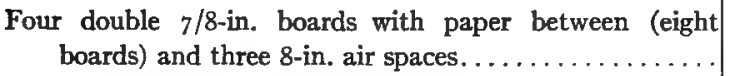 & 2.7 & 76 . \\
\hline Hair-quilt insulator, four boards, four quilts, hair. . . . . . & $2 \cdot 5 \mathrm{I}$ & 70.9 \\
\hline $\begin{array}{l}\text { One } 7 \text {-in. board, } 6 \text {-in. pat. silicated strawboard, air cell } \\
\text { finished inside with thin layer pat. cement. . . . . . }\end{array}$ & $2.4^{8}$ & 69.8 \\
\hline $\begin{array}{l}\text { One } 7 / 8 \text {-in. board, paper, } 3 \text {-in. sheet cork, paper, one } 7 / 8 \text {-in. } \\
\text { board } \ldots \ldots \ldots \ldots \ldots \ldots \ldots \ldots \ldots \ldots \ldots \ldots \ldots \ldots \ldots \ldots \ldots \ldots \ldots \ldots\end{array}$ & 2.10 & 60. \\
\hline $\begin{array}{l}\text { Two } 7 / 8 \text {-in. boards and paper, 8-in. mill shavings and paper, } \\
\text { two } 7 / 8 \text {-in. boards and paper. . . . . . . . . . . }\end{array}$ & I. 35 & 38.3 \\
\hline Same slightly moist. . . . . . . . . . & 1.80 & 50.7 \\
\hline Same $\operatorname{damp} \ldots \ldots \ldots \ldots \ldots \ldots \ldots \ldots \ldots \ldots \ldots \ldots$ & 2.10 & 60 . \\
\hline 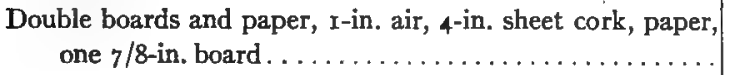 & I. 20 & 33.6 \\
\hline Same, with ${ }$-in, sheet cork $\ldots \ldots \ldots \ldots \ldots \ldots \ldots \ldots$ & .90 & $25 \cdot 3$ \\
\hline $\begin{array}{l}\text { 7/8-in. board, paper, } 1 \text {-in. mineral wool, paper, } 7 / 8 \text {-in. board } \\
\text { Double boards and papers, } 4 \text {-in. granulated cork, double }\end{array}$ & $4 \cdot 6$ & I3o. \\
\hline boards and paper. . . . . . . . & $\mathbf{1} .7$ & 48. \\
\hline
\end{tabular}

C. Insulating Walls. - Pine wood is a good insulator. When used for walls, the value for $n$ has been given as 2 B. T. U. 
Brick is a much better conductor of heat and therefore a poorer insulator. In accordance with results obtained in Germany, 1 the value of $n$ for a brick wall ro inches thick is $8.5 \mathrm{~B}$. T. U. If an air space is added to the wall, this figure is reduced to 6.I B. T. U. If the wall is absolutely air-tight, the thickness of the air space is immaterial.

According to the same report, sandstone and limestone are still higher conductors of heat than brick. In a I2-inch wall built from sandstone, the value was found to be Ir.o B. T. U.; and in a wall built from limestone of the same thickness, $n$ proved to be equal to $\mathrm{I}_{3} \mathrm{~B}$. T. U.

For a single-sashed window, the factor $n$ may be taken as I 2; for a double-sashed window, as 7 (Box).

D. Thickness of Insulation. - The heat-conducting powers of any insulation are approximately inversely proportional to its thickness, other conditions being equal. A Io-inch brick wall will transmit $8.50 \mathrm{~B}$. T. U., whereas a 40 -inch wall under the same conditions will transmit only $3.85 \mathrm{~B}$. T. U.

2. Temperature to be Maintained. - A decrease in the temperature to be maintained requires a corresponding increase in insulating power. This is illustrated in the following table:

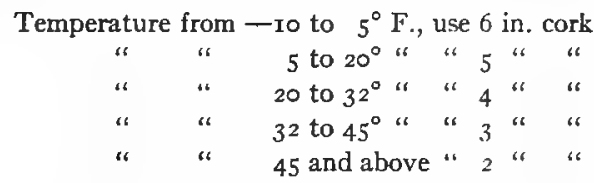

3. Climatic Conditions. - These will naturally affect the difference in temperature on the two sides of a wall and will consequently affect the transmission of heat. They should be given due attention when constructing a cold-storage room close to an engine room or a boiler room, or when constructing it with an outside wall face, or when locating it on a south rather than a north exposure.

4. Other Factors. - The materials used for insulation should be free from rot, mold, and offensive odors. In both nature of

${ }^{1}$ Siebel's Compend. of Mechanical Refrigeration and Engineering, I9I1, p. 382. 
materials and form of construction, the walls should be verminand germ-proof and should give no inducement for mice and rats to nest within them. Insulation should be not only moistureproof, but also elastic and of light weight to prevent settling. Other qualities to be regarded are the degree of fireproofness, durability, strength, appearance, cost, etc.

Construction for Insulation. - All refrigerators should be constructed with a vestibule. When the door of the vestibule is open, the door of the refrigerator should be kept closed, and vice versa.

I. Dead Air Space. - This is the oldest form of insulation. Although the air itself is a good insulator, it should be divided into small air cells to be most efficient. In a large space, heat is carried readily from one side of the wall to the other by convection, and the slightest crack or even nail hole will tend greatly to reduce insulating power.

The inefficiency of this form of construction is demonstrated by Ruddick." A refrigerator thus constructed with a 6-inch dead air space melted I,879 pounds of ice. During the same time and under the same conditions, a refrigerator of the same size and of same construction, except that the 6-inch hollow space was filled with sawdust, melted $\mathrm{I}, 328$ pounds of ice. The third type of refrigerator, similarly constructed with 6 inches of shavings, melted 1,055 pounds of ice during the same time and under the same conditions. The average temperature held in the refrigerators was $42^{\circ} \mathrm{F}$. for the one built with air spaces, $4 \mathrm{I}^{\circ} \mathrm{F}$. for the one insulated with sawdust, while the temperature was reduced to $37.6^{\circ} \mathrm{F}$. in the one insulated with shavings.

2. Sawdust and Shavings. - As already stated, both are efficient insulators; but they must be kept dry. Sawdust absorbs moisture more readily than shavings. When damp, both lose greatly in efficiency; and sawdust will then not merely become a most excellent conductor of heat, but will also settle and leave an empty space on top. Shavings, if properly packed, will not settle. They are, as a whole, the most satisfactory of the two materials.

1 Canada Dairy Commr. Rept. for 1906, pp. 52-55. 


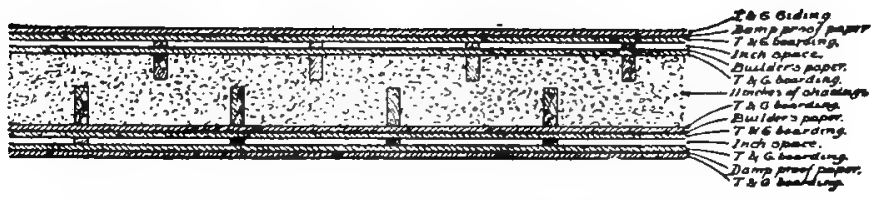

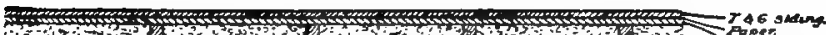

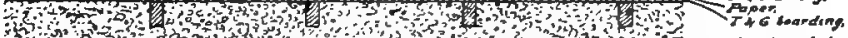

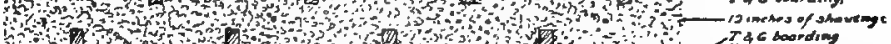

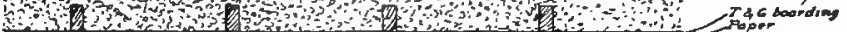

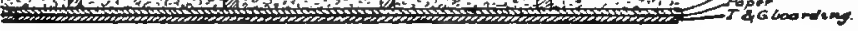
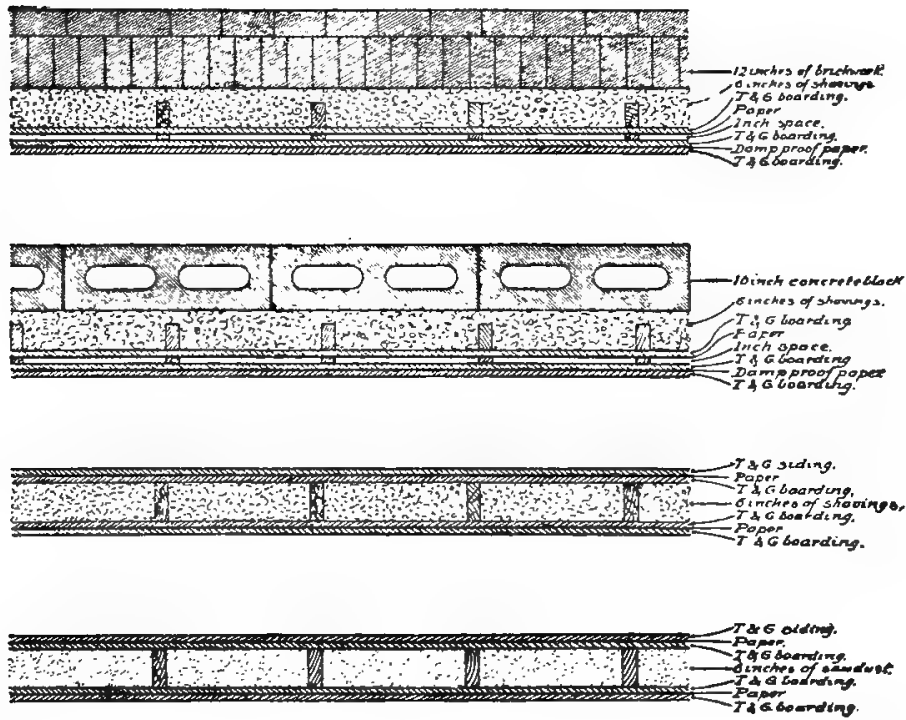

Fig. 10. - Sections of insulated walls by Ruddick. 
3. Cork. - Cork is perhaps one of the most satisfactory materials for both efficiency and durability. It is used in the form of granulated cork and also as cork slabs. Slabs are put on in one or more courses, in the latter case all joints being broken.

In accordance with instructions given by a constructing firm the cork board should be erected in a half-inch Portland cement mortar mixed in the proportion of one part Portland cement to two parts clean, sharp sand. Against the exposed surface of this cork board, a Portland cement plaster finish, about $1 / 2$ inch in thickness, is applied in two coats. The first coat is approximately $1 / 4$ inch in thickness, mixed in the proportion stated above, and rough scratched; the second coat is approximately $1 / 4$ inch in thickness, mixed in the proportion of one part Portland cement to one and one-half parts of clean, sharp sand, and brought to a finish with a steel trowel. The plaster should be kept wet by daily sprinkling for at least a week after the second coat is applied, in order to reduce cracking to a minimum.

The ceiling and floor are insulated in a manner similar to the wall. The cork boards should fit closely together at the corners (see Fig. II). The floor, if a ground floor, should be dug down to such depth that, after the insulating material has been applied, it will be level with other floors in the building. Such a floor may be constructed as follows: After the ground has been properly graded, cinders to the depth of about 4 inches or more may be added. These are thoroughly packed and on them is placed about 4 inches of concrete. On top of this the cork boards are laid so as to join with the cork boards of the walls. The floor is finished by adding about 4 inches of concrete on top of the cork and then about $1 / 2$ inch of finishing cement, as in laying any other cement floor.

4. Mineral Wool. - Mineral wool is made from the slag of blast furnaces. It will absorb moisture; but aside from that, it meets the requirements of an efficient insulating material. It is now fumished in slabs as the most convenient form for use. In this form it may be put on walls in the same manner as cork slabs; but, not being waterproof, it is usually put on 


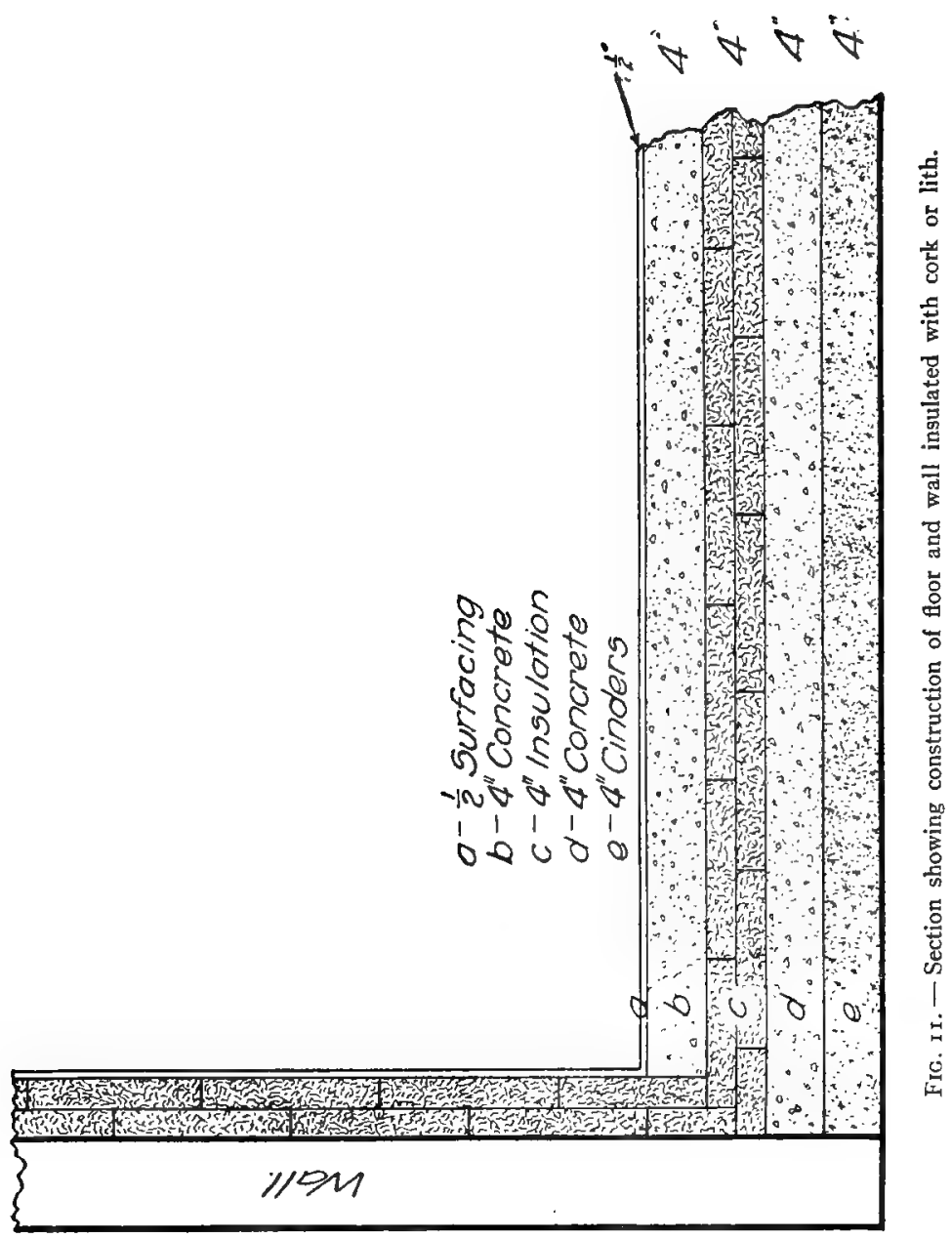


with a waterproof hot cement made from a mixture of pitch and asphaltum. As in the case of cork, it is finished in a smooth cement plaster.

5. Lith. - Lith is considered to be as satisfactory an insulating material as cork, except that it takes up moisture more readily. It is cheaper than cork. The construction with lith is the same as with cork. ${ }^{1}$

6. Other Materials. - Other insulators, such as hair felt, might be mentioned; but this has not become of much importance for creamery-storage insulation.

\section{SYSTEMS OF REFRIGERATION}

Two systems of refrigeration exist - the "Natural" and the "Mechanical." The natural system uses ice as its source of refrigeration; while the mechanical system removes the heat by merchanical methods.

\section{NATURAL REFRIGERATION}

Methods. - In natural refrigeration, the ice used for cooling purposes must be stored, requiring an ice house more or less insulated. In using that ice for chilling stored products, the refrigerator may be cooled by any one of three different methods. The temperature may be lowered by the use of ice placed in an ice bunker located in the refrigerator, or by connecting the refrigerator with a contiguous insulated ice house, or by installing a tank above the refrigerator from which ice-cooled brine is circulated through the refrigerator in a system of pipes.

1. Ice Bunker Method. - This is the oldest form of refrigeration and is yet in most common use in the smaller creameries. The ice is placed in a bunker overhead and usually at one end of the refrigerator. The refrigerator is frequently built against an outside wall through which a small refrigerator door admits ice from outside to the ice bunker. By leaving this door open during cool nights, the refrigerator may be kept in good condition without ice during a good portion of the year.

\footnotetext{
${ }^{1}$ For mineral wool slabs and Lith metal lath should be used for holding the plaster.
} 
The ice bunker should be so placed and constructed that it will cause circulation of the air in the refrigerator. This is done by placing a tight board screen on one side of the bunker and slats or cleats 'on the opposite side (Fig. I2). The air will then enter the ice bunker from above the board screen and come in contact with the ice. The moisture from the air unites with the water melting away from the ice and is carried away with it; the air, which thus becomes dryer and chilled by the ice, descends through the open side of the bunker. If both sides

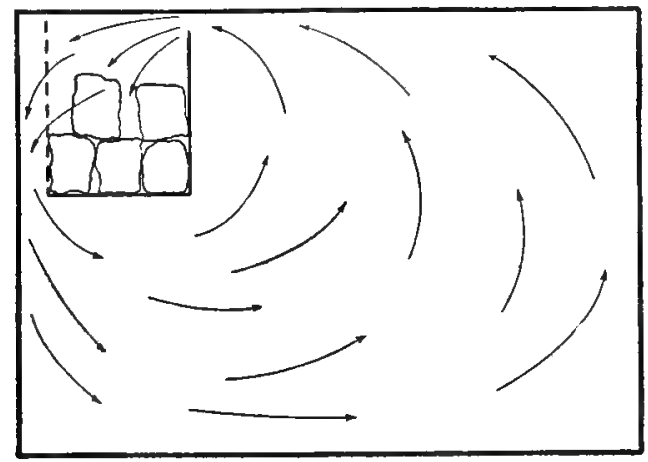

FIG. 12. - Section showing perfect air circulation in an ice bunker refrigerator.

were open, the air would descend from both sides and thus result in conflicting currents which would check the circulation.

The bottom of the ice box on the inside is covered with galvanized iron sheeting turned up on the walls of the box from 4 to 6 inches. From this galvanized pan a galvanized iron pipe carries the water away. This water may be collected outside of the refrigerator and, if the ice is clear, may be used for testing and other laboratory purposes. The pipe carrying water from the ice pan should be equipped with a trap to prevent communication of air between the refrigerator and the outside. The bottom of the ice box should be insulated on the outside and the ends of the box tightly boarded up. 
2. Insulated Ice House Method. - By this method, the refrigerator is connected directly with the ice house. This plan, as far as known, originated in Minnesota ${ }^{1}$ and in Canada. ${ }^{2}$

A. Advantages. - The principal claim made for this ice house is its saving of labor, as the ice need not be handled after once placed in the ice house. It is also more sanitary than the old-style ice bunker, and the refrigerator connected with the insulated ice house is always dry and well cooled. Furthermore, as the ice taken from it is always clean, none is lost through having to cleanse it before using. The only disadvantage that might be mentioned here is the original cost of construction.

B. Construction. ${ }^{3}$ - For the construction of this system, it is recommended that the ceiling in the ice-storage part should be as high as possible - from 16 to $22 \mathrm{feet}$, while the refrigerator room should be from $61 / 2$ to $7 \mathrm{~T} / 2$ feet high. The walls between the ice house and refrigerator need not be as heavily insulated as the outside walls; but they should be as nearly air-tight as possible, except near the floor and ceiling where openings should be provided for circulation of air. The cold air will pass from the ice-storage room into the refrigerator through the floor vents, will gradually warm up and rise to the ceiling, and will thence pass back into the ice-storage room again through air flues, coming there in contact with the ice and depositing its absorbed moisture. The air flues from the upper vents are necessary in order to make the air pass over to the farther wall and thus effect a complete circulation throughout the ice house. To allow free circulation, the total area of all openings at the floor should equal about 600 square inches, with the same total for ceiling vents. These vents should be closed during winter weather to keep the refrigerator from getting too cold.

The walls, ceiling, and floor of this ice house should be insulated in the same manner as regular cold-storage rooms, not less than 4 inches of cork or lith being used. It is recommended that the floor of the ice room have a slope of $3 / 8$ inches to the

${ }^{1}$ Bulletin 4I, Minnesota Dairy and Food Department, Igr2.

${ }^{2}$ Report of Dairy Commissioner for the Dominion of Canada, rgo6.

${ }^{3}$ Bulletin No. 4 I of Minnesota Dairy and Food Department, Igr 2. 
REFRIGERATION

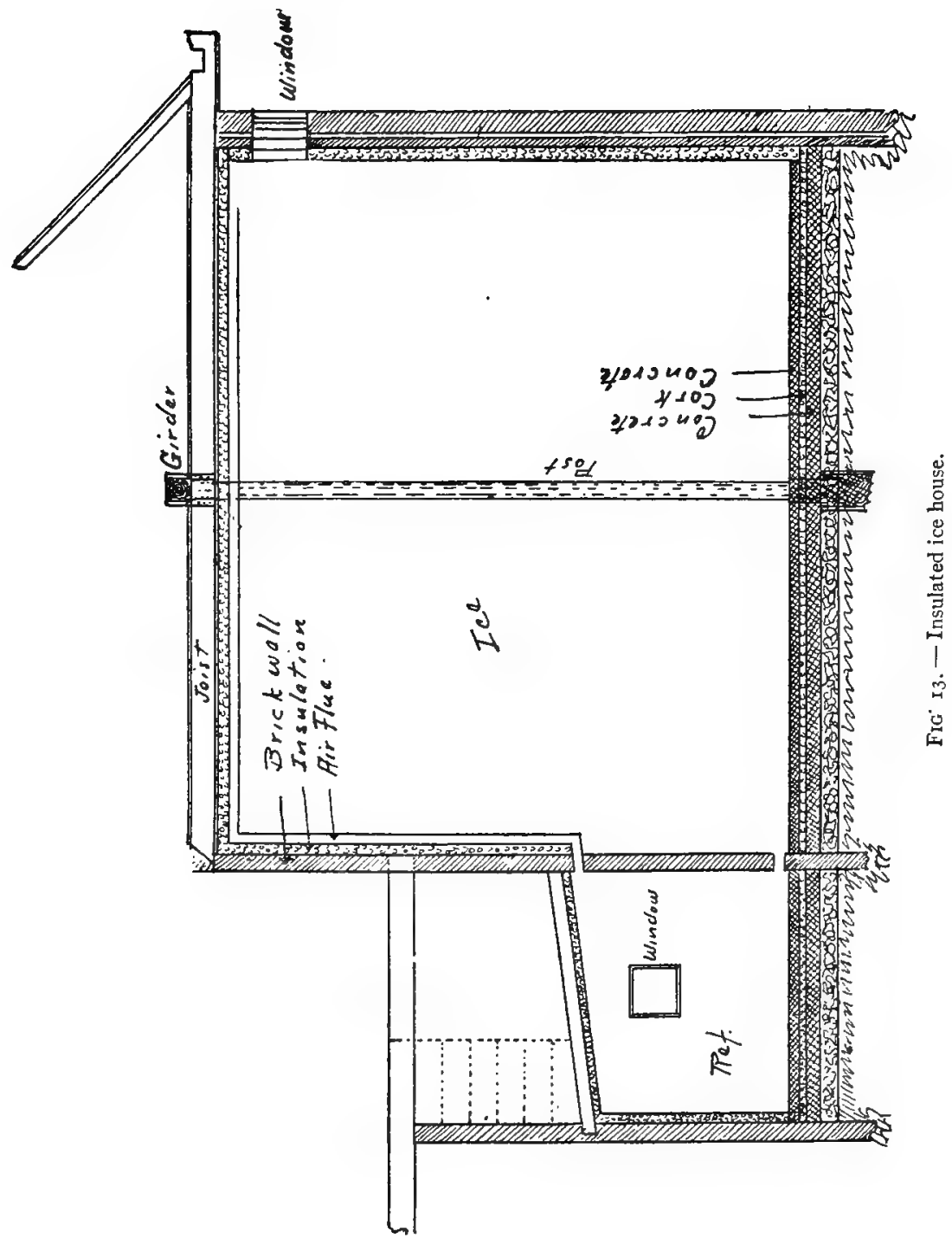


foot, leading to a cement tank set in the corner of the ice-storage room to catch ice meltage. This meltage can be pumped thence to the cream vats for cooling purposes. The tank should be 3 feet by 4 feet by 8 feet deep, or larger, and set flush with the floor. It should have an overflow connected with the sewer through a trap. Two $1 / 1 / 4$-inch galvanized iron pipes should be laid in asphalt and granulated cork 4 feet below the floor, connecting the tank with the cream vats through a pump. By one pipe the cold water will be carried from the bottom of the icemeltage tank to the bottom of the cream vats, and by the other pipe that water will be returned to the same tank from the surface of the cream vats. If the water in the tank is not sufficient to cool a large amount of cream, ice may be placed in this tank instead of bringing it into the creamery.

A small window with six or seven layers of sash, giving five or six intervening air spaces, should be placed next the ceiling of the ice room to give light. Another similar window should be placed in the refrigerator, about 5 or 6 feet above the floor.

The outside door to the ice house should be 3 by 7 feet.

C. Filling the Ice House. - While packing the ice, a working space about the size of four cakes of ice should be left inside the doorway. It is recommended that the ice be cut into oblong cakes and be piled lengthwise and crosswise in alternate layers, thereby binding together and preventing the ice from leaning against the wall. When the ice room has been filled, the outside door should be closed and sealed with suitable insulation.

3. Gravity-Brine Method. - This method of refrigeration consists of a system of continuous coils of pipe containing brine of such strength that it will not freeze. Part of this system of coils extends through a salt-and-ice tank above the refrigerator. Here ice and salt are mixed in proper proportions to insure the desired temperature for the brine passing through it. The brine thus cooled descends by force of gravity through the lower portion of the coil extending through the storage room. There it takes up the excess heat from the room and is again forced up through the cooling tank by the cooler and heavier brine, thus establishing a complete circulation. The greater 
the difference between the temperature in the cooling tank and the temperature of the refrigerator, the greater is the velocity of circulation.

4. Common Ice House. - This is the kind of ice house used with the ice bunker and with the gravity-brine methods of re-

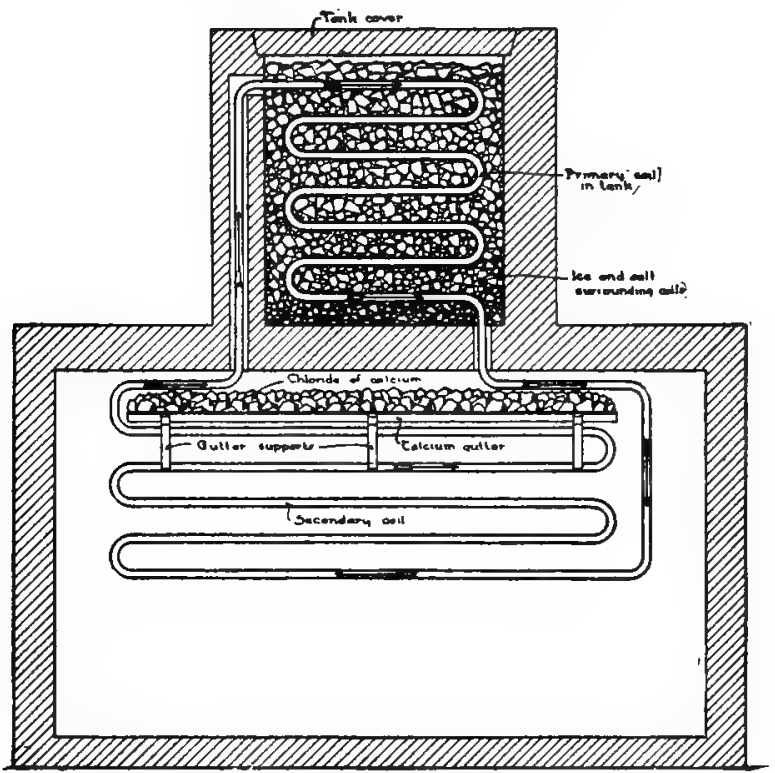

Frg. I4. - The Cooper gravity brine system and chloride of calcium process.

frigeration. It is not connected with the refrigerator and is seldom insulated to the extent of the one used in the insulated ice-house method. It is often constructed from one thickness of boards; and when packing the ice, space is allowed for one foot of sawdust to be packed between the ice and the wall. Some ice houses are built with a double wall insulated with from 8 to 12 inches of shavings. If the walls are thus insulated, it is advisable to have the floor also insulated; and for this purpose no insulation is more satisfactory than cinders and cork. 
The ice should be packed as already described, and may be covered with prairie hay.

Estimating Ice Storage. - In building for ice storage, it is necessary to determine the space required which, in turn, is dependent on the amount of ice likely to be needed during the year. For these estimates there are more or less definite methods of calculation.

I. Amount of Ice Required. - In determining the amount of ice to store, we should consider the loss of ice due to melting in the ice house, the loss of ice in the refrigerator due to conduction of heat through walls, floor, ceiling, etc., the amount of ice required for chilling the particular products kept in the refrigerator, and the amount of ice used in the factory for various purposes. In the problems that follow, it is supposed that ice will need to be used for refrigeration only about 6 months in the year, on the average.

A. Loss from Shrinkage in Stored Ice. - In an ice-storage house without artificial refrigeration, Siebel ${ }^{1}$ estimated the shrinkage from January to July to be I/Io pound of ice every 24 hours for every square foot of wall surface; or, in round numbers, from 6 to ro per cent of the ice stored during the 6 months mentioned. In the average creamery ice-storage house, the shrinking is usually estimated to be nearer 20 per cent; and this latter rate is the factor used in the following calculations.

B. Loss from Imperfect Insulation of Refrigerator. - (See also the general formula, p. 62.) In refrigerators constructed in accor ance with Table I (p. 63), the average loss in refrigeration per day is 3 B. T. U. for each square foot, for each degree of difference in temperature between the outside of the refrigerator an its inside. This average of $3 \mathrm{~B}$. T. U. may reasonably be considered as the unit of loss in 24 hours from the average creamery refrigerator. Consider that, in a refrigerator to feet square by 8 feet high, the temperature within the refrigerator is $40^{\circ} \mathrm{F}$. and that outside of the refrigerator is $70^{\circ} \mathrm{F}$. - a fair average for the 6 months. Then area of walls, floor, and ceiling is equal to 520 square feet.

${ }^{1}$ Siebel's Compend. of Mechanical Refrigeration and Engineering, 191 I, p. 207. 
The amount of ice melted due to heat that is being conducted through walls, floor, and ceiling during a period of 6 months or I 80 days is equal to

$$
\frac{520 \times 3(70-40)}{284,000} \times 180=29.66 \text { tons. }
$$

C. Ice Required for Chilling Prolucts Stored. - Different products take up a different amount of refrigeration for each degree that temperature is reduced. This depends on the specific heat ${ }^{1}$ of the product. The specific heat of butter at $60^{\circ} \mathrm{F}$. is .53 B. T. U.; ${ }^{2}$ that of cream at the same temperature is .84 . Suppose the refrigerator is used for butter only, and that 600 pounds daily has to be reduced in temperature from $60^{\circ}$ to $40^{\circ} \mathrm{F}$. Then

Daily heat removed from 600 pounds of butter $=$

$$
600 \times .53 \times(60-40)=6,360 \text { B. T. U. }
$$

If the butter is packed in tubs or boxes, it will furthermore be necessary to reduce the temperature of these containers to the same extent. Suppose ash tubs of 60 pounds capacity are used, that each tub weighs Io pounds, and that the specific heat of wet ash wood be $.4 .^{3}$ Then

Daily heat removed from to tubs $=100 \times 4$ B. T. U. $X_{20}$ $=800 \mathrm{~B}$. T. U.

Daily ice required for cooling butter and tubs $=\frac{6,360+800}{142}$ $=50.42$ pounds.

Total ice required for 6 months $=50.42 \times 180=9,075.6$ pounds; or, $\frac{9,075.6}{2.000}=4.54$ tons.

${ }^{1}$ The specific heat of any substance is the amount of heat, expressed in B. T. U., which will be absorbed by $I$ pound of that substance in raising its temperature $\tau^{\circ}$ F.; conversely, it is the amount of heat, in B. T. U., which will be given off by I pound of that substance in lowering its temperature $I^{\circ} \mathrm{F}$.

${ }^{2}$ Research Bul. 14, Iowa Agr. Expt. Sta., Igr3

${ }^{3}$ Bulletin I IO, U. S. Forestry Bureau, gives the specific heat of dry white ash as .327 . 
D. Ice Used in the Factory. - In a creamery where only butter is manufactured, ice is used in the factory only for cooling the cream to churning temperature - in this instance, supposed to be $50^{\circ} \mathrm{F}$. Cream is usually cooled first with water to about $65^{\circ} \mathrm{F}$. If the water is quite cool, it may be used to reduce cream temperature to $60^{\circ} \mathrm{F}$. or even lower.

In manufacturing 600 pounds of butter daily, we can estimate the amount of cream handled daily to be about $I, 800$ pounds. Then

Daily ice required to cool cream from $65^{\circ} \mathrm{F}$. to $50^{\circ} \mathrm{F} .=$ $\frac{\mathrm{I}, 800 \times .84 \times 15}{142}=\mathrm{r} 59.7 \mathrm{I}$ pounds.

Total ice required for 6 months $=\mathbf{I} 59.7 \mathrm{I} \times \mathbf{I} 80=28,747.8$ pounds; or, $\frac{28,747.8}{2,000}=14.37$ tons.

In addition to this, a further loss -- probably ro per cent is to be reckoned in for ice lost in handling, in cooling water used for circulation, and in absorption of heat from the atmosphere. Losses in refrigeration due to opening of doors and to heat given off by persons, lights, etc., do undoubtedly occur; but there seems no way of reducing them to definite calculation. It should furthermore be borne in mind that ice is used for cooling purposes during the entire year and that the creamery during the winter months is handling about 50 per cent as much product as during the summer season. Therefore

Total ice used for cooling cream for $\mathrm{I}$ year

$$
=14.37 \times \frac{10}{9}+\frac{14.37 \times \frac{10}{9}}{2}=23.95 \text { tons. }
$$

Total amount of ice used for the creamery during the year:

Loss due to conduction from refrigerator. . . . . . 29.66 tons

Ice required for chilling the product. . . . . . . . 4.54

Ice required for cooling cream, etc. . . . . . . . . 23.95 
Adding to this the 20 per cent loss of ice in the ice house, we arrive at the total amount of ice that should be stored for a plant of such size and operated under such conditions as specified.

$$
58.15 \times \frac{\text { IO }}{8}=72.69 \text { tons. }
$$

2. Space Required for Ice Storage. - The weight of I cubic foot of water at $60^{\circ} \mathrm{F}$. equals 62.355 pounds; the specific gravity of ice is considered to be from .917 to .922 , the average being .92. Therefore

Weight of $\mathrm{I}$ cubic foot of ice $=62.355 \times .92=57.37$ pounds.

Space in cubic foot required to store 72.7 tons of ice $=\frac{72.7 \times 2,000}{57.37}=2,534$ cubic feet.

In addition to this, from Io to 20 per cent should be allowed for spaces between ice-blocks and for sawdust insulation in the ice house.

An ice house built in the form of a cube is most satisfactory. Each dimension of this cube of ice, with insulation, is, with 20 per cent allowance, equal to $\sqrt[3]{2,534 \times \frac{120}{100}}=14.5$ feet.

To this figure should be added the amount of overhead space required for working purposes. 


\section{CHAPTER VI \\ MECHANICAL REFRIGERATION}

\section{GENERAL DISCUSSION}

History of Mechanical Refrigeration. - The mechanical system of refrigeration is of rather recent origin. In 1834, Jacob Perkins of London invented an ice machine using volatile liquid. In this machine ether was vaporized and expanded under reduced pressure maintained by the suction of a pump, the heat required for such vaporization being abstracted from the substance to be cooled. The resulting vapor was compressed by the same pump into a vessel cooled by water, where it was liquified.

This machine contaired all four of the essential features present in all modern compression systems; namely, the evaporator or expansion coil, the compressor, the condenser, and the regulating valve between the condenser and the evaporator. Yet his system was not generally adopted, and it was not until 186 that an ice machine was successfully used for commercial enterprises.

Principles Involved. - Mechanical refrigeration is based upon the fact that a liquid, when converted into vapor, absorbs heat from surrounding bodies. Chemicals which at boiling point are considerably below the temperature of the surrounding air, which are reasonably cheap, and which can be handled with the least danger to life and property, are therefore used in the refrigeration process. The chemical complying most fully with such requirements is ammonia, and it is the liquid most frequently used for mechanical refrigeration. Other chemicals, such as carbonic acid and sulphuric dioxide, are used to a limited extent.

Ammonia. - Ammonia is used in one of two forms, either as 
"Anhydrous ammonia" or as "Aqua ammonia." The former is free from water and exists in both gaseous and liquid form; the latter is in the form of a solution of which about $29 \mathrm{I} / 2$ per cent is anhydrous ammonia. The anhydrous ammonia is used in refrigerating machines of the compression type; aqua ammonia is used in refrigerating machines of the absorption type.

Pure anhydrous ammonia, under ordinary temperature and atmospheric pressure, exists in the form of gas or vapor; but under atmospheric pressure at a temperature of $-30^{\circ} \mathrm{F}$., it becomes liquid. It will also liquefy at higher temperatures if the pressure is sufficiently increased. In its liquid form it is colorless, has a strong alkaline reaction, boils at $-29^{\circ} \mathrm{F}$. under atmospheric pressure, and its latent heat of vaporization is 555 B. T. U. ${ }^{1}$ Its specific gravity at $32^{\circ} \mathrm{F}$. is 0.6364 . One pound of this liquid, after being vaporized and the vapor raised to $32^{\circ} \mathrm{F}$., will occupy a space of 21.017 cubic feet under atmospheric pressure.

Ammonia attacks copper and brass but not iron or steel, and this fact determines the metal from which compression machinery must be made. Ammonia decomposes at $900^{\circ} \mathrm{F}$. if in pure condition; but if it contains impurities, it may decompose at comparatively low temperatures. Ammonia may contain impurities which will not influence its stability; but if mixed with another brand of ammonia containing a different kind of impurities which alone would not have any influence on its stability, such ammonia may deteriorate much more readily owing to the fact that the impurities of one supplement the impurities of the other and cause decomposition. This explains the advisability of not mixing different brands of ammonia.

\section{COMPRESSION SYSTEM}

In this type of refrigeration, the ammonia operates in a cycle: First, the liquid or inactive stage; second, the vaporizing or actively refrigerating stage, taking place in the expansion

${ }^{1}$ The latent heat of vaporization for any liquid is the total amount of heat, expressed in B. T. U., which is required to change I pound of that liquid at the boiling point into vapor. 
coils; third, the liquefying stage, during which the vapor or gas is again reduced to its liquid form in two successive steps compression and heat extraction or condensation. Being thus returned to its original liquid form, the ammonia may be used over and over again in successive cycles of refrigerating activity.

The machinery through which this cycle operates is composed of four principal parts: First, the expansion coil; second, the ammonia compressor; third, the condenser, and fourth, the expansion or regulating valve.

Expansion Coil. - This is that part of the system where refrigeration takes place. Through reduction in pressure, the liquid ammonia is there changed into a gas, thus absorbing heat from its surroundings and thereby effecting refrigeration.

This expansion coil may be located directly in the refrigerator and serve as the refrigerating coil, in which case it is called the "Direct Expansion" method of cooling. On the other hand, the expansion coils may be placed in a tank of brine from which the brine in turn is circulated through refrigerating coils located in the refrigerating room. This indirect method of cooling is known as the "Brine Method."

I. Direct Expansion. - The system of direct expansion is adapted especially for rooms that are to be cooled to an extremely low degree of heat and in places where the machine is operated constantly. It cannot, therefore, be considered the most ideal method for the smaller creamery or dairy.

2. Brine Method. - This is the system which is most suitable for the average creamery. The brine tank should be located in the refrigerator in a position and with insulation similar to that of the ice bunker described under the natural system of refrigeration (Chapter $\mathrm{V}$ ). The larger body of brine retains a more constant temperature, and in a smaller dairy the compressor may be operated only for a short time daily in order to reduce the temperature of the brine and so maintain the necessary refrigeration.

The brine, when thus cooled, may be circulated by the aid of a pump through a system of coils extending through various refrigerator rooms. This brine carries back to the brine tank 


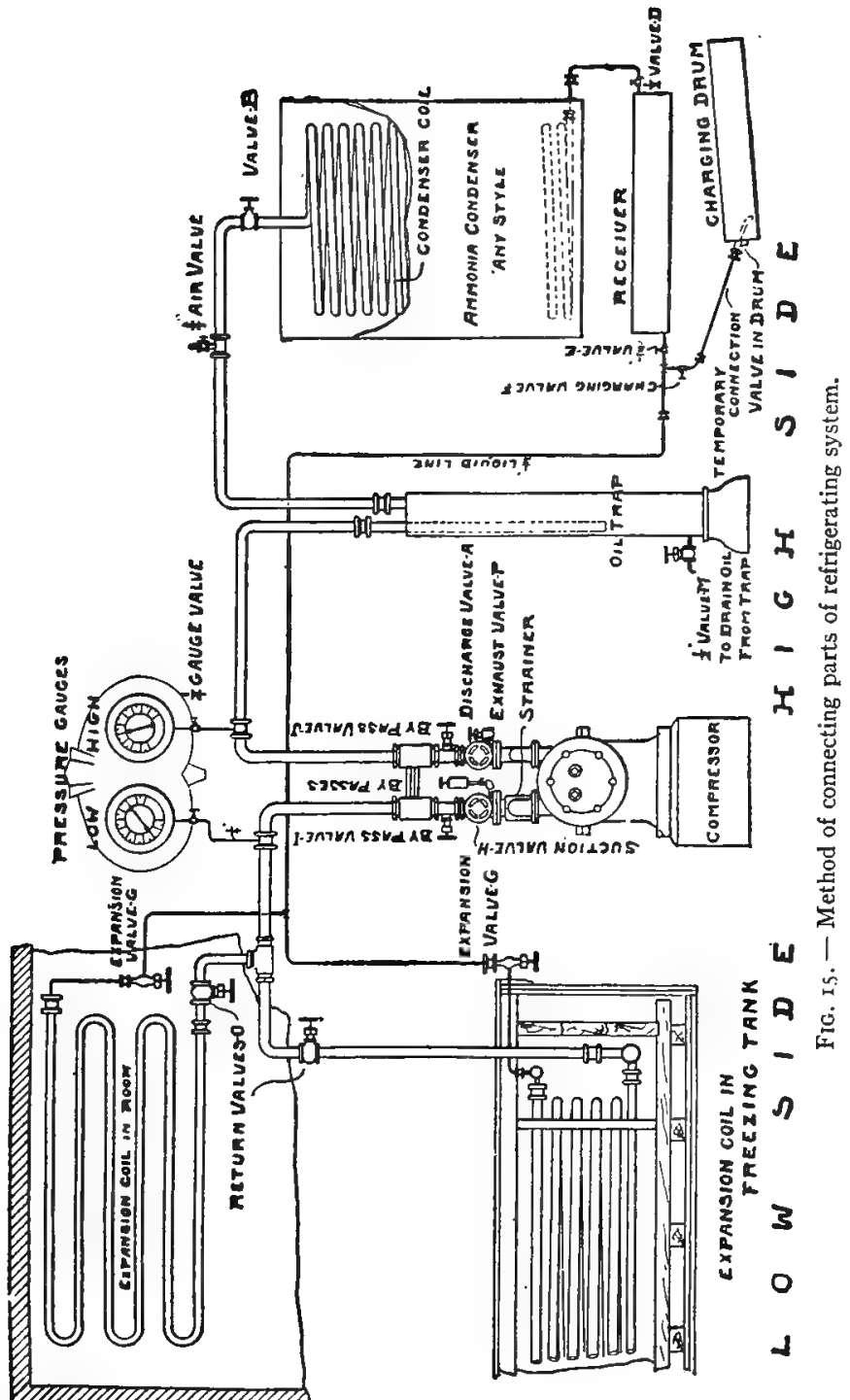


the heat it has removed from these rooms; here, in turn, this heat is taken up by the vaporizing ammonia in the expansion coils. Ice-cream freezers and cooling tanks may be connected with the brine circulation, thus saving the handling of ice for cooling purposes and its consequent loss from meltage. It may not be advisable, however, to connect the brine directly to the cream ripeners as it is apt, in time, to cause the cooling coil of the cream vat to leak. The more satisfactory way is to have a separate cooling tank in which the water used for cooling the cream is first cooled by the brine.

3. Brine-Tables. - The brine may be made from either sodium chloride or calcium chloride. The latter is most commonly used, owing chiefly to the fact that it does not cause the iron pipes and pumps to deteriorate as does the former. The brine should be kept at such a strength that it will not freeze; therefore, if lower temperatures are desired, the brine should be of higher specific gravity. For readily determining what strength of solution will give a desired result under a given temperature, tables have been published.

The table on page 73 is that prepared by Van Schaack \& Sons of Chicago.

4. Piping Required for Each Method. - The amount of piping required for a refrigerator room depends primarily on the temperature to be maintained in the room and the temperature of the refrigerating medium. Siebel estimates that for direct expansion one running foot of 2 -inch pipe ${ }^{1}$ will take care of 10 cubic feet of space in rooms that are kept below freezing to a temperature of $10^{\circ} \mathrm{F}$.; that one running foot of 2-inch pipe will take care of 40 cubic feet of space in rooms to be kept at or above $32^{\circ} \mathrm{F}$. or thereabout. It is a general rule in practice to allow from one and a half to two times as much surface for brine circulation as for direct expansion.

Ammonia Compressor. - The ammonia compressor is a machine which draws the ammonia gas from the expansion coil into the compressor, whence it is forced into the condenser

${ }^{1}$ The surface of one running foot of 2 -inch pipe is equal to 1.44 feet of $11 / 4$-inch pipe, or to 1.8 feet of 1 -inch pipe. 
MECHANICAL REFRIGERATION

TABLE II

Table of High Test Chloride Calcium Solutions

\begin{tabular}{|c|c|c|c|c|c|c|}
\hline \multicolumn{2}{|c|}{$\begin{array}{c}\text { Chlor. of Calcium } \\
\text { to I Gallon of } \\
\text { Solution }\end{array}$} & $\begin{array}{l}\text { Degrees } \\
\text { Baumé } \\
60^{\circ} \mathrm{F} .\end{array}$ & $\begin{array}{c}\text { Salomeler } \\
60^{\circ} \mathrm{F} .\end{array}$ & $\begin{array}{l}\text { Spccifle } \\
\text { Gravity } \\
60^{\circ} \mathrm{F}\end{array}$ & $\begin{array}{l}\text { Pcr Cont } \\
\text { of } \\
\text { Calcium }\end{array}$ & $\begin{array}{c}\text { Freezing } \\
\text { Point } \\
\text { Fahren- } \\
\text { heit }\end{array}$ \\
\hline - & & I & 4 & 1.007 & & $+3 \mathrm{I}$. \\
\hline 一 & & 2 & 8 & I.OI4 & 2. & +30 . \\
\hline - & & 3 & I 2 & I . O2I & 2. & +29. \\
\hline- & & 4 & I6 & 1.028 & $3 \cdot 5$ & +28.5 \\
\hline $1 / 2 \mathrm{pc}$ & and & 5 & 20 & I. .035 & 4. & +28 \\
\hline- & & 6 & 24 & I. 043 & 5 & +27 \\
\hline- & & 7 & 28 & 1.051 & 6. & +25.5 \\
\hline - & & 8 & 32 & I. $05^{8}$ & 7. & +24 \\
\hline $\mathbf{I}$ & “" & 9 & 30 & I. .066 & 7.9 & +23 \\
\hline- & & 10 & 40 & 1.074 & 9. & +22 \\
\hline- & & II & 44 & 1.082 & 9.8 & $+2 \mathrm{I}$ \\
\hline- & & I 2 & $4^{8}$ & 1.090 & 10.5 & +20 \\
\hline $11 / 2$ & " & 13 & 52 & I. .098 & II. 5 & +19 \\
\hline -- & & I 4 & 56 & I. 107 & I 2.5 & +17 \\
\hline- & & I 5 & 60 & I. I I 5 & $13 \cdot 5$ & $+\mathrm{I} 4.5$ \\
\hline 2 & " & I6. 5 & 62 & I.I 22 & I5. & +12. \\
\hline- & & I 7 & 64 & I. 133 & I 5.5 & +10.5 \\
\hline- & & 18 & 68 & I. 142 & I6. 5 & +8 \\
\hline- & , & 19 & 72 & I . I 5 I & I 7.5 & +5 \\
\hline $21 / 2$ & " & 20 & 80 & I. I6o & I8. I & +2.5 \\
\hline - & & 21 & 84 & 1. 169 & I9. 1 & 0 \\
\hline - & & 22 & 88 & I. I79 & 20.2 & -2.5 \\
\hline 3 & $"$ & 23 & 92 & I. I 88 & $2 I \cdot 3$ & -5 \\
\hline - & & 24 & 96 & I. I93 & 22.3 & -8 \\
\hline- & & 25 & IOO & 1. 208 & 23.2 & 一I 2 . \\
\hline $31 / 2$ & " & 26 & IO4 & I. $2 \mathrm{I} 8$ & $24 \cdot 2$ & $-\mathrm{I} 7$ \\
\hline- & & 27 & 108 & 1.229 & $25 \cdot 5$ & -22 \\
\hline 4 & " & 29 & I 16 & I. $25^{\circ}$ & 27 & -32 \\
\hline $41 / 2$ & $"$ & 32 & I 28 & I. 283 & $29 \cdot 5$ & -54 \\
\hline 5 & “ & $34 \cdot:$ & I 38 & I. 307 & 32.1 & \\
\hline
\end{tabular}




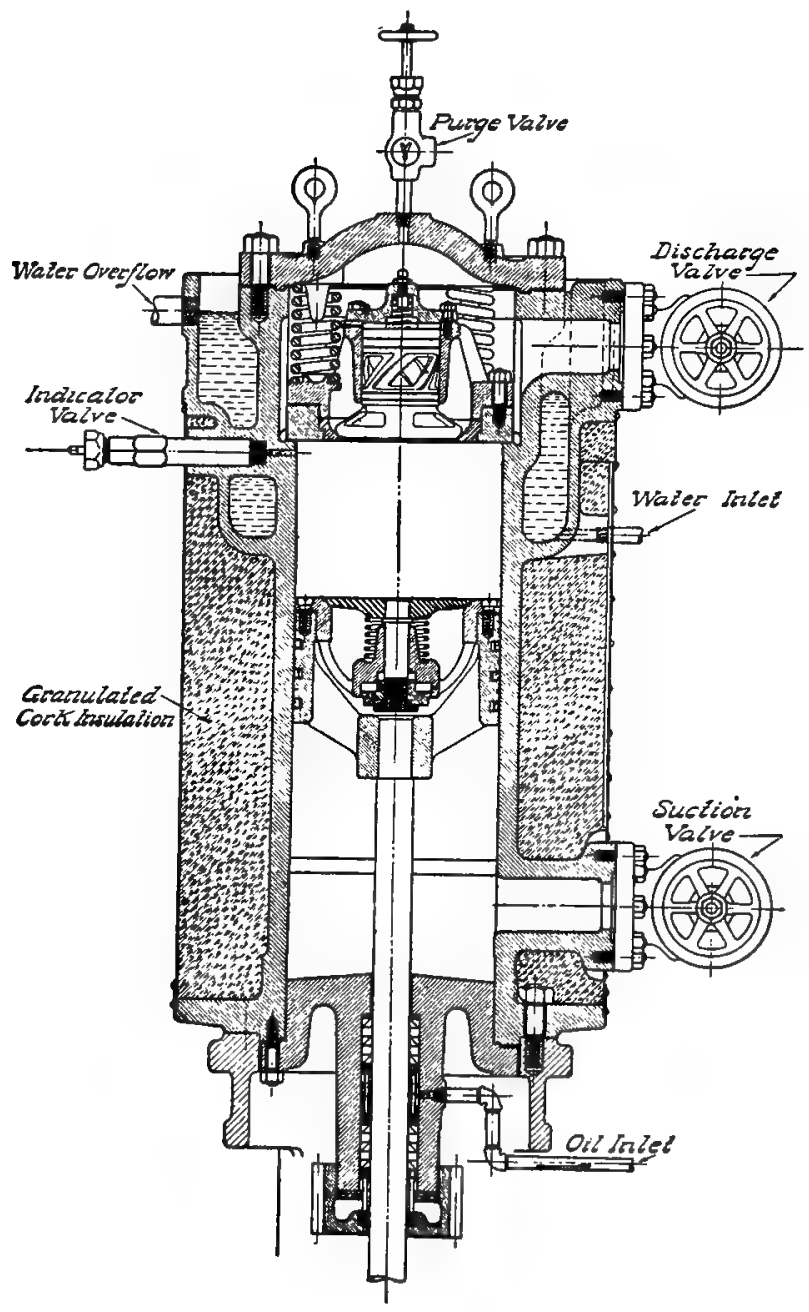

FIG. 16. - York single-acting ammonia compressor. 
and there condensed back to its liquid form. The compressor takes care of the first factor in this liquefaction; namely, the subjection of the ammonia gas to the pressure necessary for liquefaction. The condenser takes care of the second factor; namely, the removal of heat and the resultant condensation to liquid form.

We distinguish between two forms of compressors - the "SingleActing" and the "Double-Acting." The single-acting compressor is always of vertical construction; the doubleacting is most commonly horizontal, although a few of them are of the vertical type.

I. Single-Acting Compressor. - Fig. I6 represents the compressor cylinder of a single-acting compressor. The gas enters at the bottom of the cylinder, passes up through the suction valve in the piston, and by the up stroke of the piston is compressed and driven out through the discharge valve in the

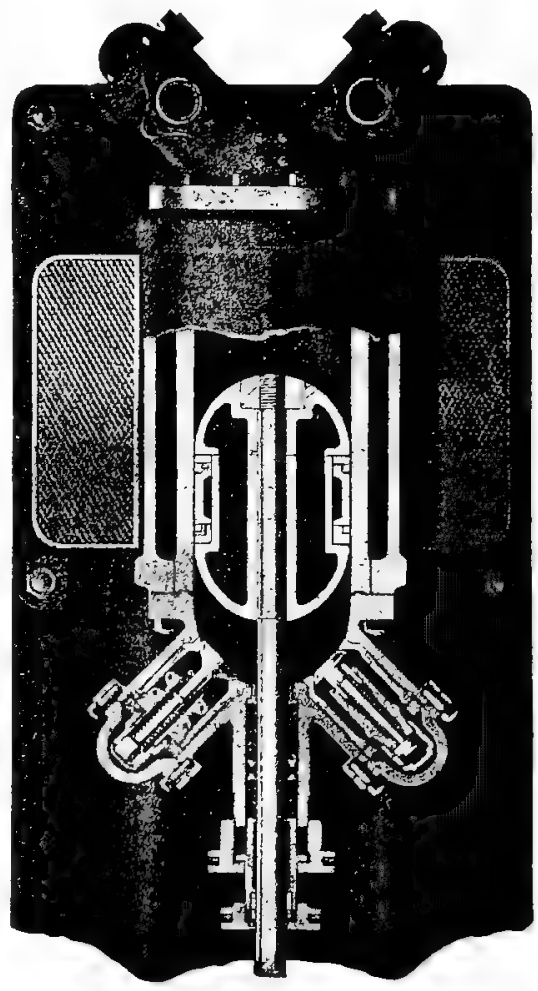

FIG. 17. - Vilter double-acting ammonia compressor. center of the safety head. The piston and the bottom of the safety head, each being faced off square and coming in contact, allow a complete discharge of the gas. The compressor of this type is incased in a water jacket. The water keeps the com- 
pressor walls cool and thus removes a portion of the heat in the ammonia.

2. Double-Acting Compressor. - Fig. I7 represents the compressor cylinder of a double-acting compressor. This cylinder has both a suction and a discharge valve in each end of the cylinder, and while the gas is being discharged from one end of the cylinder the other end is being filled with gas at suction pressure.

3. Advantages of Each Type of Compressor. - The principal advantages and disadvantages of each type of compressor have been considered by F. Newkirk, ${ }^{1}$ as follows:

"The single-acting machine has a simpler stuffing box for the reason that it is not subjected to high pressure as in case of the double-acting machine. The double-acting machine has a deep stuffing box which must be kept very tight in order to prevent loss of ammonia. This causes much friction on the piston rod and requires more oil. This, if not properly separated from the ammonia before same enters the ammonia condenser, will be carried along to the condenser and reduce the efficiency of same. In case of the vertical machine, the piston does not wear on one side due to its own weight; the valves are more readily adjusted, so the clearance is reduced to the minimum. It is evident that the machine of the least clearance is of the greatest efficiency.

"The double-acting machine, if properly adjusted, does nearly as much work in one cylinder as the single-acting does in two cylinders. The machine is low down and therefore more convenient to look after, and it has only about half as many moving parts as has the vertical machine."

Ammonia Condenser. - This consists of a series of coils kept constantly cooled by water applied as a bath or as a trickling stream. Into these cooled coils the compressed ammonia vapor is forced from the compressor, passing through an intervening oil separator. As the ammonia vapor passes through these coils, the cold water absorbs the excess heat from the ammonia and the latter collapses and passes out of the con-

${ }^{x}$ Creamery Journal, July I, rigr. 


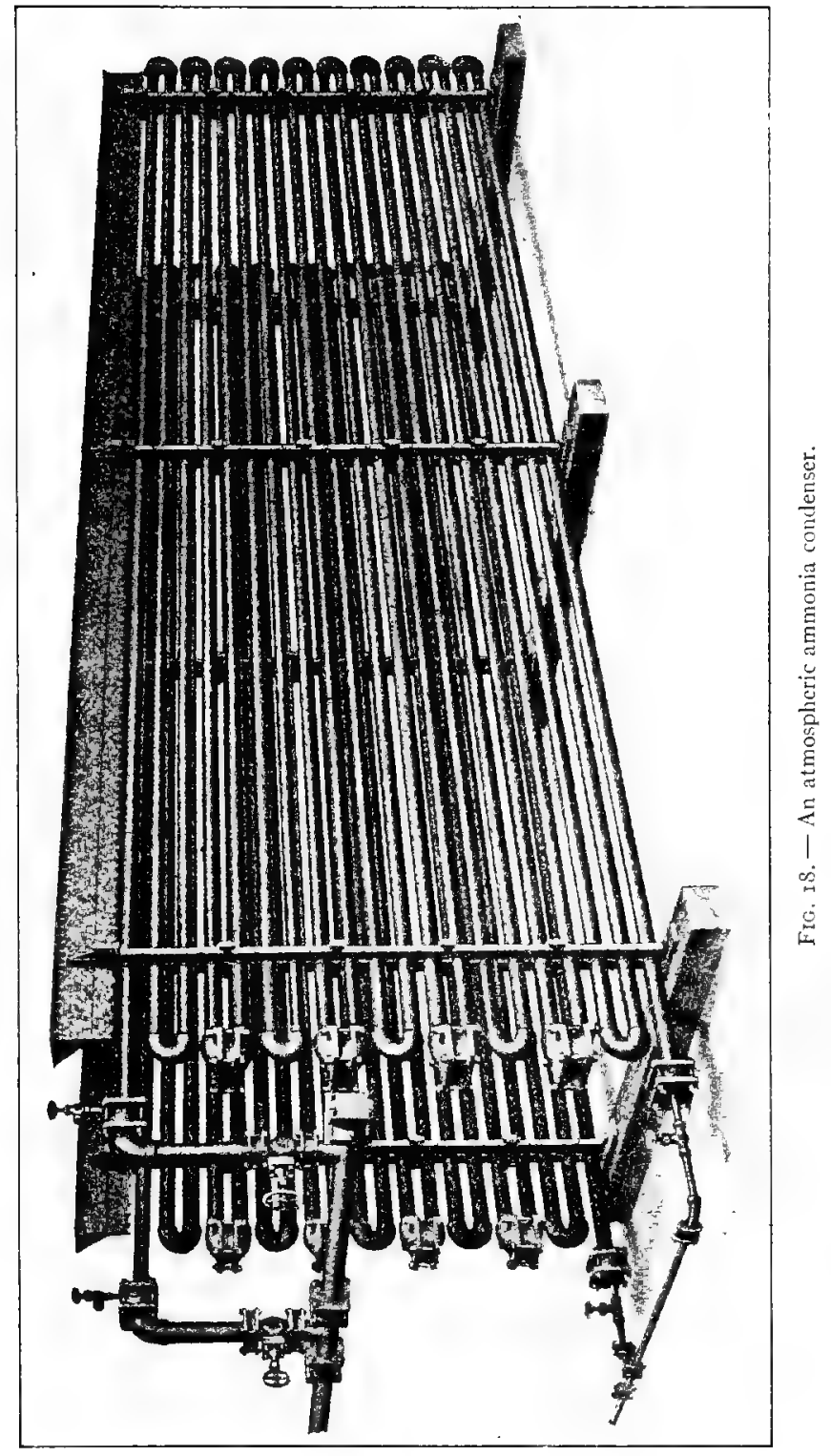


denser in liquid form, thus completing the second and final step in liquefaction.

On its journey through the system, the ammonia has risen in temperature owing to heat acquired in two places - the latent heat of vaporization taken up in the expansion coils, and the heat of compression that represents work done on the ammonia by the compressor. Some of this total acquired heat is absorbed by the water jacket of the compressor; the remainder passes into the condenser and is there removed by the cold water.

The temperature of the gas is, therefore, higher in the compressor and condenser coils than in the expansion coils. But there is a definite relation between the pressure of the gas and its temperature. At a pressure of 15 pounds, the ammonia gas has a temperature of $0^{\circ} \mathrm{F}$., while at a pressure of $15 \circ$ pounds it has a temperature of $80^{\circ} \mathrm{F}$. Consequently, a great disparity between the temperature in the condenser coils and that in the expansion coils means a corresponding disparity between the high pressure in the condenser coils and the low pressure (or back pressure) in the expansion coils. The less this disparity, the more efficient is the working of the machine. Consequently, the low or back pressure should be reasonably high, since the capacity of the machine is governed by the density of the gas. The high or condenser pressure should be as low as possible, since it requires less power to pump against a low pressure, and since the temperature of compression is decreased with decreasing pressure. As the temperature of the water used for cooling determines the pressure of the gas, the water used for that purpose on compressor and condenser coils should be as cold as it can be had.

The most common styles-of condenser are the atmosph ric ammonia condenser and the double-pipe ammonia condenser. - former is more economical and is usually placed on the roof. :t - used mostly where the condenser is placed inside.

Expansion Valve. - The expansion or regulating valve is the valve between the receiver and the expansion coil. When this valve is opened the liquid escapes into the expansion coil, and thus the cycle is completed. 


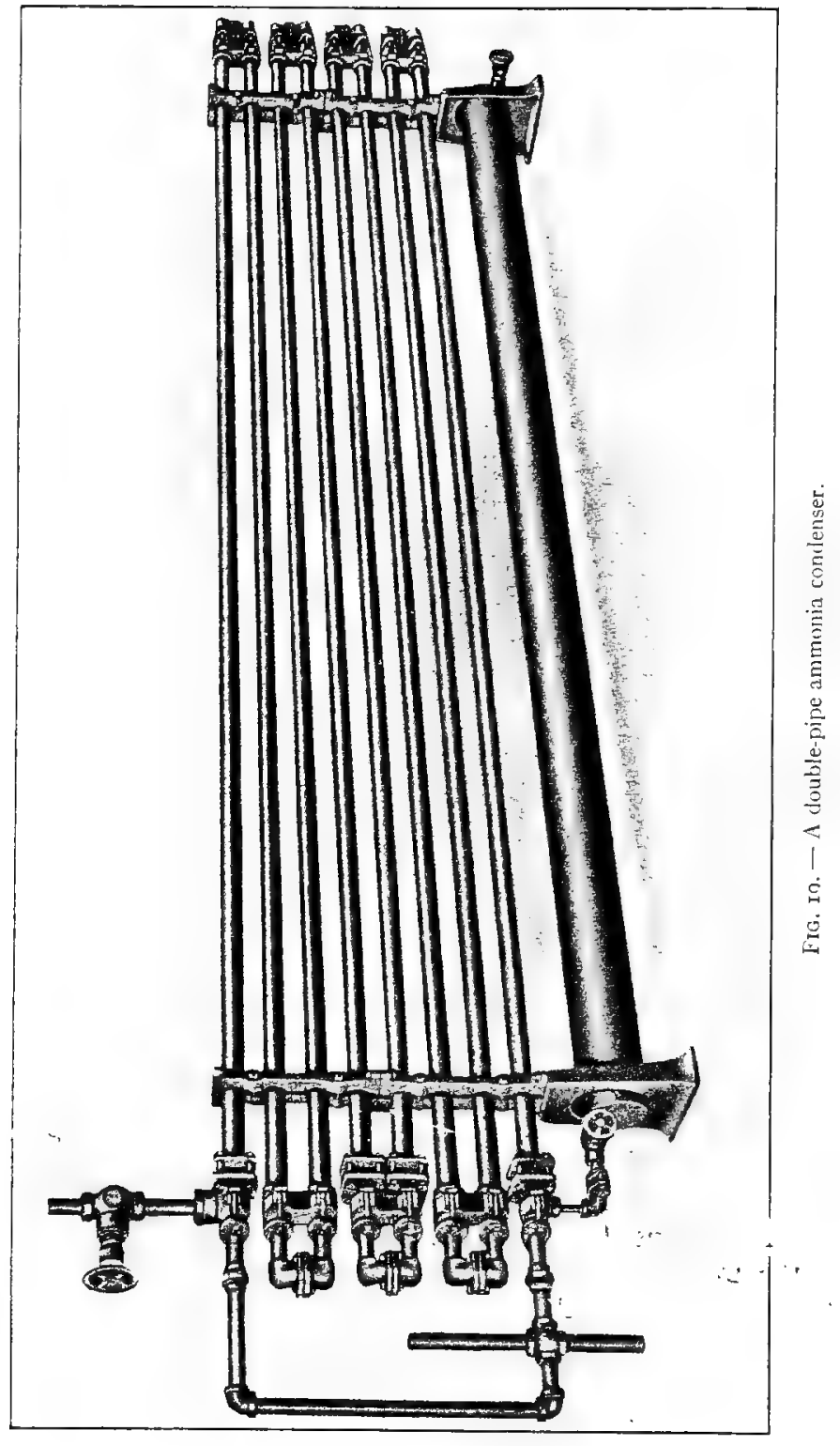


Size of Machinery Required. - In determining the size of machinery needed, an estimate should be made of the heat units to be removed during a period of 24 hours. To this result should be added at least 20 per cent for clearance ${ }^{1}$ and other losses. The size of a compressor is usually designated in tons of refrigeration per 24 hours, basing it on the heat units required for melting one ton of ice from $32^{\circ} \mathrm{F}$. to water of the same temperature. A 4 -ton compressor has, therefore, the capacity of removing $2,000 \times \mathrm{I}_{4} 2 \times 4=\mathrm{I}, \mathrm{I} 36,000 \mathrm{~B}$. T. U. of heat in 24 hours. If this amount of work is to be accomplished in onefourth the time, a machine of four times that capacity will be required.

Cost of Producing Refrigeration by Compression. - The relative amount of power required for operating an ammonia compressor differs inversely with the size of the compressor. Thus, a compressor of Io tons capacity or less usually requires two horse power or more per ton of refrigeration. A larger machine will require proportionately less; while for large compressors, the power required may be reduced to about one horse power per ton of refrigeration. It is safe, however, to figure on the size of the engine being one and a fourth times as great as the theoretical power required to propel the compressor. Bowen ${ }^{2}$ estimates the amount of steam consumed by the common creamery engine as 40 pounds per horse power per hour. If a 6-ton compressor is operated for 24 hours, and if it requires a $15-\mathrm{H}$. P. engine for operating, and if each pound of coal produces 6 pounds of steam, then

Amount of coal consumed in operating compressor 24 hours $=\frac{40 \times 24 \times 15}{6}=2,400$ pounds.

Figuring coal at $\$ 5$ per ton, the cost for coal per ton of refrigeration will amount to one dollar. In addition, there should be added the cost of water used for boiler and for the ammonia condenser, the cost of labor, of oil, waste, etc. The amount of water required for the ammonia condenser will amount to about

${ }^{1}$ Clearance is the dead space between the piston and the cylinder head.

2 U. S. Bureau Animal Industry, Circular 209, 1913. 
I I $/ 2$ gallons at $60^{\circ} \mathrm{F}$. per minute per ton of refrigeration. The amount of ammonia used should not exceed one twentieth of a pound per ton of ice manufactured in an economically operated plant.

Cost of Making Ice. - The cost per ton for manufacturing ice is nearly double that for refrigeration per ton. This is due to the fact that, in ice making, the water must first be cooled to freezing point, and, after being frozen, the ice must be cooled still lower until it reaches the temperature of the surrounding brine.

It is often claimed that natural ice will yield a greater amount of refrigeration than artificial ice. There should be absolutely no difference if both are properly frozen. In artificial ice made from raw water, the cake of ice often has a reddish or, in some cases, a milky or cloudy core through the center. The former is due to iron; the latter is due to carbonates and sulphates of calcium and magnesia. The discoloration may be overcome to some extent by agitating the water with air during the freezing process.

\section{ABSORPTION SYSTEM}

General Principles. - This system of refrigeration is based on the fact that water has the power of absorbing various vapors having a low boiling point, and that such vapors are again readily separated from the water by heating the liquid.

In reality, there is much similarity between the compression system and the absorption system. Common to both are the condenser and the expansion coils, including the brine tank and the entire circulating system. In the absorption system there is a pump, but no compressor. The generator, the ammonia receiver, and the absorber are also important parts. In addition, we have the analyzer, the exchanger, the dehydrator, and other parts of less importance which are added primarily to make the system more complete in its operation.

Operation. - This system may be operated without any great amount of steam, the only steam required being that used for the pump and the exhaust steam for the generator. 


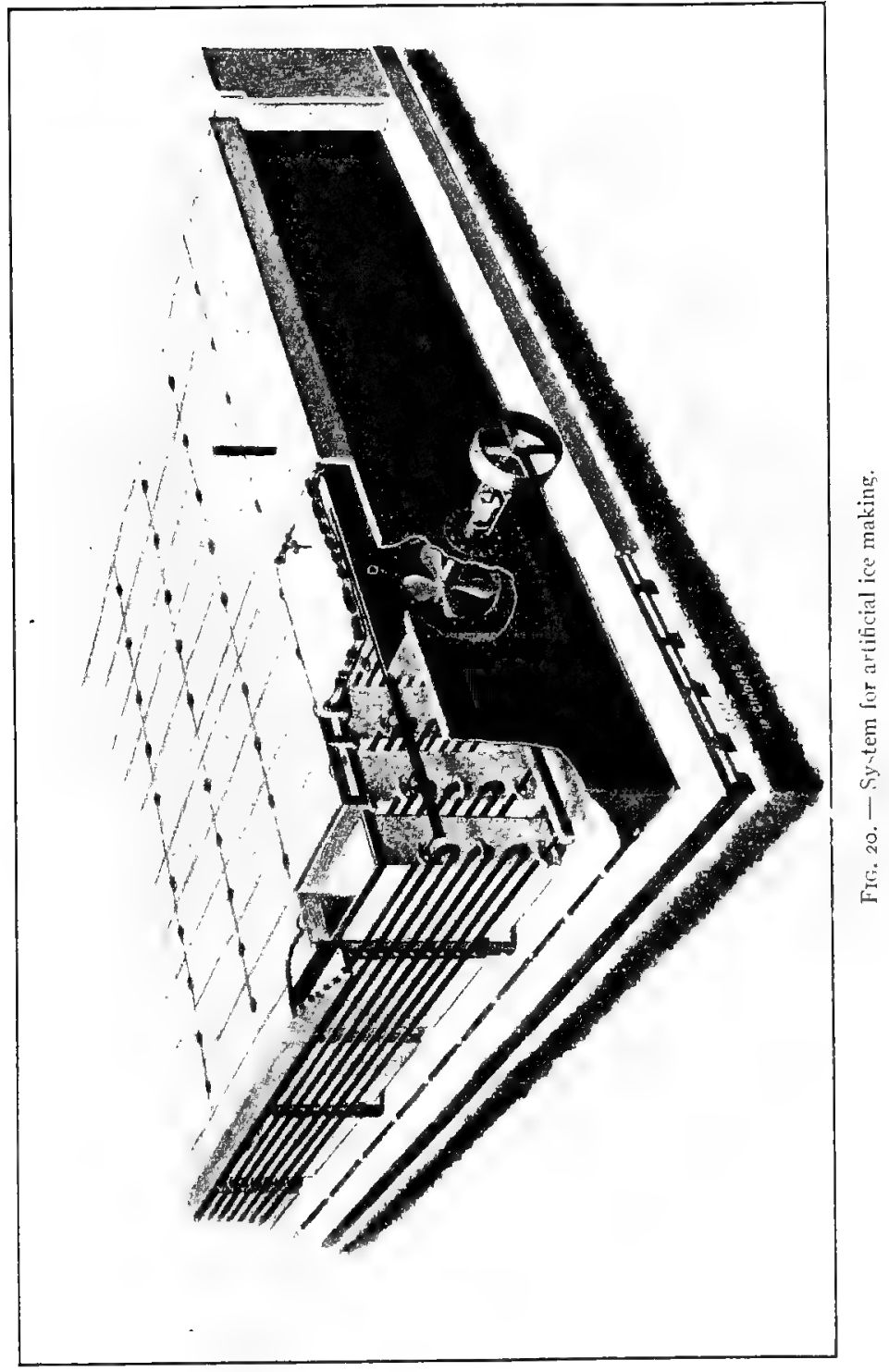


The strong-aqua tank is charged with aqua ammonia containing $29 \mathrm{I} / 2$ per cent of anhydrous ammonia. The ammonia is pumped from the strong-ammonia tank to the generator, where it is heated and the anhydrous ammonia distilled off. This ammonia gas enters the condenser where it is condensed, and from there it enters the ammonia receiver as liquid ammonia. From the receiver, the ammonia is admitted through the expansion valve to the brine cooler, where it is again converted into a gas, taking up heat from the brine. From the brine cooler, the gas enters the absorber to be reabsorbed by the water. The absorber and the generator are so connected that the water in the generator, from which the anhydrous ammonia has been distilled, is again transferred to the absorber and thus the cycle is completed.

The absorption system has not been adopted so generally as the compression system, and is used for plants of large capacity only. Plants of less than ro tons' capacity have not been constructed on the absorption system. 


\section{CHAPTER VII}

\section{LABOR}

\section{ORGANIZING A STRONG WORKING FORCE}

THE organization of a strong working force is most readily accomplished by employing capable men, mentally as well as physically, by properly training and educating the employees, and by creating loyalty among them.

Hiring the Employees. - When employing men, employ such as will eventually work up to more responsible positions. The employee who is not seeking additional responsibility will never prove satisfactory in any position. The man who is in demand is the one who has capacity for work, who will not shirk details, who is anxious to learn, and who is of a strong moral character.

To secure better information about men who may be hired, some business houses, and among them creameries, submit to each applicant a blank to be filled out by himself. Form I represents a blank for that purpose used by an Iowa creamery. Form II represents a blank that is mailed to the reference furnished by the applicant. This application blank, together with the references, is filed for future reference, usually under the head of the department in which employment is sought. Under the department they are filed alphabetically according to the names of the applicants. It is convenient to have a sheet in front of each department file on which is listed the names of the applicants appearing to be most capable.

I. Employment of Personal Friends and Relatives. - Employment of personal friends and relatives may have some advantages, but has many more disadvantages. Employees connected with the management by friendship or family ties often create a feeling of dissatisfaction among the other employees. 


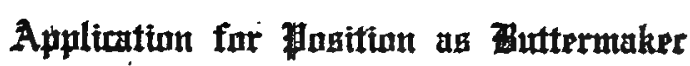

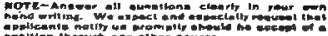

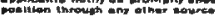

Ful Nare

Pon Ofice

- Sente.

Phooe of Wire Adtrem

Are.

Single on Maried.

Nasonisy

How neay yean experience as Butermaker

What Syeen (Whole Mits a Cachered Cream)

By Whom Employed

Sute How Lani at Euch Plece

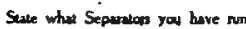

Hare you uned Combined Churns.

Sele what kind

Do you thoroughty wadendend Babcock Testing of Mill and Crean

Do you underenad Padewrizing. Whas Pateruizer

Hzve you aperated Surter Cans............ . Stuse what kind

Have you operued Crean Rupenen. . Stave when tind

Can you ras Refngerating Appomatas.

Whyt Salary do you command.

Do you we Intoricatine Liquort.

Hove you ever been Dischurged. Cire Reawon:

C. you Reopond to tmomedite Cl:

Cin you teep al Books for Creamery il mocewery

REFERENCES 


\section{FORM II}

To

We have received from $M r . \ldots \ldots \ldots \ldots \ldots \ldots \ldots \ldots \ldots \ldots \ldots$ who gives his age as ...... appliation for position as. . . . . . . . . . . . . . . . . . . . . .

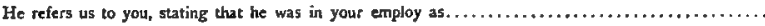
from

Would be obliged if you would turnish the information alled for below regarding his record while with you. IVe will consider your reply as absolutely confidential and if occasion affords will be glad to reciprocate. Yours truly,

Pex

Questions
tom bien:

2 Are you coopected with blo by selastoasblp, or otherwitec, It 20 , in what way?

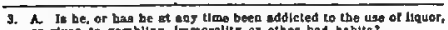
or gived to gambling. lmmarally or othor bad babits?

6. Ha be ever beed auspected of fraud, dLhoncty or disboborable conduat?

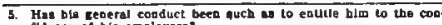
hidesces of bis omplayersi

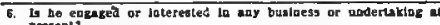

7. Has he ever talled in busineas; If so, pleaso give elreumstances aad termg of $5 \div$ thlement?

8. It ever to your eerrice, on what date ald he enter kad leave yow employ?

9 What goostuon ald be tul?

10. For whas cabe did te tiouly leave your euploy?

11. A While to your employ did he tate tbe custody of moneref condulan when be left

12 A. Ware bla vervicos stithtaclory?

Have you reaseon to cosolder bilm competent to titt the pous ton be lo spplicant for?

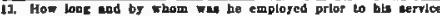
with you?

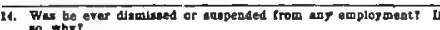
mo, thy

16. How or by thom was the emplayed efter lesting your aervice of

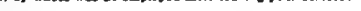

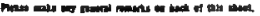

Signature

Business or Occupation.

Date

\section{ANSWERS}

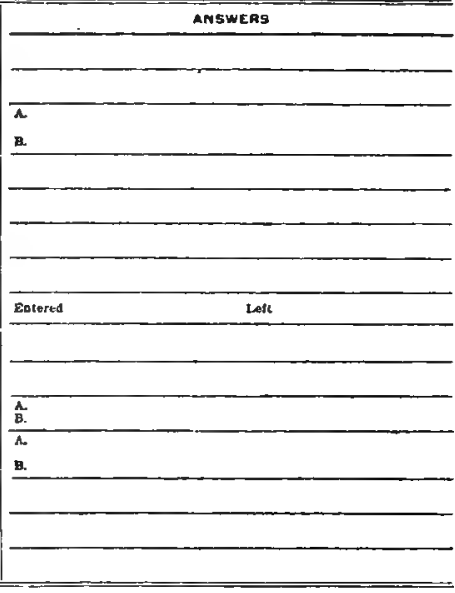


The foreman or the superintendent is at times, even without realizing it, inclined to favor such employees more than their fellow workers and unless they are of exceptionally strong character they will often believe that they can get along by doing less work and perhaps even work of poorer quality and are tempted to take advantage of this circumstance. At some coöperative creameries it is customary to employ personal friends or relatives of the directors, but it is often found that such employees return less in labor than they are paid for.

Training and Educating the Employees. - The superintendent or other person in charge of subordinate employees should take an interest in them and in the way they perform their work. If the employees do various kinds of work during the day, then it is beneficial to have each keep a systematic record of his day's work. To illustrate, a young man who started as a helper in a small creamery made a written outline of his day's work, even to the extent of marking the time he took to perform his various duties. Thus his attention was daily called to the quantity as well as to the quality of his own work, and as a result he made rapid advances.

I. Encouraging Originality. - The management should encourage originality among its employees. Wherever the leader of an establishment has developed his own originality and that of the employees he often finds this to be a source of great income to the employers. In order to promote originality the employer should reimburse his employees for new ideas and inventions in proportion to the value thereof to the firm. Some large industrial concerns are offering valuable premiums for useful ideas and inventions made by the employees. Such inventions are usually along the particular line of work in which the employee is engaged. The same policy along similar lines is being adopted by manufacturers of dairy products. It is deserving of even wider adoption, for it gives added pleasure and dignity to labor and it stimulates the employee to more effective work because he likes to work and not because he has to. Originality is very important to consider in the organi- 
zation of a working force; it is often this originality which determines the success or failure of an enterprise.

2. The Factory School. - The factory school has come into existence during recent years. To our knowledge the first school of that kind was established by a large corporation of Dayton, Ohio, in 1892 . This company was organized in 1884 . Its business increased from year to year, but it found its organization to be weak; its employees had no heart in their work. The management conceived the idea of establishing a factory school to teach the employees about the business and to interest and encourage them. The first school met in an old church which the company purchased and had fitted up as a lecture hall. The lectures were illustrated with pictures, a plan which has been continued in the company's schools ever since. On July 8, I9I2, the company reported that it had for educational use over 30,000 stereoptican slides and over I50,000 feet of motion-picture film covering a variey of subjects. The school long ago was removed from the old church building to a new school hall erected at a cost of over $\$ I_{50,000}$ and with a seating capacity of 800 . This school is now divided into about twenty separate divisions. The company considers that this school is responsible in a great measure for its remarkable growth.

The first creamery schoolroom built in connection with a private creamery was that of a large creamery of Omaha. It was completed in I9II. In this room the superintendent, manager, and directors meet with the employees to discuss value of system, methods of systematizing the work, etc. Here the employees begin to learn the value of thinking for themselves and to express their ideas in language understood by others.

Each subject taken up in a factory classroom before a group of employees should be most exhaustively discussed by the employees as well as by their employers and supervisors so that before the discussion closes the subject is fully understood by all. When all have a clear understanding of the work in general there will be more harmony and better work will be done by 
the individual employees. Meeting of employees for educational purposes should be held weekly. Other meetings may be held, such as for the education of the superintendents, salesmen, etc.

It may be argued that such subjects as market requirements and the science of butter making and ice cream making should not be given as a general course of instruction to employees. It has been found, however, that lectures of that nature are of interest to the entire organization and particularly to the manufacturing department, for it is very important that the butter maker should know about the demands of the buyers; if he has this knowledge he will be better able to satisfy their demands.

3. Crealing Loyalty among the Employees. - The employer who is taking an active interest in the welfare of his employees will invariably succeed in gaining their confidence and loyalty. It is to the advantage of the business concern to have the employees feel keenly that they are part of the organization. It is also important that there should exist the very best feeling among the employees so that the work of the different departments may be carried on harmoniously. Social gatherings, picnics, and entertainments of various kinds are becoming more customary as factory functions. The employees thus become better acquainted and warmer friends, and they become more loyal to the company by which they are employed.

Organization of the Working Force. - It is not necessary to consider the labor organization of a small factory where the secretary and the butter maker do all the work, nor of a plant which hires from one to three helpers. In both cases a man of ordinary intelligence can readily organize such a small force so that it will render the greatest amount of service.

I. Division of Responsibility. - But as the creamery industry becomes more centralized, the factories become larger and the organization of labor becomes a more complex problem. This may be seen by a glance at the following chart which illustrates the more common form of organization of labor in a large plant for the manufacture of butter and ice cream. 
Directors
General $\left.\begin{array}{c}\text { Superintendent of } \\ \text { manufacturing } \\ \text { manager }\left\{\begin{array}{l}\text { Butter maker } \\ \text { Ice cream maker }\end{array}\right.\end{array}\right\} \begin{aligned} & \text { Asst. butter makers } \\ & \text { Cream receiving dept. } \\ & \text { Helpers }\end{aligned}$
Asst. ice cream makers
Helpers

The general manager is held responsible to the directors and the superintendents are held responsible to the general manager for their respective departments. The superintendent of the manufacturing department will in turn hold the butter maker and ice cream maker responsible for their respective divisions. The object is to hold each individual employee responsible for the performance of a certain task. The organization thereby becomes so permanent that even if the manager or superintend- 
ent is absent the work in the departments will be carried on with the same degree of accuracy as if he were present.

The superintendent should maintain this perfection of organization and outline the work for his subordinates. He should always know the details of the work allotted to each individual employee in his department and the length of time required for each one to complete his particular task.

The superintendents should hire the employees for the respective departments. Some managers prefer to hire the employees themselves. The objection to that system is that under it the superintendent will not be held in as high esteem and respect by his subordinates and his work may therefore suffer in efficiency. The manager naturally hires the superintendents, but he should give them full authority to hire the men for their respective departments. However, if the superintendent is a man of diplomacy and unselfishness, he will consult the manager in reference to the man he is about to employ, as to qualification, salary, etc. The superintendent of the manufacturing department should likewise consult the butter maker or the ice cream maker, for he should not place a man in their divisions in whom they have no confidence.

The directors should keep in touch with their employees and preferably call them by their given names. Their position toward the employees is not that of giving orders but more that of educators, as orders are best given by the immediate superior of an employee. As educators, they will exercise greater influence over their employees and they will build a stronger organization.

Surety Bond for Employees. - An employee holding a responsible position in charge of money or valuable property should give to his company a surety bond to the amount determined by the directors of the company; by this the employer is insured against loss due to fraud or dishonesty of the employee. Such a bond should be purchased through one of the leading surety companies and usually the employer pays the annual premium. 
PAYING FOR LABOR

Productive and Nonproductive Labor. - Productive labor is the active manufacturing labor. In the creamery and ice cream factory such labor is produced by the butter maker, ice cream maker, and their subordinates and is charged directly against the department in which they labor. The superintendent of the manufacturing department will be considered under productive labor if he himself is engaged in the work of manufacturing; if he is merely supervising the work in the manufacturing department then his time will be considered under the head of nonproductive labor. Nonproductive labor includes the labor of clerks, bookkeepers, superintendents, etc. It is noncreative labor, but it is required for making the organization more efficient. Such labor may be charged directly against a definite department for such as are working for that department exclusively, but usually the employees engaged in nonproductive labor are working for more than one department and their wages must therefore be proportioned among the various departments. Such labor is often known as indirect labor.

Payment for labor may be according to one of several systems; the day-wage system, the piecework system, and the premium system.

The Day-Wage System. - This system provides for a definite compensation per unit of time. It is the oldest of the three systems mentioned, yet it has few advantages to its credit. The employees, as a rule, are more particular and careful when hired for day wages, as they are not so tempted to sacrifice quality of work for speed. The disadvantages are mainly that the employer must depend on the integrity and skill of the individual workman and for that reason the standard of efficiency for each employee is different and the manufacturer has no fixed rate of cost per unit of labor.' By making a difference in the rate of wages between employees doing the same kind of work dissatisfaction is created among the employees. This system is entirely satisfactory where each employee has a def- 
inite amount of work outlined for the day and is responsible for the completion of such work.

The Piecework System. - This system provides for a definite compensation per unit of labor. The manufacturer has the advantage that he has a fixed rate of cost for labor and that the same amount of work will be accomplished in less time and therefore save in factory cost. The piecework system will invariably decrease the cost of labor per unit. The only disadvantage to the manufacturer is that the employees are more tempted to sacrifice quality for speed.

To the employee this system appeals more strongly than the day-wage system. The industrious and skilled laborer receives his advance over the less ambitious and inexperienced. Under this system the employees feel greater freedom and independence, which tend to create satisfaction.

In deciding on a piece rate great caution is necessary, for if the rate is too high and it is found necessary to reduce it later dissatisfaction will always result among the employees. A rate should not be fixed before the matter has been thoroughly studied through a series of experiments.

The Premium and Percentage System. - This system provides for the payment of the entire salary or a part thereof on some premium or percentage basis. It is customary in some creameries to pay the butter maker a comparatively small monthly wage and a certain per cent of the profit which will be turned over to him annually or semiannually. When such agreements are made with the butter maker the basis of paying for butter fat should be fully understood and should be regulated by the butter quotations of one of the leading butter markets. If the butter maker is also responsible for the soliciting of cream patrons, then he may be allowed a certain per cent on business from new customers or on business increase, or he may receive a definite fraction of a cent per pound of butter manufactured. He may also receive a premium for quality. The percentage system may be applied to all of the employees. A definite portion of the annual profits might be set aside to be divided among the employees in proportion to their earning capacity. The 
monthly wages are usually so adjusted that it would be fair to use them as a basis for dividing the earnings belonging to the employees.

Such work as butter wrapping usually comes under the head of piecework, but in connection therewith the premium system may be adopted to advantage by paying a certain rate for the first thousand pounds, a slight increase for the second thousand, still another increase for the third thousand, etc. By this method the employees should produce still greater results than by a regular piecework system.

Haulers are successfully employed on the percentage system. Any increase in salary may be based on the accuracy of their work regarding weighing and sampling; it may be based on an increase in the amount of butter fat received on a route over the previous year, or it may be paid on butter fat received from new customers, or finally, it may be paid on the quality of cream delivered by the driver, which encourages the hauler to care properly for the cream while on the road and to instruct properly the patrons in the matter of care of cream on the farm.

The premium and percentage method, if properly managed, should prove a big success. It makes the employee feel as if he had a financial interest in the business and as a rule the company receives from such an employee the best service he is able to render.

Prompt Pay. - The employees are usually in need of the money as soon as it has been earned and if they are paid promptly it creates a better feeling toward the employer which means better work and a financial gain to the company. If the employees are paid monthly they should receive their wages not later than on the first day of the following month. It is more satisfactory to pay all employees at the close of each week. Some business concerns are paying their employees on the tenth, fifteenth, or twentieth of each month for work done during the previous month. Such a method of withholding the employees' money can scarcely be considered businesslike and there is no good reason therefor, as in a well-managed business establishment the employees' pay roll is completed at the close 
of the month. Therefore when such a system is employed it either shows poor management or that the company is withholding the employees' money for the sake of making use therefor in their business, which can hardly be considered legitimate.

Time Keeping. - In creameries it is perhaps most satisfactory for the superintendent to keep a card for each employee working as a day laborer. The time clock is used in some of the larger creameries, but it is more satisfactory if such a feeling can be created among the employees that the time clock will be unnecessary. The time clock, regardless of how useful it is, may impress the employees as being an indication of mistrust and as a result may destroy loyalty on the part of the employee.

Reducing the Cost of Labor. - It is not so important how much per day or month a man is paid, but his labor cost per unit and the quality of the work he produces are of utmost importance. One butter maker is easily worth $\$ 25$ or $\$ 50$ per month more than another, but the manager will not know the difference unless he keeps a record of the labor cost per unit and of the difference in quality of goods produced by the two butter makers.

I. Reducing Cost of Productive Labor. - In a well-managed creamery the productive labor will not stand much reduction. The careful superintendent adjusts as nearly as possible the amount of labor to the amount of goods manufactured. It is quite essential that the superintendent keep a record of the wages paid by his department, figuring therefrom the cost per unit manufactured.

FORM III

Creamery Productive Labor Cost Record - Butter Department

\begin{tabular}{l|c|c|c|c|c|c}
\hline Dale & $\begin{array}{c}\text { Regular } \\
\text { employees }\end{array}$ & $\begin{array}{c}\text { Extra } \\
\text { employees }\end{array}$ & $\begin{array}{c}\text { Tohal } \\
\text { cost }\end{array}$ & $\begin{array}{c}\text { Lbs. } \\
\text { butter } \\
\text { mfg. }\end{array}$ & $\begin{array}{c}\text { Cost } \\
\text { per lb. } \\
\text { butter }\end{array}$ & Remarks \\
\hline & & & & & & \\
\hline & & & & & \\
\hline
\end{tabular}


The information furnished by Form III keeps the superintendent properly informed daily. When the labor cost per pound of butter increases he will make an effort to dispose of some of the extra men. If other departments are operated by the same firm he may be able to turn them over to other departments needing men at that particular time.

At the close of the month the average daily cost of regular and extra employees is figured as well as the average amount of butter manufactured for the month and the average cost of labor per pound of butter manufactured. A comparison should be made with similar reports for the corresponding month of the previous year. By noting the rate of increase or decrease in amount manufactured between corresponding months it will be comparatively easy to determine as to the amount of labor required for the following month.

2. Reducing Cost of Nonproductive Labor. - The cost of nonproductive labor should be carefully regulated and the work of each employee whose labor is thus classified should be analyzed and the profit to the company from the labor of the employee in question should be determined as nearly as possible. Bookkeepers and certain clerks are indispensable, although their value to the company is not readily determined. There are other nonproductive employees in the office and around the factory from whom a definite return is expected. Before engaging an employee for doing nonproductive labor the following points should be considered:

I. Will the labor of this employee show direct and immediate result?

2. Will the company make any profit on such labor?

3. Is it possible to accomplish this work with the present working force?

4. Is the nature of the work such that the employee may be engaged on a percentage basis?

Distributing the Cost of Labor. - Productive labor is generally charged directly against the respective departments. The nonproductive labor of an employee may be charged directly if the entire time of that employee has been devoted to one 
department. The employee may work for more than one department, but the nature of his work may be such that a definite amount of time is devoted to each department; thus his salary is divided among the different departments for which he has rendered service in proportion to the time devoted to each. The work of some employees is of such a nature that a satisfactory division of the cost of their labor is almost impossible. Consider as an example the work of the bookkeeper, the cashier, the order clerk, and the shipping clerk; they are working for the different departments of the factory at the same time and it is difficult to determine the amount of time devoted to each.

In the case of the order clerk it might be possible, but perhaps not practical, to divide his time by counting the orders written for each department and taking for granted that it requires the same unit of time for writing an order for one department as for the other.

Nonproductive labor may be divided among departments on the basis of the amount of sales made by each department. Consider for example that there are three departments - butter, ice cream, and sweet cream. The sales of butter amount to $\$$ Io,000 for the month, ice cream to $\$ \mathrm{I}, 000$, and sweet cream to $\$ 500$. The cost of nonproductive labor for the month amounts to $\$$ II5, then the amount of this cost to be carried by each department is in proportion to the total sales, as follows:

Butter department $=\$ I_{I 5} \times \frac{10,000}{I I, 500}=\$ 100$.

Ice cream department $=\$ \mathrm{II}_{5} \times \frac{\mathrm{I}, 000}{\mathrm{II}, 500}=\$ 10$.

Sweet cream department $=\$$ II $\times \frac{500}{\text { II }, 500}=\$ 5$.

Through a careful study of the various departments it is soon learned that a direct proportion in accordance with sales is not absolutely satisfactory, as it requires a greater amount of nonproductive labor for one department than for the other on the same volume of business. It may be found that the non- 
productive labor required for the manufacturing and marketing of $\$ 2.00$ worth of butter is equivalent to the labor required for manufacturing and marketing $\$ 1.00$ worth of ice cream and that $\$ 1.00$ worth of cream requires the same amount of nonproductive labor as $\$ 2.00$ worth of ice cream. In that case the figures by which to proportion the nonproductive labor in the above problem are as follows:

Butter department pays $\$$ II $5 \times \frac{\text { I0,000 }}{\text { I4,000 }}=\$ 82$. I4

Ice cream department pays $\$$ I I5 $\times \frac{2,000}{I_{4}, 000}=\$ 16.43$.

Sweet cream department pays $\$$ II $_{5} \times \frac{2,000}{\text { I }_{4}, 000}=\$ 16.43$.

No definite rules can be offered by which to make the proper distribution of nonproductive labor, as that is governed largely by the nature of the business as well as by local conditions, but the manager should make a thorough study of the problem and place the cost as nearly as possible where it belongs. If he does not do this the statements in reference to cost of the departments will be misleading.

When proportioning the cost of labor at the close of the month a permanent record should be preserved giving the monthly cost of direct and indirect or proportionate labor (Form IV). 


\section{FORM IV}

Creamery Proportioned Yearly labor Record

\begin{tabular}{|c|c|c|c|c|c|c|c|c|c|c|c|c|c|}
\hline \multirow{3}{*}{ Month } & \multicolumn{4}{|c|}{ Butter Dept. } & \multicolumn{4}{|c|}{ Ice Cream Dept. } & \multicolumn{4}{|c|}{ Sweet Cream Dcpt. } & \multirow{3}{*}{ Total } \\
\hline & \multicolumn{2}{|c|}{ Direct } & \multicolumn{2}{|c|}{$\begin{array}{c}\text { Propor- } \\
\text { tionate }\end{array}$} & \multicolumn{2}{|c|}{ Direct } & \multicolumn{2}{|c|}{$\begin{array}{l}\text { Propor- } \\
\text { tionale }\end{array}$} & \multicolumn{2}{|c|}{ Direct } & \multicolumn{2}{|c|}{$\begin{array}{l}\text { Propor- } \\
\text { tionate }\end{array}$} & \\
\hline & $\frac{3}{3}$ & 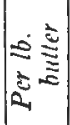 & ङ & 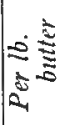 & छัँ & 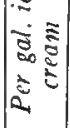 & $\underset{5}{5}$ & 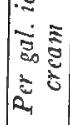 & ह & $\begin{array}{l}\overrightarrow{5} \\
\dot{5} \\
2^{2}\end{array}$ & כa & 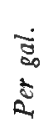 & \\
\hline \multicolumn{14}{|l|}{ Jan. } \\
\hline \multicolumn{14}{|l|}{ Feb. } \\
\hline Etc. & & & & & & & & & & & & & \\
\hline
\end{tabular}




\section{CHAPTER VIII \\ PURCHASE OF MILK AND CREAM}

\section{SYSTEM OF DEALING WITH THE PATRONS}

THE buyer of the raw material should be a good judge of human nature. When calling on a patron or a prospective patron it is advisable to start a conversation along lines which are of interest to the producer. The condition of the farm buildings, lawn, and fields, as well as the appearance of the farmer himself, should interest the solicitor, and assist him in determining what topic of conversation is likely to be of greatest interest to the person. The solicitor should have the highest regard for the ideas of his fellow men, for even though they may not coincide with his own, by approaching them on some subject in which they are interested he is assured of a hearing and it should then be possible for him, if he uses good judgment, to present his own case in an acceptable manner.

Paying for Milk and Cream on Quality Basis. - It is evident that cream which is of good quality is worth more money than that which is of poor quality. If butter is made from the separate lots the butter made from the best cream will invariably sell for the most money. Therefore the manager should, as nearly as possible, pay for the cream according to what it is worth if made into separate lots of butter. The creamery paying the same price for inferior as for good cream is encouraging and paying a premium on carelessness which will tend to lower the quality of raw material instead of improving it.

I. Grading the Cream. - Some creameries accept only what is called first-grade cream, others receive first and second grades, while a third will receive cream grading as first, second, and third. No general classification of grades has been recognized 
as standard, as a standard which is practical for one state or locality might not be at all practical elsewhere. But in the leading dairy districts it is generally considered that cream classified as first grade should be what is called sweet cream, containing not to exceed 0.20 or 0.25 per cent acid and be free from taint or foreign flavors. Second-grade cream is generally understood to be cream of a higher acidity; it may even include cream of a sharp acid flavor but should be free from undesirable foreign flavors. Cream below second grade in quality should be classified under the head of third grade.

At some creameries the acidity is the only factor on which the quality is based, while other creameries have a more elaborate method of cream judging, exemplified by the following method adopted by the Iowa State College: flavor, 45; acidity, 25; richness, 20; body and cleanliness, ro.

A. Flavor. - Flavor is judged by tasting the cream and by grading it in accordance with the quality of butter that may be made from it under ideal conditions.

B. Acidity. - Cream is scored perfect on acidity when containing 0.2 of I per cent acid or less. For each 0 . I of I per cent acid in excess of this amount should be deducted three points from the perfect score.

The acidity of the cream may be determined by a decinormal alkali, using phenolphthalein as an indicator, or by an alkali solution prepared from alkali tablets. It is often most convenient to prepare the solution of such a strength that it will be applicable for the rapid determination method. By this method the solution is prepared by adding one, two, or three tablets to each ounce of water. For taking the sample of milk or cream to be tested, use is made of a dipper of the same size as a No. Io cartridge. The same amount of the prepared solution is added. If the mixture, after being thoroughly mixed, is pink the milk or cream is as sweet as required. If the mixture is white the milk or cream contains a higher degree of acidity than is desired. If we adopt a standard of $\mathrm{r} /$ Io per cent acidity then a solution is prepared by adding one tablet to each ounce of water; for a $2 /$ Io per cent acidity standard two tablets are 
used; for a $3 /$ Io per cent acidity standard three tablets are used, etc.

C. Richness. - Cream testing 28 per cent of fat or above will receive a perfect score on richness. One point will be deducted for each per cent below 28 per cent.

D. Body. - The body should be smooth and uniform. It may be injured by being partly churned, by being frozen, or by being curdy. Cleanliness of the cream and container is considered in this connection.

2. Market Value of Various Grades of Cream. - The market values of the various grades of cream fluctuate in accordance with market conditions as well as with local conditions. At a time when there is a scarcity of butter on the market a butter made from a second-grade cream may sell for nearly as much money as the butter made from cream of the highest quality. When there is an oversupply of butter there is a wider range in price between first and second grades and the second-grade cream is then of less value as compared with cream of first grade. Local conditions may afford opportunities for disposing of the lower grades of butter at a comparatively high price. Therefore it is impossible to establish any set rule to which all creameries might be required to conform. By making a thorough study of the local conditions in a definite locality and considering them with the more general conditions it is usually possible for the creamery manager to settle on some definite basis by which to pay for cream of the various grades. Whenever practicable it will be most satisfactory to make remittance for the cream after the butter has been sold, and then remit for each grade in proportion to the returns. The difference made between cream of different grades varies from nothing to five cents per pound of butter fat. Some creameries refuse to receive any milk or cream which will not grade as first. This system is advisable wherever possible. It is generally conceded that it is very seldom advisable to accept third-grade cream.

Eliminating Business Secrets. - There is no business concern that is depended on for square dealing to a greater extent than the creamery. The producers deliver their milk and 
cream usually without any definite knowledge of the amount of butter fat it contains or the price it will bring. They depend on the management of the creamery for a square deal. If the manager allows any ground for suspicion it will eventually result in a big loss in patronage. It is, therefore, of importance that the creamery maintain the unlimited confidence of its patrons. This is most readily accomplished by the manager's willingness to have the patrons become familiar with the method of management so far as it interests them.

The most common cause for misunderstanding between the patrons and the management of a creamery is found in weighing and testing. The weighing should be done in the presence of the patron, if possible, and the manager should encourage his patrons to be present as often as possible when the testing is done. If it is found impossible to have the patrons witness the weighing and testing then it is advisable to encourage them to buy their own scales and hand testers. If attempt in that direction also fails, it may be to the advantage of the creamery to keep a few sets of spring balances and testers on hand to lend to such patrons. A dissatisfied patron should never be allowed to discontinue on a mere suspicion of dishonesty. It is usually possible for the scrupulous business man, by methods similar to those mentioned, to convince his patrons of the integrity of his firm.

Promptness in Dealing with the Patrons. - The manager of a creamery as well as all of his subordinates should be prompt in all matters pertaining to the business. The drivers collecting milk or cream should call at each farm at definite, prearranged days and hours. Neglect on the part of the driver in complying with this requirement will invariably result in loss of patronage. Checks for products received should also be delivered at a definite time. If checks for milk or cream are sent through the mail they should be mailed on a definite day so that the patrons will always have the satisfaction of knowing when they may expect to receive remittance.

The cash system of paying for cream makes promptness in the matter of remittance a necessity. This system is there- 
fore a good educator for the manager who considers promptness to be of secondary importance. In some localities the cash system is attractive to the producers, but to the manufacturer it has the disadvantages that it increases the cost of bookkeeping, the cost of labor in the testing room, and it increases the amount of capital required for carrying on the business. In some territories it is unnecessary to pay cash for cream, providing the company has a satisfactory standing financially. A coöperative creamery usually pays once or twice monthly, but the payments, regardless of when they are made, should always be made promptly on a definite, prearranged day. Instead of paying cash for cream it is usually possible to arrange with the patrons for paying the day following delivery. By that system the manufacturer will economize in labor, as the testing can all be done at the same time. The same is true about making out the checks and other records.

Follow-up System for Securing Patrons. - When the solicitor has become acquainted with a producer but has been unable to buy his raw material, he should carry on a systematic campaign until the producer eventually decides to sell him his products.

In carrying on a campaign for patrons it should be the object of the solicitor first to find out who are the leaders of the community, as it is to his interest to have these men fully understand his proposition. A solicitor who has a good, fair, and square proposition to make to producers will always be most readily received by the more intelligent of the farmers and it is that class of people that usually command leadership. Therefore when the leaders take kindly to a proposition it is an indication of good progress. The solicitor should not, however, be deceived and work with people who expect to receive such personal advantages as will not be shared with the others who later may become patrons.

I. Map of the Territory. - The buyer of the raw material should have systematic and simple but comprehensive records from which he can readily obtain desired information in reference to his territory. A map of the territory should be made 
from information received from the solicitor. For that purpose a blank divided into squares is convenient (Fig. 2I), each square representing a section. A creamery manager should have so complete a control over the work in his territory that

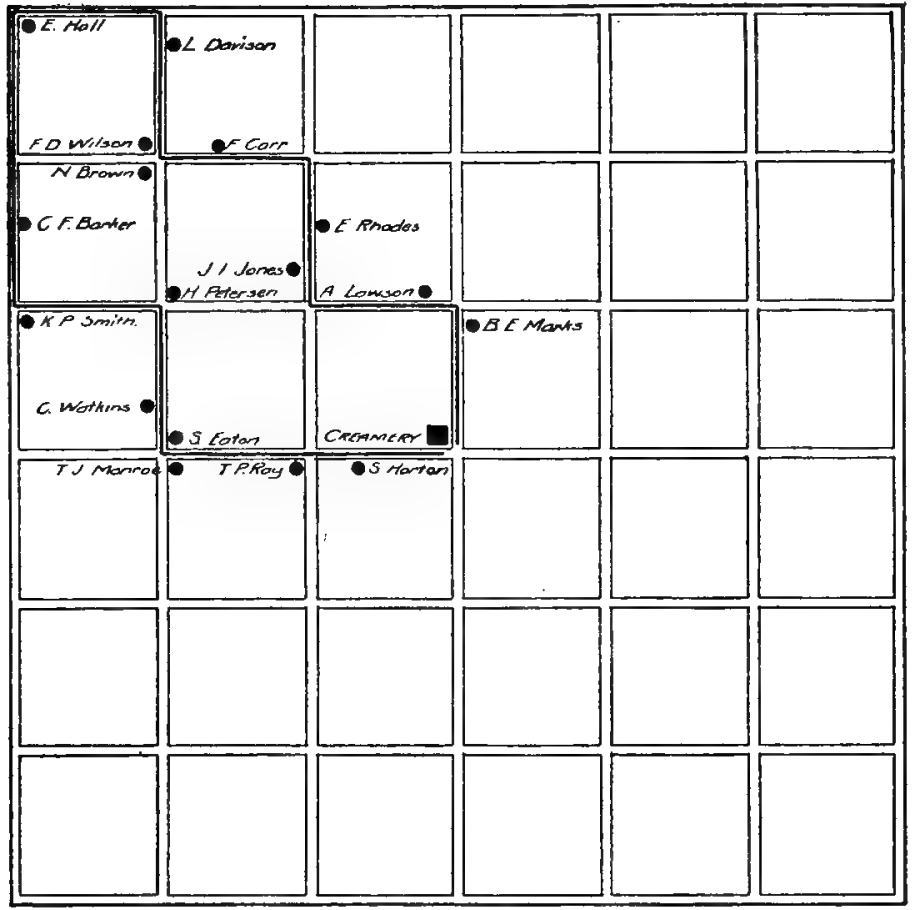

Fra. 21. - Map of the territory.

he can produce maps of all routes showing location of patrons on each route, of patrons delivering their own cream, and farmers with whom the creamery is not yet dealing. The latter may be marked with a prominent lead pencil mark which can readily be removed when they become patrons. The manager will, from a glance at such a map, have a fair understanding 
of the condition of his territory and know where the most vigorous field work should be conducted.

2. Card Records. - Card records consisting of three different files will be useful: File A, active patrons; File B, discontinued patrons; and File $\mathrm{C}$, prospective patrons. The cards of active patrons may be filed alphabetically, divided under routes or stations. These cards should be removed from one file to another as they become patrons or discontinue. A card 4 inches by 6 inches should be large enough. Form $V$ will serve as an illustration.

\section{FORM V}

\section{Creamery Fifid Record}

Naine. Address.

Route. No. of cows

Disposition of product.

Reason for not selling to us.

Called on him, dates.

Result. Remarks

Wrote, dates................

Result.....................

Started to sell to us, date

Discontinued, date.

Cause

By making a comparison between this card and the territory map the manager is enabled to direct the field work from his office desk. He can start a new man and furnish him with all necessary information in reference to the parties whose patronage he is soliciting. If the solicitor receives a promise from one of the prospective or discontinued patrons that he will be ready to deliver his products at a certain time, then the party in charge of the field work should keep a record of such a promise. This can be done most readily by what is called a tickler, which is merely a small card file that is intended to be kept on the office desk. This file contains index cards for the twelve 
months, each with an index card for each day of the month. Cards containing future dates are filed at the proper places, and each morning before starting on the regular routine of work, the cards filed under that particular day are given due attention.

3. Daily Record of Active and Discontinued Patrons. - It is to the advantage of a creamery to keep a complete record of active and of discontinued patrons. Some creameries keep a separate record of each so that they may be informed immediately when a patron discontinues. It is less difficult to have him resume shipping if an effort to do so is made at once. The following form may be used for that purpose. ${ }^{1}$

FORM VI

Monthly Record of Patrons - July

\begin{tabular}{l|c|c|c|c|c|c|c|c|c}
\hline \multirow{2}{*}{ Name of Palron } & \multicolumn{7}{|c}{ Day of Month } \\
\cline { 2 - 5 } & I & 2 & 3 & 4 & 5 & 6 & 29 & 30 & 3 I \\
\hline J. Jones....... & 30 & 34 & & & 23 & & & & \\
\hline S. Mann....... & & 40 & & & 38 & & & & \\
\hline
\end{tabular}

On this report are made daily entries of tests; by making this entry for each shipment it becomes easy to locate errors made in the testing room. As an example consider the record of J. Jones (Form VI); it is quite possible that a mistake was made on July 5 th and it is therefore the duty of the manager to write Mr. Jones concerning it in order to have the matter adjusted satisfactorily to the patron. Report (Form VI) is furthermore of importance in the matter of determining the frequency of delivery and may furthermore be used for checking the quality of cream delivered by each patron by also marking score or grade of each shipment or delivery.

\footnotetext{
${ }^{1}$ Securing patrons by correspondence will be considered in chapter on "Business Correspondence."
} 


\section{SYSTEMS OF MILK AND CREAM PURCHASE AND DELIVERY}

Frequent delivery of the raw product to the creamery is one of the principal prerequisites for the manufacture of a desirable product. It has always been customary to make frequent deliveries to a whole milk plant. There the milk is usually delivered daily during the summer season and from three to four days a week during the winter season. Such frequent deliveries are made because the producers realize that they will sustain a financial loss if the deliveries are less frequent, as milk containing a high degree of acidity cannot be properly skimmed. The older milk is also more variable in quality and therefore less desirable as a feed for calves.

The attitude of the producer in reference to frequency of delivery is somewhat different in the gathered cream territories. This is brought about partly by the manufacturer who sometimes in his greed for more business informs producers that it is unnecessary to make daily deliveries when selling cream. His statement is partly true, inasmuch as the cream does not deteriorate as readily as does milk. But cream absorbs odors more readily than milk, and because it has less bulk than milk cream is often left in the kitchen or in the cellar, places where the milk is very seldom kept, and it will therefore soon acquire undesirable flavors. If the frequency of delivery had not been lessened by the introduction of the hand separator, dairying as a whole throughout the United States would have gained in profit and prestige.

The system of organization of territory may for convenience be considered under the heads of: The individual system, the coöperative system, the route system, the station system, the local agent system, and the coöperative selling system.

The Individual System of Delivery. - Under this system the producer delivers his own milk or cream to the creamery in person or ships it by rail.

I. Delivering of Cream in Person. - At many local creameries the producers deliver their own milk and cream and for 
the local creamery there is possibly no more satisfactory system. It has the advantage that full remittance is made without deduction for hauling; it brings the producer in close touch with the butter maker or manager and each learns to appreciate the work and effort of the other. If the product delivered by a patron is of poor quality the butter maker can discuss the matter directly with him and make valuable suggestions as to how such difficulties may be overcome.

The main criticisms that may be offered against this system are: it may increase the cost per pound of butter fat delivered by the route driver. This objection is naturally confined to territories in which routes are also operated. The individual system is not far-reaching; farmers living from five to six miles from the creamery can be interested in this system only with difficulty. The busy farmer finds delivery of cream a burden and as a result he often starts to make butter on the farm; such a patron is often slow to return. The time required for handling a given amount of milk or cream at a creamery is somewhat increased by the individual system.

2. Producer Shipping Cream by Rail. - The system of shipping cream by rail has become rather popular during recent years. By this system it is possible for the producer in a more thinly settled district where a creamery cannot be operated profitably to sell his butter fat at market price. Formerly such farmers were compelled to sell their butter in the country store. The system has met opposition, as it is claimed that it reduces the patronage of the local creamery. It is hardly logical that an up-to-date local creamery should experience much difficulty on that account, as the local creamery has the advantage of saving the shipping expenses and receives cream of better quality.

3. Creamery System of Handling Individual Shipments. - A creamery receiving individual railroad shipments should immediately upon receipt of the first shipment from a producer write a personal letter to that shipper. This letter should be written in such a tone that it will encourage future shipments. It should also contain a report of weight and test of cream received 
and value of butter fat. It should explain in detail the creamery's method of paying, of sending reports, and of returning empty cans, and furnish any other special information which might be of value to the shipper.

A. General Letter of Information. - General letters of information in reference to care of milk and cream, causes of variation in test of milk and cream, should be mailed to the patrons. Such a letter should be brief enough so the patrons will take time to read it. It should cover merely the essential points. Letters in reference to care of milk and cream might present the following ideas: First, the value of cooling the milk and cream immediately and before it is mixed with cream from the previous milking, and of leaving it in fresh, cold water at a place where the atmosphere is pure; second, the advantage of skimming rich cream; third, care of cream separator and utensils, discussing the value of using slacked lime or washing powder in the dairy for cleaning purposes; fourth, the value of keeping the barn and cows clean; fifth, the value of using a sanitary milking pail, if a practical sanitary pail can be furnished the customers addressed. Other points on the care of milk and cream may be discussed in such a letter, but all should be offered in the form of suggestions and not in the form of rules and no suggestion should be offered unless the writer is able to prove that it will be to the advantage of the producer to follow it.

B. Shipping Tags and Seals. - Shipping tags and seäls are usually furnished by the creamery. A shipping tag should bear the creamery firm name and address and blank lines to be filled in by the shipper with his name, shipping station, and post office. Some creameries have a rubber stamp made for each of their shippers and stamp the tags with the name and address of the patron. This tag will be used for the following shipment. A new leaden seal is also dropped in the empty can and this is used by the shipper, who has a seal press furnished by the creamery, perhaps bearing the creamery name on one side and the number on the other side.

Other forms of tags are used, such as brass tags. These are 


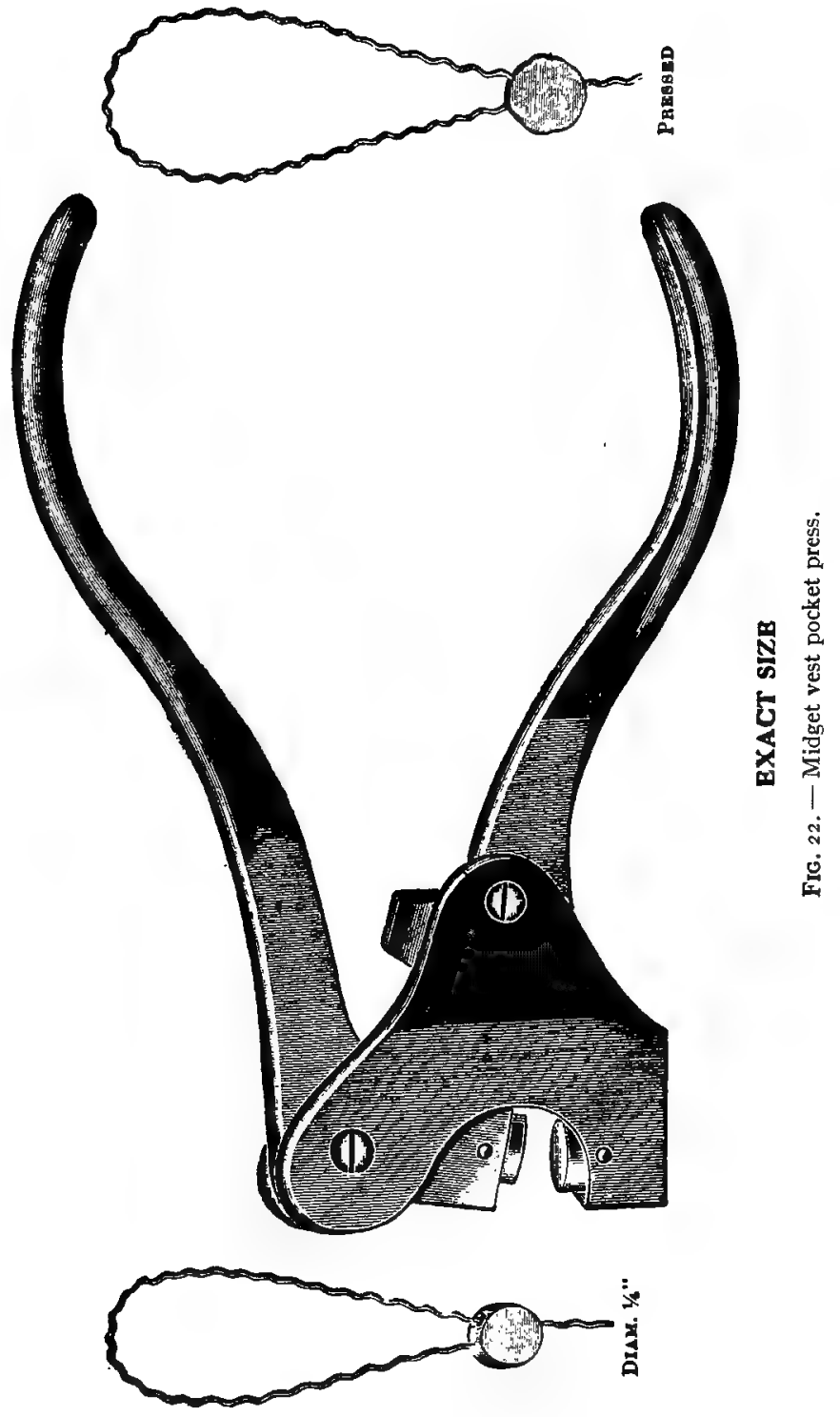


furnished by the creamery. The addresses of the creamery and patron are pressed into the brass and in order that they may be read easily the letters are filled with black paint. The brass tag may be soldered onto the breast of the can or fastened to the can with a wire loop about four inches in length and two inches in width. The ends of this loop are riveted together. The cover of the can is often fastened to the can with this loop. The advantage thereof is that the covers of the cans will not be exchanged; the disadvantage is that the can is more difficult to clean when the cover is attached, especially if a can-washing machine is used. .

C. The Cream Can. - The cream can, before being returned, should be properly marked. It should have the name of the shipper painted on the breast, and below, in large letters, the name of the shipping station. The weight of the empty can with cover should be painted on the can, as that will facilitate the work of the one who receives the cream at the creamery. The creamery manager should insist on receiving the transportation company's receipt for empty cans, then in case of loss of cans the transportation company, even though it is not held responsible, will make a greater effort toward locating them.

A large creamery with a separate receiving department may keep a special record of the number and size of cans received from each patron; the empty cans when returned are checked against such a record (Form VII).

FORM VII

Receiving Clerk's Can Record

\begin{tabular}{c|c|c|c|c}
\hline \multirow{2}{*}{ Name } & Address & \multicolumn{3}{|c}{ No. of cans } \\
\cline { 2 - 4 } & & Io-gal. size & 8-gal. size & 5-gal. size \\
\hline J. Johnson.... & Boro & $\mathrm{I}$ & & $\mathrm{I}$ \\
\hline C. Jones....... & Simpson & & 2 & \\
\hline Route No. .... & Albany & 8 & & $\mathrm{I}$ \\
\hline
\end{tabular}


The bills received from the transportation company are also checked against the receiving clerk's can record.

The cream is next turned over to the cream department where it is weighed and tested and a record thereof kept on the daily cream receiving blank (Form VIII). The samples should be tested in duplicate and retested if they do not check with previous tests of cream delivered by the particular patron.

The individual shippers usually furnish their own cans. Some creameries furnish cans for their new patrons for trial shipments, but demand that the producers later furnish their own cans. A ledger entry is made of cans thus furnished the patrons and if cans are kept longer than the time for which they were promised as a loan, then the value of the cans is deducted from the cream check of the patrons. This method of collecting for cans should be fully understood by the patron at the time when the can is turned over to him. Other creameries are willing to loan cans to all of their patrons. This latter system, however, encourages negligence on the part of the patrons in taking care of the cans, and the loss sustained on account of lost cans is usually heavy.

\section{FORM VIII}

\section{Sunset Cefartery}

\section{Daim Cream Recejving Recofo}

SUTYSET, LA.

Date

\begin{tabular}{|c|c|c|c|c|c|}
\hline \multirow{2}{*}{ 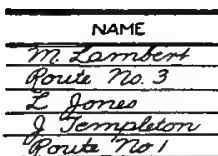 } & \multicolumn{5}{|r|}{ REMARRS } \\
\hline & Treenurees & & & & \\
\hline & & & & & \\
\hline & & & & & \\
\hline & & & & & \\
\hline & & & & & \\
\hline & & & 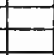 & & \\
\hline & & $\#$ & & $\square$ & G \\
\hline
\end{tabular}


The Coöperative System of Delivery. - By this system patrons conveniently located join in changing off in hauling their products to the creamery. Such an association of patrons is usually known as a club. This method of delivery has these advantages over the individual system: First it reduces the time required by each individual for hauling; second, more distant producers can deliver their products at a profit, and third, the work of receiving at the creamery is somewhat reduced. This system is practically the same as the individual system and the same methods adopted for the individual system apply to the coöperative system.

Route System of Delivery. - The route system is the method of delivery by which the milk or cream is collected by a person (the driver) who receives (from the patrons) a definite compensation for service rendered. The driver may be hired by the patrons or by the creamery to which he delivers, but if he receives his salary from the creamery the total amount paid for his services should be deducted from the patrons' checks, in proportion either to the amount of butter fat or to the pounds of milk or cream delivered by each patron.

The following advantages may be mentioned for this system: First, it increases the territory of the creamery; routes are successfully operated to a distance of from twelve to fifteen miles from the creamery. In some districts this system has developed to the extent that the original routes receive cream from sub-routes which start where the original routes discontinue and cover territory still farther distant from the creamery; second, distant patrons are always pleased to be relieved of hauling, especially during the summer season; third, an able driver should be in a position to greatly increase the patronage of the creamery; fourth, the cream collected on the routes is usually of higher quality than that brought by individuals, as it is as a rule collected at shorter and more uniform intervals.

Disadvantages may be mentioned as follows: First, cost of hauling; if the cost of hauling exceeds three cents per pound of butter fat in cream and five cents per pound of butter fat 
in milk after the route has been well established, then the future success of such a route may be considered rather questionable; second, scarcity of capable haulers; third, increased length of time during which the cream is in transit to the creamery; this objection is practically eliminated if the cream receives proper care by the hauler.

I. Residence of the Driver. - The most convenient residence for the driver collecting milk is at the end of the route of greatest distance from the creamery. All the milk will be collected on the way to the creamery and the skim milk will be delivered to the patrons when making the return trip.

The driver collecting cream should be located close to the creamery so that, when starting on his route in the morning, he can collect the cream produced along one road and when returning to the creamery collect the cream along another road. A driver's travel from the creamery to his home, after completing his day's work, represents nonproductive labor.

2. Collecting in Individual or in Common Cream Gathering Cans. - The cream may be collected in individual cans; the weighing and sampling of the cream is then usually done at the creamery. Or the driver may collect in common cream gathering cans and weigh and sample the cream at the farm. The cream from several patrons is thus mixed in the same can.

The advantages of using individual cans are: First, elimination of losses due to inaccurate weighing and sampling; it is usually difficult for one of less experience to secure an accurate sample for testing, especially during the winter season when some of the cream may be frozen; second, less cream is lost to the patrons as the cream can all be removed from the cream can at the creamery by applying warm water on the outside of the can. Heavy cream adhering to the can is removed with difficulty on the farm where there is usually a scarcity of warm water; third, it gives the butter maker better control of the quality. He can grade the cream as he deems best. $\mathrm{He}$ knows the defect of each individual's cream and can talk intelligently to the producer about how to improve it; fourth, it 
makes it possible to make use of a less competent driver when an able man cannot be secured.

Advantages in using the common cream gathering cans and weighing and sampling the cream when receiving it at the farm are:

First, patrons who prefer to do so may witness the weighing and sampling of their cream. Such patrons may, however, be satisfied by using the individual cans if the driver brings a pair of scales and weighs the cream when he receives it. The can may be marked with its tare weight so the net amount of cream is readily determined. It may also be advisable at places for the hauler to take the sample even though the individual cans are used.

Second, the same amount of cream makes less of a load and occupies less space on the wagon.

Third, churning of the cream on the road is prevented by filling the cans or by using cans equipped with float. This advantage, as in the case of the second mentioned, is in part secured for the individual can system by using a special individual can which is equipped with float and so constructed that two or more can be placed on top of each other in the wagon.

Fourth, when less cans are needed on the wagon less labor will be required for keeping the cream cold while in transit. This is true especially when the jacketed cream can is used.

3. Care of Cream while on the Route. - If the cream is mixed by the driver, care should be taken to mix cream of same quality together, and to use separate cans for each grade. If the cream is bought on a quality basis, then some system should be adopted for grading which can be operated intelligently by the hauler, for the cream should be graded when it is received by the driver.

If the regular steel milk cans are used for cream, in the summer they should be wrapped with burlap. This should be kept wet. The bottom of the wagon should be covered with a wet blanket, canvas, or several thicknesses of burlap. This should be wet frequently by throwing a few pails of cold water over it. Each pound of water that is converted into steam takes up heat. 
It has been demonstrated that not merely will cream cared for in this manner remain without increase in temperature, but will often reach the creamery cooler than when received from the patrons.

A special can with a deep cover in which ice may be placed has been used to advantage by several creameries. Others use a small steel two-quart can with a tight-fitting cover. This is filled with crushed ice and put into the cream can. The ice is carried by the driver in an insulated wooden box.

4. Checking Butter Fat Losses of the Cream Route. - If individual cans are used, the cream from the routes will be handled as by the individual system and the driver is not held responsible for butter fat losses sustained from such patrons. If the cream is weighed and sampled by the hauler, then he should furnish a record of the amount of cream credited to each patron (Form IX). The total amount of cream, according to the hauler's report, should equal the weight of the entire load as weighed at the creamery. The individual samples, as well as the composite sample of cream from the entire route, are tested at the creamery, and the total amount of fat paid for according to the driver's report should be equal to the amount of fat received at the creamery, figured from the creamery weight and composite sample. 
I II 8

MANAGEMENT OF DAIRY PLANTS

FORM IX

DRIVER'S REPORT

Route No.
ROYAL CREAMERY CO.

Royal, France

Date

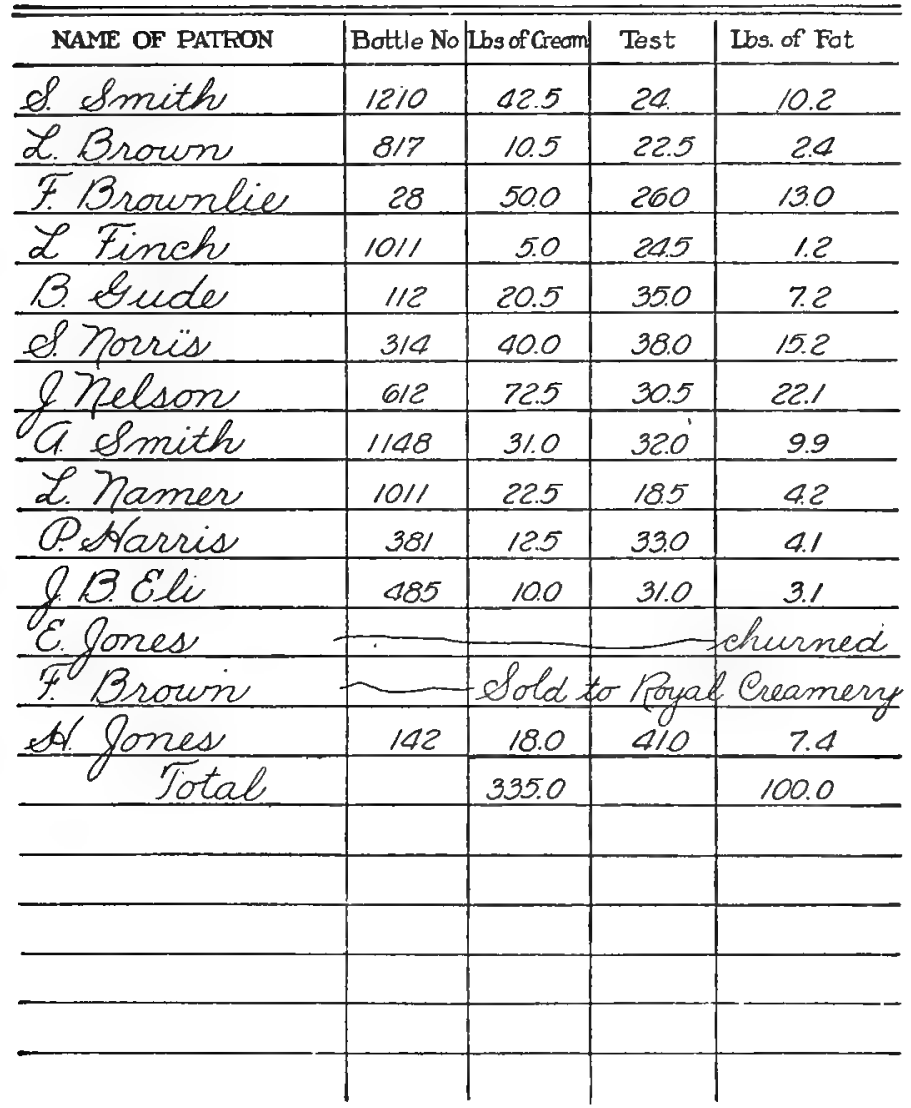


FORM X

ROUTE-CHECKING RECORD

Route No. 3

\begin{tabular}{|c|c|c|c|c|c|c|c|c|c|}
\hline \multirow{2}{*}{ Dals } & \multicolumn{3}{|c|}{ Amount Received } & \multicolumn{2}{|c|}{ Amt. paid for } & \multicolumn{2}{|c|}{ Overage } & \multicolumn{2}{|c|}{ Shortage } \\
\hline & Cream & Test & Fat & Cream & Fat & Cream & Fat & Cream & Fat \\
\hline March & & & & & & & & & \\
\hline I & $3 \circ 3$ & 30.5 & 92.4 & 303 & 91.5 & & .9 & & \\
\hline 3 & 340 & 29.0 & 98.6 & $34 \mathrm{I}$ & IOI.O & & & I & 2.4 \\
\hline 5 & $33 \mathrm{I}$ & 29.0 & 96.0 & 335 & 100.0 & & & 4 & 4.0 \\
\hline
\end{tabular}

Total

The route-checking record (Form $\mathrm{X}$ ) is kept up daily for the purpose of checking the accuracy of the work done by the drivers. It is unnecessary to have special printed blanks for this purpose, a cheap book being satisfactory. A page should be allowed for each route. This book should be left at a place where the drivers have access to it, as they are usually as much interested in having their work check as is the creamery operator.

On examining the sample route-checking record (Form X), it will be noted that there were some errors either in taking the samples or in testing. The person doing the testing should always be certain that his own work is done correctly. To do this he must make duplicate tests. If it is evident that the driver is making mistakes in taking the samples, then he should be so informed, and properly instructed so that future errors will be avoided. If errors in weights of cream are noticed, it is most likely due to inaccuracy of the scales, or failure to balance the scales for each weighing.

It is advisable to have the names of patrons written on the driver's report at the office. The names should be written in the order in which the hauler calls on the patrons. By this method the names are written more plainly and fewer mistakes 
will occur. Furthermore this plan brings immediate information to the office in reference to discontinued patrons.

Station System. - A cream station is a plant rented or owned and operated by a creamery for the purpose of buying and usualy pasteurizing cream collected from the surrounding territory, and then sending it to the creamery for manufacture. The station itself may receive cream from individual patrons and from routes, and so far as the cream purchasing is concerned this is managed in the same manner as in a small creamery. A building ${ }_{5} 5$ by 30 feet in size usually answers the purpose, and the main equipment needed is a 4 to ro horsepower boiler, a 2 horse-power engine, a water pump, a steam tester, and a cream ripener which may be used both as a cream pasteurizer and as a cooler. For a skimming station one or more separators should be added and the size of the boiler and engine increased in proportion.

The greatest advantages of the station are that the creamery, through its agent (the station operator), can keep in close touch with its more distant customers and that the quality of the cream is improved by pasteurizing and properly cooling it before it is shipped to the central plant. The main objection to the station system is the cost of operation and the investment involved.

A station should receive cream from not less than 300 to 400 cows in order to keep the expense per pound of butter fat within a reasonable limit. The expense may be somewhat reduced if it is possible for the station operator to haul the cream from one of the routes three days of the week and receive cream at the station on the other three days. Some of the stations manufacture butter enough to take care of local demand.

I. Station Reports. - Form XI is a report blank, which may be used by the stations in reporting to the central plant. It will be noted that part of this blank is filled out at the central plant. The statement is intended to give a complete record of the daily cream receipts of the station. Losses sustained, due to improper weighing or testing, and the disposition of the product reported by this record are checked at the central plant. 
FORM XI

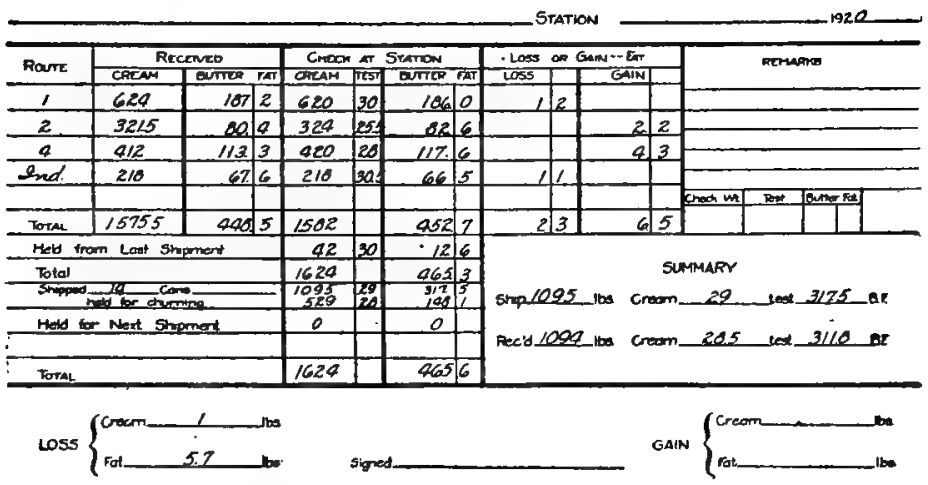

2. Shipping the Cream to the Central Plant. - Each can is properly addressed and billed as explained on page rro, but in addition one of the cans bears a tag of conspicuous color; on one side may be written the address of the firm for whom the shipment is intended, on the other side it carries the following information:

No. cans shipped.

Lbs. cream shipped

Test of cream.

Lbs. butter fat .

Remarks.

Signed.

Station

The receiving department of the main plant is by this report enabled to learn whether cream has been lost while in transit or if there is a variation from weights or tests reported. If variation is found it should be noted if there are any indications of loss while in transit, such as one of the cans being only part full. If cream has been lost it is readily indicated by the old cream line on the inside of the can and the seal is likely to be 
broken or perhaps replaced with another seal not bearing the proper stamp. If it is evident that the cans have been tampered with, it is advisable to call the inspector of the transportation company and request that he inspect the shipment before the cream is removed from the cans. When it has been inspected, it is handled in the usual manner and a claim is made out against the transportation company for loss sustained. In presenting this claim to the transportation company it should be explained in detail how and when the shipment was received, where it originated, by whom shipped, etc. This letter should be accompanied with original bill of lading or expense bill.

Local Agent System. - Under this system the central plant employs a person (the cream buyer) whose duty it is to buy for, and ship the cream to, the central plant.

The advantage of this system is that the creamery will obtain more cream from a distant territory by having a local man as buyer. The main disadvantage is the cost of collecting, such a buyer usually receiving from one to three cents per pound of butter fat for collecting. There may also be a decrease in quality of cream from such agents, due mainly to incapability and disinterest on the part of the buyer; he is paid for collecting the cream often regardless of quality and frequently he is even unable to decide as to quality. Decrease in quality may also be due partly to the condition of the place where the cream is kept after it has been collected, for it is not always arranged with facility for cooling.

Coöperative Cream Selling System. - A coöperative cream selling organization is an association of producers formed for the purpose of collecting and selling the cream produced by its members. It eliminates the unnecessary expense of hauling by competitive creameries sending teams over the same road. It reduces the expense of soliciting by competitive creameries. It increases the selling price of the cream by selling to the highest bidder. It promotes greater interest in dairying and as a result the quality and quantity of the cream will be increased. 


\title{
CHAPTER IX \\ PURCHASING EQUIPMENT AND SUPPLIES
}

\author{
THE BUYER
}

THE qualified buyer is the one who obtains the $:$ ost value for his money without defrauding the salesman of money which is justly due him. A business transaction has been defined as being an exchange of values. Therefore, if a permanent business relationship is established between two firms, the business transaction between them must be mutually beneficial.

The Buyer Should Know the Present Value of the Goods He Is to Buy. - The unqualified buyer is ignorant of values. He may realize his own ignorance and imagine that the salesman is taking advantage thereof. As a result he may make an arbitrary offer which is perhaps even less than the cost of the goods to the manufacturer. $\mathrm{He}$ is not willing to pay the price at which the goods are offered by the salesman, regardless of how fair such a price may be.

The salesman who is anxious to do business studies the character of the buyer. It is soon clear to him that he is dealing with a man who is either ignorant as a buyer or perhaps a man who is unwilling that the manufacturer or dealer should make a fair profit. The latter class of men are not considered as desirable to do business with and some firms even refuse to sell them goods. If the salesman considers that the buyer belongs to the first class mentioned he may be inclined to ask a price high enough so he can afford to reduce it as much as he thinks necessary. The buy $r$ in this case is placed at a disadvantage, and it is quite likely that he will pay more than market value for the goods he buys.

The successful buyer studies the goods he buys. He should know the source of raw material from which they are manu- 
factured, the cost of such material, fluctuation in value thereof, if any, cost of manufacturing, cost of selling, value of patent rights, and the legitimate profit for the manufacturer and dealer.

The general market value of an article is ascertained by writing to various firms handling that particular article. Information thus obtained should be filed. For smaller firms a letter file will be satisfactory and the letter itself may be filed for reference. For larger firms a card file will be more satisfactory. The information may be filed alphabetically and for creameries the file may be divided into two sections, the first dealing with equipment and the second with supplies. For example, if letters are received in reference to the cost of equipment the information may be filed under the general names of such equipment as churns, vats, engines, testers, etc., and alphabetically in reference to firm names.

The Buyer Should Know the Future Value of the Goods He Is to Buy. - A buyer will know when to buy and how much to buy if he has a fair conception of the future value of the goods. Consider, for example, such an article as coal, which fluctuates more or less in value. In order to determine the advisability of 'buying several months' supply at a time the buyer should consider the principal factors which may affect the future value of the coal. Such are general demand, labor strikes, transportation, and local conditions. Under the head of transportation should be considered both the ability of the transportation company to give prompt service as well as difference in rate of transportation between smaller and larger quantities. Some factories are so located that they can take advantage of water rate at certain seasons of the year, while at other times they must ship by rail. Under the head of local conditions should be considered price charged by local dealers, cost of drayage, amount of money available, interest on money, storage facilities, loss of fuel value of coal, etc.

The Buyer Should Know the Quality and the Need of the Goods He Buys. - He should be able to make a wise choice as to quality and determine whether the article in question is 
absolutely needed. Goods are often bought because they are cheap and it is expected they will be needed later on. A few mistakes of this nature will be sufficient to reduce the annual dividend several per cent. In order that the buyer may know what is needed it is well for him to keep a want book in which to write down articles needed so that they may be ordered together with the next regular order.

\section{HOW TO BUY}

Contracting for a Year's Supply. - Most creameries buy supplies in small lots, placing orders for them with various dealers. For that reason the dealers find it necessary to have their traveling solicitors make frequent calls in order to be assured of their share of the business. The cost of such calls is naturally charged up against the cost of selling the goods and the buyer has to pay the expenses. Many of such expenses could be eliminated if creamery managers would estimate the amount of supplies required for the coming year. This is readily done, especially after a creamery has been operated for a year or more, as its requirements will vary from month to month much as they did during the previous year. A buyer should be able to estimate to a fair degree of accuracy if the business will show a general decrease or increase for the year. The inventory record of supplies for the previous year will present a fair estimate of the proportion of the supplies needed for each month of the coming year. Therefore, whenever submitting an order to dealers for bids they may be requested to submit bids under various specified conditions. For example, a buyer might request that dealers submit bids on the entire order to be shipped in one shipment at a definite stated time, also that they submit bids on the same order to be shipped in four separate shipments, each shipment to consist of a definite stated quantity which will naturally vary in accordance with the demand; as a third bid he might request dealers to submit bids on monthly shipments in amounts as stated by the purchaser.

In determining the size of shipment to take at each delivery a buyer should consider the difference in cost, amount of money 
available, rate of interest, storage facilities, and cost of transportation.

In submitting the order to the various dealers for quotations it is convenient to have a blank for that purpose. A duplicate should be kept in the office for reference. After the quotations have been received and compared the successful bidder is notified that his quotation has been accepted. The quotations are filed in a letter file. For convenience this file may be marked as No. I.

Promptness in Making Remittance for-Goods Purchased. - This is an important factor in securing the lowest rate from the dealer. If the firm buying is in such financial circumstances that it can pay cash, that will be most satisfactory to all concerned, and by that method it will secure the lowest quotation. A business firm should have a definite time, say the tenth of each month, when to pay all bills, and it is business policy to arrange for having all checks for goods purchased, not including material purchases which are usually paid oftener, mailed promptly on that date.

Cash Discount. - Some firms allow a special cash discount on accounts paid within a time designated on the bill. Such bills should always be paid promptly, as the discount is usually large enough to be profitable to the buyer. When entering such bills in the purchase journal, the labor of bookkeeping is reduced by deducting the discount on the bills and entering the actual amount paid.

\section{RECORDS}

Receiving Record. - The person who receives merchandise purchased, whether he be a special receiving clerk or the butter maker, should make an entry thereof in a book kept for that purpose. This book is known as "the receiving book." This record should state when goods were received, name of shipper, kind of goods, amount, and condition in which goods were received. In larger creameries the manager will often furnish the receiving clerk with a memorandum of kind of goods purchased and from whom purchased. On this memorandum, however, 
he should not include the quantity ordered, as by receiving this information the receiving clerk might neglect to check it when received. If the goods are short the factory is notified at once. If damaged in transportation the railroad inspector is notified and a claim is filed for amount of damage.

Filing of Invoices and Bills. - The invoice for goods ordered is usually received before the goods arrive. Upon receipt thereof the invoice is checked against the order filed in file No. I, and when the goods are received the invoice is checked against the receiving book; the extensions are also checked and, if found to be correct, the invoice is pinned to the order and returned to file No. I. These items should be filed in alphabetical order, according to firm names, and each firm's invoices should be filed in order of dates.

At the close of each month the various firms usually mail bills. If not, bills should be called for. Upon receipt of the bill it is checked against the invoices in file No. I and if found rorrect it is marked "O. K.," pinned together with the various invoices, and filed alphabetically in a similar file marked "No. 2." It is now ready for payment and a check, together with the bill, is mailed to the creditor. A receipted bill is returned to the purchaser. This is pinned to the invoices and filed for future reference. A similar file may be used, but it should be marked, giving the period of time covered by the bills it contains. A large creamery may use a separate file for each month and this file is then marked with the name of the month and the year. A smaller creamery may be able to file in one file all its bills for an entire year; the file is then marked with that year.

Supply Room Records. - In the smaller plants the butter maker is in full charge of the supply room. It speaks well for a butter maker if he keeps his supply room as it should be kept, with shelves and cupboards around the walls for the various articles, such as parchment papers, butter color, tub tins, etc. with tubs, barrels, and boxes piled in systematic order. There should be a place for everything and everything in its place. By keeping the supply room in order less goods will spoil, less work 
will be required in taking the monthly inventories, and less room will be required for holding the supplies.

1. Receiving Goods from Supply Storage Room. - The larger creameries often have a special stock clerk who receives the supplies from the receiving department, and places them in the supply room. The various departments receive their supplies from this stock clerk on written orders signed by the foreman of the department.

Form XII may be considered as a convenient blank for such orders.

FORM XII

Creamery Order for Supplies

No. 720.

Date.

Please deliver to our department the following supplies. 4,000 butter wrappers.

Butter Mfg. Dept.,

(Signed) J. BROWN.

These blanks may be put up in pads about 4 inches by 5 inches in size. They may or may not be written in duplicate.

2. Monthly Inventory Record of Supplies. - The monthly inventory record of supplies on hand is of value: First, for determining the amount of supplies used during the month; second, as a guide for placing orders for supplies; third, as a check record on waste in supplies, and fourth, as a record in case of fire loss.

Form XIII represents an inventory blank which may be made to cover the entire year. This blank is self-explanatory. The purchases are entered from the purchase journal. The amount used during the month is equal to the amount on hand on the morning of the first day of the month, plus purchases made during the month, less amount on hand on the morning of the first day of the following month. 
FORM XIII.

INVENTORY OF SUPPLIES

\begin{tabular}{|c|c|c|c|c|c|c|c|c|c|c|c|c|c|c|c|}
\hline \multirow{3}{*}{ Article } & \multicolumn{6}{|c|}{ Janwary } & \multicolumn{5}{|c|}{ Fobruary } & \multicolumn{4}{|c|}{ March } \\
\hline & \multicolumn{2}{|c|}{ On hand } & \multicolumn{2}{|c|}{ Purchased } & \multicolumn{2}{|c|}{ Used } & \multicolumn{2}{|c|}{ On hand } & \multicolumn{2}{|c|}{$\begin{array}{l}\text { Pur- } \\
\text { chased }\end{array}$} & Used & On & \multicolumn{2}{|c|}{$\begin{array}{l}\text { Pur- } \\
\text { chased }\end{array}$} & \\
\hline & $\overrightarrow{\mathrm{E}}$ & है & $\frac{\dot{\vec{E}}}{\mathrm{E}}$ & $\overline{3}$ & $\stackrel{z}{\Sigma}$ & i & ह & $\vec{s}$ & E & $\mid \begin{array}{l}5 \\
\vdots \\
0\end{array}$ & $\frac{1}{8}$ & & 妾 & $\begin{array}{l}\dot{3} \\
0 \\
0\end{array}$ & $\mid \begin{array}{l}\vec{E} \\
\end{array}$ \\
\hline Coal. . & $\begin{array}{c}\text { Tons } \\
20\end{array}$ & $\$ 60.00$ & 30 & $\$ 90.00$ & 25 & $\$ 75.00$ & 25 & $\$ 75.00$ & & & & & & & \\
\hline Butter tubs. & 150 & 39.00 & 600 & 156.00 & 500 & $\overline{130.00}$ & 250 & $\overline{65.00}$ & & & 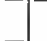 & & & $1-$ & \\
\hline Butter boxes. & & & & & & & & & & & & & & - & \\
\hline $\begin{array}{r}\text { Butt } \\
\text { wr } \\
\end{array}$ & & & & & & & - & & & -1 & - & -1 & & - & 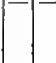 \\
\hline & & & & & & & & & & 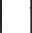 & & & & $-1-1$ & $-1-$ \\
\hline
\end{tabular}

In order to facilitate the work of taking the inventory a record, such as Form XIV, will be of much value. This blank is fastened to the shelves on which the supplies are kept. Whenever the butter maker removes supplies an entry is made on this record. In the case of a stock clerk the total amounts of supplies delivered in accordance with his order blanks are entered daily or weekly and at the close of the month these records contain full information in reference to the amount of supplies on hand. By that system one annual inventory count of the supplies on hand is usually found to be sufficient. 


\section{- FORM XIV}

Kind or SUPples Butter Whopeno

\begin{tabular}{r|c|c|c}
\hline DATE & DEPT To WHICH CHARGED & DELIVERED & RECEIVED \\
\hline fan 1 & on hand & & 10,000 \\
\hline 4 & Butter depantment & 5,000 & \\
\hline 6 & Durehased & & 100,000 \\
\hline 8 & Butter department & 0,000 & \\
\hline 15 & Butter department & 9,000 & \\
\hline 25 & Butter department & 10,000 & \\
\hline Feb 1 & on hand & & 78,000 \\
\hline
\end{tabular}




\section{CHAPTER $\mathrm{X}$ \\ COST OF POWER}

UNTrL recently only steam power has been considered practical for the creamery. It is now recognized that the gasoline engine and the electric motor may also be used to advantage in our modern plants.

\section{STEAM POWER}

Fuel. - The power is produced from fuel. The value of the fuel is measured by the heat units which its combustion will generate. The combustible portion of the fuel is the part of it which burns; other ingredients as ash remain and are without fuel value, the ash varying from 2 to $3^{6}$ per cent in different fuels.

Coal is the most important fuel known. It is used as a fuel in most dairy establishments. It has been estimated ${ }^{1}$ that on an average one pound of coal is equal for steam-making purposes to two pounds of dry peat, two and one fourth to two and one half pounds of dry wood, and to three and one fourth to three and three fourths pounds of wheat or barley straw. Table III by the same author gives the chemical composition of several typical kinds of solid fuels.

${ }^{1}$ Steam, its Generation and Use. 
TABLE III

Composition of Fuers

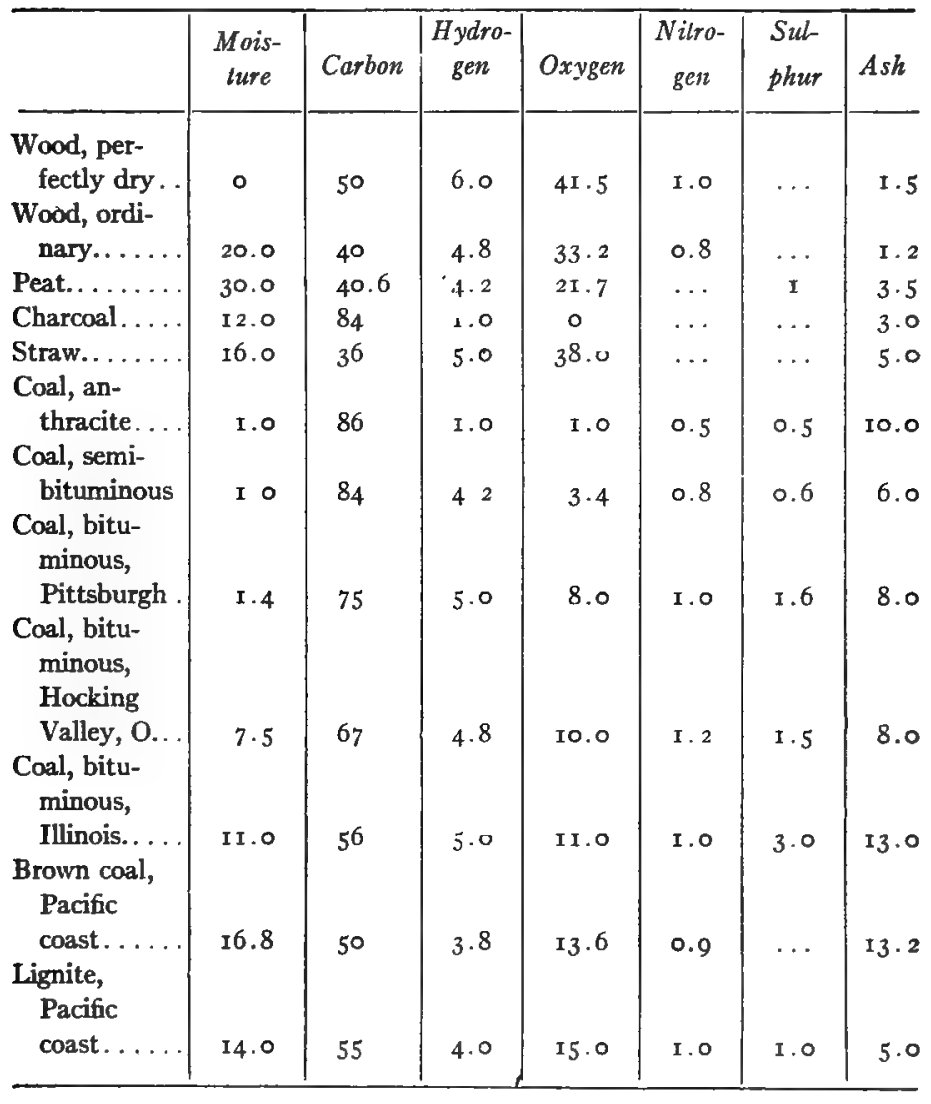

Heating Value of Fuel. - The amount of heat generated by combustion of carbon, hydrogen and sulphur is as follows: Carbon, 14,500 heat units per pound; hydrogen, 62,000 heat unit's per pound; sulphur, 4,000 heat units per pound.

Carbon and hydrogen are the only elements considered to 
possess practical fuel value. The heating power of fuels containing carbon and hydrogen is approximately expressed by the formula:

$$
\mathrm{h}=\mathrm{I} 45(\mathrm{C}+4.28 \mathrm{H})^{1}
$$

A manufacturer purchasing a quantity of fuel will do well in having a sample thereof subjected to chemical analysis, and the heat value is thus readily determined. Take as an illustration the analysis of Hocking Valley Coal, Table III, and the heat value is as follows:

- $\mathrm{h}=\mathrm{I} 45(67+4.28 \times 4.8)=\mathrm{I} 2,694$ B. T. U. per pound.

Heat Required for Producing Steam:- Water at $212^{\circ} \mathrm{F}$. takes up $966 \mathrm{~B}$. T. U. when converted into steam of the same temperature. Therefore if one pound of coal produces 12,694 heat units then a pound of such coal will produce $I 2,694 / 966$ or 13.I4 pounds of steam of $2 \mathrm{I} 2^{\circ} \mathrm{F}$. from water of the same temperature. The amount of heat thus required to produce a pound of steam is known as the latent heat of vaporization.

In practice more heat is required for producing a pound of steam, as the water that is converted into steam is usually at a temperature much below $212^{\circ} \mathrm{F}$. Possibly $60^{\circ} \mathrm{F}$. will come nearer to the temperature of the boiler feed water as used in most creameries. Furthermore the steam in the boiler is heated to a temperature exceeding that of $212^{\circ} \mathrm{F}$. Consider that a creamery is using boiler feed water at $60^{\circ} \mathrm{F}$. and carrying a steam-gauge pressure of 80 pounds, it will then require $I, I 53$ heat units for each pound of steam produced, or one pound of the above-mentioned coal will produce $\frac{I 2,694}{I, I 53}$ or I I pounds steam.

Losses of Heat When Producing Steam. - If there were no losses to consider it would be comparatively easy to determine the amount of fuel of a known composition required for producing a definite amount of steam. It will be impossible even for the most careful engineer to reach the theoretical efficiency. It should be possible, however, for many engineers to materially

${ }^{1}$ Siebel's Compend. of Mechanical Refrigeration and Engineering, I9I r, p. 96. 
reduce many fuel losses in the boiler room and often throughout the entire factory.

Creamery boiler losses in a small creamery are estimated by Bowen ${ }^{1}$ as averaging about 50 per cent of the theoretical efficiency. For a steam plant operated under most economical conditions the following estimate is furnished:

Loss due to unconsumed particles of coal falling through grate.... $2 \%$ Loss due to incomplete combustion.................... $2 \%$ Loss due to heat being carried away in stack gases........... $23 \%$ Radiation and other losses....................... $8 \%$

Total boiler losses. . . . . . . . . . . . . . 35\%

Such losses will further reduce the amount of steam produced from a pound of coal, so instead of having I I pounds of steam produced this figure is reduced to

I I $\times \frac{65}{100}$ or 7.15 pounds of steam, which is being finally produced from a pound of coal when considering the second estimate. The theoretical efficiency obtained from the coal in this case is 65 per cent. Inder the small creamery conditions where we figure on a 50 per cent efficiency the amount of steam produced from a pound of coal is I $\times \frac{50}{100}=5.5$ pounds.

Losses of Heat When Converting It Into Mechanical Work. - Heat is converted into power through the steam engine. The amount of power produced is spoken of in terms of horse power. One horse power corresponds to 33,000 foot pounds ${ }^{2}$ per minute; 778 foot pounds correspond to one British thermal unit. The amount of heat therefore required to produce one horse-power hour is equal to

$$
\frac{3.3,000 \times 60}{77^{8}}=2,545 \text { B. T. U. }
$$

It is estimated that a good engine will require from $I_{5}$ to 30

1 Circular 209 , B. A. I., I9r3.

${ }^{2} \mathrm{~A}$ foot pound is the power required to raise one pound one foot per minute. 
pounds of steam per horse-power hour. It is to be assumed that the average creamery engine will be operated at a greater loss of steam and it may be fair to estimate that it will require 40 pounds of steam per horse-power hour. The heat required to produce that amount of steam at 80 pounds gauge pressure from water of $60^{\circ} \mathrm{F}$. is equal to $\mathrm{I}, \mathrm{I} 53 \times 40=46,120 \mathrm{~B}$. T. U. The per cent of the heat converted into mechanical work is equal to

$$
\frac{2,545 \times 100}{46, \text { I } 20}=5.5 \text { per cent. }
$$

Methods by Which Heat Losses Are Reduced. - The exhaust steam from the engine contains much heat. By saving at least a part thereof, it will result in a reduction of amount of fuel required. The exhaust steam may be used for heating the boiler feed water and wash water, for pasteurization, for heating the building, etc. The losses are furthermore reduced by proper firing, by keeping the boiler clean, and by keeping boiler and steam pipes properly insulated.

I. Value of Exhaust Steam for Heating the Feed Water. - It has been stated that it requires I,I53 B. T. U. of heat for producing a pound of steam, 8o pounds of gauge pressure, from water at $60^{\circ} \mathrm{F}$. It should be possible to heat the water by exhaust steam to $200^{\circ} \mathrm{F}$. before the water enters the boiler. Water of $200^{\circ} \mathrm{F}$. when converted into steam of 80 pounds pressure will require only $\mathrm{I}, \mathrm{I} 53-\mathrm{I} 4 \mathrm{O}=\mathrm{I}$.0I3 $\mathrm{B}$. T. U. The saving of heat in this instance is

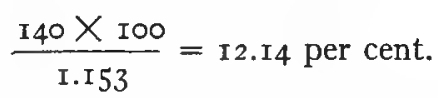

Table IV ${ }^{1}$ gives the percentage of saving in fuel by preheating the boiler feed water from various initial temperatures to different final temperatures.

Table $V^{1}$ gives the annual cash saving of fuel on a 40 horse-power boiler by heating the feed water from various initial temperatures to a final temperature of $200^{\circ} \mathrm{F}$.

1 Circular 209, B. A. I., I913. 


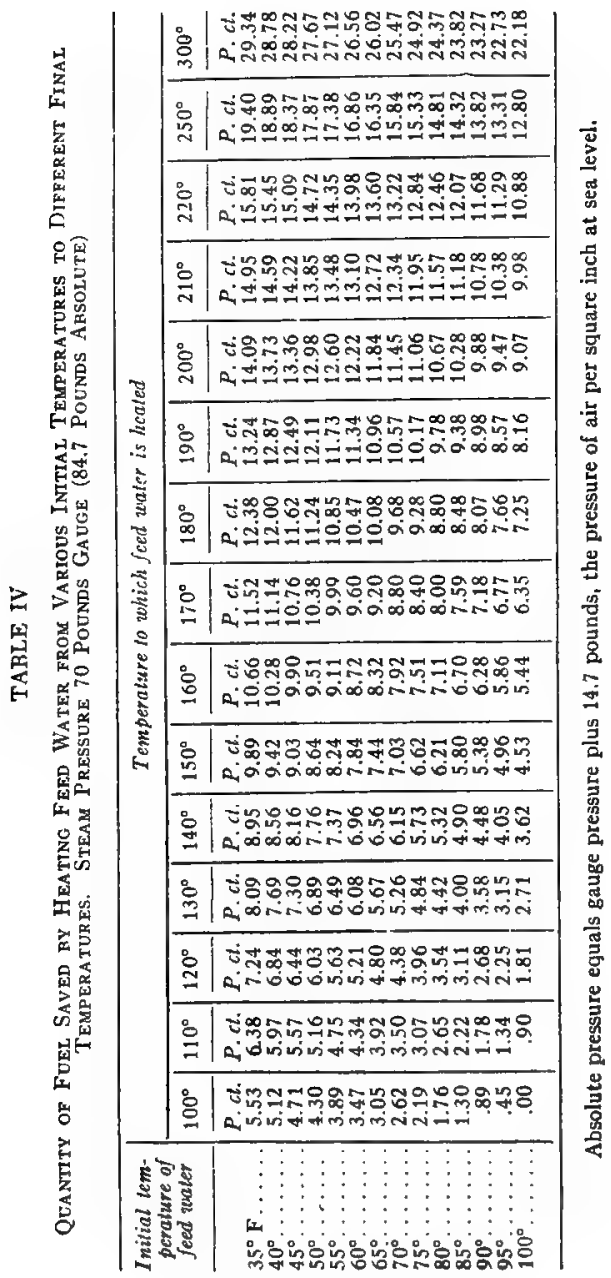




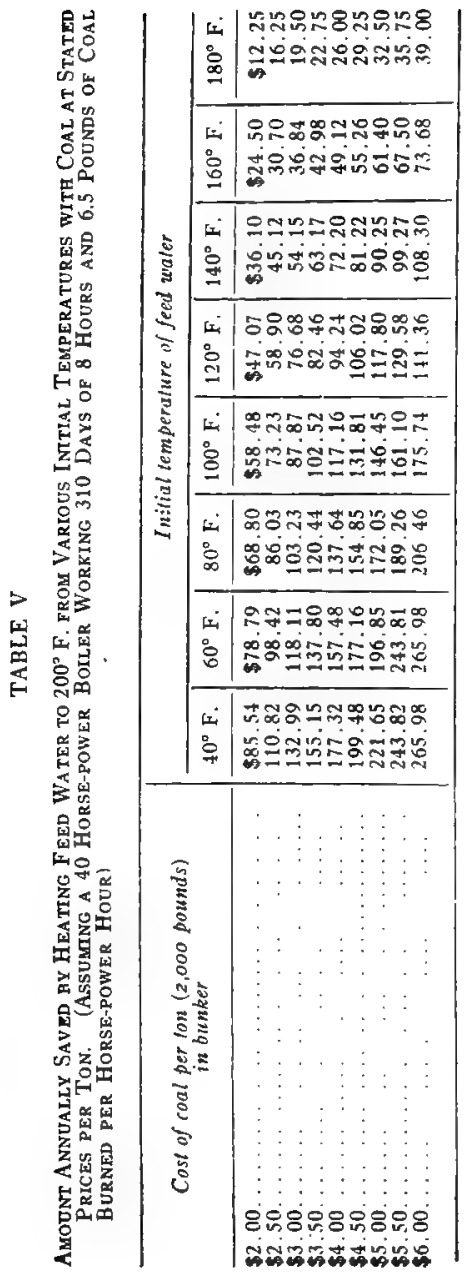


Heating of feed water may be done by two methods - either by exhaust steam or by chimney gasses. The heater used for the latter is known as "Economizer." It is the former method which will be most practical for the average creamery. There are two objects for heating the feed water: First, there is a saving in heat when heating the feed water by exhaust steam, and second, the water is heated to such a temperature so that it will not injure the boiler as will water of a low temperature.

When using water heaters, the best oil traps obtainable should be used, as the oil, if entering the boiler, will mix with the solids of the water and finally adhere to the sides of the boiler, which will naturally lessen the efficiency of the boiler. It is to be preferred that the steam pass through the heater through a system of coils, thus eliminating the steam from the water in the tank. Fig. $23^{1}$ illustrates a plant with water heating apparatus.

2. Firing. - The method employed in firing the coal may involve big losses. The ability of being able to obtain the greatest amount of heat from the fuel burned lies in the ability of the fireman to supply the right amount of air to the fuel under the right conditions. Only such an amount of oxygen should be supplied as is necessary to combine with the combustible portions of the coal. The coal should be added in small quantities at a time; it should be spread evenly over the grate. The fire should have a thickness of from three inches to six inches; it should be clean and should leave no burned-out places or holes.

Proper installation of the boiler is of importance in order to obtain the highest efficiency. It is estimated that it will require from one third to one half square foot of grate surface for each horse power of a horizontal tubular boiler. Complete plans and specifications for installation of the boiler and for building the chimney are furnished by the manufacturer of the boiler and the installation should be made and retained in accordance therewith.

3. Keeping Boiler Clean. - The efficiency of the boiler is greatly reduced if the exterior of the tubes is covered with soot

${ }^{1}$ Circular 209 , B. A. I., I9I3. 


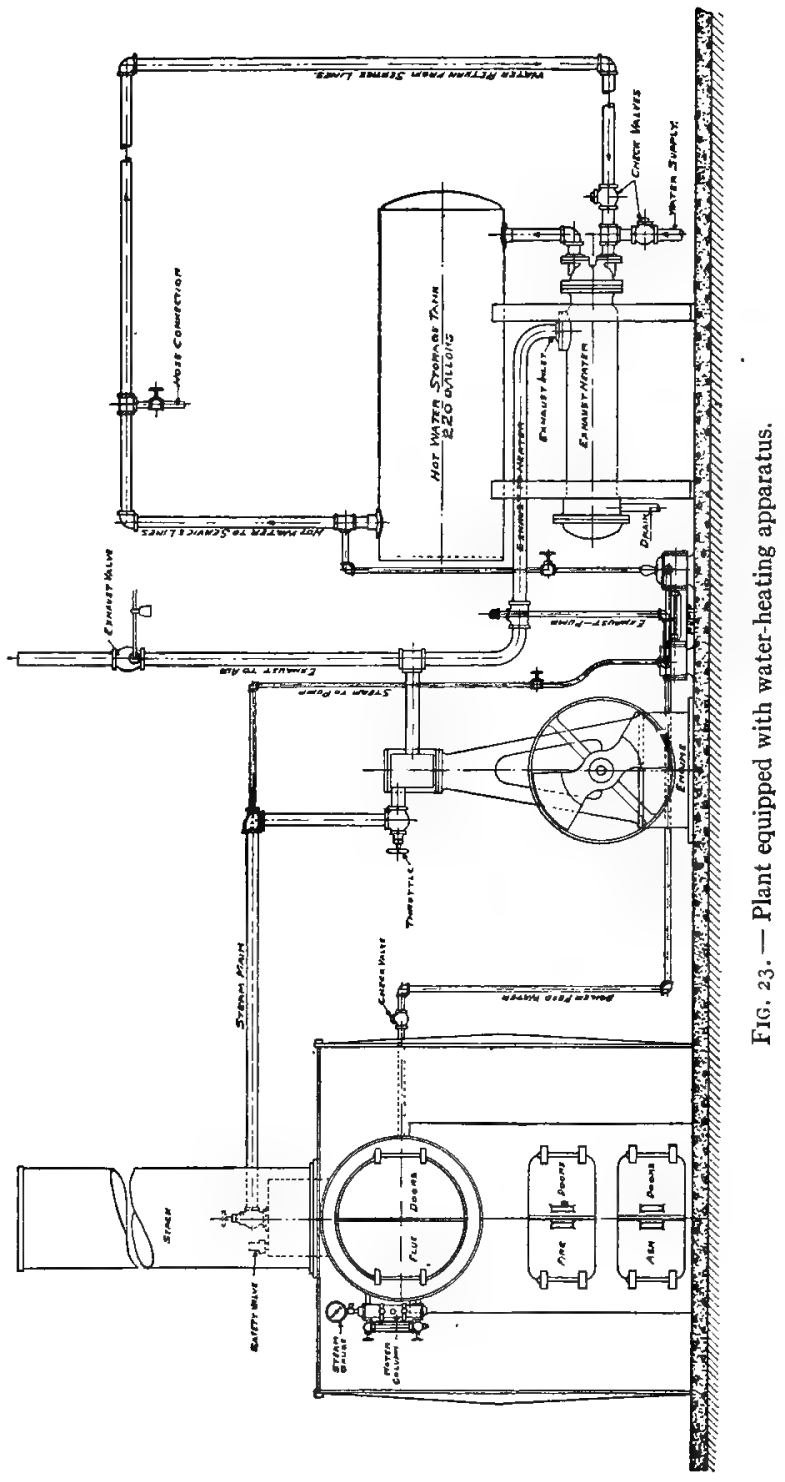


or the interior of the boiler with scale. The exterior of the tubes is readily cleaned and should be done daily. The formation of scale on the inside of the boiler is more difficult to prevent. The most common impurities in water causing formation of scales are sulphates and chlorides of lime and magnesia and bicarbonate of magnesia and lime; also iron silica and other ingredients are found. It is recommended to use caustic soda in the proportion of one fourth pound per horse power; the boiler is then steamed for a day before cleaning. The scales become soft and are readily removed. Soda ash or carbonate of soda will decompose sulphates and chlorides of lime and magnesia.

4. Insulation of Boiler and Steam Pipes. - Losses of steam from boiler, pipes, and engine due to radiation and leakage are estimated variously by writers. Such losses may be estimated for the average creamery at ro per cent of the steam produced. This loss may be reduced by having boiler and steam pipes properly insulated and by preventing leakage from pipes and valves.

Cost of Power When Operating a Steam Engine. - Consider that I pound of coal produces 5.5 pounds of steam and that the cost of such coal is $\$ 5.50$ per ton of 2,000 pounds. If 40 pounds of steam are used for a horse power per hour then the amount of coal required is $\frac{40}{5.5}$ or 7.27 pounds. The cost of a horse power per hour is equivalent to.

$$
\frac{7.27 \times 550}{2,000} \text { or } 2 \text { cents }
$$

\section{GASOLINE FOR POWER}

The gasoline engines have during recent years been installed in several creameries. The principal advantages claimed for them are:

1. Economical in cost of fuel and attendance.

2. Automatic in operation. 
3. For intermittent service - no expense when not in operation.

4. No water is used except for the cooling tank, and this water may be used over and over again.

5. It is safe and easy to handle, and no danger from fire. As disadvantages might be considered:

I. Subject to great wear and tear.

2. The original cost of a gasoline engine is greater than that of a steam engine.

3. The strong odor from the exhaust. However, this may be fairly well conducted from the building; nevertheless it is most satisfactory that the gasoline engine is placed in a separate room which can be thoroughly ventilated.

Cost of Operation. - A gasoline engine will consume about one tenth of a gallon of gasoline per horse power per hour. If the cost of gasoline is 24 cents per gallon then the cost per horse-power hour is 2.4 cents.

\section{KEROSENE FOR POWER}

The kerosene engine may be operated either with kerosene or gasoline. As advantages and disadvantages for this machine the same might be mentioned as enumerated under the head of gasoline engines. The odors from the kerosene engine are somewhat stronger, the original cost about 25 per cent higher, but the cost of operation with kerosene is much less.

Cost of Operation. - About one eighth of a gallon of kerosene is required for producing one horse-power hour. If the cost of kerosene is 12 cents per gallon then the cost per horsepower is $I .5$ cent.

\section{ELECTRIC POWER}

Electric power is measured in kilowatts (K.W.). A watt is $\mathrm{I} / 746$ of a horse power and a kilowatt is $\mathrm{I}, 000$ watts or $\mathrm{I} \mathrm{I} / 3$ horse power. A small amount of power is lost due to friction in the bearings and to heating of wires, therefore a motor receiving a kilowatt power will transmit slightly less than that amount. 
Cost of Operation. - If the cost per kilowatt hour is 5 cents, then the cost per horse power is $33 / 4$ cents.

Power is often saved when using electric power by installing smaller units, that is, using separate motors for the various machines or departments and motors of the proper size. This system prevents the use of a I $_{5}$ to 25 horse-power engine for yielding one or two horse power which is usually sufficient for stirring the cream or for pumping water. The system of individual motors furthermore reduces the amount of shafting and as a result the amount of loss due to friction. 


\section{CHAPTER XI \\ PASTEURIZATION}

Pasteurization should be considered as one of the necessary expenses in the modern factory of dairy products, for as long as the inspection of individual dairies is impossible it will not be safe to convert raw products obtained from such dairies into finished products to be offered for sale unless they have been subjected to pasteurization. Even though the dairy farm from which the cream is delivered is under inspection, it is at times possible that germs causing disease may also there gain entrance into the milk unbeknown to the producer. It is therefore generally recognized that if an absolutely safe product is produced it should be made from material which has been pasteurized to a temperature of not less than $140^{\circ} \mathrm{F}$. for twenty minutes or longer or to a temperature of not less than $180^{\circ} \mathrm{F}$. when exposed to flash heat. Pasteurization also improves the immediate quality as well as the keeping quality of the butter and causes a more uniform product to be produced.

\section{A. COST OF PASTEURIZATION}

The expenses incurred by pasteurization may conveniently be divided into three groups: I, cost of steam required for heating; 2 , cost of cooling water; 3 , cost of labor and equipment.

I. Cost of Steam Required for Heating. - Theoretically the amount of heat obtained from a pound of steam at a definite gauge pressure is a known quantity, but in practice it is not possible to obtain a hundred per cent of the theoretical effciency. Losses sustained in transferring the heat to milk or cream to be pasteurized are primarily due to radiation of heat from the steam pipes and pasteurizer. It is therefore economy to have the steam pipes leading from boiler to pasteurizer as well as the pasteurizer itself properly insulated so as to reduce such radiation to a minimum. 
It has been the experience of the writer that under ordinary creamery conditions when a steam-gauge pressure of from 40 to 80 pounds is maintained it is reasonably safe to figure that a pound of steam will yield about 900 B. T. U. of heat. From this estimated heat value of steam the amount of steam required for pasteurization may be quite accurately determined. As the difference in amount of heat required to raise a pound of water one degree on different parts of the thermometer scale is very slight, when considering the range of temperatures made use of in pasteurization, it will be safe in this connection to consider a B. T. U. as the amount of heat required to heat one pound of water any one degree on the Fahrenheit thermometer scale.

Example: How much steam is required to heat 10,000 pounds of milk from $60^{\circ} \mathrm{F}$. to $185^{\circ} \mathrm{F}$.?

Answer: $\frac{10,000 \times .94^{\prime} \times(185-60)}{900}=1,305.6$ pounds of steam.

I. Method by Which to Determine the Heating Value of Sleam. - More accurate determination of steam required for heating may be obtained by determining the heating value of the steam. This determination may be made as follows: Admit live steam into a known amount of water held in an insulated container; weigh the water after it has been heated to the desired temperature - the increase in weight is due to amount of steam condensed.

Example: 80 pounds of water are heated from $60^{\circ} \mathrm{F}$. to $180^{\circ}$ F. The water has increased in weight ro pounds. How much heat has been obtained from a pound of steam?

Answer: Let $y$ stand for amount of latent heat obtained from each pound of condensed steam used. Then,

Io $[y+(2 \mathrm{I} 2-180)]=80(180-60) ; y=928$ B. T. U.

The total amount of heat obtained from each pound of steam used is equal to $928+32=960 \mathrm{~B}$. T. U.

2. Weighing the Condensed Steam. - The amount of steam required for doing a definite amount of work is determined in 
the most practical manner by collecting the condensed steam and weighing it. This is readily collected from such types of pasteurizers as the continuous machines. It becomes more difficult when a cream ripener is used as a pasteurizer. However, even then it can be determined with a reasonable degree of accuracy. The condensed steam is secured through the circulating water overflow pipe. The circulating tank for the vat is first filled with water until it overflows. The agitator should be in motion for some time before pasteurization begins so the coil becomes properly filled. The amount of circulating water required may be determined once for all by weighing it into the tank. After the circulating water has become constant the steam may be admitted; however, the steam line should be equipped with a drain valve and the condensed water already in the pipe should be drained out and not be admitted into the circulating water. The amount of steam required for pasteurization is equal to the overflow minus the amount of the overflow due to expansion of the circulating water.

TABLE VI

Densities and Specific Volumes of Water 1

\begin{tabular}{|c|c|c|c|c|c|}
\hline Tcmp. & $\begin{array}{c}\text { Grams per } \\
\text { cubic centi- } \\
\text { moter }\end{array}$ & $\begin{array}{c}\text { Cubic centi- } \\
\text { melers per } \\
\text { gram. }\end{array}$ & Tentp. & $\begin{array}{c}\text { Grams per } \\
\text { cubic centi- } \\
\text { meter }\end{array}$ & $\begin{array}{l}\text { Cubic centi- } \\
\text { meters per } \\
\quad \text { gram }\end{array}$ \\
\hline$\circ^{\circ} \mathrm{C}$. & 0.999874 & I . 000127 & 55 & 0.98579 & I.OI 442 \\
\hline 5 & 0.999992 & I . 000008 & 60 & o. 98331 & I . oI697 \\
\hline IO & $0.99973^{6}$ & I. .000265 & 65 & o. 98067 & I. 0187 I \\
\hline I 5 & 0.999 I43 & I. .000857 & 70 & 0.97790 & I. 02260 \\
\hline 20 & 0.998252 & I. $.00175 \mathrm{I}$ & 75 & 0.97495 & I. 02569 \\
\hline 25 & 0.997098 & I. .0029 II & 80 & 0.97191 & I . 02890 \\
\hline 30 & 0.995705 & I. . & 85 & o. 96876 & I. .03224 \\
\hline 35 & 0.994098 & 1. .005936 & 90 & $0.9655^{\circ}$ & I. 03574 \\
\hline 40 & 0.99233 & 1.00773 & 95 & 0.96212 & I. 03938 \\
\hline 45 & 0.99035 & I. 00974 & 100 & $0.95^{86} 3$ & I. .04315 \\
\hline 50 & 0.988 I 3 & I. OI 201 & & & \\
\hline
\end{tabular}

${ }^{1}$ This table by Thiessen, Schell, and Marek is taken from "Mechanics and Heat," by Wm. S. Franklin and Barry MacNutt. 
Example: State amount of steam used for pasteurizing a definite amount of cream in a ripener when the circulating water weighs 428 pounds at $50^{\circ} \mathrm{F}$. $\left(10^{\circ} \mathrm{C}\right.$.) . Final temperature of circulating water being $15^{\circ} \mathrm{F}$. $\left(70^{\circ} \mathrm{C}\right.$.), and amount of overflow being equal to 236 pounds.

Answer:

The amount, by weight, of circulating water overflowing by being heated from $50^{\circ} \mathrm{F}$. to $158^{\circ} \mathrm{F}$. is

$$
\frac{428 \times 1.02260-1.000265}{1.02260}=9.35 \text { pounds. }
$$

Amount of steam used for pasteurization is

$$
236-9.35=226.65 \text { pounds. }
$$

3. Difference in Amount of Steam Used for the Continuous or Flash Method and the Holding Method of Pasteurization. - By the continuous method of pasteurization the milk or cream is heated to a higher temperature, about $180^{\circ} \mathrm{F}$, and the condensed steam is also discharged at a higher temperature, usually at from $200^{\circ} \mathrm{F}$. to $210^{\circ} \mathrm{F}$. When pasteurizing by the holding method the cream is heated to about $145^{\circ} \mathrm{F}$. and the condensed steam is discharged at a temperature of about $150^{\circ}$ to $160^{\circ} \mathrm{F}$. This saving in heat by the latter method is somewhat reduced, due to the fact that a certain amount of circulating water has to be heated most often from a temperature of about $50^{\circ} \mathrm{F}$. to about $150^{\circ} \mathrm{F}$. The additional amount of steam required for heating the circulating water is reduced per pound of butter fat as the amount of milk or cream in the vat is increased. Therefore when pasteurizing in the vat the steam required for pasteurization per pound of butter fat is greater when the vat is only half full of cream than when it is full. The following examples illustrate fairly well the amount of steam required for pasteurization under practical conditions.

Example:

I. Determine amount of steam required per pound of butter fat when pasteurizing 2,000 pounds of 30 per cent cream from $60^{\circ} \mathrm{F}$. to $185^{\circ} \mathrm{F}$. by the continuous method of pasteurization, 
the condensed steam leaving the pasteurizer at $2 \mathrm{I} 2^{\circ} \mathrm{F}$, 900 B. T. U. of heat being obtained for each pound of steam used.

2. Determine amount of steam required per pound of butter fat when pasteurizing same cream in a vat, heating it to $145^{\circ} \mathrm{F}$., the condensed steam leaving at a temperature of $155^{\circ} \mathrm{F}$, 500 pounds of circulating water being used, initial temperature of this water being $50^{\circ} \mathrm{F}$. and final temperature $160^{\circ} \mathrm{F}$.

3. Determine amount of steam required per pound of butter fat when $I, 000$ pounds of 30 per cent cream are pasteurized under the same conditions as specified in 2.

Answer:

(I) $\frac{2000 \times 0.84 \times 125}{900}=233.33$ pounds of steam $\frac{2.3 .3 \cdot 3.3}{2,000 \times 0.30}=0.389$ pound of steam per pound of butter fat.

(2) $\frac{2,000 \times 0.84 \times 85+500 \times \text { I I0 }}{900+\left(2 \mathrm{I}_{2}-\mathrm{r} 55\right)}=206.69$ pounds of steam. $\frac{206.69}{2,000 \times 0.30}=0.344$ pound of steam per pound butter fat.

(3) $\frac{\mathrm{I}, 000 \times 0.84 \times 85+500 \times \mathrm{IIO}}{900+(2 \mathrm{I} 2-\mathrm{I} 55)}=\mathrm{I} 32.08$ pounds of steam. $\frac{1.32 .08}{1,000 \times 0.30}=0.440$ pound of steam per pound of butter fat.

II. Cost of Cooling. - The cost of cooling depends primarily on the amount of water required to remove the quantity of heat taken up by the milk or cream during the process of pasteurization. A small part of this heat, however, is removed by evaporation. This latter factor is of greater importance when using an open cooler, such as a tubular, while of less significance when cooling in a cream ripener.

The amount of water required for doing a certain amount of cooling decreases in proportion to the number of heat units taken up by each pound of water. Therefore the greatest cooling efficiency is obtained when the difference is the greatest between the temperature of the cooling water as it enters the 
cooler and the temperature of the same water as it leaves the cooler. The amount of water required for cooling may differ greatly in proportion to the amount of water admitted through the cooler. If more water is admitted the cooling will be done more rapidly but at a greater expense than when the water flows through the cooler more slowly. It is evident that the temperature of the cooling water greatly influences the cost as well as the rapidity of cooling.

I. Efficiency of Coolers. - The tubular cooler may be considered to be of high efficiency. The author found that the cooling water when a certain type of tubular cooler was used took up $4 \mathrm{r} .59$ B. T. U. of heat per pound as against I2.58 B. T. U. when cooling with the vat, or it required 3.3 times as much water for cooling with the vat as with the tubular cooler, when cooling with water of $54^{\circ} \mathrm{F}$. It was also observed that the evaporation was slightly greater when using the tubular cooler; however, that shall be left out of consideration in the following.

2. Cost of Cooling-Water. - From experiments referred to, the cost of cooling was figured on the basis of the cream containing 30 per cent of butter fat. About 2,000 pounds of cream were pasteurized at a time. The cost of the water was figured at ten cents per thousand gallons. The cost per pound of butter fat for cooling when using a tubular cooler was found to be 0.009 cent as against $0.02 \mathrm{I}$ cent when cooling in the vat.

3. The Regenerator. - The regenerator may be considered as a saving device for the pasteurizing and cooling equipment. It is an apparatus over which the cool and hot milk pass simultaneously, the cool milk taking up heat from the hot milk, thus saving both in steam and cooling water. Bowen ${ }^{1}$ reduced the cost of coal about 50 per cent and the cost of refrigeration approximately 60 per cent by installing a regenerator.

III. Cost of Labor and Equipment. - The cost of labor varies somewhat with the different type of pasteurizer employed. Thus a continuous pasteurizer requires more of a person's attention than is required when the cream ripener is used as a

I Bul. 85, U. S. Dept. of Agriculture, 19 r4. 
pasteurizer. Furthermore the former method involves a greater expenditure and therefore more depreciation and interest on investment. By the latter method practically no additional machinery will be required.

Considering that a creamery is pasteurizing 2,000 pounds of 30 per cent cream for 300 days in the year and that for such work is used a continuous pasteurizer and cooler of 2,000 pounds per hour capacity costing $\$ 500$, the cost for the year may be summarized as follows:

Labor pasteurizing and cleaning, 400 hours at 30 cents..... \$120

Depreciation of 20 cents.................. 100

Interest on investment..................... 25

Total ............... $\overline{\$ 245}$

Cost per pound of butter fat $=\frac{24,500}{2,000 \times .30 \times 300}=0.136$ cents.

If the ripener is used for such work then the labor represents about fifteen minutes daily or a total of 75 hours at 30 cents, or $\$ 22.50$. Carrying $\$ 50$ annually of depreciation and interest, then the cost per pound of butter fat is equal to 0.04 cent.

IV. Total Cost of Pasteurization. -

I. Cost of Pasteurization by Continuous Method. - It was estimated, page 147 , that when a 30 per cent cream is pasteurized by the continuous method it will require 0.389 pound of steam per pound of butter fat. Figuring that 5.5 pounds of steam are produced from coal costing $\$ 5.5^{\circ}$ per ton the cost of pasteurizing per pound of fat is equal to

$$
\frac{0.389 \times 550}{5.5 \times 2,000}=0.019 \text { cent }
$$

The expenses per pound of butter fat when pasteurizing by the continuous method may be summarized as follows:

Cost of steam. .............. 0.019 cent

Cost of cooling. ............... 0.009 "

Cost of labor and equipment........ 0.136 "

Total............... 0.164 " 
2. Cost of Pasteurization by Vat Method. - Taking for granted that the vat used for pasteurization is of proper size, the amount of steam required per pound of butter fat when pasteurizing a 30 per cent cream has been estimated at 0.344 pound. The value of this being equal to

$$
\frac{0.344 \times 55^{\circ}}{5.5 \times 2,000}=0.017 \text { cent. }
$$

The total expenses may be summarized as follows:

Cost of steam.............. 0.or7 cent

Cost of cooling ............. 0.02I "

Cost of labor and equipment........ 0.040 "

Total............... 0.078 "

Bowen 1 estimates the cost of pasteurizing one gallon of milk at 0.313 cent and one gallon of cream at 0.634 cent. The same investigator found that it requires approximately I 7 per cent more heat for flash pasteurization than for vat pasteurization.

It is possible to reduce the expenses of pasteurization slightly by utilizing exhaust steam instead of live steam as has been considered in the above.

\section{B. THE ECONOMIC EFFICIENCY OF PASTEURIZING MACHINERY}

The economic efficiency of pasteurizing machinery depends on the amount of heat that in a definite time will be transmitted to milk or cream in the heating chamber from steam or water in the surrounding chamber, known as the steam chamber. The amount of heat thus transmitted depends on: First, size of heating surface; second, thickness of the heating wall; third, difference in temperature on the two sides of heating wall, and fourth, thermal conductivity of the metal from which the heating wall is constructed.

1 Bul. 85, U. S. Dept. of Agriculture, I914. 
I. Conductivity of the Heating Wall. - The amount of heat that in a given time will pass through the heating wall of a pasteurizer may be expressed by the following formula:

$$
Q=\frac{K \times A\left(t_{1}-t_{2}\right)}{d} \times T \text {. }
$$

$Q$ represents quantity of heat in B. T. U. conducted.

$\mathrm{K}$ represents the quantity of heat in $B$. T. U. conducted through one square inch of a wall one inch thick per second when the difference in temperature on the two sides of the wall is $\mathrm{I}^{\circ} \mathrm{F}$.

A represents area, in square inches of heating surface.

$t_{1}$ represents temperature in Fahrenheit degrees in steam chamber.

$t_{2}$ represents temperature in Fahrenheit degrees in heating chamber.

$\mathrm{T}$ represents time in seconds.

d represents thickness of wall in inches.

The heating wall of a pasteurizer should be constructed from metal which is of high thermal conductivity. Copper has been found very satisfactory for that purpose, its thermal conductivity being 0.72 . Only one metal, silver, is a better conductor than copper, its thermal conductivity being 1.096, but its use is prohibited on account of its cost. Aluminum is next to copper in thermal conductivity, being 0.343 , while tin is only 0.152 .

Taking for granted that copper will be used for the construction of the heating wall of the pasteurizer we know that 0.72 calorie ${ }^{1}$ of heat will be conducted per second through one square centimeter of a copper wall one centimeter in thickness when the difference in temperature on the two sides of the wall is one degree Centigrade.

The British thermal unit is a measure for heat which is mostly used in practical work. As one pound is equal to $453.6 \mathrm{grams}$ then one B. T. U. is equal to $453.6 \times \frac{100}{180}=252$ calories.

1 One calorie is the amount of heat required to heat one gram of water one degree Centigrade from $4^{\circ} \mathrm{C}$. to $5^{\circ} \mathrm{C}$. 
The amount of heat which will be conducted per second through one square centimeter of copper one centimeter in thickness when the difference in temperature on the two sides of the copper wall is one degree Fahrenheit is equal to

$$
0.72 \times \frac{100}{180}=0.40 \text { calorie. }
$$

The amount of heat in B. T. U. which in one second is conducted through one square centimeter one centimeter thick is equal to $\frac{0.40}{25^{2}} \mathrm{~B}$. T. U. with a difference in temperature of one degree Fahrenheit.

The value of $K$ is equal to ${ }^{1}$

Example:

$$
\frac{0.40}{25^{2}} \times \frac{(2.54)^{2}}{2.54}=0.004 \text { B. T. U. }
$$

Determine the amount of milk which should be pasteurized per hour when using a pasteurizer of $I, 400$ square inches heating surface; thickness of copper, 0.05 inch. The temperature in the steam chamber is $212^{\circ} \mathrm{F}$, the average temperature of milk in pasteurizer, $152^{\circ} \mathrm{F}$. and the milk is heated from $60^{\circ} \mathrm{F}$. to $180^{\circ} \mathrm{F}$.

Answer:

$$
\mathrm{Q}=\frac{0.004 \times \mathrm{I}, 400 \times 60}{0.05} \times 3,600=24,192,000 \mathrm{~B} . \mathrm{T} . \mathrm{U} .
$$

Amount of milk to be pasteurized $=$

$$
\frac{24,192,000}{120 X .94}=214,468 \text { pounds. }
$$

II. Factors Reducing the Efficiency of a Pasteurizer. From the above problem it is evident that the theoretical efficiency is not obtained in practical work. About one per cent of the theoretical efficiency is as much as may be expected when using a pasteurizer of a continuous type. By this it is not understood that ninety-nine per cent of the heat is lost, for

' One inch is figured as being equal to $2.54 \mathrm{c} . \mathrm{m}$. 
the loss of heat is comparatively slight, but the time required for doing the work is greatly increased. It is already understood that the area of the heating surface, the thermal conductivity of the metal, the thickness of the metal, and the temperatures applied are all factors which influence the efficiency of the pasteurizer. Factors greatly affecting the conductivity of the pasteurizer wall are the formation of a layer of water on the outside of the heating cylinder and the burning on of milk solids on the heating surface.

r. Layer of Water on Outside of Heating Surface. - The layer of water on the outside of the heating surface is formed by condensation of steam during the process of pasteurization. As the thermal conductivity of water is only .00I24 the thermal conductivity of copper is $58 \mathrm{I}$ times greater than that of water; it is therefore economy to have the thickness of the layer of water reduced to the minimum.

The Danish Experiment Station succeeded in increasing the efficiency of the continuous pasteurizer materially by soldering on the outside of the heating cylinder a series of rings at a downward angle of $45^{\circ}$. These rings remove the water quickly, the thickness of the layer of water was reduced, and the economic efficiency of the machine increased about 50 per cent (Fig. 28.) ${ }^{1}$

2. Burning of Milk Solids on Heating Surface. - Burned-on milk is extremely poor in conductivity. It is therefore of much importance that all particles of burned-on milk are properly removed after each time the machine has been used. This is done most readily by filling the machine with water and washing powder immediately after pasteurization. By leaving the dasher revolving from ten to fifteen minutes it is quite easy to remove with a brush all milk particles adhering to the heating surface. A knife or any kind of metal should never be used for scraping the surface, as such tools will cause rough places and when the milk strikes such it will readily burn on. If any amount of milk has burned on to the pasteurizer slacked lime and sal soda mixed in equal proportions will prove of greater

1 Bul. 43, Danish Experiment Station, 1899. 


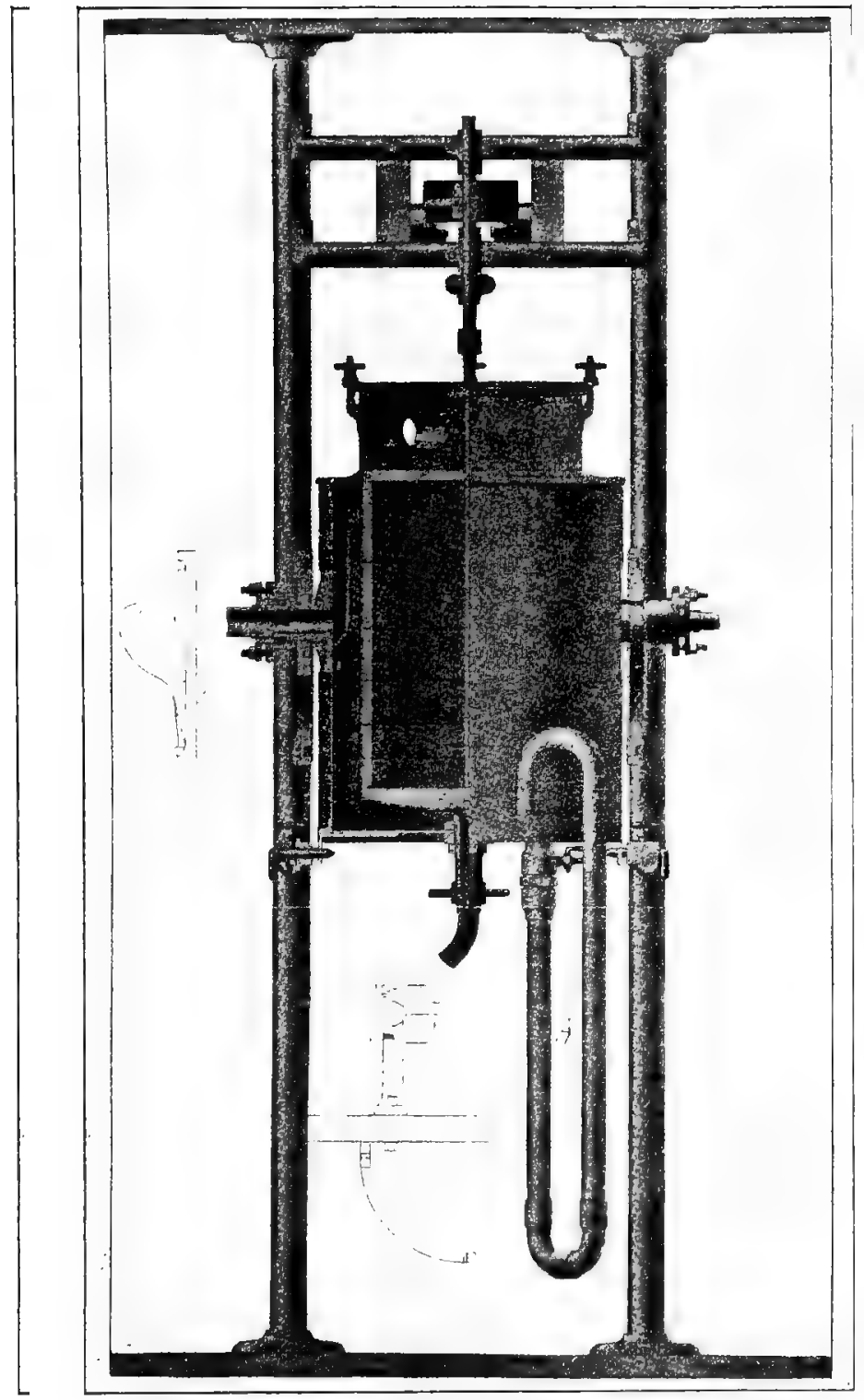

FIG. 24. - Pasteurizer with the Danish Experiment Station Improvements. 
efficiency than washing powder, but this should not be used unless necessary, as it has a dissolving effect on the tin. The following are the most significant causes for milk burning on to the heating surface.

A. Too Thin Metal. - As the copper wall becomes extremely thin the heat is conducted so readily through the wall that the heating surface becomes too hot. The albumin when striking this surface is coagulated and burns on. The increase in the thickness of the heating wall will represent a comparatively slight decrease in efficiency. This decrease, however, is insignificant as compared to that caused by burned-on milk and as copper is so efficient as a thermal conductor it is advisable to have a copper wall of not less than one-twentieth of an inch in thickness. Copper of such thickness will not cause the milk to burn on readily and the pasteurizer, furthermore, becomes of sufficient durability.

B. Too High Heat in Steam Chamber. - The heat in the steam chamber should not exceed $214^{\circ} \mathrm{F}$. The higher the heat the greater the danger of burning on. The amount of heat in the steam chamber of pasteurizer (Fig. 28) is controlled by steam trap A. Through this trap all water condensed in the pasteurizer escapes. The higher this water column extends above the bottom of the pasteurizer the greater the steam pressure and temperature in the steam chamber. Steam should never be allowed to escape through this trap, as this will represent a loss of heat and indicate that the pasteurizer is operated above its capacity.

C. Too High Pasteurizing Temperature. - It is natural that the heating surface has to be kept at a much higher degree of heat when the high pasteurizing temperatures are employed, thus causing more of the milk to burn on. It is often noticeable that a ring of burned-on milk is formed around on the upper part of the heating surface where the milk has reached its highest temperature.

D. Too Hot Steam Coming in Contact with the Warm Milk. - The steam when entering the pasteurizer, if of high pressure, is considerably above $214^{\circ} \mathrm{F}$. and it is most important 
that such steam enters the pasteurizer at a point close to the inlet of the cold milk.

E. Milk Moving too Slowly Over the Heating Surface. - If the milk is moving rapidly over the heating surface there is no part of the milk solids that will remain long enough in touch with the heating surface to burn on. It is therefore essential that the heating surface is smooth; rough places either due to imperfect metal or to burned-on particles retard the speed of small parts of milk and therefore at such places more or less burned-on milk solids will be found. Higher speed of the agitator may prevent the milk particles from burning on.

The Danish Experiment Station ${ }^{1}$ (Fig. 28) placed horizontal plates on the agitator of a pasteurizer of the continuous type. This caused the milk to move over the heating surface at a higher rate of speed and as a result less milk solids burned on to the heating wall. The horizontal plates on the dasher furthermore assured uniform heating of all particles of milk pasteurized by preventing milk just entering the pasteurizer from splashing, whereby some of the cold milk might be discharged with the milk properly pasteurized. More particles of the milk will come in direct contact with the heating surface of the pasteurizer and the economic efficiency of the machine is thereby increased.

\section{Purchasing Equipment for Pasteurization.}

I. Pasteurizer. - When purchasing a pasteurizer the buyer should request that the manufacturer furnish a guaranty as to its economic efficiency. If a machine is represented to be of I,, 00 pounds capacity per hour the temperature of pasteurization should be considered, as it takes about twice as long to pasteurize a given amount from $60^{\circ} \mathrm{F}$. to $185^{\circ} \mathrm{F}$. as is required to pasteurize the same amount from $60^{\circ} \mathrm{F}$. to $145^{\circ} \mathrm{F}$. The pasteurizer should be constructed from material of sufficient strength and the heating surface should be smooth.

2. Cooler. - The cooler should be of a size sufficient for cooling the milk or cream to within $2^{\circ}$ to $4^{\circ} \mathrm{F}$. of the temperature of the water. If a tubular cooler is used the tubes should be con-

' Bulletin 43, Danish Experiment Station, 1899. 
nected with metal strips which insures a more complete spreading of the milk or cream.

3. Steam Boiler. - It is important that the boiler is of sufficient size. The capacity of a boiler is rated by the amount of water it is able to evaporate. A horse power is equivalent to the evaporation of $34 \mathrm{I} / 2$ pounds of water per hour at $212^{\circ} \mathrm{F}$. If milk is pasteurized to a temperature of $145^{\circ} \mathrm{F}$. from initial temperature of $60^{\circ} \mathrm{F}$. then it will require approximately one horse power for every 400 pounds of milk pasteurized per hour or it will require approximately one horse power for 300 pounds of milk per hour if it is heated to $180^{\circ}$ or $185^{\circ} \mathrm{F}$. It is advisable to provide for surplus boiler capacity, as forcing the boiler results in excessive fuel requirements. 


\section{CHAPTER XII \\ COST OF WATER}

WHERE the water is pumped in the creamery it is scarcely realized that water costs money. In that instance it will also be unnecessary from the stand point of profit and loss to determine the cost of the water for a small plant, as that will be included under the total cost of fuel, labor, supplies, depreciation, etc. If the water is purchased from the city the item of expense is apparent, and first, then, the creamery manager begins to make an effort to reduce the cost thereof and in doing so it is essential to know what the water is used for. This is most readily determined by having separate meters on the water pipes leading to the different departments. Water may be used to advantage in great quantities in the creamery, but it should not be wasted.

\section{A. POWER REQUIRED FOR PUMPING WATER}

The amount of power required to elevate water varies directly with the quantity and with the height to which it is to be elevated. Therefore it requires twice as much power to elevate roo pounds 20 feet per minute as is required to elevate $5 \circ$ pounds 20 feet per minute, and it requires twice as much power to elevate roo pounds of water 40 feet as is required to elevate the same amount of water 20 feet.

The theoretical power required for pumping water is calculated in terms of horse power from the following formula:

$$
\mathrm{Y}=\frac{\mathrm{g} \times 8.35 \times(\mathrm{h}+\mathrm{f})}{33,000^{1}}
$$

1 One horse power is 33,000 foot pounds per minute. 
When $\mathrm{Y}$ represents horse power required

$\mathrm{g}$ represents gallons of water per minute

$h$ represents height of elevation, measured from the surface of water in well to the highest point to which the water is raised.

Example:

f represents the friction head in the water pipes.

Determine the theoretical horse power required to pump I 2,000 gallons of water per hour through a 4-inch pipe 200 feet long, the water being raised roo feet.

Answer:

The friction head ${ }^{1}$ is $1.22 \times 2.3=2.8$ for a pipe roo feet long. For a pipe 200 feet long $\mathrm{f}=2.8 \times 2=5.6$

$$
\mathbf{Y}=\frac{\frac{12.000}{60} \times 8.35 \times(100+5.6)}{33,000}=5.34 \text { H. P. }
$$

As the efficiency of small pumps usually ranges from 60 to 45 the theoretical horse power should be doubled when applying it to practical work. For large pumps a higher efficiency is obtained.

The following table gives the friction loss in pounds pressure per square inch for each roo feet of length in different size clean iron pipes discharging given quantities of water per minute. This friction loss is greatly increased by bends or irregularities in the pipe.

To find "friction head" in feet multiply figures by 2.3

1 Table VII. 
TABLE VII ${ }^{1}$

\begin{tabular}{|c|c|c|c|c|c|c|c|c|}
\hline \multirow{2}{*}{$\begin{array}{l}\text { Gal. per } \\
\text { minute }\end{array}$} & \multicolumn{8}{|c|}{ Size of pipes, inside diameler } \\
\hline & $\begin{array}{c}3 / 4 \\
\text { inch }\end{array}$ & I inch & $\begin{array}{l}I 1 / 4 \\
\text { inch }\end{array}$ & $\begin{array}{l}I 1 / 2 \\
\text { inch }\end{array}$ & 2 inch & $\begin{array}{l}21 / 2 \\
i n c h\end{array}$ & 3 inch & 4 inch \\
\hline 5 . & $3 \cdot 3$ & 0.84 & 0.31 & 0.12 & $\ldots \ldots$ & $\ldots \ldots$ & $\ldots$ & $\ldots$ \\
\hline IO. . & 13.0 & 3.16 & I. 05 & 0.47 & 0.12 & $\ldots$ & $\cdots \cdots$ & $\ldots$. \\
\hline$I_{5} \ldots \ldots$ & 28.7 & 6.98 & 2.38 & 0.97 & 0.26 & $\ldots$ & $\cdots \cdots$ & 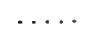 \\
\hline 20. & 50.4 & 12.30 & 4.07 & I. 66 & $0.4^{2}$ & $\ldots$. & $\ldots$. & $\ldots$ \\
\hline $25 \ldots \ldots$ & 78.8 & $19 . \infty$ & 6.40 & 2.62 & 0.64 & 0.21 & 0.10 & 0.27 \\
\hline 30.... & $\cdots$ & $27 \cdot 50$ & 9.15 & $3 \cdot 75$ & 0.91 & $\ldots$ & $\cdots \cdots$ & $\ldots$ \\
\hline 35 & $\ldots$ & $37 . \infty$ & 12.40 & 5.05 & I. 22 & $\ldots$ & $\ldots \ldots$ & $\cdots$ \\
\hline 40. & $\ldots$ & 48.00 & 16.10 & 6.52 & I.60 & $\ldots$ & 0.20 & \\
\hline 45. & $\ldots$ & $\ldots$ & 20.20 & 8. I $_{5}$ & 2.02 & $\ldots$ & $\ldots$. & $\ldots$ \\
\hline $50 \ldots$ & $\ldots$ & $\ldots$ & 24.90 & 10.00 & 2.44 & $0.8 \mathrm{I}$ & 0.35 & 0.09 \\
\hline 75 & $\ldots$ & $\ldots$ & $56 \cdot 10$ & $22 \cdot 40$ & $5 \cdot 32$ & 1.80 & 0.74 & 0.23 \\
\hline 100. & $\cdots$ & $\cdots$ & $\ldots$ & 39.00 & $9 \cdot 46$ & 3.20 & I. 3 I & 0.33 \\
\hline I25. & $\ldots$ & $\ldots$ & $\ldots$ & $\ldots$ & I4. 90 & 4.89 & 1.99 & 0.49 \\
\hline I5o. & $\ldots$ & $\ldots$ & $\ldots$ & $\ldots$ & 21.20 & $7 . \infty$ & 2.85 & 0.69 \\
\hline I75. & $\ldots$ & $\ldots$ & $\ldots$ & $\ldots \ldots$ & 28. IO & 9.46 & 3.85 & 0.94 \\
\hline 200 & $\cdots$ & $\ldots$ & $\ldots$ & $\ldots$ & $37 \cdot 50$ & I 2.47 & 5.02 & 1.22 \\
\hline 250. & $\ldots$ & $\ldots$ & $\ldots \ldots$ & $\ldots$. & $\ldots$ & $19 \cdot 5^{6}$ & $7 \cdot 76$ & I. 89 \\
\hline 300. & $\ldots$ & . & $\cdots$ & $\cdots$ & $\ldots$ & 28.06 & II .20 & 2.66 \\
\hline 350. & $\ldots$ & $\ldots$ & $\ldots$ & $\ldots$ & $\ldots$ & $\ldots$ & I5. 20 & 3.65 \\
\hline $400 \ldots$ & $\cdots$ & $\ldots$ & $\ldots$ & $\ldots$ & $\ldots$ & $\cdots$ & 19.50 & $4 \cdot 73$ \\
\hline $45^{\circ}$. & $\ldots$ & $\ldots$ & $\ldots$ & $\ldots$ & $\ldots$ & $\ldots$ & 25.00 & 6.01 \\
\hline 500. & $\ldots$ & & $\ldots$ & & $\ldots \ldots$ & $\ldots$ & 30.80 & $7 \cdot 43$ \\
\hline 600. & & $\ldots$ & $\ldots$ & $\ldots$ & $\ldots$ & $\ldots$ & $\ldots$. & $9 \cdot 54$ \\
\hline $700 \ldots$ & $\ldots$ & $\ldots$ & $\ldots$ & $\ldots \ldots$ & $\ldots$ & $\ldots$ & $\ldots \ldots$ & $14 \cdot 32$ \\
\hline
\end{tabular}

\section{B. WATER PUMPS}

The most important pumps to be considered by the creamery manager are the piston or plunger pump, the rotary and the centrifugal pump. The air lift may also be considered in this connection.

' Kidder, Architects' and Builders' Pocketbook, I9I2. 
I. The Piston or Plunger Pump. - The piston or plunger pump is most commonly used in the creamery. This may be belt driven or it may be operated with steam direct. The former method is the most economical providing the pump is large enough, and that a supply tank of sufficient size is provided so that all the pumping is done while the engine is being operated for other purposes. It would not be profitable to operate a large engine merely for the purpose of pumping water. Then it would be more advisable to install a pump driven by steam direct.

II. The Rotary Pump. - The rotary and the centrifugal pumps may be used for shallow wells. For small lifts of 4 to 5 feet they are considered to have a higher efficiency than the piston pumps, but for higher lifts their efficiency is less and they will not be practical for lifting water to exceed I5 to 20 feet.

III. The Air Lift. - The air lift consists of a well tubing, inside of it is a small pipe through which compressed air is blown. The compressed air lifts the column of water. By this system water may be lifted I 30 feet above its lower level. It is said to be of greatest efficiency when the depth at which the discharge tube stands under water in the well is one and a half times the height of the discharge pipe above the water. By reducing the proportion of the pipe below the water surface the efficiency is gradually decreased and the system cannot be operated if the portion above the water is increased to one and a half times the size of the pipe below the water surface. ${ }^{1}$ It is claimed 2 that the cost of raising $I, 000$ gallons of water by the air lift, including fuel, labor, oil, interest on cost of well, boiler, compressor, foundations, pipes, real estate, erection, taxes, and I5 per cent for depreciation runs from one-fifth to two and onehalf cents according to size of plant, height of lift, and other local conditions.

1 Siebel's Compend. of Mechanical Refrigeration and Engineering, I9Ir.

2 Reported by Kidder in Architects' and Builders' Pocketbook, I9r 2. 


\section{ECONOMY IN PUMPING WATER AT THE CREAMERY}

It is not considered advisable for a creamery to buy water from the city if permanently located, as the city water is usually warmer than water drawn directly from a well. It will also be more expensive. The lowest rate for water used for creamery purposes that has come to the observation of the author is 5 cents per 1,000 gallons. Most cities will charge Io cents or even more. Some of the smaller towns that have comparatively expensive waterworks and labor are not able to pump water as economically as the creamery. 


\section{CHAPTER XIII \\ RENT, DEPRECIATION, INTEREST, AND INSURANCE}

\section{A. RENT}

WHERE the creamery building is owned by the creamery company it is often customery not to charge rent but to charge interest on the investment, and insurance and depreciation on the building. There is a good reason, however, for charging rent, as the investment of money in real estate should be considered as a separate investment and a detailed record should be kept thereof the same as of money invested in the business. Therefore a special ledger account should be kept of the building. The rent is entered monthly to the credit of this account, and insurance, depreciation, and the current rate of interest on the investment are entered on the debit side of the ledger. The current rate of rent should be charged for the property. From this record it will be evident whether or not the investment in real estate is profitable. Perhaps it might pay to sell the property and then lease it from the purchaser or possibly other property might be rented and be even more suitable for the business. Such factors are determined by studying local conditions.

If more than one department is operated in the same building the rent should be divided among the departments in proportion to the amount of space and the value of the space occupied by each. The value of the space should be determined on the basis of what the income from it would be if it were leased to others. If the building were located in the retail district of a city it would soon be discovered that the front part, or perhaps the entire first floor, would net more money if leased for retail 
purposes and not used for manufacturing. Often the office is located in the most desirable part of the building. If the proper rent were charged for the office room it might impress the creamery owner that the office would be of just as much service to the company if located in a part of the building less serviceable for factory purposes.

\section{B. DEPRECIATION}

The depreciation deducted for wear and tear of machinery, equipment and building should be great enough to cover the natural decrease in value of the property. The average life of the various kinds of machinery and equipment should be determined and the rate of depreciation estimated in proportion thereto. The amount depreciated should always be such that the book value of the property is equivalent to the real value thereof.

The life of a creamery boiler and engine is about fifteen years. Suppose the original cost of the boiler and engine were $\$ 500$, then the monthly depreciation of the boiler and engine would be $\frac{500}{\text { I }_{5} \times \text { I } 2}=\$ 2.78$

A churn if properly cared for should last for five years. In some of the larger plants it may not last for more than three years. The life of a milk can, including both wear and loss, is about three years, and of ice-cream containers and tubs from three to four years.

The building, if built from hard-burned brick, cement blocks, or similar material, should last for forty years or more, if a frame structure, twenty years will be the life thereof. If the location is favorable it is often possible that the value of the ground on which the building stands will increase in proportion to the depreciation in the value of the building. It is safe, however, to be conservative and not place fictitious values on any of the property. Such items as good will, advertising, etc., if considered as a financial asset of the company should be liberally depreciated, as such assets are not always marketable. 
Repairs may or may not be charged against permanent improvements and then depreciated. Smaller repairs may conveniently be considered under the head of current expenses and charged against the expenses for the month or year when the repairs were made. Other repairs are of such a nature that they would naturally be added to the value of the permanent property and in the future stand for their share of depreciation.

The manager who usually buys the supplies for the creamery is seldom authorized to purchase machinery or permanent equipment except by the approval of the board of directors; thus the company guards against any unnecessary increase of its investment.

\section{INTEREST}

The coöperative creamery association when organizing often borrows the money required for building, equipment, and operating expenses. The interest and part of the principal is paid annually and is charged directly against the general expenses of the creamery. After several years, when the entire principal has been paid, the creamery is owned by the organization and the paying of interest ceases. No more loans should be made, as the amount accumulated to cover depreciation of the property or what is often known as sinking fund should remain in the treasury and should be sufficient for replacing worn-out machinery with new.

The joint-stock company will continue to pay interest on stock held by its stockholders. Such interest, as well as interest on money borrowed, is charged directly against the general expenses. The current interest on money invested in any proprietary creamery should be considered as a general expense and the manufacturing department will pay its share thereof.

\section{INSURANCE}

Insurance as defined by Webster is a contract whereby, for a stipulated consideration called a premium, one party undertakes to indemnify the other against loss by certain risks. The party agreeing to make the compensation is called the insurer 
or the underwriter, the other party to the contract is called the insured, the written contract is called the policy, and the event insured against, the risk.

I. Fire Insurance. - Fire insurance is a contract whereby the insurer indemnifies the insured against fire risk. This form of insurance should be carried at all times and in such amounts that not merely the building, machinery, and equipment are insured to their full value, but the stock of merchandise on hand should also be fully covered. If the business transacted is of such a nature that the stock of merchandise carried on hand is of much higher value at one season than at another, then it is usually advisable to add additional insurance to apply only for the season while the stock is of greatest value.

It is the duty of the insured to give immediate notice in writing of fire loss to the insurance company and within 60 days after date of fire render an itemized statement of losses sustained to the insurance company, this statement to be signed and sworn to by the insured.

II. Employer's Liability Insurance. - Employer's liability insurance is a contract whereby the insurer indemnifies the insured against liability for accidents to employees. While such accidents are seldom heard of in the smaller plants they are rather frequent in larger manufacturing establishments.

III. Fidelity Insurance. - Fidelity insurance is a contract which protects the employer against loss by the fraud or dishonesty of his employees. This contract is usually known as a bond. It is to be recommended that any employee handling any of the company's money furnish a bond issued by some reliable fidelity insurance company. The company for which the employee works should pay the premiums on such bonds.

In addition to the above forms of insurance there are many others such as steam-boiler insurance, plate-glass insurance, credit insurance, etc.

IV. Insurance Records. - The manager should have some convenient method by which to know the amount of insurance carried on the different lines of property, and the date when the contracts expire. Form XV may answer for that purpose. 


\section{FORM XV}

InSURANCE RECORD

\begin{tabular}{|c|c|c|c|c|c|c|}
\hline \multirow{2}{*}{ Agent } & \multicolumn{4}{|c|}{ Property Insured } & \multicolumn{2}{|c|}{ Expiration } \\
\hline & Building & Machinery & Fixlures & Stock & Date & Year \\
\hline C. Smith. & $5, \infty 00$ & & 2,000 & & Jan. 25 & I9 I 5 \\
\hline C. Jones. & & $3, \infty 00$ & & & Feb. 28 & 1917 \\
\hline Total & & & & & & \\
\hline
\end{tabular}

All of the above-mentioned expenses enter into the cost of manufacturing of products. In addition to these there are other miscellaneous items not mentioned in the foregoing. 
CHAPTER XIV

\section{THE BUTTER OVERRUN AND THE RELATION BE- TWEEN CHEMICAL COMPOSITION OF BUTTER AND OVERRUN}

\section{THE BUTTER OVERRUN}

The Actual Butter Overrun. - By this is understood the difference between amount of butter obtained and the amount of fat contained in the milk or cream used for the manufacture thereof. This definition is the most practical and fair to all concerned; it is with this meaning that the term ovcrun is used in this book.

The Final Butter Overrun. - By this is understood the difference between amount of butter sold and amount of fat purchased for the manufacture thereof. This butter fat may be purchased locally or through receiving stations.

This definition for overrun may be quite practical to the creamery manager, but unfair to the butter maker unless the latter is in full charge of cream purchasing, butter making and selling, as the loss of fat in any department where the cream is being handled from the time it is purchased until it is manufactured into butter reduces the overrun. The advantage to the manager of determining the overrun in accordance with this definition is primarily that the overrun suggests to him a profit or loss; he is usually clear as to the amount of overrun he should obtain for making a profit.

The Chemical Butter Overrun. - This is the difference between the amount of butter obtained and the amount of butter fat contained in the butter. In accordance with this definition the overrun is equal to ingredients other than the butter fat of which the butter is composed, and the overrun might thus be determined from chemical analysis of the butter. 
Per Cent Butter Overrun. - By per cent butter overrun is understood the amount of butter made in excess of each hundred pounds of butter fat used therefor. If $\mathrm{r} 20$ pounds of butter are produced from roo pounds of butter fat, the overrun is 20 per cent. Therefore if y stands for per cent overrun, b for pounds of butter obtained from $f$ pounds of butter fat then

$$
\mathrm{b}=\mathrm{f}+\frac{\mathrm{f}}{100} \times y \text { or } \mathrm{y}=\frac{(\mathrm{b}-\mathrm{f})}{\mathrm{f}} \times 100
$$

Example: 1,800 pounds of cream containing 30 per cent of butter fat produce 630 pounds of butter. Determine per cent of butter overrun.

Answer:

$$
\frac{630-1,800 \times \frac{30}{100}}{1,800 \times \frac{30}{100}} \times 100=162 / 3 \text { per cent }
$$

The above formula may also be written as follows:

$$
y=100\left(\frac{b}{f}-r\right)
$$

Thus the per cent of overrun from the foregoing example is determined as follows:

$$
y=100\left(\frac{630}{I, 800 \times \frac{30}{100}}-I\right)=162 / 3 \text { per cent }
$$

The Financial Value of the Overrun. - The manufacturers of butter consider that the overrun or even a part thereof is sufficient to pay for manufacturing expenses and dividends on the investment. It is therefore evident that the matter of overrun is of vital importance to the creamery manager. He knows the manufacturing cost per pound of butter, and if he also knows the value of the overrun based on each pound of butter manufactured, or on each pound of butter fat used in manufacturing, then he will be fairly well informed as to the extent of his profit or loss. The exact value of the overrun per pound of butter or of butter fat, when the overrun and the selling price of butter are known, is determined as follows:

If $y$ represents the value of overrun per pound of butter, $z$ the value of overrun per pound of butter fat, $d$ the market 
value of the butter, and $g$ the per cent of overrun obtained, then

$$
\begin{aligned}
& y=d \times \frac{g}{100+g} \\
& z=d \times \frac{g}{100}
\end{aligned}
$$

Example: The overrun is 20 per cent on butter sold for 30 cents per pound; determine the value of the overrun per pound of butter and per pound of butter fat.

$$
\begin{aligned}
& y=30 \times 20 / 120=5 \text { cents. } \\
& z=30 \times 20 / 100=6 \text { cents. }
\end{aligned}
$$

Tables Nos. VIII and IX illustrate the effect which the increase or decrease of per cent of overrun and the market value of the butter have on the value of the overrun per pound of butter and per pound of butter fat.

\section{RELATION BETWEEN CHEMICAL COMPOSITION OF BUTTER AND OVERRUN}

Composition of Butter. - The composition of normal American butter in accordance with the analysis made by the Department of Agriculture, 'Washington, D. C., of 695 samples is as follows:

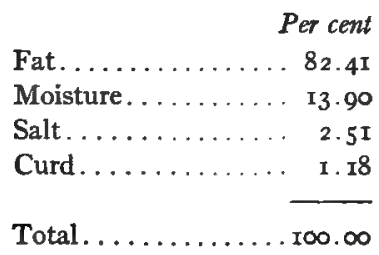

Butter Fat Content of Butter. - The butter fat is the principal ingredient both in regard to amount and to its commercial value. An increase in fat content of butter means a corresponding decrease in butter overrun and vice versa. An increase in fat content of the butter increases the cost of the butter to the manufacturer. 
Moisture Content of Butter. - The moisture is second in importance because it is present in comparatively large amounts and the per cent thereof is readily increased or reduced, and the overrun thereby correspondingly increased or reduced. Moisture is an essential ingredient, inasmuch as it adds pliability to the butter. However, the body of the butter becomes short and injured if the moisture content is increased to above the amount which is normally held in the butter. Normal butter, in accordance with the Federal standards, should contain less than 16 per cent of moisture.

The average moisture content of the butter cannot be considered uniform through the year, even if the butter is manufactured under uniform conditions, because the chemical composition of the butter fat is influenced by various factors. Butter containing a high per cent of softer fats will contain more moisture than butter containing less of such fats. This explains the tendency of the butter to take up more moisture during the spring of the year than during the winter season.

TABLE VIII

Table Giving Value of Overrun per Pound of Butter and per Pound of Butter fat when Market Value of Butter is 30 Cents per Pound

\begin{tabular}{c|c|c|c}
\hline $\begin{array}{c}\text { Per cent } \\
\text { overrun }\end{array}$ & $\begin{array}{c}\text { Market value } \\
\text { of butter }\end{array}$ & $\begin{array}{c}\text { Value of overrun } \\
\text { per pound butter }\end{array}$ & $\begin{array}{c}\text { Value of overrun } \\
\text { per pound butter fat }\end{array}$ \\
\hline & Cents & Cents & Cents \\
15 & 30 & 3.913 & 4.5 \\
16 & 30 & 4.138 & 4.8 \\
17 & 30 & 4.359 & 5.1 \\
18 & 30 & 4.576 & 5.4 \\
19 & 30 & 4.790 & 5.7 \\
20 & 30 & 5.000 & 6.0 \\
21 & 30 & 5.207 & 6.3 \\
22 & 30 & 5.410 & 6.6 \\
23 & 30 & 5.610 & 6.9 \\
24 & 30 & 5.807 & 7.2 \\
25 & 30 & 6.000 & 7.5 \\
\hline
\end{tabular}


TABLE IX

Table Giving Value of Overrun per Pound of Butter and per Pound of Butter Fat When a 20 PER CENT Overrun is Obtained

\begin{tabular}{|c|c|c|c|}
\hline $\begin{array}{l}\text { Per cent } \\
\text { overrun }\end{array}$ & $\begin{array}{c}\text { Market value } \\
\text { of buiter }\end{array}$ & $\begin{array}{l}\text { Value of overrun } \\
\text { per pound butter }\end{array}$ & $\begin{array}{l}\text { Value of overrun } \\
\text { per pound butter fat }\end{array}$ \\
\hline & Cents & Cents & Cents \\
\hline 20 & 25 & 4.167 & 5.0 \\
\hline 20 & 26 & 4.333 & $5 \cdot 2$ \\
\hline 20 & 27 & 4.500 & $5 \cdot 4$ \\
\hline 20 & 28 & 4.667 & 5.6 \\
\hline 20 & 29 & 4.833 & 5.8 \\
\hline 20 & 30 & 5.000 & 6.0 \\
\hline 20 & $3 I$ & $5 \cdot 167$ & 6.2 \\
\hline 20 & 32 & $5 \cdot 333$ & 6.4 \\
\hline 20 & 33 & $5 \cdot 500$ & 6.6 \\
\hline 20 & 34 & 5.667 & 6.8 \\
\hline 20 & 35 & 5.833 & 7.0 \\
\hline 20 & 36 & 6.000 & 7.2 \\
\hline 20 & 37 & 6.167 & $7 \cdot 4$ \\
\hline 20 & $3^{8}$ & 6.333 & 7.6 \\
\hline 20 & 39 & 6.500 & 7.8 \\
\hline 20 & 40 & 6.667 & 8.0 \\
\hline 20 & $4 \mathrm{I}$ & 6.833 & 8.2 \\
\hline 20 & 42 & 7.000 & 8.4 \\
\hline 20 & 43 & $7 \cdot 167$ & 8.6 \\
\hline 20 & 44 & $7 \cdot 333$ & 8.8 \\
\hline 20 & 45 & $7 \cdot 500$ & 9.0 \\
\hline 20 & 46 & 7.666 & 9.2 \\
\hline 20 & 47 & 7.833 & $9 \cdot 4$ \\
\hline 20 & 48 & 8.000 & 9.6 \\
\hline 20 & 49 & 8.167 & 0.8 \\
\hline 20 & 50 & 8.333 & 10.0 \\
\hline 20 & $5^{2}$ & 8.667 & 10.4 \\
\hline 20 & 54 & 9.000 & 10.8 \\
\hline 20 & $5^{6}$ & $9.333^{\circ}$ & II . 2 \\
\hline 20 & 58 & 9.666 & I I . 6 \\
\hline 20 & 60 & IO. $\infty 00$ & I2.0 \\
\hline 20 & 62 & IO. 333 & I 2.4 \\
\hline
\end{tabular}


TABLE IX-Continued

\begin{tabular}{|c|c|c|c|}
\hline $\begin{array}{l}\text { Per cent } \\
\text { overrun }\end{array}$ & $\begin{array}{c}\text { Market value } \\
\text { of butter }\end{array}$ & $\begin{array}{l}\text { Value of overrun } \\
\text { per pound butter }\end{array}$ & $\begin{array}{c}\text { Value of overrun } \\
\text { per pound butter fat }\end{array}$ \\
\hline 20 & $\begin{array}{c}\text { Cents } \\
64\end{array}$ & $\begin{array}{c}\text { Cents } \\
\text { Io. } 666\end{array}$ & $\begin{array}{l}\text { Cents } \\
\text { I } 2.8\end{array}$ \\
\hline 20 & 66 & I I ,,$\infty$ & I 3.2 \\
\hline 20 & 68 & I I. 333 & I 3.6 \\
\hline 20 & 70 & II. 666 & 14.0 \\
\hline 20 & 72 & I 2.000 & I 4.4 \\
\hline 20 & 74 & I 2.333 & I 4.8 \\
\hline 20 & 76 & I2. 666 & 15.2 \\
\hline 20 & 78 & I 3.000 & I5.6 \\
\hline 20 & 80 & I3 333 & 16.0 \\
\hline
\end{tabular}

I. Moisture Control. - It is possible for the butter maker, by careful study of conditions, to regulate the moisture content so it may remain nearly constant regardless of the composition of the butter fat. The principal factors to be considered in this connection and factors which are under control of the butter maker are presented in bulletin No 76, Iowa Experiment Station, as follows:

"Churning in a warm room and raising the temperature of the cream and wash water cause the butter to become softer and unite into lumps, in which condition it holds and retains moisture to a greater extent than when butter is firmer.

"An increase in the size of granules due to over-churning increases the moisture content gradually and only to a small extent. By churning into lumps, the moisture content of butter is increased greatly.

"The moisture content of butter can be regulated by controlling the temperatures, the amount of wash water, and degree of churning in the wash water.

"The richer the cream is at the time of churning, the more moisture the butter obtained will contain, providing all other conditions are alike. 
"The degree of ripeness has very little if any influence upon the moisture content of butter.

"When all other conditions are the same, butter from pasteurized cream contains about I I/2 per cent less moisture than that made from raw cream.

"If it were possible to keep all conditions alike the fullness of churn will have no influence on the moisture content of butter."

In accordance with results obtained by the Indiana Experiment Station t the acidity of cream, method of salting, and amount of salt used do not materially influence the moisture content of the finished butter, but large churnings yield butter with a higher per cent moisture than small churnings, and working butter in water regardless of temperature increases the moisture content of butter.

Moisture tests should be made from each churning so that the butter maker may learn to control the moisture content of his butter. Such tests are also of importance so that he may know whether or not he is making a legal butter. It will be taken for granted that butter makers and creamery managers are fully familiar with the use of the moisture test.

Salt Content of Butter. - The salt content of butter may vary from I to 5 per cent. Thus it becomes evident that the salt content influences the overrun materially. Salt is added to butter primarily because the consumers demand it. The salt content should be uniform: First, because it influences the uniformity of the flavor, and second, the profit obtained by the manufacturer from added salt should remain constant.

The markets influence the amount of salt that may be added to the butter. Enough salt should be added to satisfy the consumers and no more. The European markets demand a lower salt content than the markets in the United States. The Eastern markets in the United States demand from I I/2 to 2 I $/ 2$ per cent salt and would not be satisfied with butter con-

'Bulletin I60, 1912, by Hunziker, Mills, and Spitzer. 
taining from 3 to 5 per cent salt, which is often preferred in the Western markets.

I. Amount of Salt that May be Dissolved in Butter. - The amount of salt that may be dissolved in butter depends upon the moisture content of the butter, as the fat has no power as a salt solvent. Well-worked butter will contain brine of as much as 16.78 per cent sodium chloride. ${ }^{1}$ Suppose the butter contains I5.5 per cent of moisture, then the amount of salt contained in the solution in such butter is 2.6 per cent. Any amount contained in excess of that will be left in the butter as undissolved salt. If the proportion of undissolved salt becomes too high, the butter appears gritty. It is possible that butter containing only 2.5 per cent of salt may appear gritty. This may be due either to a low water content of the butter or to insufficient working.

2. Unsalted Butter. - Unsalted butter is manufactured from ripened cream, no salt being added to the butter. This is often incorrectly called sweet butter, which term rightfully belongs only to such butter as is made from unripened cream and without the addition of salt. The moisture and casein content of unsalted butter is practically the same as that of salted butter while fresh, but as the butter becomes older the salted butter has a tendency to lose more in moisture content than the corresponding unsalted butter. The greater difference between the composition of the two kinds of butter, however, is the lack of salt in one and a corresponding increase in fat which brings about a corresponding decrease in the overrun. Unsalted butter is therefore of greater value per pound to the manufacturer than salted butter. The corresponding value of unsalted butter may be determined as follows:

Let $s$ represent per cent of salt contained in salted butter, $p$, price per pound of salted butter, and $y$, price per pound of unsalted butter.

Then

$$
\mathrm{y}=\mathrm{p} \frac{\mathrm{roO}}{\mathrm{100- \textrm {s }}}
$$

${ }^{1}$ Bulletin 80, by McKay and Larsen, Iowa Experiment Station, I904. 
Example: What should be charged for unsalted butter when butter containing 3 per cent of salt is sold for 30 cents per pound?

Answer:

$$
y=30 \times \frac{100}{100-3}=30.93 \text { cents per pound. }
$$

If allowance is made for cost of salt in the salted butter and the additional shrinkage in moisture of the same butter, then the difference between the value of salted and unsalted butter will be slightly decreased.

3. Salt Control. - The loss of salt during the working process is a factor which is usually given but very little attention. The butter when worked should be of such a consistency that it will most readily retain the salt. By the careful butter maker the loss of salt may be reduced to less than 5 per cent. However, most operators will lose more. If one ounce of salt were added to each pound of unsalted butter and if all this salt were retained, then Ioo pounds of unsalted butter would produce ro6.25 pounds of salted butter. The salt content of this butter figured in per cent would be equal to $\frac{6.25 \times 100}{106.25}=5.88$ per cent. It is most convenient in practical work to use the amount of butter fat in the churn as a basis for the amount of salt to add. The per cent of salt which should thus be obtained in the finished butter if no salt were lost during the process of working is determined as follows:

Let $y$ represent the per cent of salt the finished butter should contain.

a represent the amount of sait in ounces added to each pound of butter fat.

$\mathrm{m}$ represent the per cent moisture, casein, and ash contained in the finished butter. This figure is reasonably well known by the butter maker.

$f$ represent the per cent of fat contained in the finished butter. 
Then,

$$
\begin{aligned}
& f=y \times \frac{16}{a} \\
& y \times \frac{16}{a}+y+m=100 \\
& y=\frac{100-m}{\frac{16}{a}+I}
\end{aligned}
$$

Example:

A sample of salted butter contains 15.5 per cent of moisture and . 5 per cent of casein and ash; if .6 ounce were added for each pound of butter fat how much salt in per cent would be contained in the finished butter if no loss of salt occurred?

Answer:

$$
y=100-\frac{(15.5+1.5)}{\frac{18}{.6}+I}=3 \text { per cent of salt. }
$$

Suppose a sample of butter which had been salted in the proportion of .6 ounce of salt per pound of butter fat was found to contain $8 \mathrm{I}$ per cent fat, I5 I/2 moisture, I I/2 casein and ash, then the per cent of salt retained in the butter would be equal to

$$
\frac{100-(8 \mathrm{I}+\mathrm{I} 5.5+\mathrm{I} .5)}{8 \mathrm{I} \times \frac{.6}{16}} \times 100=65.84 \text { per cent. }
$$

For determining the amount of salt to add per pound of butter fat to obtain a definite per cent of salt in the finished butter the following formula may be used:

$$
a=\frac{I 6}{\frac{I 00-m}{y}-I}
$$

Example:

How much salt should be added per pound of butter fat to obtain 4 per cent in the finished product when $m=16$ per cent? 
Answer:

$$
\mathrm{a}=\frac{\mathrm{I} 6}{\frac{\mathrm{I00}-\mathrm{I} 6}{4}-\mathrm{I}}=.8 \text { ounce. }
$$

The amount of salt to add for every hundred pounds of fat may be quite accurately determined in accordance with the following simple formula, if the fat content of the finished butter is reasonable constant.

Per cent salt desired in butter $\times \frac{100}{\text { Per cent fat in butter }}$

\section{Example:}

How much salt should be added per hundred pounds of butter fat to obtain 4 per cent in the finished product when the fat content of the finished butter is 80 per cent?

Answer:

$$
4 \times \frac{100}{80}=5 \text { pounds of salt. }
$$

It is essential that the butter maker tests each churning for salt in order to gain control over the salt content of the butter. Many operators have not become familiar with the operation of the salt test. For that reason, the following system of testing for salt is outlined.1

4. The Salt Test. - For determining the salt content in butter the following reagents and glassware will be required:

A silver nitrate solution

A potassium chromate solution or indicator

One 500 c. c. flask

One 250 c. c. graduate

One 50 c. c. burette

One 25 c. c. pipette

One 2 ounce drop bottle for indicator Two beakers or cups

A. The Silver Nitrate Solution. - The silver nitrate solution if held for any great length of time will gradually undergo

1 This system is a modification of the official method of testing for salt in butter. 
chemical changes and be reduced in strength. Such changes take place very readily if exposed to light. It is therefore necessary for the operator to prepare his own solutions, which should be prepared in rather small quantities. Chemically pure silver nitrate, $\mathrm{AgNO}_{3}$, should be used. This may for the sake of convenience be weighed into small gelatin capsules, each capsule containing 2.906 grams. If chemical balances are not available a druggist might be able to do such weighing; if not, the capsules of silver nitrate might be supplied by a manufacturing chemist. The capsule is closed and wrapped with tinfoil to exclude the light. Such capsules have been kept in a dark, dry place for several months in perfect condition, although it is recommended that the silver nitrate be put up in small brown bottles if to be kept to exceed two months.

Preparing the Silver Nitrate Solution. - A gelatin capsule is placed in the flask and from 200 to $300 \mathrm{c}$. c. of distilled water heated to within a few degrees of boiling are added. 'The flask is shaken with a gentle rotary motion until the capsule with its contents has been dissolved. The flask is then wrapped with brown paper in order to exclude the light and it is left in a dark place until the temperature of its contents is the same as that of the room. The flask is then filled to the $500 \mathrm{c}$. c. mark with distilled water (condensed steam) of room temperature. The solution is kept in a place where light is excluded.

B. The Potassium Chromate Solution. - Ten grams of potassium chromate are dissolved in $90 \mathrm{c}$. $\mathrm{c}$. of distilled water.

C. Manipulation of the Test. - A representative sample from the butter to be tested is secured. The beaker containing the butter is placed in warm water until the butter which is being constantly stirred is of the consistency of a sirup, when it is transferred to ice water and stirred with a spatula until the butter congeals. Ten grams of this sample are weighed into a beaker. To this is added about $25 \mathrm{c}$. c. of hot distilled water. After the butter has been thoroughly dissolved the contents of the beaker are transferred to the $250 \mathrm{c}$. c. graduate. The beaker is rinsed several times with distilled water which is transferred to the graduate, using about $25 \mathrm{c}$. c. of water at a 
time. The graduate is finally filled with cold distilled water to the $250 \mathrm{c}$. c. mark, the butter fat to be above the mark; it is closed with a cork stopper and shaken gently a couple of times to insure that the contents of the graduate are thoroughly mixed.

From the brine solution thus prepared 25 c. c. are taken with the pipette. The solution should be of nearly room temperature, yet for all practical purposes from to to 20 degrees of variation will not affect the results. The sample taken with the pipette is transferred to a beaker. Six drops of the potassium chromate indicator are added and from the burette is added silver nitrate solution until the color changes to a reddish or brownish tint. The reading is taken from the burette of the number of c. c. of silver nitrate required.

The silver nitrate solution has been prepared to such a strength that it will require $5 \mathrm{c}$. $\mathrm{c}$. of it for each per cent of salt. Therefore if it required $15 \mathrm{c}$. c. of the solution to produce the brownish color, the butter contains 3 per cent of salt.

$\frac{\text { No. c. c. of silver nitrate solution required }}{5}=$ per cent of salt in butter.

Curd Content of Butter. - The curd of the butter, however important to the butter maker in the production of high flavor, is not considered by the manager to be a factor of great importance in butter overrun. The curd content of the butter cannot be changed to any great extent without injuring the quality of the butter. A butter of a high curd content will usually possess poor keeping qualities. 


\section{CHAPTER XV}

\section{MECHANICAL LOSSES AND THEIR INFLUENCE ON BUTTER OVERRUN}

Mechanical losses are such as occur during the various stages of the manufacturing process and in the testing of milk and cream. Mechanical losses are not absolutely avoidable, yet many of such losses may often be materially reduced.

\section{LOSSES THAT OCCUR DURING THE MANUFACTURING PROCESS}

Fat Losses in Skim Milk. - The loss of butter fat in the skim milk is a factor of importance to creameries receiving whole milk. In accordance with Danish experiments, 1 the average loss of fat in skim milk based on a series of experiments with three different types of factory cream separators amounts to about .07 per cent. It will probably be close to the actual loss if it is estimated at . I per cent for the American creameries.

Washburn, Dahlberg, Sorensen, and M. P. Mortensen ${ }^{2}$ found that 1.64 per cent of the total fat received at the factory was lost in the skim milk.

For ascertaining the amount of fat lost in the skim milk, the amount of skim milk obtained is not conveniently determined by weighing, but it may readily be calculated. For that purpose let $\mathrm{m}$ represent pounds of whole milk to be skimmed, $\mathrm{s}$, pounds of skim milk, c, pounds of cream obtained, p, the per cent of fat contained in the whole milk, $\mathrm{p}_{1}$, the per cent of fat contained in the cream, and $a$, the per cent of fat in the skim milk.

1 Beretning No. 70 fra den $\mathrm{Kgl}$. Veterinaer og Landbohojskoles Laboratorium for landokonomiske Forsog, I9ro.

2 Bulletin 177, Minnesota, 1918. 
The value of $\mathrm{s}$ is then determined as follows:

$$
\begin{aligned}
& \mathrm{m} \times \mathrm{p}=(\mathrm{m}-\mathrm{s}) \mathrm{p}_{1}+\mathrm{s} \times \mathrm{a} \text { or } \\
& \left.\mathrm{s}=-\frac{\mathrm{m}}{\mathrm{p}_{1}-\mathrm{p}}-\mathrm{p}\right)
\end{aligned}
$$

Or pounds skim milk obtained $=$ pounds whole milk $X$ per cent fat in cream - per cent fat in whole milk per cent fat in cream - per cent fat in skim milk

This formula becomes practical, inasmuch as the weight of the whole milk skimmed is always known, and the test of the cream and skim milk obtained as well as the test of the whole milk are known figures.

As the weight of the cream in a whole milk plant is usually determined with difficulty, the above formula may also be of value in determining the amount of cream obtained from the milk as $\mathrm{c}=\mathrm{m}-\mathrm{s}$. Or without figuring the amount of skim milk, the amount of cream may be determined from the following formula:

$$
\mathrm{c}=\frac{\mathrm{m}(\mathrm{p}-\mathrm{a})}{\mathrm{p}_{1}-\mathrm{a}}
$$

Or pounds cream obtained $=$ pounds whole milk $X$ per cent fat in whole milk - per cent fat in skim milk

per cent fat in cream - per cent fat in skim milk

Example I. - Determine the amount of fat contained in the skim milk obtained from skimming 30,000 pounds of milk testing 3.6 per cent of fat when the cream obtained tests 33.6 per cent of fat and the skim milk. I per cent of fat.

Answer:

$$
\begin{aligned}
& s=\frac{30,000(33.6-3.6)}{33.6-. I}=26,865.67 \text { pounds. } \\
& 26,865.67 X .001=26.87 \text { pounds of butter fat. }
\end{aligned}
$$

Example II. - Determine the overrun obtained in a creamery for a day when they received 20,000 pounds of 4 per cent 
milk from which was produced 35 per cent cream. The loss of butter fat in skim milk was . I per cent. The cream was made into butter containing 80 per cent of butter fat.

Answer:

$$
\mathrm{c}=\frac{20,000(4-. \mathrm{I})}{35-. \mathrm{I}}=2,234.96 \text { pounds. }
$$

The amount of butter fat used for making the butter is the amount contained in the cream or

$$
2234.96 \times .35=782.236 \text { pounds. }
$$

The overrun is determined on amount of butter fat purchased as whole milk. This overrun is therefore equal to

$$
\frac{(782.236 \times 100 / 80-20,000 \times 4 / 100)}{20,000-4 / 100} \times 100=22.224 .
$$

Had no butter fat been lost in the skim milk then the overrun obtained would have been equal to

$$
\frac{\text { I00-80 }}{80} \times \text { IOo or } 25 \text { per cent. }
$$

Therefore the overrun due to the loss of .I of a per cent fat in the skim milk has been reduced 2.776 per cent. It will be noted from Table $\mathrm{X}$ that this reduction in overrun is decreased slightly as the fat content of the butter increases. It is increased as the fat content of the whole milk is decreased (Table XI), and is decreased as the richness of cream decreases (Table XII). 


\section{TABLE $\mathbf{X}$}

Table Illustrating how the Fat Content of the Resulting ButTer INPLUENCES THE REDUCTION IN PER CENT OF OVERRUN WHEN II OP t Per cent Fat is lost in the Skim Milk

\begin{tabular}{|c|c|c|c|c|c|c|}
\hline $\begin{array}{c}\text { Per cent } \\
\text { fal in } \\
\text { whole } \\
\text { milk }\end{array}$ & $\begin{array}{c}\text { Per cent } \\
\text { fat lost } \\
\text { in skim } \\
\text { milk }\end{array}$ & $\begin{array}{l}\text { Per cent } \\
\text { fat in } \\
\text { cream } \\
\text { obtained }\end{array}$ & $\begin{array}{c}\text { Per cent } \\
\text { fat in } \\
\text { butter }\end{array}$ & $\begin{array}{l}\text { Por cent } \\
\text { overrun }\end{array}$ & $\begin{array}{c}\text { Per cent } \\
\text { overrun } \\
\text { had no loss } \\
\text { occurred in } \\
\text { skim milk }\end{array}$ & $\begin{array}{c}\text { Per cent } \\
\text { reduction } \\
\text { in overrun } \\
\text { due to loss } \\
\text { in skim milk }\end{array}$ \\
\hline 4 &. $\mathbf{I}$ & 35 & 80 & 22.224 & 25.000 & 2.770 \\
\hline 4 &. $\mathbf{I}$ & 35 & $8 I$ & 20.725 & 23.457 & $2.73^{2}$ \\
\hline 4 &.$I$ & 35 & 82 & I9. 234 & $2 I .95 I$ & 2.717 \\
\hline 4 &. $\mathbf{I}$ & 35 & 83 & I7. 807 & 20.482 & 2.675 \\
\hline 4 &.$I$ & 35 & 84 & 16.406 & 19.048 & 2.642 \\
\hline 4 &.$I$ & 35 & 85 & I 5.035 & I 7.647 & 2.621 \\
\hline 4 &.$I$ & 35 & 90 & 8.644 & & 2.467 \\
\hline
\end{tabular}

\section{TABLE XI}

Table Illustrating how the Fat Content of the Whole Milk INFLUENCES THE REDUCTION IN OVERRUN WHEN .I OF I PER CENT Fat IS LOST IN THE SKIM MILK

\begin{tabular}{|c|c|c|c|c|c|c|}
\hline $\begin{array}{c}\text { Per cent } \\
\text { fat in } \\
\text { whole } \\
\text { milk }\end{array}$ & $\begin{array}{c}\text { Per cent } \\
\text { fai lost } \\
\text { in skim } \\
\text { milk }\end{array}$ & $\begin{array}{c}\text { Per cent } \\
\text { fat in } \\
\text { cream } \\
\text { obtained }\end{array}$ & $\begin{array}{c}\text { Per cent } \\
\text { fat in } \\
\text { butler }\end{array}$ & $\begin{array}{l}\text { Per cent } \\
\text { overrun }\end{array}$ & $\begin{array}{c}\text { Per cent } \\
\text { overrun } \\
\text { had no loss } \\
\text { occurred in } \\
\text { skim milk }\end{array}$ & $\begin{array}{c}\text { Per cent } \\
\text { reduction } \\
\text { in overnun } \\
\text { due to loss } \\
\text { in skim milk }\end{array}$ \\
\hline 4 & , I & 35 & 80 & 22.224 & 25 & 2.776 \\
\hline $3 \cdot 5$ & .1 & 35 & 80 & 21.774 & 25 & 3.226 \\
\hline 3 & .1 & 35 & 80 & 21.179 & 25 & $3.82 \mathrm{I}$ \\
\hline
\end{tabular}




\section{TABLE XII}

Table Illustrating how the Fat Content of Resulting Cream InFLUENCES THE REDUCTION IN OVERRUN WHEN I OF I PER CENT Fat IS LOST IN THE SKIM MILK

\begin{tabular}{|c|c|c|c|c|c|c|}
\hline $\begin{array}{c}\text { Per cent } \\
\text { fat in } \\
\text { whole } \\
\text { milk }\end{array}$ & $\begin{array}{c}\text { Per cent } \\
\text { fat lost in } \\
\text { skim } \\
\text { milk }\end{array}$ & $\begin{array}{c}\text { Per cent } \\
\text { fal in } \\
\text { cream } \\
\text { oblained }\end{array}$ & $\begin{array}{c}\text { Per cent } \\
\text { fat in } \\
\text { butter }\end{array}$ & $\begin{array}{l}\text { Per cent } \\
\text { overrun }\end{array}$ & $\begin{array}{c}\text { Per cent } \\
\text { overrun } \\
\text { had no loss } \\
\text { occurred in } \\
\text { skim milk }\end{array}$ & $\begin{array}{c}\text { Per cent } \\
\text { reduction } \\
\text { in overrun } \\
\text { due to loss } \\
\text { in skim milk }\end{array}$ \\
\hline 4 &. $\mathbf{I}$ & 40 & 80 & 22.180 & 25 & 2.820 \\
\hline 4 &. $\mathbf{I}$ & 35 & 80 & 22.224 & 25 & 2.776 \\
\hline 4 & $\mathbf{I}$ & 30 & 80 & 22.283 & 25 & 2.717 \\
\hline 4 &. $\mathbf{I}$ & 25 & 80 & $22 \cdot 3^{6} 5$ & 25 & 2.635 \\
\hline 4 &. $\mathbf{I}$ & 20 & 80 & 22.487 & 25 & 2.513 \\
\hline
\end{tabular}

Fat Losses in Buttermilk. - The loss of fat in buttermilk will affect the overrun to a less degree than the loss of butter fat in skim milk, because the proportion of buttermilk is small as compared with the proportion of skim milk. The average per cent of fat lost in the buttermilk during a series of experiments carried on by the Iowa Experiment Station " under ordinary factory conditions was .I68 per cent from sour cream pasteurized while sweet. The loss from churning the same kind of cream raw was .I98 per cent. Sour cream pasteurized by flash heat produced a loss of .207 per cent. The same kind of cream churned raw produced a loss of .152 per cent. Sour cream pasteurized by the holding method or vat method caused a loss of .225 per cent while the same kind of cream churned raw produced a loss of only .098 per cent.

In accordance with Minnesota experiments 2 the buttermilk retained 0.93 per cent of the total fat received when handling whole milk.

1 Bul. 156, Iowa Experiment Station, 1918.

2 Bulletin 177, Minnesota Ex. St., rgr8. 
The amount of fat lost in the buttermilk is readily determined, as the weight of the cream churned is a known quantity and the weight of the butter obtained is also known. The weight of the buttermilk in which the loss occurs is the difference between the weight of the cream churned and the weight of unsalted butter obtained.

Example. Determine the amount of butter fat lost in the buttermilk from churning 2,000 pounds of cream when 700 pounds of butter containing 3 per cent of salt is obtained, and the buttermilk contains .2 per cent of fat.

Answer: $(2,000-700 \times .97) .002=2.642$ pounds.

A formula similar to that used for determining fat loss in skim milk is also applicable in this connection. The following formula may be used when unsalted butter is concerned:

$$
\mathrm{b}=\frac{\mathrm{c}\left(\mathrm{F}-\mathrm{p}_{1}\right)}{\mathrm{F}-\mathrm{f}}
$$

In the foregoing $\mathrm{b}$ is to represent pounds of buttermilk obtained, $f$, per cent of fat in the buttermilk, and F, the per cent of fat in the butter. These factors are not absolutely correct in practical applications, as the water used for washing the butter may have a slight influence on the moisture content of the butter; however, not to such an extent that it will be of importance for the creamery manager to consider.

It will be noticed from Table XIII that the loss of .I per cent of fat in the buttermilk reduces the overrun .2 per cent when the fat content of cream used is 35 per cent and of the butter manufactured 80 per cent. This factor decreases slightly as the fat content of the butter increases and it increases as the fat content of the cream decreases (Table XIV).

Miscellaneous Manufacturing Losses. - Such losses occur in transferring cream from the receiving cans to vats, from vats to churns, and in handling cream or butter. They should not normally exceed .2 of one per cent of butter fat received. In accordance with Minnesota experiments 1 about one-half of one per cent of the total fat received was lost in vats, pipes,

1 Bulletin 177, Minnesota Ex. St., 1918. 
etc., where handling whole milk. In handling small amounts and by transferring for pasteurization these losses may be slightly increased; however, not at any time in excess of .5 per cent. A loss of .2 per cent will reduce the overrun .25 per cent when considering that the fat content of the butter is 80 per cent. If the fat content of butter becomes less, this loss will slightly increase the loss in overrun and vice versa.

\section{TABLE XIII}

Table Illustrating how the Fat Content of Resulting Butter INFLUENCES THE REDUCTION IN OVERRUN WHEN .I OF I PER CENT FAT IS LOST IN BUTTERMILK

\begin{tabular}{|c|c|c|c|c|c|}
\hline $\begin{array}{l}\text { Per cent } \\
\text { fat lost in } \\
\text { butter- } \\
\text { milk }\end{array}$ & $\begin{array}{c}\text { Per cent } \\
\text { fal in } \\
\text { cream }\end{array}$ & $\begin{array}{c}\text { Per cent } \\
\text { fal in } \\
\text { buller }\end{array}$ & $\begin{array}{l}\text { Per cenl } \\
\text { overrunt }\end{array}$ & $\begin{array}{c}\text { Per cent } \\
\text { overrun had no } \\
\text { loss occurred in } \\
\text { bullermilk }\end{array}$ & $\begin{array}{c}\text { Per cent } \\
\text { reduction } \\
\text { in overrun } \\
\text { due to loss } \\
\text { in buttermilk }\end{array}$ \\
\hline $\mathbf{I}$ & 35 & 80 & 24.800 & 25.000 & .2 \\
\hline I & 35 & 85 & I $7 \cdot 45^{\circ}$ & I7. 647 & .197 \\
\hline.$I$ & 35 & 90 & I0.9I7 & II.III & .194 \\
\hline
\end{tabular}

TABLE XIV

Table Illustrating how the Fat Content of Cream Influences the REDUCTION IN OVERRUN WHEN . I OF I PER CENT FAT IS LOST IN BUTTERMILK

\begin{tabular}{c|c|c|c|c|c}
\hline $\begin{array}{c}\text { Per cent } \\
\text { fat lost in } \\
\text { butter- }\end{array}$ & $\begin{array}{c}\text { Per cent } \\
\text { fat in } \\
\text { milk }\end{array}$ & $\begin{array}{c}\text { Per cent } \\
\text { fat in } \\
\text { butter }\end{array}$ & $\begin{array}{c}\text { Per cont } \\
\text { overrun }\end{array}$ & $\begin{array}{c}\text { Per cent } \\
\text { overrun had no } \\
\text { loss occurred in } \\
\text { bultermilk }\end{array}$ & $\begin{array}{c}\text { Per cent } \\
\text { reduction } \\
\text { in overrun } \\
\text { due to loss } \\
\text { in buttermilk }\end{array}$ \\
\hline .I & 40 & 80 & 24.8425 & 25 & .1575 \\
.I & 35 & 80 & 24.8000 & 25 & .2000 \\
.I & 30 & 80 & 24.7400 & 25 & .2600 \\
.I & 25 & 80 & 24.6560 & 25 & .3440 \\
.. & 20 & 80 & 24.5300 & 25 & .4700 \\
\hline
\end{tabular}


The following example will illustrate how miscellaneous losses may be determined.

Example:

2,000 pounds of 30 per cent cream were purchased. From this were manufactured 740 pounds of butter containing 80 per cent of butter fat and 3 per cent of salt. The buttermilk contained .2 per cent of fat. Determine miscellaneous losses.

Answer:

Amount of fat lost in buttermilk is equal to $(2,000-740$ $\times .97) \times .002=2.5644$ pounds.

Amount of butter fat lost due to miscellaneous losses is equal to

$$
\begin{aligned}
& (2,000 \times .30-2.5644)-740 \times .80=5.4356 \text { pounds. } \\
& \frac{5.4356 \times 100}{2000 \times .30}=.9056 \text { per cent. }
\end{aligned}
$$

\section{LOSSES DUE TO INACCURACY IN WEIGHING}

\section{AND TESTING}

Losses Due to Inaccuracy in Weighing. - It should hardly be necessary to consider such losses; nevertheless they frequently occur, and the manager should be ready to guard against them. Often the receiving scales on which the milk or cream is weighed are not as sensitive as they should be. This may be due to the buying of poor scales or the scales may not be kept clean and in working order. Scales on which cream is weighed should always be sensitive to one-fourth of a pound. It is possible to save ten dollars on the first cost by buying second-grade scales, but it is also possible for such scales to lose several hundred dollars annually to the creamery. Poor scales are too expensive at any price, but when good scales have been purchased it is the duty of the manager to see to it that they are always kept in good working order. The scales should be balanced several times daily and once or twice daily they should be tested with a standard weight. A fifty-pound standard weight is very satisfactory for that purpose. 
Losses Due to Inaccuracy in Testing. - The testing department is perhaps the department which experiences greater difficulty than any other department in giving satisfaction. It should also be realized by the managers that great losses may occur in that department unless properly checked. Form XVI may serve as a convenient factory report for checking, not merely the losses due to testing and weighing, but other mechanical losses as well.

FORM XVI

Churn Record

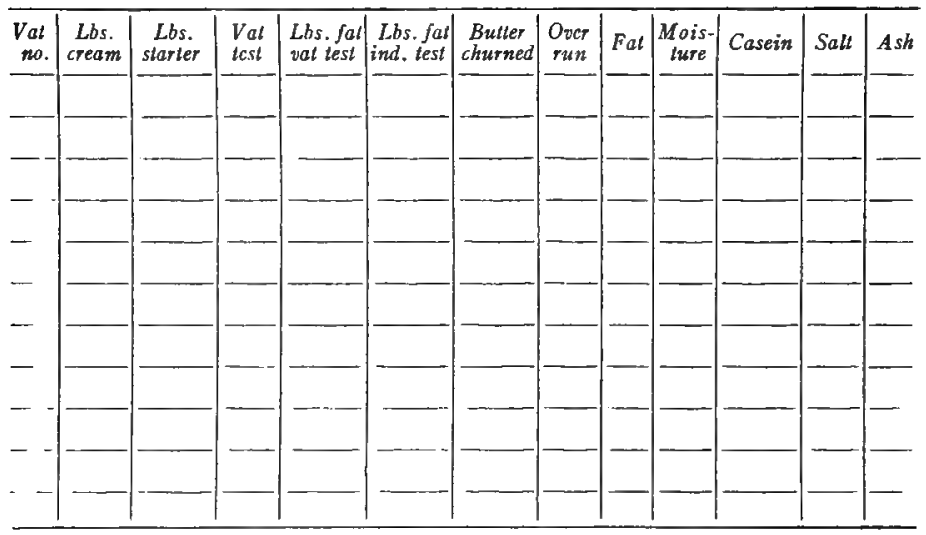

The principal reasons for errors in the testing department are inaccurate glassware, inaccurate measure or weight of sample, improper care of samples, and improper method of reading the tests and general carelessness on the part of the operator.

I. Inaccurate Glassware. - All glassware should be properly calibrated before it is brought into service. Several states have laws making it a criminal offense to use inaccurate glassware for testing. Even without such laws it should be to the interest of all creamery operators to assure themselves of the accuracy of the glassware they are using. It was found by the 
Indiana Station ${ }^{1}$ that 2 I $4 /$ ro per cent of the cream-test bottles used in Indiana creameries were incorrect; the maximum error was ro per cent.

2. Inaccurate Measure or Weight of Sample. - Incorrect measure or weight of samples may be due to an inaccurate pipette, or to balances that are not sensitive, or to carelessness on the part of the operator.

When the sample is measured, as is done when testing milk, the pipette used should be calibrated and if found correct it is evident that it will measure out the correct amount, if the pipette is also kept properly cleaned. The weights should be tested against standard weights. It is often convenient to have a standard 9 gram or 18 gram weight. This weight is not used for any other purpose than that of testing the weights which are in daily use. The state dairy commissioners are usually willing to test weights for operators in their respective states.

Balances should be sensitive to one centigram. If the balances are not sensitive it usually results in too high tests and a loss to the creamery. To keep balances sensitive they should be properly cleaned and kept in a dry place, preferably in a special case provided therefor. A balance constructed for carrying several bottles at each weighing is less sensitive than one constructed for carrying only one or two bottles.

The operator when weighing out samples of cream should not sacrifice accuracy for speed. It is considered that an experienced operator can test from 200 to 300 cream samples daily and do accurate work.

3. Improper Care of Samples. - A composite cream sample should never be considered accurate unless cream from which the sample is prepared is very thin. A composite sample taken from cans containing cream varying greatly in fat content will naturally be far from correct, as the sampler used will discharge less of the richer than of the thinner cream. Furthermore, if the sampler is not thoroughly cleaned each time when it is brought from the rich to the thin cream, it is quite possible that

1 Bul. 145, Indiana Agr. Experiment Station, I910. 
rich cream remaining in the tube will be discharged together with part of the thinner sample. The safest system to adopt is that of taking a sample from each can of cream, testing it separately, and cleaning the sampler in warm water for each sample taken. But if it is found convenient to take only one sample from two or more cans of cream, then the cream should first be thoroughly mixed in a receiving vat or can.

By daily testing the manager is enabled to check the mechanical losses daily and thus save money for the creamery. It has been the experience of the practical manager that the cream samples usually increase in per cent of fat by age. The Indiana Experiment Station has found that exposure of samples for two weeks to the receiving-room temperature in summer caused sufficient evaporation to raise the test 3.5 per cent even in bottles with a tight seal. When samples were kept in loosely sealed bottles there was a rise of I per cent in the test of the samples kept in the refrigerator and 4.5 per cent in the test of the samples kept on the receiving platform. In open bottles the test of the samples in the refrigerator rose 3.5 per cent, and that of the samples on the receiving platform increased I0.5 per cent.

Table $\mathrm{XV}^{1}$ illustrates the financial loss sustained by a creamery taking composite samples under the above-stated conditions. These calculations are based on the creamery receiving 20,000 pounds of fat per month. The loss of fat is figured on $39 \mathrm{I} / 2$ per cent cream; the price of fat is calculated at 25 cents per pound.

${ }^{1}$ Bụl. 145, Indiana Agr. Experiment Station, Igro. 
TABLE XV

\begin{tabular}{|c|c|c|c|c|c|}
\hline Place of storage & $\begin{array}{c}\text { Fat, } \\
\text { per } \\
\text { cent }\end{array}$ & $\begin{array}{c}\text { Av. } \\
\text { single } \\
\text { test }\end{array}$ & $\begin{array}{c}\text { Increase in } \\
\text { composite } \\
\text { test } \\
\text { per cent }\end{array}$ & $\begin{array}{c}\text { Pounds fal } \\
\text { paid too } \\
\text { much }\end{array}$ & $\begin{array}{c}\text { Creamery } \\
\text { lost, } \\
\text { dollars }\end{array}$ \\
\hline Ice Box & & \multirow{8}{*}{$39 \cdot 5$} & & & \\
\hline Tight seal & $39 \cdot 5$ & & none & none & none \\
\hline Loose seal & 40.5 & & 1.0 & 506 & 126.50 \\
\hline Open bottle & 43.0 & & $3 \cdot 5$ & $I, 772$ & 443.00 \\
\hline Receiving Platform & & & & & \\
\hline Tight seal & 43.0 & & 3.5 & $\mathrm{I}, 772$ & 443.0 \\
\hline Loose seal & 44.0 & & $4 \cdot 5$ & 2,278 & $569 \cdot 5^{\circ}$ \\
\hline Open bottle & 50.0 & & 10.5 & 5,316 & $1,329.00$ \\
\hline
\end{tabular}

4. Improper Method of Reading the Test. - In order to comply with the Babcock system of testing the tests should be read at a temperature at which the melted butter fat has a specific gravity of .9. This temperature varies somewhat with the composition of the butter fat, but is not far from $120^{\circ} \mathrm{F}$., a temperature ranging from $120^{\circ} \mathrm{F}$. to $140^{\circ} \mathrm{F}$. is usually recommended. The Iowa Experiment Station has obtained satisfactory results when reading the tests at a temperature of $130^{\circ} \mathrm{F}$. For the purpose of obtaining a definite temperature the test bottles should be placed in a water bath at $130^{\circ} \mathrm{F}$. for about fifteen minutes before the reading is taken. In accordance with experiments conducted by Webster and Gray ' the average increase in reading a 39.8 per cent cream test when the temperature is raised from $110^{\circ} \mathrm{F}$. to $140^{\circ} \mathrm{F}$. is 0.5 per cent (Table XVI).

1 Bul. No. 58, B. A. I., '1904. 
TABLE XVI

Influence of Temperature on Reading of Test

\begin{tabular}{|c|c|c|c|c|}
\hline Style of botlle & $\begin{array}{l}140^{\circ} \text { to } \\
130^{\circ} \mathrm{F}\end{array}$ & $\begin{array}{l}130^{\circ} \mathrm{to} \\
120^{\circ} \mathrm{F}\end{array}$ & $\begin{array}{l}120^{\circ} \text { to } \\
110^{\circ} \mathrm{F}\end{array}$ & $\begin{array}{l}140^{\circ} \text { to } \\
110^{\circ} \mathrm{F} .\end{array}$ \\
\hline $30 \%, 9$ inch, 9 gram. & $\begin{array}{c}\text { Per Cent } \\
\text { O.I }\end{array}$ & $\begin{array}{c}\text { Per Cent } \\
\text { o. I }\end{array}$ & $\begin{array}{c}\text { Per Cent } \\
0.05\end{array}$ & $\begin{array}{c}\text { Per Cent } \\
0.25\end{array}$ \\
\hline Same doubled ........... & .2 & .2 &.$I$ & .5 \\
\hline $50 \%, 6$ inch, 18 gram. . . . . & .2 & .2 & .0 & .4 \\
\hline $50 \%, 6$ inch, I8 gram. & .2 & .2 & .2 & .6 \\
\hline
\end{tabular}

Babcock recommends that a milk test should be read from the top of the meniscus to the bottom of the fat column. D. E. Bailey, Iowa Experiment Station ${ }^{1}$ found that the Babcock test for milk when read from the top of the upper meniscus to the bottom of the lower meniscus gave results which were higher than those obtained by the gravimetric (Roese-Gottlieb) method. On the average of Igo comparisons the difference amounted to 0.06 per cent. Webster and Gray ${ }^{2}$ recommend reading a cream test as follows:

I. See that line between fat and water is straight, and read from bottom to extreme top of fat column.

2. Read the depth of meniscus and deduct four-fifths of it from previous reading. A careful operator can estimate this.

3. Add 0.2 per cent to the result.

4. For 9 gram sample, double reading before adding 0.2 per cent.

5. Read at a temperature close to $I 20^{\circ} \mathrm{F}$.

6 . If bottles are placed in bath to regulate temperature, allow them to stand for fifteen minutes before reading.

Farrington and Woll ${ }^{3}$ recommend that the reading of a cream sample be taken from the bottom of the fat column to the bottom of the meniscus and that the reading be taken at $140^{\circ} \mathrm{F}$.

I Journal of Dairy Science, Vol. II, No. 5, September, r9rg.

2 Bul. 58, B. A. I., 1904.

'Testing Milk and Its Products, 1910. 
The Indiana Experiment Station ${ }^{1}$ suggests that one-third of the meniscus be included, and readings taken in this way, checked with the gravimetric fat estimation. It further recommends that glymol colored with alkanet root be added

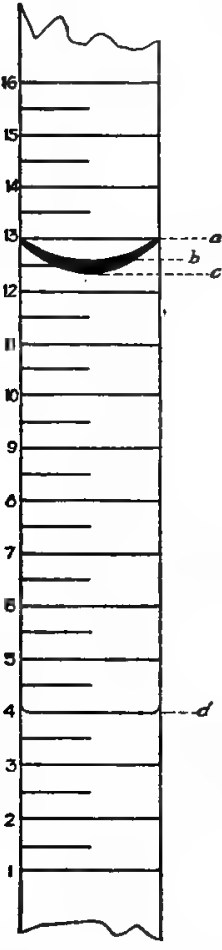

FIG. 25. - Reading a butter-fat test. immediately after the last centrifuging. Glymol, being lighter than the butter fat, will float on top; the meniscus is formed from the glymol and the line between the fat column and the glymol is straight, so the reading can be taken with greater degree of accuracy.

Professor C. H. Eckles first conceived the idea of leveling the fat column when testing cream. He recommended the addition of amyl alcohol colored with fuchsine. As alcohol is a fat solvent, Farrington recommended the saturation of the alcohol with fat before using it. As it is also poisonous and the odors therefrom injurious to health, glymol should be recommended for laboratory and for commercial work.

The author has obtained satisfactory results when reading the fat column of a cream test from $d$ to $b$ (Fig. 25), the reading taken at $130^{\circ} \mathrm{F}$. It is most satisfactory, however, to level the fat column, as that overcomes all disagreements in reference to the reading.

It cannot be too strongly emphasized that great care should be taken in reading the cream test. With the glassware used for the Babcock system it is practically impossible to read closer than to one-fourth of one per cent and by being a little careless the test is readily overread or underread one per cent. One per cent overreading on a 30 per cent cream, from which butter containing 80 per 
cent fat is manufactured will reduce the overrun about 4.03 per cent.

The total mechanical losses are summarized by Washburn ${ }^{1}$ as follows: "The creamery receiving cream lost about 1.4 per cent of the total butter fat received during the process of manufacture and saved about 98.6 per cent. The creamery receiving milk lost about 3.17 per cent of the butter fat during the process of manufacture and saved about 96.83 per cent.

\section{PER CENT OVERRUN WHICH MAY BE}

\section{LEGALLY OBTAINED}

This is determined primarily by the state and Federal butter standards. A moisture standard of 16 per cent and a fat standard of 80 per cent may under normal conditions be considered identical, as butter containing 16 per cent moisture, 2.8 per cent salt, and I.2 per cent casein also contains 80 per cent of butter fat. More casein may be incorporated, but incorporation of a high per cent of casein decreases the keeping qualities of the butter. A limited number of markets would accept butter containing a higher per cent of salt, but the manufacturer who makes an attempt to use salt as an adulterant has lost all regard for quality and is sacrificing his business when he makes such attempt. Salt is added to the butter for the sake of aiding it in flavor and not for the sake of adulterating it.

It is evident that under a mere moisture standard the unscrupulous manufacturer might adulterate his butter with casein and salt and in that way obtain a high per cent of overrun and yet manufacture an article of butter which the law would recognize as legal. If the butter standard is based on the fat content of the butter then it becomes comparatively easy to estimate a possible theoretical overrun. The following calculations are based on an 80 per cent butter-fat standard.

\footnotetext{
${ }^{1}$ Bulletin 177, Minnesota Ex. St., rg18.
} 
A butter containing 80 per cent butter fat should, if no losses occur, produce

$$
\frac{(100-80) 100}{80} \text { or } 25 \text { per cent overrun. }
$$

Considering that a creamery receives gathered cream containing 35 per cent of butter fat, from which is manufactured butter containing 80 per cent of butter fat, the reduction in overrun due to .2 per cent loss in the buttermilk is equal to .4 per cent ${ }^{1}$ on the overrun. Miscellaneous losses figured at .2 per cent will reduce the overrun .25 per cent. Considering these two losses, we might expect a theoretical legal overrun of $25-(.4+.25)=24.35$ per cent.

This overrun is higher than could be expected in general practice, even though no avoidable loss would occur, as it is well known that it is impossible to produce butter which always would contain even 80 per cent of butter fat. It is furthermore recognized that two or more samples may be taken from butter of the same churning, but packed in different containers, and even from the same container and yet differ in excess of one-half of one per cent in fat content. It is therefore only fair to consider that if we have an 80 per cent fat standard, the butter, in accordance with our method of analysis, should contain about $8 \mathrm{I}$ per cent of fat. This will reduce the overrun $\mathrm{I} .54$ per cent, which, subtracted from $\mathbf{2 4 . 3 5}$ per cent, leaves an overrun of $22.8 \mathrm{I}$ per cent for gathered cream butter. If whole milk were received and the loss of butter fat in the skim milk amounted to .I per cent, then the overrun would still be decreased to the amount of 2.73 per cent, or the overrun would in that case be 20.08 per cent.

Losses Due to Butter Shrinkage. - In the foregoing discussion no reference has been made to shrinkage of butter from churn to dealer; this shrinkage varies in accordance with workmanship of the butter, the time of holding, and the temperature at which it has been held. A creamery allowing 8 
ounces of overweight on 63 pounds of fresh butter containing 80 per cent of butter fat is losing about one per cent on the overrun. Hibbard and Hobson ${ }^{1}$ estimate that a tub of butter loses two-fifths of a pound of moisture on the way to market. Guthrie ${ }^{2}$ reports a shrinkage of 0.29 per cent on 100 tubs of butter held in cold storage for 134 days at $0^{\circ}$ to- $10^{\circ} \mathrm{F}$.

1 Bulletin 270, Wisconsin, ror6.

2 Journal of Dairy Science, Vol. I, No. 2, I9I7. 


\section{CHAPTER XVI}

\section{COST OF MANUFACTURING BUTTER}

THE items to be considered in determining the cost of manufacturing butter have been discussed in the foregoing chapters, and may be briefly summarized as follows:

Labor, direct and indirect.

Coal and power.

Ice and refrigeration.

Water.

Butter tubs, boxes, liners, and wrappers.

Salt, color, washing powder, and miscellaneous supplies.

Rent.

Interest on investment.

Insurance.

Taxes.

Depreciation.

Repairs.

It is only by exhaustive study of each factor which adds to the manufacturing cost that a manager will be able to reduce such cost to the minimum.

The size of the creamery is one of the primary factors that influence the cost of manufacturing. If the receipt of raw material is small the cost of manufacturing a pound of butter will naturally be high due to fixed expenses which cannot be reduced. Wright 1 found that the cost of manufacturing a pound of butter in the Iowa creameries was as follows:

1 I8th Annual Report, I904, of the Iowa State Dairy Commissioner. 
Creamery making 40,000 pounds

Creamery making 50,000 pounds

Creamery making 60,000 pounds

Creamery making 70,000 pounds

Creamery making 80,000 pounds

Creamery making 90,000 pounds to

I25,000 pounds

Creamery making 150,000 pounds

Creamery making 175,000 pounds

Creamery making 200,000 pounds

and above

cost of making is 4
cost of making is 3.4
cost of making is 3.0
cost of making is 2.88 "
cost of making is 2.66 "
cost of making is $2.00 "$
cost of making is 1.85 "
cost of making is 1.65
cost of making is 1.44 "

Hibbard and Hobson ${ }^{1}$ found the cost of making a pound of butter in Wisconsin to be 2.33 cents (Table XVII). Macklin ${ }^{2}$ found this expense to be somewhat higher for Kansas (Table XVIII).

\section{TABLE XVII}

Who GeTS The MONEX?

\begin{tabular}{|c|c|c|}
\hline & Cents & Per cent \\
\hline Farmer........... & $23 \cdot 33$ & 67.7 \\
\hline Hauling. . . . . . . . . . . . . . . . . . & I. 50 & $4 \cdot 3$ \\
\hline 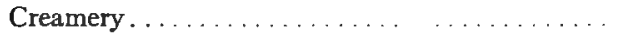 & 2.33 & 6.7 \\
\hline 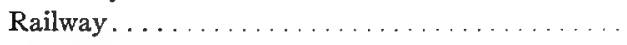 & .80 & $2 \cdot 3$ \\
\hline Storage. . . . . . . . . . . . . . . . & .18 & 0.5 \\
\hline Shrinkage. . . . . . . . . . . . . . & .23 & 0.7 \\
\hline Receiver ) & & \\
\hline $\left.\begin{array}{l}\text { Jobber } \\
\text { Broker }\end{array}\right\} \ldots \ldots \ldots \ldots \ldots \ldots \ldots \ldots \ldots$ & 1.75 & 5.0 \\
\hline Packaging. . & $\mathrm{I} . \infty$ & 2.9 \\
\hline \multirow[t]{2}{*}{ Retailer..... . . . . . . . . . . . . . . . } & $3 \cdot 43$ & 9.9 \\
\hline & $34 \cdot 55$ & 100.0 \\
\hline
\end{tabular}

These expenses from the Iowa report appear to be rather low and it is likely that some of the expenses, perhaps such as in-

'Bulletin 270, Wisconsin, I9r6.

2 Bulletin 21 7, Kansas, 1917. 


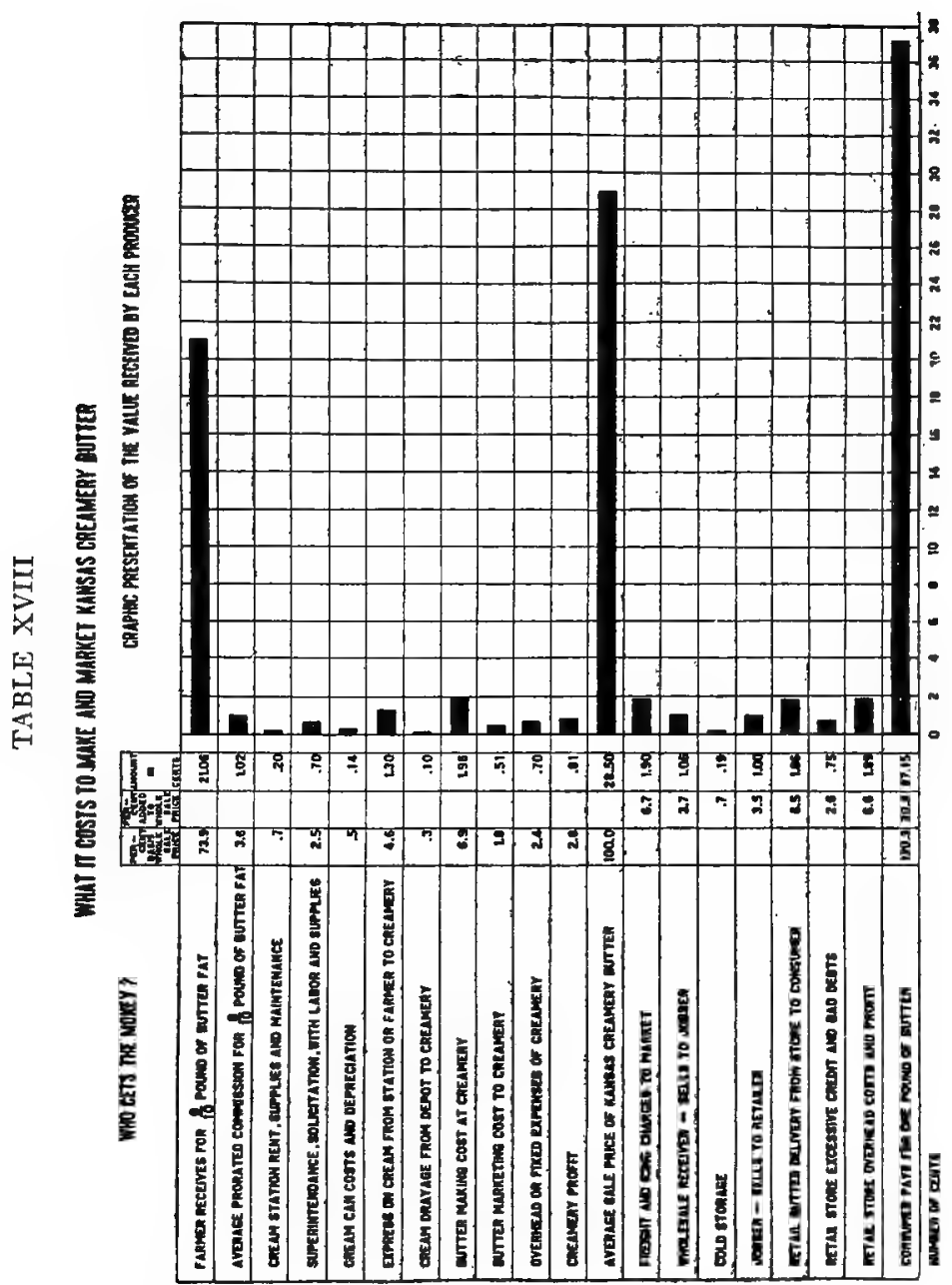


surance, interest, and depreciation, were, at least in part, left out of consideration. In accordance with estimate No. I, page 3 , of this book, the cost per pound of butter for manufacturing in a creamery manufacturing 67,200 pounds annually amounts to 4.70 cents. For creamery No. 2, manufacturing I 34,000 pounds of butter annually, the cost of manufacturing is reduced to 3.08 cents per pound of butter. It is difficult even in the best managed creameries to reduce the average cost of manufacturing to less than from 2 to 3 cents per pound if all expenses are accounted for. During the summer season the cost of manufacturing will naturally be comparatively low, but in the small creamery it will increase nearly in proportion to the decrease in output. The larger plants are able to manufacture butter at a low cost during the summer season, but it is equally true that some of the large plants are operating under so heavy expense during the winter season that in reality their advantage in the cost of manufacturing becomes insignificant. Such conditions, however, when they occur are due to lack of management.

The cost of manufacturing could often be reduced by reducing the general expenses, as are enumerated above.

Labor usually constitutes the big item of expense. It is not possible to make a statement as to what the cost of labor per pound of butter should be. This cost depends primarily on the size of the creamery. It is possible to increase the cost of labor per pound of butter materially and at the same time greatly increase the general profits to the creamery. It never pays to engage a cheap man as butter maker, for although by so doing the cost per pound of butter manufactured will be reduced, the general profits will usually be reduced because the man who is willing to work cheaply is a man without experience or without even ordinary ability. Labor and how the cost thereof may be reduced are discussed in Chapter VII.

For the purpose of guarding against unnecessary expenses it is advisable that a daily cost record be kept (Form XVII). Such a record contains information that is most essential to the manager. 


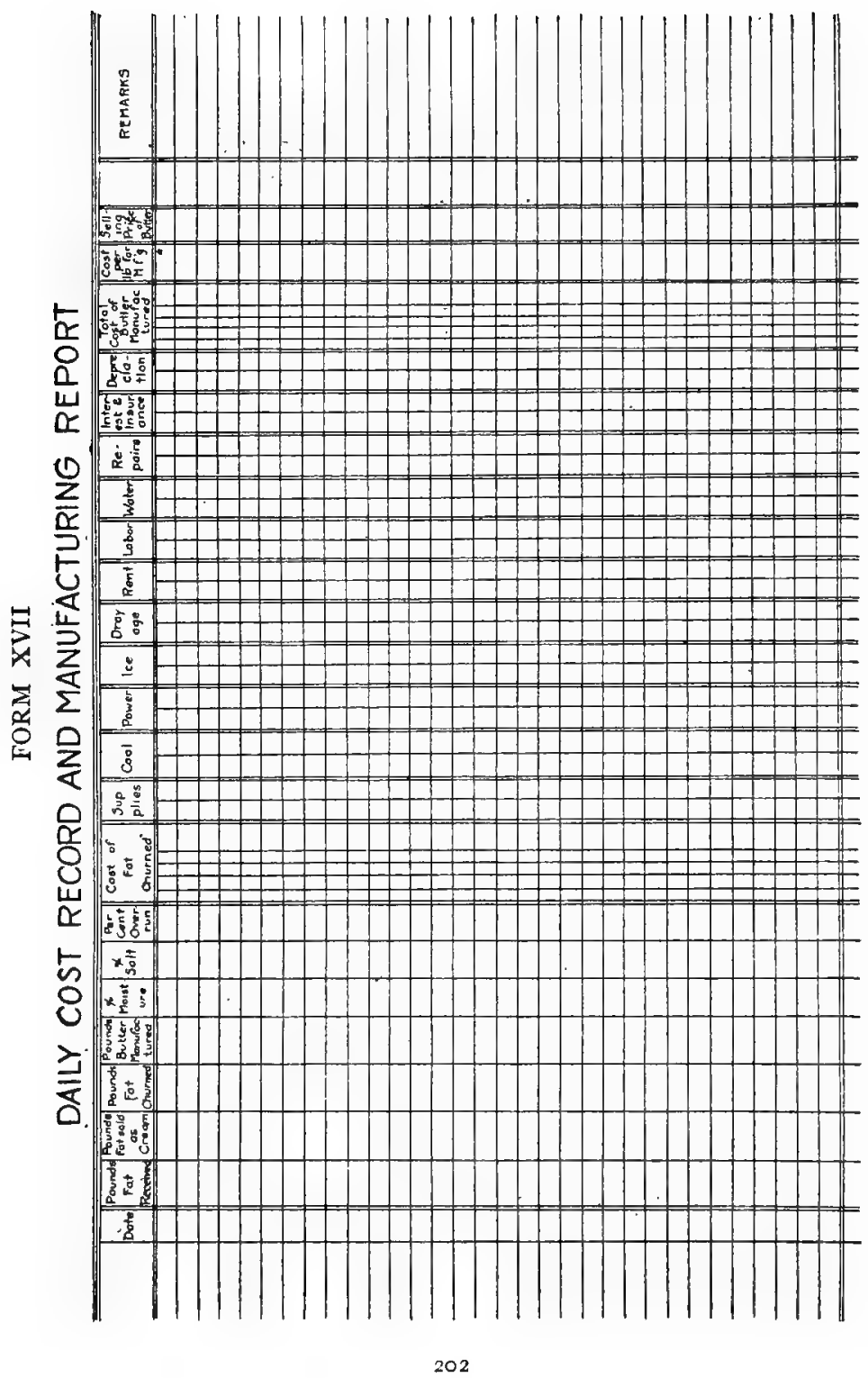




\section{CHAPTER XVII}

\section{PROFITS OBTAINED FROM THE MANUFACTURE OF ICE CREAM}

THE general factors influencing the profits obtained from the manufacture of ice cream may be enumerated under the heads of A, cost of material; B, yield of ice cream obtained; and C, general expenses.

\section{A. COST OF MATERIAL}

That the cost of material used for the manufacture of ice cream is a factor of importance is illustrated by the following formulas. Each formula represents the amount of material required for manufacturing ten gallons of ice cream. For the one formula a high-grade material is used, while for the other a material of lower quality is used.

Formula No. ${ }^{1}$

42 lbs. 20 per cent cream at 50 cents per $1 \mathrm{~b}$. butter fat.......\$4.20

8 lbs. sugar at 6 cents. .............................

4 oz. vanilla at $\$ 8.00$ per gallon....................... $\quad .25$

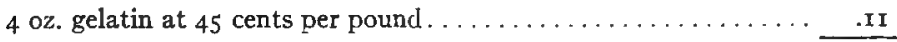

Total cost of material. ............. $\$ 5.04$

Cost of material for onc gallon ice cream............... $\quad .504$

FORMULA No. 2

$44 \mathrm{lbs}$. I6 per cent process cream at 40 cents per lb. butter fat.... \$2.8I

8 lbs. sugar at 6 cents.................................

$4 \mathrm{oz}$. vanilla at $\$ 3.00$ per gal.......................... .

$4 \mathrm{oz}$. gelatin at 15 cents per pound $\ldots \ldots \ldots \ldots \ldots \ldots \ldots \ldots \ldots, .04$

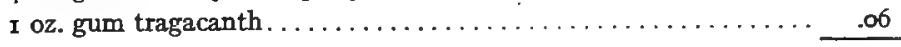

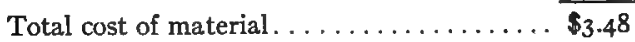

Cost of material for one gallon ice cream.............. $\quad .348$

${ }^{1}$ Figures are based on prewar conditions. 
It will be noted from the foregoing formulas that the difference in the cost of the cream made a difference of 15.6 cents per gallon of the finished product. The difference in cost of vanilla made a difference of 1.6 cents per gallon of ice cream. The cost of gelatin does not affect the final cost to a great extent, as it is comparatively cheap, and if the cheaper grades are used it will require greater quantities in order to accomplish the same result.

I. Cream. - The cream is the most important ingredient of ice cream. By reducing the richness of cream from 20 to I9 per cent in formula No. I, the cost of the ice cream was reduced 2.I cents per gallon. The reduction would in reality be a trifle less, as a decrease in fat content of the original cream would slightly decrease the yield of ice cream. It is evident that the uniformity of the fat content of the original cream is essential not merely for the purpose of producing an ice cream of uniform quality, but also for the purpose of controlling the cost of the finished product.

The richness of the cream should be determined by testing it for butter fat and if not of proper richness it should be standardized. It is often taken for granted that cream skimmed with the same centrifugal separator is of uniform richness and that testing and standardizing of such cream is unnecessary. This does not coincide with modern teaching, as it has been found that cream produced by the same separator may readily vary as much as 5 per cent in fat content fron one skimming to another, even though the cream screw may be left unchanged.

I. Standardization of Cream. - By standardization of cream the manufacturer is not merely controlling the cost of cream required, but is furthermore in a position to manufacture a uniform product which is essential to the successful marketing thereof.

A. Reducing the Richness of Cream with Skim Milk. - In that instance the cream to be standardized contains the entire amount of fat which the standardized cream will contain. Therefore the number of pounds of original cream multiplied by the number representing the test of same divided by the num- 
ber representing the desired richness gives the amount of standardized cream produced.

Example I:

Reduce the richness of 80 pounds of 30 per cent cream to 20 per cent by addition of skim milk.

$80 \times 30 / 20=120$ pounds of 20 per cent cream.

$\mathrm{I} 20-80=40$ pounds of skim milk required.

When a given amount of standardized cream is desired, using skim milk for reducing, then the pounds of original cream used are equal to the number representing pounds of standardized cream multiplied by the number representing the richness of the standardized cream, dividing the product by the figure representing the richness of the original cream.

Example 2:

Prepare 300 pounds of 20 per cent cream from 30 per cent cream and skim milk.

$300 \times 20 / 30=200$ pounds of 30 per cent cream required.

$300-200=100$ pounds of skim milk required.

B. Reducing the Richness of Cream with Whole Milk. - The following method by Pearson is easy and accurate for determining the quantity of milk or thin cream that must be added to a rich cream to produce a cream of required richness or fat content:

Draw a square and write at the two left-hand corners the percentages of fat in the fluids to be mixed, and in the center place the required percentage. At the upper right-hand corner put the number which represents the difference between the two numbers standing in line with it, $i . e$. , the number in the center and the one at the lower left-hand corner. At the lower right-hand corner put the number that represents the difference between the two numbers in line with it. Now let the upper right-hand number refer to the upper left and the lower right-hand to the lower left, then the two right-hand numbers show the relative quantities of the fluids represented at the left-hand corners that must be combined to give a fluid of the desired standard which is represented in the center. 
Example 3:

Prepare 260 pounds of cream containing 25 per cent fat from 4 per cent milk and 30 per cent cream.

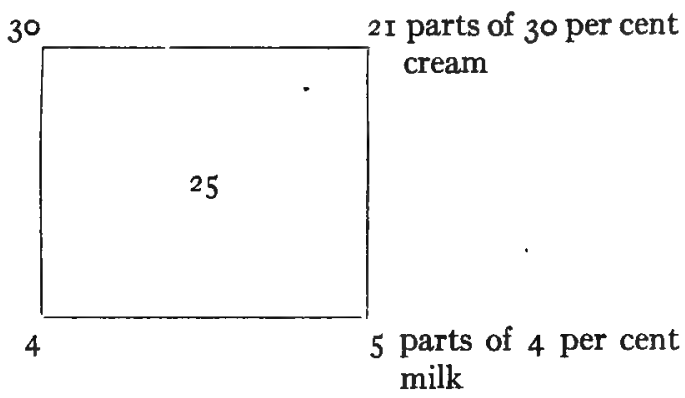

$260 \times \frac{2 I}{26}=210$ pounds of 30 per cent cream required.

$260 \times \frac{5}{26}=50$ pounds of 4 per cent milk required.

Example 4:

Prepare 25 per cent cream from 23I pounds of 35 per cent cream and 4 per cent milk.

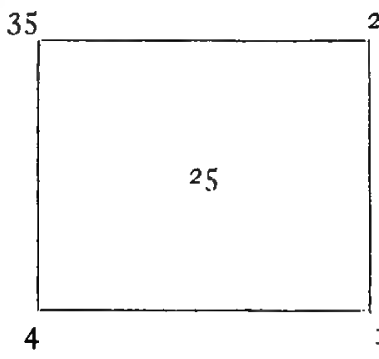

2I parts of 35 per cent cream

to parts of 4 per cent milk

$23 \mathrm{I} \times \frac{3 \mathrm{I}}{2 \mathrm{I}}=34 \mathrm{I}$ pounds of 25 per cent cream.

$34 \mathrm{I}-23 \mathrm{I}=\mathrm{I}$ Io pounds of 4 per cent milk required or $34 \mathrm{I} X$ $\frac{\text { IO }}{3 I}=\mathrm{I}$ IO pounds of 4 per cent milk required. 
The following method by the author ${ }^{1}$ is also easy and quick for the operator to use:

Let $\mathrm{C}_{1}$ represent amount of original cream.

$\mathrm{C}_{2}$ represent amount of standardized cream.

$M$ represent amount of milk.

t represent test of milk.

$t_{1}$ represent test of original cream.

$\mathrm{t}_{2}$ represent test of standardized cream.

If the value of $C_{1}$ is given, but the value of $C_{2}$ is unknown, then

$$
\begin{aligned}
& C_{2} \times t_{2}=C_{1} \times t_{1}+\left(C_{2}-C_{1}\right) t \text { or } \\
& C_{2}=C_{1} \times \frac{t_{1}-t}{t_{2}-t}
\end{aligned}
$$

This may be expressed as follows: "When a definite amount of original cream is to be standardized with milk of known richness then the amount of standardized cream is equal to the figure representing pounds of original cream used multiplied by figure representing the difference between test of original cream and test of milk, this product divided by figure representing the difference between test of standardized cream and test of milk."

\section{Example 5:}

Prepare 20 per cent cream from roo pounds of 30 per cent cream and 4 per cent milk.

$\mathrm{C}_{2}=\mathrm{I00} \times \frac{30-4}{20-4}=\mathrm{I} 62 \mathrm{I} / 2$ pounds of 20 per cent cream

I62 I/2 - roo $=621 / 2$ pounds of 4 per cent milk to be used for standardizing.

If the value of $C_{2}$ is given the value of $C_{1}$ unknown, then from the same equation we have the following:

$$
C_{1}=C_{2} \times \frac{t_{2}-t}{t_{1}-t}
$$

This may be expressed as follows: "When a definite amount of standardized cream is desired then the amount of original

1 Creamery Journal, June I, IgI I. 
cream required is equal to figure representing the pounds of standardized cream multiplied by figure representing the difference between test of standardized and test of milk, this product to be divided by figure representing the difference between test of original cream and test of milk.

Example 6:

Prepare roo pounds of 20 per cent cream from 30 per cent cream and 4 per cent milk.

$$
\begin{gathered}
C_{1}=100 \times \frac{20-4}{30-4}=617 / 13 \text { pounds of } 30 \text { per cent cream. } \\
\text { 100-6I } 7 / 13=386 / 13 \text { pounds of } 4 \text { per cent milk. }
\end{gathered}
$$

To illustrate the similarity between the two methods suppose Example 6 had been figured by the method of Pearson; the formula would have been as follows:

$$
\mathrm{C}_{1}=100 \times \frac{20-4}{(20-4)+(30-20)}
$$

Example 5 by that method would be solved as follows:

$$
\mathrm{C}_{2}=100 \times \frac{(20-4)+(30-20)}{20-4}
$$

For the purpose of facilitating the work of the ice cream department standardization tables may be used to advantage.

The same rules and formulas as apply for standardization of cream may also be used for standardization of milk.

2. Homogenization of Cream. - By homogenization cream is subjected to energetic mechanical treatment. The Gaulin system is the oldest and possibly the best known in the United States.

The cream enters the machine at a high temperature. It is forced through fine metal capillary tubes and against a conical agate-valve disk at a pressure of from 2,000 pounds to 3,000 pounds per square inch. The fat globules in cream thus treated are broken up to such an extent that they are removed with difficulty with a cream separator if the homogenization is properly done.

For butter making this treatment is of no advantage but 
of disadvantage, for the reason that homogenized cream cannot be churned.

A. Its Value in Ice Cream Making. - In ice cream making this treatment of the cream has the advantages that the cream acquires a firmer and smoother body so that a 20 per cent homogenized cream will produce an ice cream of a similar consistency as ice cream made from a richer cream. Ice cream made from homogenized cream possesses better keeping qualities and will yield more services per gallon than that made from cream which has not been so treated. It is furthermore entirely free from butter particles which are so readily formed in untreated cream during the process of freezing.

Since the introduction of the homogenizer it has been learned that by heating skim milk to a high temperature and then adding melted butter in definite quantities and homogenizing, it is possible to produce a cream which in appearance is identical with normal cream. This system has the disadvantages: First, that it discourages the production of sweet cream, which means much to the dairy states, as it is well known that the ice cream manufacturer is recognized to be the principal educator for quality; second, it discriminates against the smaller ice cream manufacturer, as he cannot afford to install a homogenizer and is therefore compelled to buy more expensive cream; and third, if butter from sour cream is used then it becomes nothing less than a renovating process.

The production of artificial cream in places where dairying is not well enough developed should not be discouraged, for if the cream has to be shipped a great distance it is more economical and fully as sanitary to produce the cream from butter made from sweet cream, from a practically sterilized milk powder, and from sterilized water.

B. Cost of Homogenization. - The machine after it has been started requires but little attention. One man's time while the homogenizer is operated is sufficient. In addition to that the main cost is the cost of power and the interest on the investment. A homogenizer of sixty gallons' capacity per hour requires 3 horse power. By installing a larger homogenizer 
some reduction will be made in the cost of power, as a machine of a capacity of 200 gallons per hour only requires 6 horse power.

3. Storing of Cream. - As the demand for ice cream is governed largely by weather conditions and local events, the ice cream manufacturer sustains annually much loss on cream, for if he has too big a supply on hand under ordinary conditions he is usually compelled to sell it to the butter manufacturer at a loss. At other times, when the demand for a short time is above normal, it may even be impossible to secure a sufficient supply. The storing of cream for from one week to ten days will to a great extent eliminate such difficulties.

A. Preparation of Cream for Storage. - The cream should be cared for immediately upon arrival at the factory. If left on the creamery floor without attention it will soon become unfit for ice cream making. Cream used for the manufacture of ice cream should not contain above .2 per cent of acid. It should be free from undesirable flavors. If the cream is received during a period of several hours it should be placed in a tank of ice water as soon as received, or better, in a cooling vat. When the cream has all been collected it is standardized to the desired richness and then pasteurized.

The method of pasteurization most satisfactory for cream for ice cream making is that of heating the cream to a temperature of from $140^{\circ}$ to $145^{\circ} \mathrm{F}$. and holding it at that temperature from twenty to twenty-five minutes. From the pasteurizer the cream is cooled to within a few degrees of freezing. It is then put away in cans into a brine tank or a cold-storage room which is held at a temperature of a few degress below freezing. The cream is stirred frequently until it has reached the freezing point, when it is left until enough of the cream has frozen to form ice on the side of the can to a thickness of from a half to one inch. The cans may now be packed in crushed ice or placed in a cold-storage room at $32^{\circ} \mathrm{F}$. and kept in that condition until used. All cream used for ice cream making should be treated in this manner and held for not less than twenty-four hours at $32^{\circ} \mathrm{F}$. before used. By so doing the body is improved and the yield increased. 
The cans containing the cream held for storage should be sealed. This is done very satisfactorily by placing a parchment paper over the top of the can, then placing a tight-fitting cover on the can. The parchment paper will fit in between the cover and the collar of the can and act as a seal.

B. Length of Time for Storage. - The length of time that cream may be safely stored is not satisfactorily known. The cream may retain its fresh flavor for from three to four weeks if the cans are properly sterilized and sealed and if the cream is kept at a temperature of $32^{\circ} \mathrm{F}$. It has been found, however, that when the cream has been held over ten days or two weeks the bacteria are apt to increase at a high rate. ${ }^{1}$ It is not known what effect this increase will have on the wholesomeness of the product.

\section{Flavoring Materials. -}

I. Sugar. - Sugar is one of the important ingredients in ice cream. The most common sugar used is fine granulated cane sugar. Beet sugar is used by several manufacturers and is sold for á fraction of a cent less per pound. There is a difference in opinion as to the relative value of the two; however, it is most generally considered that the difference is insignificant.

2. Flavoring Extracts. - Extracts become of much importance for the reason that vanilla ice cream constitutes from 75 to $9 \circ$ per cent of the ice cream manufactured and for vanilla ice cream an extract is the only practical flavoring to use. Of other extracts used by the ice cream factories, might be mentioned lemon, orange, almond, pistachio, peppermint, rose, etc. It is most satisfactory to use berries, fruits, and nuts direct as flavoring, and extracts should not be used unless in case of necessity.

A. Vanilla Extract. - Vanilla extract is prepared from the fully matured, unripe cured fruit of the perennial climbing vine, vanilla planifolia. Several varieties of vanilla beans are on the market. The difference in the delicacy of flavor determines the difference in value between the various kinds of beans. In market value the Mexican bean ranks highest and sells at from

1 Bulletin 134, Iowa Experiment Station, rgI2. 
$\$ 8$ to $\$ 30$ per pound. The Bourbon bean ranks second, selling at from $\$ 5$ to $\$ 14$ per pound, the South American bean sells at from $\$ 4$ to $\$ 6$ per pound. The cheapest of the various varieties is the Tahiti bean, which sells at from $\$$ I.75 to $\$ 2.25$ per pound. ${ }^{1}$

The flavoring material contained in the vanilla bean is slightly soluble in water, but readily soluble in alcohol. For that reason a weak alcohol is used for extracting the flavoring material from the beans.

The United States standard defines vanilla extract as being the flavoring extract prepared from the vanilla bean, with or without sugar or glycerin and contains in Ioo c. c. the soluble matter from not less than ro grams of the vanilla bean.

According to this standard the United States oficial method for manufacturing vanilla extract is as follows:

"Mix 650 c. c. of alcohol with 350 c. c. of water. Macerate I00 grams of vanilla beans, which have been previously cut into small pieces and bruised in a mortar, in $500 \mathrm{c}$. c. of the mixture for twelve hours; then drain off the liquid and set aside. Transfer the vanilla to a mortar, beat it with 200 grams of sugar into a uniform powder, then pack it in a percolator and pour upon it the reserved liquid. When this has disappeared from the surface, continue percolation by gradually pouring on sufficient menstruum to make I,000 c. c. of extract."

Material cost of preparing one gallon of vanilla in accordance with the United States official method is as follows, figuring that the extract is manufactured from a Mexican vanilla bean at \$1o per pound:

650 c. c. alcohol at 70 cents per liter............ \$0.46

200 grams sugar at 6 cents per pound . . . . . . . . . 0.03

Io grams vanilla bean .................... 2.21

Material cost of $\mathrm{r}, 000 \mathrm{c}$. c. vanilla extract.......... \$2.70

I gallon $=3,785 \mathrm{c}$. c.

Material cost of I gallon $=\$ 10.22$.

${ }^{1}$ Flavoring extracts by R. A. Kuever. 
Suppose Tahiti beans at $\$ 2$ per pound are substituted for the Mexican vanilla bean, the material cost of a gallon of vanilla extract will then be reduced to $\$ 3.53$.

An extract resembling vanilla extract and often sold for vanilla extract is manufactured synthetically and its cost of production is much less than the cheapest true vanilla extract manufactured. Therefore, in purchasing vanilla extract, the writing on the label of the bottle should be carefully read and at times a sample of the goods might be sent to the State Experiment Station for analysis.

The extract made from the Tahiti bean is of a lighter color than that manufactured from other beans and is therefore readily distinguished unless artificially colored.

Although it may appear to be profitable for the ice cream manufacturer to manufacture his own vanilla extract, it has been found by many who have attempted to do so in a small way that they have not been successful in producing an extract equal to the commercial product.

B. Lemon Extract. - Lemon extract, in accordance with the United States standard, is the flavoring extract prepared from oil of lemon or from lemon peel, or both, and contains not less than 5 per cent by volume of oil of lemon.

Oil of lemon is the volatile oil obtained by expression or alcoholic solution from the fresh peel of the lemon, has an optical rotation ${ }^{1}$ of not less than $+60^{\circ}$ in a $100 \mathrm{~mm}$. tube and contains not less than 4 per cent by weight of citral.

The direction for preparing a tincture of lemon peel is as follows:

500 grams lemon peel from the fresh fruit in thin shavings and cut in narrow shreds.

Alcohol of sufficient quantity to make I,000 c. c.

"Macerate the lemon peel in a stoppered, wide-mouthed container in a moderately warm place with $I, \infty 00 \mathrm{c}$. c. of alcohol during forty-eight hours with frequent agitation; then filter through purified cotton, and when the liquor has drained off 
completely gradually pour on enough alcohol to make I,000 c. c. of tincture and filter."

As noted above, a lemon extract may readily be prepared by any manufacturer. The most expensive material used for the preparation of a lemon extract is the alcohol, therefore the manufacturers of extract often prepare cheap terpeneless extracts. It requires at least 80 per cent by volume of alcohol for a lemon extract containing 5 per cent of lemon oil. Deodorized or purified alcohol is to be preferred.

Lemon is not a popular flavor for ice cream, but is used for nearly all water ices and lactos; however, for the manufacture of these, we depend mainly on the juices of the fruit.

Orange extract is prepared in a similar manner as lemon extract.

C. Detection of Artificial Extracts. - The ice cream maker is seldom capable of making chemical analyses, but there are a few simple tests by which the maker may obtain a fair idea as to the purity of some of the more common extracts.

If normal acetate of lead solution is added to a sample of vanilla extract a heavy precipitate is formed if the extract is pure. If the extract remains clear, or if only a mere cloudiness is formed, it is conclusive evidence that the extract is artificial.

Lemon and orange extracts are readily tested by placing a small sample in a test tube; if by adding an equal amount of water a heavy precipitate is formed, then it is an indication that the extract is of good quality. The heavier the precipitate the better the extract.

The following method by Mitchell is for determination of oil in a lemon or orange extract: "Transfer by a pipette $20 \mathrm{c}$. c. of the extract to a Babcock milk bottle, add I c. c. of dilute hydrochloric acid ( $\mathrm{I}: \mathrm{r}$ ); add 25 to $28 \mathrm{c}$. c. of water previously warmed to $60^{\circ} \mathrm{C}$. mix, and stand in water at $60^{\circ}$ for five minutes; centrifuge for five minutes; fill with warm water to bring the oil into the graduated neck of the flask, and repeat the whirling for two minutes; stand in water at $60^{\circ}$ for a few minutes, and read the per cent of oil by volume. Where the oil of lemon is present in amounts over 2 per cent, add to the percentage of oil 
found 0.4 per cent to correct for the oil retained in solution. Where less than 2 per cent and more than I per cent is present, add 0.3 per cent for correction."

3. Fruit and Berries. - Most fruits and berries possess distinctive flavors which are desirable in the manufacture of ice creams and ices. It is very seldom possible to prepare from such fruits or berries an extract sufficiently concentrated to be of much value when used in small quantities. For that reason most fruit extracts obtained on the market are manufactured from artificial fruit essences made up of compound ethers so as to imitate the various fruit flavors.

The ice cream manufacturer who is giving due consideration to quality does not use imitation extracts but prefers to use the pure fruit. This may be used either in the form of fruit juice or as crushed fruit, but as fruits and berries are seasonal it becomes necessary to preserve such fruits and berries for which a permanent demand has been created. It has been found ${ }^{1}$ that ordinary methods of sterilizing fruit juices by heat may be successfully applied to but a limited number of the special fruits, such as the black raspberry, blackberry, black currant, sour cherry, and peach. In the case of juices of the strawberry, red raspberry, red currant, pineapple, and the citrus fruits as well as apple cider, sterilization by heat causes loss in flavor, and where kept after heat sterilization the juices of these fruits tend to lose in color or flavor, or both.

A. Preparation of Strawberries for Storage. - Strawberries which are of great importance as flavoring for ice cream may be sterilized without injury to color but with marked injury to the fresh fruit flavor. A cooked strawberry flavor develops. Strawberries may be prepared for storing as follows:

A perfectly fresh berry of a fine and pronounced flavor should be selected. The berries should be rinsed with cold water and mashed through a fine hair sieve. The juice, which may be collected in a milk can or an ice cream can, is weighed and an equal amount of sugar by weight is added. The mixture of berry juice and sugar is stirred thoroughly at frequent 2 Bul. 24I, U. S. Dep. of Agriculture, 1915. 
intervals while it is left at ordinary room temperature from twenty-four to forty-eight hours. The object is to have the sugar thoroughly dissolved. When the sugar has thus been dissolved the fruit should be cooled, which is most readily done by packing the can or cans containing the fruit in crushed ice. The fruit should be held thus until it has reached a temperature of about $35^{\circ} \mathrm{F}$. It is then ready to be packed for storage. It may be put into earthen containers or it may be packed in larger containers such as barrels. It should not be packed in larger containers than can be emptied within two or three weeks' time unless good cold storage facilities are available.

If barrels are used these should be thoroughly cleaned and sterilized and then paraffined on the inside. When the barrel is full of fruit it is headed up and sealed with paraffin wax. It should be held at a temperature of $50^{\circ} \mathrm{F}$. or lower, if possible.

The importance of watching the fruit closely while it is being stored should not be overlooked. If there is any which shows the slightest indication of fermentation it should be used immediately or sterilized.

The cost of the fruit prepared in accordance with the foregoing direction is as follows, in accordance with results obtained by the author: 1

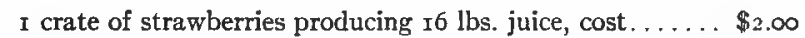

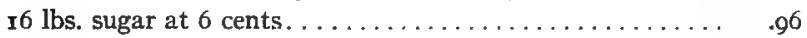

Labor . . . . . . . . . . . . . . . . . . . . . . .

Total cost for $32 \mathrm{lbs}$. sirup ............... $\$ \frac{\$ 2 I}{\$ 3.21}$

A fruit sirup thus prepared has a specific gravity of 1.32 . The weight of one gallon of sirup $=8.35 \times 1.32=\mathrm{II}$ pounds.

$32 \div$ II $=2.9 \mathrm{r}$ gallons prepared from one crate of berries.

Cost per gallon $=3.2 \mathrm{I} \div 2.9 \mathrm{I}=\$ \mathrm{I}$. Io.

The yield of fruit juice obtained in the above experiment was 80 per cent. Gore ${ }^{2}$ obtained yields from strawberries ranging from 63 to 88.06 per cent.

${ }^{1}$ From experiments conducted Igr4.

2 Bulletin 24r, U. S. Department of Agriculture, I9т 5. 
Berries and fruits of various kinds may be prepared by a method similar to that outlined for the preparation of strawberries.

B. Preparation of Cherries for Storage. - Cherry sirup has been prepared most successfully by the author by heating the cherries to about $185^{\circ} \mathrm{F}$. before crushing. After crushing, the juice is kept at $185^{\circ} \mathrm{F}$. for thirty minutes, sugar is then added in equal proportions, and the sirup is allowed to cool. The following gives the cost of cherry sirup in accordance with results obtained by the author:

I bushel of cherries produces 29 lbs. juice, cost....... $\$ 3 . \infty$

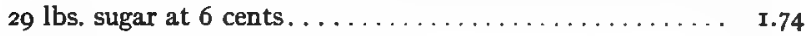

Labor..................................

Total cost for $58 \mathrm{lbs}$. sirup...............\$5.24

Specific gravity of sirup r.3.

58 lbs. sirup $=5.375$ gallons.

Cost per gallon of cherry sirup, 97.5 cents.

4. Chocolate. - Chocolate and similar flavoring material which needs to be prepared before it is added to ice cream should always be kept on hand in the form of a sirup. This sirup may be prepared when there is less regular work in the factory and no time is lost when the ice cream maker is busy.

A chocolate sirip may be prepared from a simple sirup and chocolate or cocoa. The principal difference between chocolate and cocoa is that the chocolate contains all of the oil from the bean. The cocoa bean contains close to 50 per cent of oil; this latter is of no value as a flavor-producing material and it is not particularly desirable mixed with cream, which already contains a high per cent of fat. Cocoa is the same as chocolate, except that part of the oil has been removed from the cocoa bean, and cocoa therefore contains less fat and more flavoring material. If one and a half pounds of chocolate are used for ten gallons of ice cream, the same result will be secured using about one pound of cocoa. 
A. Chocolate Sirup. - Chocolate sirup is prepared by dissolving cocoa or chocolate in simple sirup. The mixture is brought to a boil and when the chocolate or cocoa is dissolved the sirup is cooled and transferred to sterilized jugs or jars. Cocoa may be added to the sirup in the proportion of one pound of cocoa to three or four pounds of simple sirup.

B. Simple Sirup. - Simple sirup is prepared by adding twelve pounds of sugar to eight pounds of water. This is boiled until it has a specific gravity of about I. 32 at $60^{\circ} \mathrm{F}$. Such a sirup contains about 66 per cent of sugar. The weight of one gallon of simple sirup thus prepared is eleven pounds. The cost of such a sirup, figuring sugar at six cents per pound, is about forty-four cents per gallon.

III. Fillers. - Fillers are comparatively cheap, and from the standpoint of cost the manager should not be so interested as from the standpoint of quality. It was found ${ }^{1}$ that by using four ounces of a certain kind of gelatin for ten gallons of ice cream the bacteria count increased 565,000 germs per c. c. due to the organisms contained in the gelatin while a gelatin of higher quality was practically sterile.

\section{B. YIELD OF ICE CREAM}

The amount of ice cream obtained in excess of amount of mix used is called the overrun. The overrun may be figured from volume or from weight.

I. Overrun Figured from Volume. - The overrun figured from volume is determined by the following formula:

$\frac{\text { (Gallons ice cream produced }- \text { gallons mix used) } 100}{\text { gallons of mix used }}=$ per

cent overrun.

Example:

Ioo pounds of mix, of a specific gravity of 1.07 , produces 20 gallons of ice cream. Figure overrun.

1 Bulletin 134, Iowa Experiment Station, I912. 


$$
\begin{aligned}
\frac{100}{8.35 \times 1.07} & =\text { Ir.I9 gallons mix. } \\
\frac{(20-\text { II.I9) X 100 }}{\text { II.I9 }} & =78.73 \text { per cent overrun. }
\end{aligned}
$$

The weight per gallon of the finished ice cream is in this instance five pounds. The greater the overrun the lighter the finished product will be. It is possible to obtain a considerable higher overrun than that indicated in this problem, but if the overrun becomes too great the body of the ice cream becomes too light and fluffy. The weight of the finished ice cream should not be less than five pounds per gallon.

II. Overrun Figured from Weight. - The overrun may also be figured from weight in accordance with the following formula:

(Weight per gal. of $\mathrm{mix}$ - weight per gal. of ice cream) 100 weight per gal. of ice cream

per cent overrun

Applying this to problem above we have

$$
\frac{(8.35 \times 1.07-5) 100}{5}=78.69 \text { per cent overrun. }
$$

The ice cream maker should check his work from time to time during the day's run. This is most readily done by weighing a container of ice cream, thus determining the weight per gallon.

III. Figuring Overrun from Amount of Mix or Amount of Cream Used. - In the above formulas the overrun has been calculated from amount of mix. This is very satisfactory when the same formula is being used at all times. Some manufacturers prefer to figure the overrun from amount of cream used which may be considered to be equally satisfactory. For plain ice cream a hundred per cent overrun on amount of cream used may usually be considered equal to about eighty per cent overrun when figuring from amount of mix used; this, however, depends on formula used. 
IV. Factors Influencing Yield of Ice Cream Obtained. The principal factors influencing the yield of ice cream obtained are: First, condition and treatment of cream used; second, temperature of ice cream when drawn from freezer; third, temperature of circulating brine; fourth, size of batch frozen; fifth, speed of agitator. 1

I. Condition and Treatment of Cream Used. - The value of aging the cream has been formerly discussed. Rich cream produces a higher yield than thinner cream. Cream of a high temperature is likely to churn during the freezing process and the yield is, as a result thereof, decreased. Homogenized cream produces less yield than does cream which has not been so treated unless frozen longer than untreated cream. ${ }^{2}$

2. Temperature of Ice Cream When Drawn from Freezer. The temperature at which the ice cream returns the greatest yield is usually from $27^{\circ} \mathrm{F}$. to $28^{\circ} \mathrm{F}$. This, however, may vary slightly due to the condition of the cream used.

3. Temperature of Circulating Brine. - A brine of low temperature causes the ice cream to freeze before a sufficient amount of air has been incorporated. If the brine is too warm the freezing takes too long and it may result in partly churning the cream. A brine of a temperature from $8^{\circ} \mathrm{F}$. to $14^{\circ} \mathrm{F}$. is most desirable; the lower temperature is most satisfactory for a cream of lower viscosity. A cream of higher viscosity, such as homogenized cream, should be frozen with a brine of the higher temperature so as to allow longer time for the incorporation of air.

4. Size of Batch Frozen. - The larger the batch up to a certain limit the greater the yield will be. The smaller batch freezes too soon before a sufficient amount of air has been incorporated.

5. Speed of Agitator. - The freezer should be operated very slowly until it reaches the point of freezing which varies from $28^{\circ} \mathrm{F}$. to $29^{\circ} \mathrm{F}$. It should be the object to reach that point

1 Bulletin 180, Iowa Experiment Station, 1918.

2 Bulletin 180, Iowa Experiment Station, I918.

Bulletin 155, by Washburn, Vermont Exp. Station, Igro. 
before the fat globules begin to coalesce, for if not the cream is less suitable for whipping. The speed may then be increased to advantage.

V. Losses Which Influence the General Yield. - Losses of various kinds are usually found to be more frequent in the ice cream factory than in the creamery. It is only by the closest attention of the manager to the details of the work in the factory that such losses will be reduced to the minimum. The most significant of such losses are due: First, to inaccurate ice cream molds and containers; second, to molding of hard ice cream, and third, to retailing of ice cream.

I. Ice Cream Molds and Containers. - The ice cream brick molds and containers should be tested as to accuracy of size before they are placed in service. This is most conveniently done by weighing the amount of water which they hold. A 5 -gallon container if of proper size will hold exactly $8.35 \times 5$ $=4 \mathrm{I} .75$ pounds of water.

2. Molding of Ice Cream. - The molding of ice cream should be done directly from the freezer or before the cream has been thoroughly hardened; if not, the loss is increased. The loss sustained due to molding of hard ice cream may readily reduce the quantity of ice cream from to to 20 per cent.

3. Retailing Ice Cream. - The retailing of ice cream will always result in a quantity loss. This may be due partly to giving the retail customers too big measure or to the transferring of hard ice cream from one container to another. If ice cream is sold at retail it is most satisfactory to mold it in the form of a brick of a quart size direct from the freezer.

\section{GENERAL EXPENSES IN MANUFACTURING ICE CREAM}

The general expenses in the manufacture of ice cream are much similar to the general expenses. in the creamery and will be discussed here in so far as they differ.

The cost of material used for ten gallons of vanilla ice cream has previously been figured at $\$ 5.04$. This does not include 
such other expenses as labor, salt, ice, power, interest, insurance, etc.

\section{FORM XVIII}

Ice Creak Manufacturing Report Showing Cost of Material. Used Per Gallon ox IcF. Cream Manutactured

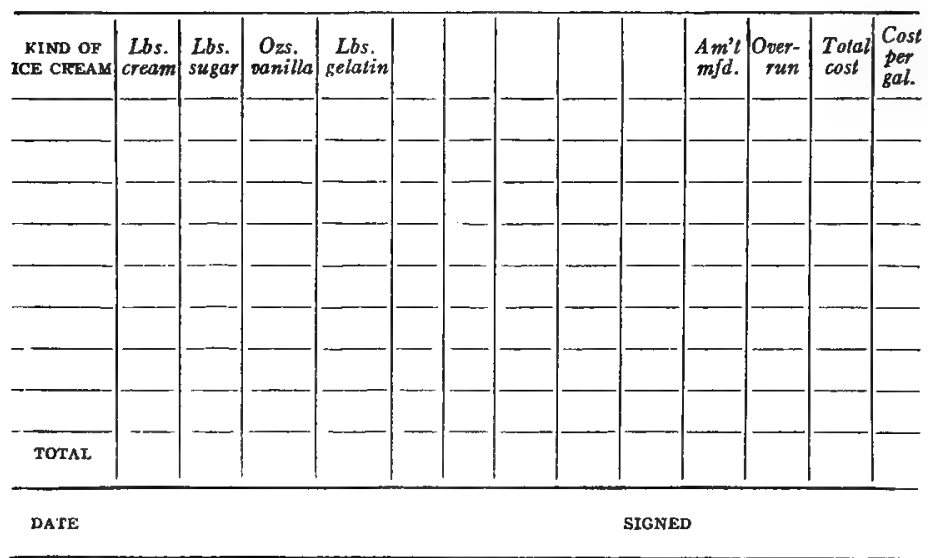

I. Cost of Labor. - Some small creameries are so situated that they need a helper during the summer season, but on account of lack of business there is less than a day's work for each of the men. Such a creamery may during the summer season manufacture ice cream for its town at practically no extra expense for labor. The amount of labor which is due to be paid for the ice cream department should, however, be figured as paid from there and the labor transferred to the ice cream department should be credited to the butter department. Some smaller ice cream plants find that labor is a big item. Some figure the cost of labor for manufacturing as high as Io. cents per gallon of ice cream manufactured.

I. The Wholesale Plant. - The amount and cost of labor required in a factory manufacturing 600 gallons of ice cream daily may be estimated as follows: 


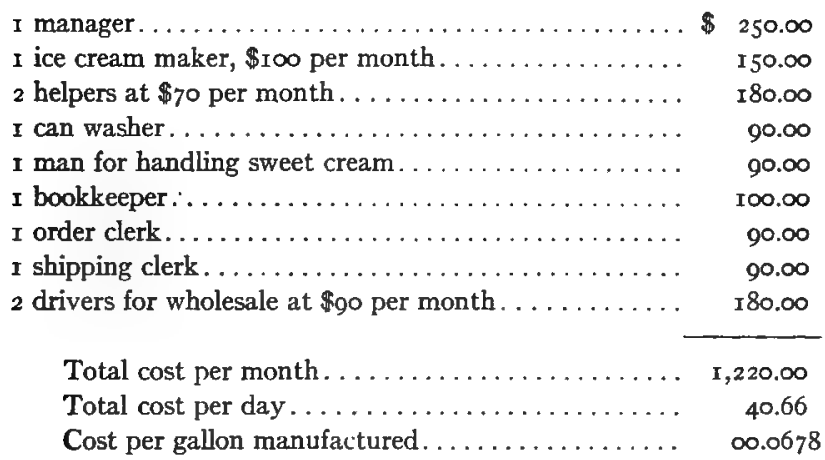

It is not entirely fair to charge all of the above expenses against manufacturing, as part of the manager's and bookkeeper's salaries and the entire salary of the order clerk and drivers should be charged against the selling expenses. In a factory of the above size the manager will take entire charge of seliing. Therefore the cost of $\$ 0.0678$ per gallon should be understood to be the cost of labor for manufacturing and selling, except the traveling expenses for the solicitor which are not included.

2. The Retail Plant. - The cost of manufacturing and selling at retail is greatly increased due to extra cost of labor, cost of delivery and bookkeeping, and shrinkage of ice cream. Therefore in making the retail prices such factors should be considered.

II. Cost of Power. - The cost of power may be determined on the basis that a ro-gallon batch freezer will require about 2 horse power. An ice crusher will require from 3 to 5 horse power.

III. Cost of Ice and Salt. - The cost of ice and salt for freezing, for hardening, repacking in the hardening tank, and repacking for shipment amounted to $7 \mathrm{I} / 2$ cents ger gallon for the entire year's business in a factory where an average of 500 gallons were manufactured daily during the summer season. The ice was figured at a cost of $\$ 3$ per ton and the salt at $\$ 7$ per 
ton. At this particular ice cream factory the hardening tanks were kept in a large open room without refrigeration. The ice cream was repacked twice daily in the hardening tanks. This expense might be reduced materially by keeping the hardening tanks in a refrigerator room. In one ice cream factory where that system of hardening was introduced it was found that the ice cream kept in most excellent condition by repacking only once daily. Some are using brine instead of ice and salt for the hardening tanks. This will tend to reduce the cost somewhat. The dry hardening rooms are the most sanitary and for larger plants the most economical, but for a very small plant that system would prove to be rather expensive. It is economy to use brine direct from the cold storage system for freezing the ice cream wherever such brine is available.

IV. Cost Due to Loss of Ice Cream Containers and Tubs. The loss of ice cream containers and tubs may be a big item unless systematic records are kept of outgoing containers. The ice cream manufacturer should select some individual color or some method of painting his tubs so that they will not resemble those of his competitors. By this individuality the packers will be generally known and will usually be returned to the proper factory. The tubs should furthermore bear the firm name and address. They should be numbered so that it may be possible to keep record of the individual containers. It is convenient to use letters for designating the size of containers. A might thus be used for ro-gallon packers, B for 5-gallon packers, $C$ for 3-gallon packers, etc. In accordance with that system the Io-gallon packers would be numbered $\mathrm{AI}_{1}, \mathrm{~A}_{2}, \mathrm{~A}_{3}$, etc.; 5-gallon packers would be numbered $\mathrm{B}_{1}, \mathrm{~B}_{2}, \mathrm{~B}_{3}$, etc.

When a shipment of ice cream is sent out a tag should be attached to the tub bearing the name and address of the customer (Form XIX).

Part of this tag bearing the name and address of the customer, the number of packer, and the date shipped is torn off from the original tag and filed on a board, properly numbered. Whenever the containers are returned the original tags are compared with corresponding stubs and destroyed. Some manu- 
facturers have a special ledger for keeping records of outgoing and incoming containers, but that method requires more labor and is less satisfactory. If proper records are kept of the containers, then it may be safely estimated that the containers and tubs, if of good quality, will serve for three years or more.

FORM XIX

Ice Cream Shtpping Tag

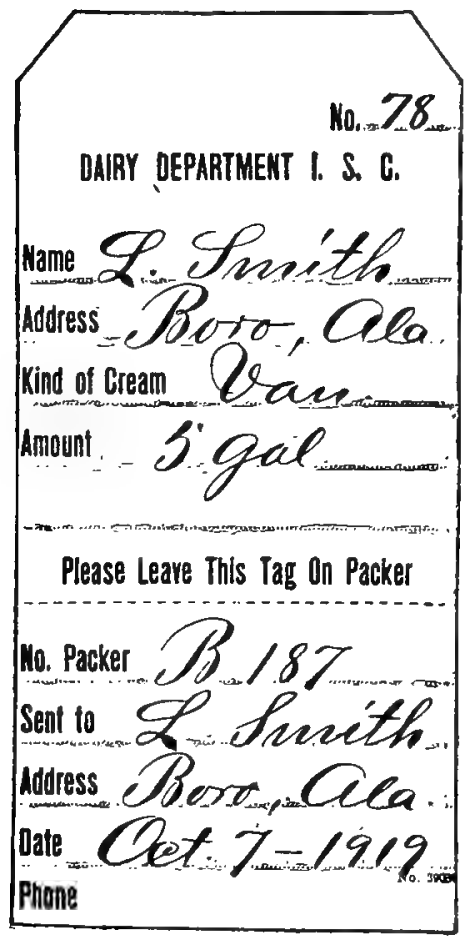




\section{CHAPTER XVIII}

\section{MARKETING OF DAIRY PRODUCTS}

\section{A. SALESMANSHIP}

THE selling of goods may be defined as an exchange of values; the act of selling is known as a business transaction. In order that a business transaction may lead to a permanent business relationship the transaction should be of mutual benefit to the parties concerned. The one who buys the goods must feel satisfied that he obtained as good value for his money as could be obtained anywhere. The one who sells the goods should likewise be satisfied with the transaction. If either of the two parties attempts to take advantage of the other the result will be that business relationship between the two will sooner or later be discontinued.

I. The Salesman. - The one who sells goods is known as the salesman. The art of selling goods becomes more important as competition becomes stronger and as business becomes more centralized. The salesman of to-day is therefore a man who must meet many requirements.

I. He Should be Honest, be of Good Moral Character, and of a Strong but Pleasing Personality. - He should cultivate taste for good company, for a man's character is often judged by that of his associates, and the modern business man is won most readily by that salesman who is of a strong character and personality. After he has won the confidence of the buyer a salesman is often tempted to sell a bigger order of goods than would be profitable for the purchaser to buy, but the salesman should look after the interest of his customers the same as he is looking after the interest of the firm by which he is employed. Whenever necessary he will make suggestions in reference to the size of orders which can be handled to best advantage by the pur- 
chaser. He should present the goods just as they are, not making any statements without authority from his house or statements which his firm is unable to back up.

2. He Should Cultivate Acquaintance with His Customers and Always be Glad to See Them. - A salesman who is afraid of meeting his customers after he has called on them a few times does not understand the secret of gaining their friendship. Such friendship can be gained only by salesmen who are in sympathy with, and have respect for, the people with whom they are dealing. The salesman should therefore be ready to observe the good qualities of his customer but slow in observing the qualities less desirable. A salesman's opportunity to be of help to his customers should be considered as a privilege, as it will result in mutual friendship, which is the strongest asset a salesman can possess.

3. He Should Know the Goods He Sells and Have Confidence in the House He Represents. - The man who sells a dairy product should know how such a product is manufactured, and if he is without technical knowledge then he should first work for some time in a dairy establishment. Even though he may have a fair technical knowledge he should spend a few days in the factory which manufactures the goods he is to sell. It is just as essential for a salesman to be in possession of such knowledge as it is for the attorney who is to conduct a case based on technical principles.

It is not merely the general principles of manufacturing, common to all establishments making the same line of goods, that should be studied, but especially such phases of the work in which the factory he represents excels the others. Particular attention should be given to sanitation, quality of raw material used, scientific principles involved in manufacturing, and quality and appearance of the finished product.

Experience thus obtained enables the representative to present properly the merits of the goods he sells. It also gives him enthusiasm and confidence in his firm. It is a difficult task for any one to sell an unknown product even at an average price; it is comparatively easy to sell a product at an advance in price 
if the salesman is fully aware of the superiority of that product. The fact that the factory is so equipped with machinery and supplied with raw material that it can meet the demand at all times of the year is also a big factor in developing confidence on the part of the one who sells the goods.

4. He Should Familiarize Himself with the Quality of Goods Sold by $\mathrm{His}$ Competitors and with Their Methods of Selling. This is entirely for the purpose of self-education and not for the direct purpose of taking undue advantage of such knowledge. A salesman should hold his competitors in high esteem. He should never speak of them when he sells goods, for if he does it is an indication that he is afraid of them and it makes him weaker in the eyes of the prospective customer.

5. He Should Have Self-Confidence. - The one who lacks self-confidence will never be able to talk convincingly. Selfconfidence should not be confused with self-conceit, for that is a very undesirable quality to possess.

6. He Should be a Judge of Human Nature. - The people he is to deal with are of different temperaments. They have different ideas, they do business in a different manner. It is therefore essential that the salesman first study the individuality of the person he expects to approach. The nature and the volume of his business have much to do in shaping the business man. The man who conducts a large retail grocery business in a large city is a busier man and requires different approach than the one conducting a grocery business in a small town.

Before approaching a person the salesman should have made a fair analysis of him and of his business. The approach is a very important part of the salesman's work. His manner of approach creates in the prospective buyer a like or a dislike, and unless he is able to make a favorable impression his chances for interesting the prospect are very poor. In order to appeal favorably he should be polite; he should not inconvenience the one he expects to do business with, but if he finds that he is busy it would possibly be advisable to call later. A salesman is at a disadvantage when trying to interest a person who for the time being has urgent business to attend to. The salesman in 
presenting his selling talk should be brief but convincing. He should watch the one he is talking to in order to observe the interest he takes in his arguments. He will thus be able to determine which points he needs to dwell upon and which be should pass lightly over. The financial interest of the merchant should always be kept in the background for a selling talk, for if it is not apparent to the merchant that he will gain something by handling that brand of goods then it is unlikely that he will become interested. The salesman should know when to talk and when to let the other person talk. Some buyers prefer to do most of the talking themselves while others will quietly listen to the arguments of the one who has the goods to sell. He should also know when it is the proper time to withdraw.

7. He Should be Persistent. - Because a few attempts fail that should not cause discouragement, but should call for renewed energy. He should take advantage of each failure as well as of each success by reviewing each selling talk, singling out the mistakes as well as the strong points of the talk. A permanent record should be kept of such analysis; a card file or a loose-leaf book is convenient for such information. A card or a leaf for each customer may be filed with information about former impressions, former conversations, and other facts of value. Such a report should be fully studied before calling on the person later. Such information is most conveniently filed geographically and alphabetically.

The salesman should furthermore keep a permanent daily record of the number of calls made, number of selling talks, and number of sales made. This should be summarized monthly. The purpose of this is for increased efficiency.

\section{The Manager in His Relation to the Salesman. -}

r. He Should be Able to Impart Enthusiasm to the Salesman. - This cannot be accomplished unless the manager himself has enthusiasm. Before the salesman starts to work the manager should take charge of him for the purpose of stirring his enthusiasm to the greatest extent. A manager should never send out a salesman before that has been done, for without 
enthusiasm the salesman will fail to present a forceful selling talk.

2. He Should Stand Back of His Salesman. - The quality of goods delivered should be the same as that represented by the salesman and it should be uniform and remain so. The practice of starting a new customer, supplying him with fancy goods for a short time, and then gradually reducing the quality, should be discouraged. A manager of such ideals cannot expect his salesmen to continue to retain business or remain enthusiastic or to maintain loyalty and respect for his firm, all of which are necessary for success.

A creamery is at times during the winter season short of butter for its regular customers. If it is marketing its butter under a certain brand which has been advertised in a way to lead the consumer or dealer to think that butter sold under that brand is manufactured by the creamery, then it would be inconsistent and unfair to the purchaser for that creamery to buy butter from other factories and sell it under its own brand. Such a procedure would make the purchaser feel that he had not been fairly treated, and it would furthermore lower the value of a trade-mark which had perhaps cost much to advertise and establish. When such a shortage occurs it would be more satisfactory if the creamery had a second established brand to be used more or less during the entire season. This brand of butter would be sold to merchants with the distinct understanding that some of it or perhaps all of it is not manufactured in the home institution. By being careful about the quality of such goods and by properly advertising same, the merchants may be willing to sell the two brands during the winter season. The disadvantages of that system will be more than overcome by the consequent assurance which the purchaser will have of the manufacturer's honesty.

It is usually understood between the salesman and the buyer what size and kind of package is to be used as well as what time the shipment is to be made. Is is of greatest importance that such agreements are complied with, inasmuch as dairy products are perishable and must be kept under refrigera- 
tion. The dealer always prefers a package of such size as will be most convenient for the refrigerator, and as he prefers to handle fresh goods he will naturally expect the goods to arrive at definite times.

The invoice, together with the bill of lading, should also be sent by the first mail leaving after the shipment has been made. Some factories put the invoice in an envolope in the package, but it is safest and more in accordance with business custom to send it through the mail. As butter fluctuates in value it is of importance that the dealer receives the invoice so that he may know the value of the goods before he sells them.

3. He Should be in Close Touch with His Salesman and $H$ is Customers. - He should receive daily reports from his salesman and should write him daily. He should always write encouraging letters and not find fault with the salesman, for there is nothing which will have a more depressing effect on a salesman than an unkind letter from the home office. If the manager has no helpful information or some word of encouragement to send his salesman, then it is advisable to save the time and expense of writing. The manager can well afford to keep in close touch with his customers and it should be well worth his while to write to them at times, if only for the sake of thanking them for their business or perhaps at times advising them when the salesman will call. Copies of such letters should be forwarded to the salesman.

\section{B. METHODS OF MARKETING}

The method of marketing should be determined: First, by the nature of the business. A market milk plant will naturally dispose of its products locally; the same is true to some extent if the product to be sold is ice cream. Soft cheese is also a product which is too perishable to be shipped great distances, whereas cheese, properly ripened and of a firm body, and butter may be shipped to any part of the globe. Second, by the location of the manufacturing establishment. A creamery located in the country lacks transportation facilities for marketing in 
smaller quantities and can usually market greater quantities to best advantage. A creamery located close to a railway station may be able to market its output in smaller lots to advantage. Third, by the quantity of finished products to be sold and the prices obtained from the various sources. Some small creameries have been able to turn their entire output over to large dealers, obtaining as much therefore as could be obtained through a market of a more local character, and thus saving the cost of establishing a special market which would necessitate the keeping of additional records and increase losses due to bad accounts. Fourth, by the business experience of the manager. If he has no experience in marketing, in keeping a systematic set of records, or in collecting accounts, then the simplest method of selling the product may be the most profitable.

I. Selling Direct to the Consumer. - This system of marketing is practiced to only a limited extent as it is a more cumbersome method of establishing a market; the cost of selling is higher and the credit risk becomes greater. Moreover, the manufacturer as a rule is a poor retail salesman and lacks the connection with the consumers which has been established by a regular retail dealer such as the grocer. The retail business cannot be eliminated entirely. The milk and cream patrons deliver the raw product at the creamery and often take butter, cheese, or ice cream as part payment. In some towns it may seem advisable to cater more or less to retail customers, especially if ice cream is manufactured. The market milk plant will naturally dispose of the greater amount of its output to the consumer direct.

II. Marketing Through Retail Establishments. - The retailer is dealing with the consumer direct. It is his business to cater to the wants of the consumer and he becomes a specialist along that line. A retailer, such as the grocer, handles numerous lines of goods and will usually make deliveries to the consumers at frequent intervals. He will therefore be able to sell at retail and deliver such products as butter and cheese at less cost than can the factory operator. Ice cream, due to its perishability, is usually marketed from the factory direct to the 
'consumer but at a high marketing cost. Milk and sweet cream are delivered from the central milk plant to the consumer at a reasonable cost as they are delivered to regular customers at regular intervals, and routes for economic distribution of such products are readily established.

1. Selling to Local Retailers. - The local market claims several advantages: First, it saves in transportation expenses and thereby either reduces the cost to the consumers or increases the profits of the local dealers. Second, it educates the people to demand a product of higher quality, as a perishable product usually appeals most favorably to our sense of taste while it is fresh, and often creamery butter sold in a town will take the place of farm butter which is commonly of inferior quality. Third, the consumers' demand for better quality results in no call for the poorer grades of farm butter. The cream which was formerly converted into farm butter will be sold to the creamery, giving the farmer a more satisfactory return and enabling the creamery to reduce its operating expenses per pound of butter manufactured. Fourth, it is of advertising value to the creamery to have its products sold by all local dealers.

If the creamery is located in a city it is often most satisfactory to establish regular routes and have a wagon call and deliver goods to retail dealers at regular intervals. Such a system is very satisfactory when handling butter and cheese. The same wagon might also deliver eggs if they are handled by the firm. This wagon driver becomes a salesman for his firm, and soliciting of new trade and keeping customers pleased are, to a certain extent, left to him. The manager should always keep himself posted on the condition of the business on each route. It is convenient for him to have a map of the city in his office on which the routes are shown. All dealers may be indicated on the map by colored pins or pegs. Prospective customers may be indicated by black pegs, active customers by white-colored pegs, etc. It may be advisable also to have colors indicating the nature of the business of the retailer so as to know whether he operates a grocery, a confectionery, or a drug store. After 
the driver has completed his day's work and returns to the creamery he should report to the manager and consult with him in reference to the business for the following day.

The drivers may be employed under different agreements. Some are employed as day laborers, but it is perhaps most common to employ them at a small monthly salary with an additional premium based on their sales. The cost of selling butter and cheese by this system can be estimated at from a half cent to one cent per pound, including both salary of driver and cost of maintaining delivery outfit and paying depreciation and interest on the investment.

Cream, milk, and ice cream are disposed of differently. Regular delivery routes are established for the delivery of milk and cream if sold at retail. The driver may or may not act as a solicitor. Some prefer to send an experienced salesman out from the office for the purpose of soliciting and organizing the routes and the driver is then merely delivering the products in accordance with his route list prepared for him.

2. Selling to Retailers More Distantly Located. - A campaign for such sales may be carried on in two different ways. First, the salesman may solicit all or part of the merchants in a certain town, and second, the salesman may select only one merchant out of a number, and offer him exclusive agency for the goods. The first method is most satisfactory in the home town, where it is comparatively easy and inexpensive to keep in touch with the various dealers. It is far more difficult and more expensive to keep in touch with the dealers in more distant towns, and for that reason the second method may there have some advantages.

The principal advantages in giving a merchant in an outside town exclusive agency are: First, the buyer takes greater interest in handling the goods. It will be to his advantage to handle a line not handled by his competitor if the goods are of high quality. It will therefore be easier to secure a customer under such conditions and he will remain more loyal to the company. Second, the retailer will be willing to advertise the goods and the manufacturer thus saves that expense. It will be 
the object of the retailer to increase the sale of such goods to the fullest extent, as he considers that he is advertising his own goods when advertising a line on which he holds exclusive agency.

The disadvantage of this system is that one merchant in a town will not sell as much as would be sold if several were handling a line. If the sentiment among several dealers is favorable to handling a particular line of goods then the exclusive agency plan will not be the most desirable. It is seldom advisable to give exclusive agency to only one merchant in a large city, because it is usually possible to select dealers in different parts of the city so located that one does not interfere with the business of the other.

III. Marketing Through the Commission and Wholesale House. -

1. The Commission Merchant. - The commission merchant does not buy goods from the manufacturer, but receives them on consignment and acts as an agent for the manufacturer and charges a fixed per cent for his commission. The usual rate of commission charged for selling butter is 5 per cent of the selling price. The commission merchant sells to the retailer direct, but also to the wholesaler. The commission merchant serves mostly the smaller manufacturers, and this system of marketing butter and cheese has been rather generally adopted. The system has not proven entirely satisfactory, however, as it has often led to misunderstanding between the manufacturer and the dealer. Therefore many dealers are now buying the products outright from the manufacturers and they thus become wholesale buyers.

2. The Broker. - The broker is a dealer who, like the commission merchant, does not purchase the goods which he handles. He usually represents the purchaser, although he often represents the seller. He has no warehouse and as a rule maintains only an office. He sells mostly in car lots and usually direct to the jobbers or wholesalers.

3. The Wholesale Dealer or Jobber. - The wholesaler buys the goods outright from the manufacturer, commission mer- 
chant, or broker and sells to the retailer. As already stated, the creameries and cheese factories sell more of their products outright at wholesale than on consignment.

IV. Marketing Through a Coöperative Selling Agency. A coöperative selling agency may be organized by manufacturers for the purpose of marketing their own products. The cost of operating the agency is borne by all its members in proportion to the amount of money obtained for goods sold through the association. Several coöperative selling agencies have been organized in the United States for the marketing of cheese, and in Europe many associations have also been organized for the marketing of butter. This has not, up to the present time, been regarded with favor in the United States, although Minnesota reports some work along that line.

Theoretically the coöperative selling agency should be encouraged, for it reduces the number of middlemen. The first difficulty that such organizations experience is lack of capital and for that reason the patrons of the creamery become discouraged, as their money is not forthcoming as soon as expected. This delay may be further increased, because the agency, when starting, has not as ready an outlet for its goods as the older and better established firms; therefore the new agency is often compelled to allow butter to accumulate in the warehouse. Such conditions will prevail until it is able to establish a satisfactory outlet for its goods; for that reason such an institution may not always, during the early part of its existence, be in a position to return a satisfactory price to the manufacturers.

The success of the coöperative selling agency depends much on the ability of its manager and directors. As the board of directors is elected, it may be criticized as lacking in stability when conparing it with an old-established and well-managed business concern. If a capable manager were secured with the understanding that he would remain permanently if he produced results and if the board of directors were also elected with the view of efficiency, then a coöperative selling agency should be a profitable investment to all interested.

The coöperative retail milk distributing association is an 
organization of milk producers organized for the purpose of selling and distributing the milk produced from their own herds. This may become a prominent organization in the near future. Under the old milk distributing system a number of small dealers deliver milk in the same city; frequently several of them will deliver through the same streets. Much unnecessary time and labor would be saved if the producers or small dealers would deliver their milk to a central plant from which it could be distributed throughout the city by one set of wagons. This system would furthermore have the advantage that the milk could be pasteurized before delivery and that an expert in charge of such a plant could guard against receiving of milk which was not suitable for human consumption. As a result the market milk of the city would often be much improved.

The municipal market milk plant is a plant owned and operated by the city for the purpose of buying the milk at wholesale from the producers and selling and distributing same among the consumers of the city. This plant has, the same as the former, been organized for the purpose of eliminating unnecessary expenses. It may be considered to be a valuable institution for a city where the producers are not inclined to coöperate.

\section{OFFICE RECORDS}

\section{Record of Active, Prospective, and Discontinued Cus-} tomers.--Records of out-of-town business are most readily kept by using a map of the territory and a card file. Differently colored pegs or pins may be used to indicate customers on the map, the same as outlined for city sales. The card files may be divided into active customers, prospective customers, and discontinued customers. These may again be subdivided geographically according to counties, towns, or any other system of division. The geographic divisions may come in alphabetical or numerical order, and finally the individuals or firms may be filed alphabetically under each geographical division.

For example, if the record of a certain territory is filed according to towns, then the main division of the file would 
be arranged with town names coming alphabetically. If Alta were the first town coming in the order stated, Boone the second, Colo the third, etc., then the names of the customers (active, prospective, or discontinued) would follow alphabetically after the town index. The territory might conveniently be divided into sub-territories known by numbers instead of by names. If such a division is adopted then the cards will follow in numerical order.

The card files are kept for the purpose of furnishing brief information about correspondence, agreements, or other facts to which it is desirable to refer without having to read through a mass of correspondence and records. A firm may write a circular letter to prospective customers. A notation thereof is made on a card; no answer may be received, and a second circular letter is written, which is again noted, etc. A notation is also made if a reply is obtained. Further reference may be made to any particular letter which is of special importance, etc. This card, in short, contains a brief summary of what the company knows about a certain firm or individual.

FORM XX

Report Card on Prospective Customers

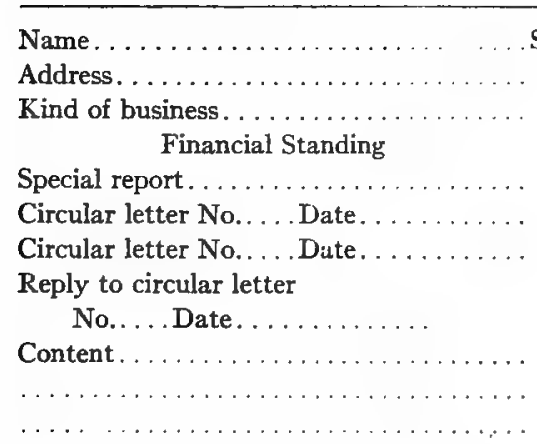

A letter should be written or preferably a personal call should be made immediately after it has been discovered that a customer has discontinued to buy goods. The longer two 
firms do business together the more intimate their business relationship should be, and it will therefore become more diffcult to retain the customer the longer he continues in his business relationship with the other firm.

II. Sales Records. - No goods should be delivered for sale from the factory stock room or refrigerator unless a proper record is made thereof. An order should be made out before the goods are delivered. (Form XXI.) Such an order is usually written in the offce. It is made out in triplicate and on three colors of paper. The original, which may be on white paper, is kept in the office. The second sheet may be of pink color and the third sheet yellow. Both the second and third sheets are turned over to the purchaser, who presents to the stock clerk the second slip as his order for the goods. No goods should be delivered on the third slip, as this is merely intended as a memorandum to be kept by the purchaser. If order blanks are used they should be numbered consecutively in triplicate by the printer, the three constituting a set bearing the same number. This is done so that possible errors may more readily be found.

FORM XXI

SALES TICKET

Sold to

M

\begin{tabular}{l|l|l||l}
\hline Weight & \multicolumn{1}{|c|}{ Articles } & Price & Amount \\
\hline & $\begin{array}{l}\text { BUTTER } \\
\text { CHEESE } \\
\text { MILK } \\
\text { CREAM }\end{array}$ & \\
& & \\
& & \\
\hline
\end{tabular}

Received the Above

N. B. If cash is paid at creamery it must be writen across the face. 


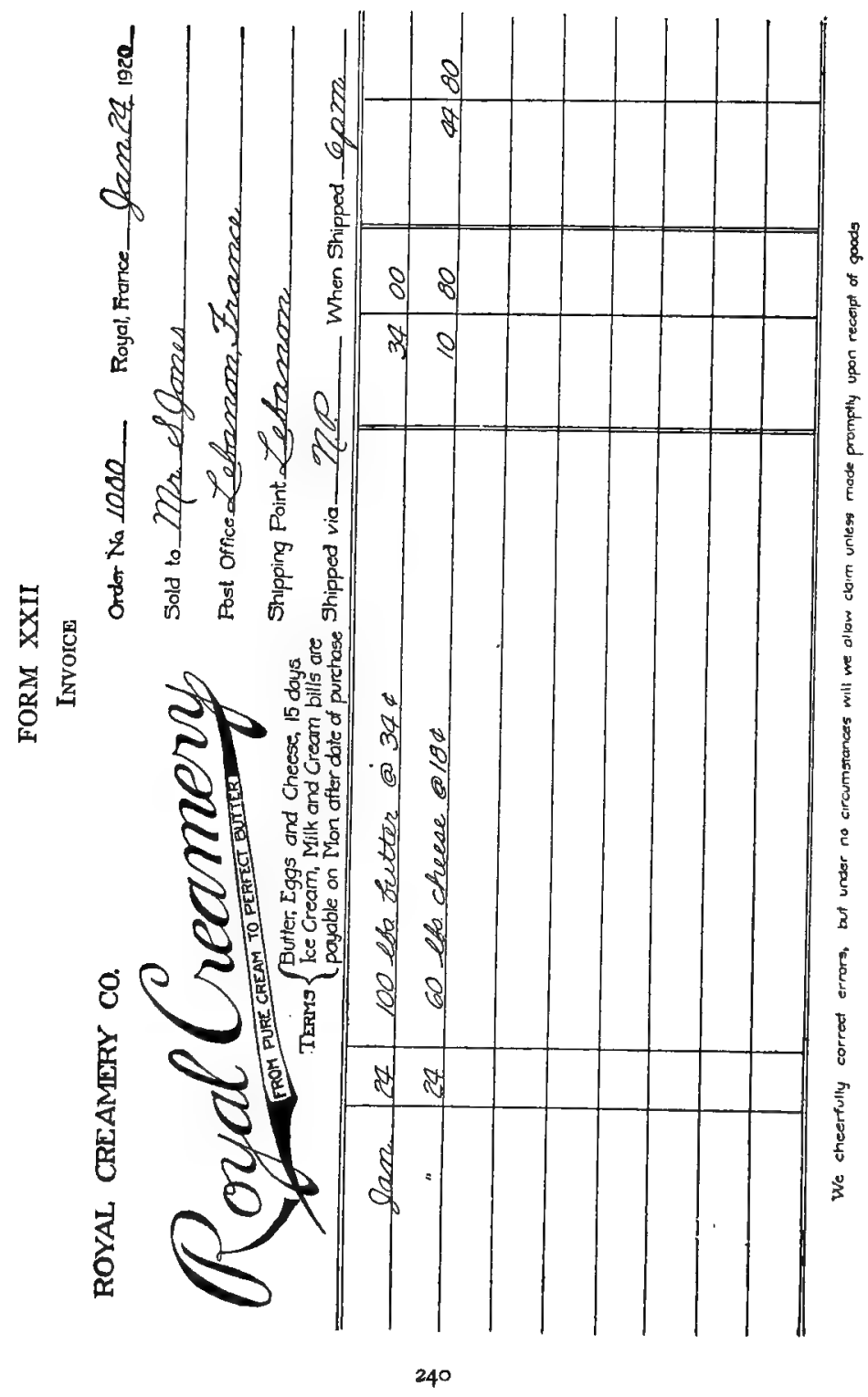


FORM XXIII

COUNTRY DEPARTMENT

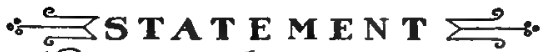

Poyal, France, fan 24, 1920

ins do Oones

Letramon. France

In Account with

MANUFACTURERS OF AND DEALERS IN

BUTTER, EGGS, CHEESE, CREAM.

BUTTERMILK, ICE CREAM, MILK.

Browne St and Pacific Ave.

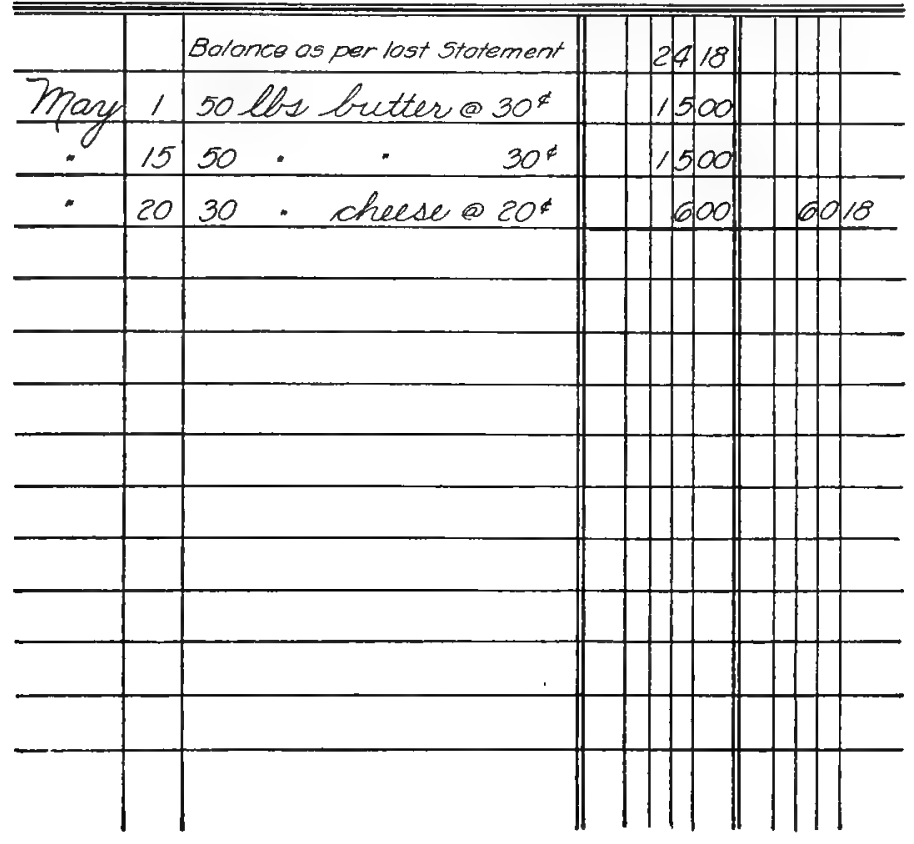


While the purchaser in the home town usually receives the sales slip as a memorandum, this is replaced by the common form of invoice (Form XXII), when goods are shipped to outof-town customers. Bills (Form XXIII) are mailed to the customer monthly or as often as collections are made.

Patrons buying butter from the creamery are usually furnished with a special order blank (Form XXIV). This is made out by the patron in duplicate unless it is made out with a stub which is retained by the patron as a memorandum. One is presented to the creamery while the duplicate is retained by the patron as a memorandum.

FORM XXIV

Patrons' Sales 'Ticket

No.........

.lbs. Butter

lbs. Cheese

........ qts. Ice Cream

No...... Cola, Iowa,................

Farmers' Co-operative Creamery,

Please deliver to bearer and charge to my account:

Amount, $\$$

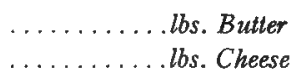

........... qls. Ice Cream

Date. .

Name of Patron

Address

Commission sales may cause some difficulty to the accountant from the fact that remittance is made later and there is usually some shrinkage in weight from the time the butter leaves the creamery until it is sold. The price is also likely to change. The author has found it most satisfactory to make a sale slip for such shipment the same as for butter sold locally, figuring actual weight the day of shipping and calculating the value on the same basis as that of butter sold to local merchants. At the same time this entry is made on the sales record, another entry is made in a book ruled similar to Form XXV. 
FORM XXV

RECORD OT CONSTGNMENTS

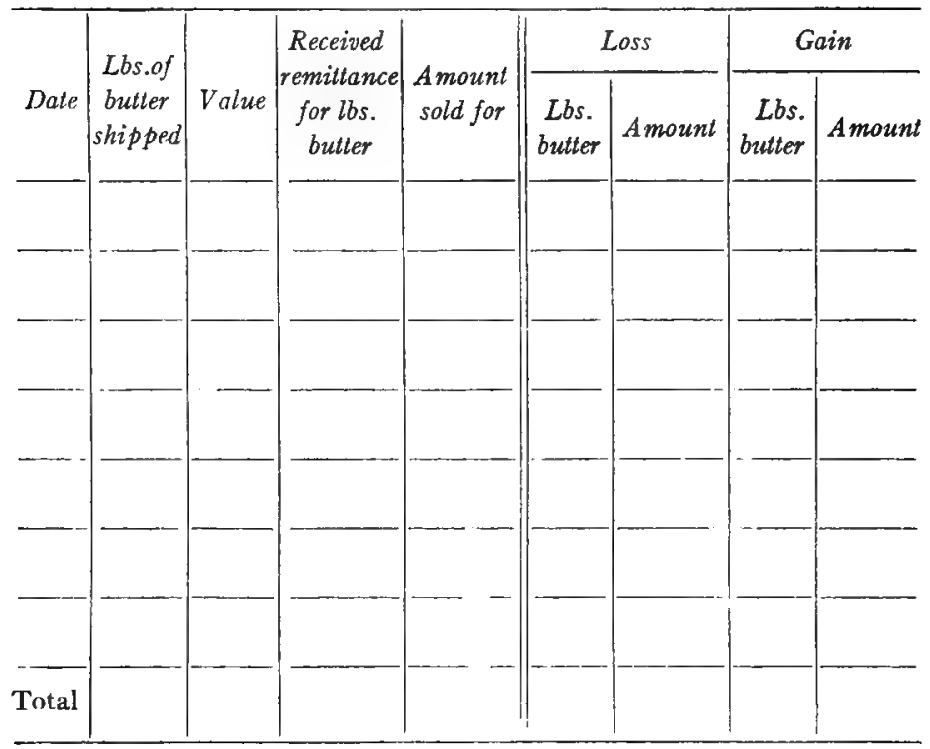

Entry is made on Form XXV when remittance has been received. This record is of value to the creamery, also, for the purpose of checking gain or loss sustained by disposing of the butter on a commission basis.

Goods delivered in the city by drivers should be checked out when loaded on to the wagon. The amount returned is checked back and returned to stock. The difference between the amount taken out and that returned should be accounted for by the driver as sales. The driver, who acts as salesman records the sale in duplicate on a sales slip (Form XXI). He keeps the original while the duplicate is turned over to the purchaser. The sales ticket should be signed by the purchaser if the goods are charged. The word Cash should be written across the face of it if the driver receives cash for what 
he sells. The driver upon his return to the creamery will turn in cash, charge sales tickets, or goods to the amount delivered to him.

Milk and cream sold at retail are often sold for tickets, the driver carrying a supply of tickets with him. The customers may pay cash for such tickets or they may be charged. A record is kept in the office of the tickets turned over to the driver and he is held responsible for them, and is required to return money, tickets, or charge-sales slip with signature of the purchaser.

Ice cream is ordered through the office and delivery made in accordance with such order. It facilitates delivery, reduces the cost, and is more satisfactory to the customers if deliveries are rnade at definite times known to the customers. A route sheet (Form XXVI) is furnished each driver before starting on his route in order that he may avoid making unnecessary drives. This sheet also has blank spaces for signatures of the customers.

FORM XXVI

ROUTE SHEET

\begin{tabular}{c|c|c|c}
\hline Name & Address & Goods purchased & $\begin{array}{c}\text { Signature of } \\
\text { purchaser }\end{array}$ \\
\hline A. Jones & 27 Ash St. & 3 qt. van. & A. Jones \\
\hline P. Simons & 4th and Clay & I qt. ice cream & P. Simons \\
\hline A. Johanson & 203 Burnside & I gal. chocolate & A. Johanson \\
\hline & & & \\
\hline & & & \\
\hline
\end{tabular}




\section{CHAPTER XIX}

\section{COST OF MARKETING DAIRY PRODUCTS}

THE principal factors affecting the cost of marketing a commodity are, according to Professor L. D. H. Weld, ${ }^{1}$ as follows:

First, Perishability, overcome in the case of some commodities by the possibilities of cold storage.

Second, Shrinkage in transit, storage, preparation for market etc.

Third, Regularity or irregularity of production throughout the year.

Fourth, Possibility of grading into definite and widely accepted market classes or grades.

Fifth, Volume in which commodity is handled.

Sixth, The relation between the bulk of a commodity and its intrinsic value, on which depends the importance of transportation as a factor in the cost of marketing.

1 The Marketing of Butter. Address before the Marketing Conference, Chicago, October 29, I9I4. 


\section{A. COST OF MARKETING BUTTER}

Creamery butter is generally sold on the markets according to quality under the following grades. "Higher scoring lots, Extras, Extra Firsts, Firsts, and Seconds." A comparison is presented in Table XIX ${ }^{1}$ of the official creamery-butter grades of different wholesale trade organizations.

\section{TABLE XIX}

Comparison of the Official Creamery Butter Grades of Different Wholesale Trade Organizations

\begin{tabular}{|c|c|c|c|c|c|c|}
\hline \multirow[b]{2}{*}{ Grade } & \multicolumn{6}{|c|}{ Scores Required for Different Grades * } \\
\hline & Boston & Chicago & Elgin & New Iork ${ }^{2}$ & $\begin{array}{c}\text { Philadel } \\
\text { phia }\end{array}$ & $\begin{array}{c}\text { San Fran } \\
\text { cisco }\end{array}$ \\
\hline Specials. & & & & $93+$ & $\cdots$ & \\
\hline Extras.... & $93+$ & $93+$ & $93+$ & 92 & $9 \mathrm{It}$ & $93+$ \\
\hline Extra First. & 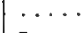 & $91-92$ & & & & ${ }^{3} 90-92$ \\
\hline Firsts.... & $87-92$ & $87-9 I$ & . & $88-9 \mathrm{I}$ & $87-89$ & $87-89$ \\
\hline Seconds. & $80-86$ & $50-90$ & & $83-87$ & $80-88$ & $80-89$ \\
\hline Thirds... & $75^{-85}$ & $75-89$ & & $76-82$ & $75-89$ & $70-76$ \\
\hline
\end{tabular}

- The plus sign $(+)$ indicates that higher scores are included.

${ }^{1}$ U. S. Dep. of Agriculture, Bul. 682, I918.

2 At the discretion of a "Butter Committee" the scores required for various grades in the New York market are subject to change.

Prime firsts. 
The price of butter is regulated by supply and demand. Butter is marketed on a comparatively small margin. According to Weld the Minnesota creameries receive a net price of about two cents less than the New York quotation. The commission of 5 per cent for selling, plus the freight to New York, will amount to between two and three cents per pound for Minnesota and Iowa creameries. Adding this to the net price obtained by the creamery gives the wholesale price of the butter in New York which, in this case, means that the Minnesota butter is sold in New York at a fraction of a cent above New York quotations. The cost of marketing Kansas butter is explained by Macklin, ${ }^{1}$ (Table XVII) and the cost of marketing Wisconsin butter is presented by Hibbard and Hobson in Table XVII.

Due to the fact that butter is handled on a small margin, it becomes more difficult for the smaller. creameries to eliminate the middleman or commission merchant. The larger creameries most often find it to their advantage to establish their own special markets. Some have a special marketing department, the butter being turned over to that department from the factory at a definite price. The marketing department here also stands as the middleman between the factory and the retail dealer, and all expenses in connection with selling are charged against that department.

The retail price of butter varies in different cities. The charges for handling a pound of butter range from about three cents to seven cents. Five cents may be considered an average. This is a reasonable margin for handling butter, as it has to be held under refrigeration and delivered to the consumer.

The amount paid by retailers and consumers above highest New York quotations for Extras is presented by Warber? in Table XX. The same investigator also found that branded butter allows a greater margin than butter which is not branded (Table XXI). By this is not necessarily understood that

'Bulletin No. 216, Kansas Experiment Station, 1917.

2 U. S. Dep. of Agriculture, Bul. 682, 1918. 
branded butter yields a greater profit to the dealer, although it is generally considered that it does, but there are additional expenses connected with the branding of butter, such as special packages, advertising, etc., all of which will naturally increase the margin. 


\section{TABLE XX}

A Comparison of Prices at which Different Grades of Butter and Butter Substttutes were sold in New York, Philadelpaia, Chicago, St. Paul, and Minneapolis

[Prices are expressed in margins of differences between highest New York quotations for Extras and the prices actually paid by retailers and consumers]

\begin{tabular}{|c|c|c|c|c|c|c|c|c|}
\hline \multirow{3}{*}{ Kind or grade } & \multicolumn{4}{|c|}{ New York } & \multicolumn{4}{|c|}{ Philadel phia } \\
\hline & \multirow{2}{*}{$\left|\begin{array}{c}\text { Number } \\
\text { of lots } \\
\text { in- } \\
\text { spected }\end{array}\right|$} & \multicolumn{2}{|c|}{$\begin{array}{c}\text { Average price } \\
\text { paid above or } \\
\text { below } N . Y . \\
\text { Extras }\end{array}$} & \multirow{2}{*}{$\begin{array}{c}\text { A verage } \\
\text { margin } \\
\text { of } \\
\text { profit }\end{array}$} & \multirow{2}{*}{$\begin{array}{c}\text { Number } \\
\text { of lois } \\
\text { in- } \\
\text { spected }\end{array}$} & \multicolumn{2}{|c|}{$\begin{array}{c}\text { Average price } \\
\text { paid above or } \\
\text { below } N . Y . \\
\text { Extras }\end{array}$} & \multirow{2}{*}{$\begin{array}{c}\text { Azerage } \\
\text { margin } \\
\text { of } \\
\text { profit }\end{array}$} \\
\hline & & $\begin{array}{c}\text { By re- } \\
\text { tailer }\end{array}$ & $\begin{array}{l}\text { By con- } \\
\text { sumer }\end{array}$ & & & $\left|\begin{array}{l}\text { By re- } \\
\text { tailer }\end{array}\right|$ & $\left|\begin{array}{l}\text { by con- } \\
\text { sumer }\end{array}\right|$ & \\
\hline & & Cents & Cents & Cents & & Cents & Cents & Cents \\
\hline Extras. & 54 & 3.8 & $9 . \mathbf{I}$ & $5 \cdot 2$ & 35 & $5 \cdot 4$ & II. 2 & 6.6 \\
\hline Firsts... & 80 & 2.6 & 6.6 & $4 \cdot 3$ & 35 & 3.7 & 8.8 & 6.1 \\
\hline Seconds..... & 28 & 1.0 & $3 \cdot 9$ & 3.8 & 24 & .4 & 2.3 & 5.0 \\
\hline Special brands & 23 & I5.4 & 21.9 & 6.5 & 34 & 14.2 & 23.6 & 6.9 \\
\hline Unclassed. . & 8 & 2.9 & 6.9 & 4.6 & 9 & 3.8 & $9 \cdot 3$ & $7 \cdot 1$ \\
\hline Totals & 193 & 3.6 & 8.0 & $4 \cdot 7$ & 137 & 7.2 & II.9 & 6.0 \\
\hline \multirow[t]{2}{*}{$\begin{array}{l}\text { Process. ......... } \\
\text { Oleomargarine. . . }\end{array}$} & $\begin{array}{r}5 \\
12\end{array}$ & $\begin{array}{l}-4.4 \\
-12.6\end{array}$ & -6.7 & $\begin{array}{l}4 \cdot 7 \\
5.8 \\
\end{array}$ & 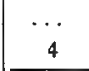 & $\begin{array}{r}\cdots \\
\text { - II. } 5 \\
\end{array}$ & $\ddot{6.9}$ & $\ddot{6.1}$ \\
\hline & \multicolumn{4}{|c|}{ Chicago } & \multicolumn{4}{|c|}{ Minneapolis and St.Paul } \\
\hline Extras......... & 14 & $1 . I$ & 3.0 & $4 \cdot 5$ & 37 & 1.3 & 6.4 & $5 \cdot 4$ \\
\hline Firsts.... . & 159 & .3 & 3.9 & $3 \cdot 5$ & 219 & $-\quad .8$ & $4 \cdot 5$ & 4.8 \\
\hline Seconds. . & I07 & $-\quad .5$ & I. 9 & $3 \cdot 3$ & 70 & -3.2 & I. 6 & $4 \cdot 5$ \\
\hline Unclassed. & 24 & 一 .3 & 3.3 & 3.4 & 39 & -1.7 & 4.4 & $5 \cdot 4$ \\
\hline Totals .... & 213 & +.05 & 3.0 & 3.9 & 365 & $-\mathrm{I} \cdot \mathrm{I4}$ & 4.12 & 4.86 \\
\hline $\begin{array}{l}\text { Process. . . . . . . . } \\
\text { Oleomargarine. . . }\end{array}$ & 4 & $-7 \cdot 1$ & $\cdots$ & $\cdots$ & 2 & -6.9 & $-\mathbf{1} \cdot 9$ & 5.0 \\
\hline Oleomargarine. & 56 & -12.8 & $\cdots \cdots$ & $\cdots$ & 26 & $|-14.4|$ & -8.9 & 5.2 \\
\hline
\end{tabular}


TABLE XXI

Comparison of Quality (Average Score) and Average Retail Price of BRANDED AND UNBRANDED BUTTER

[Retail prices expressed in margins between prices paid and local quotations for Extras]

\begin{tabular}{|c|c|c|c|c|c|c|}
\hline \multirow{2}{*}{ Market } & \multicolumn{3}{|c|}{ Branded lots } & \multicolumn{3}{|c|}{ Unbranded lots } \\
\hline & $\begin{array}{c}\text { Number } \\
\text { of lots }\end{array}$ & $\begin{array}{c}\text { Average } \\
\text { score }\end{array}$ & $\begin{array}{l}\text { Price } \\
\text { margin }\end{array}$ & $\begin{array}{c}\text { Number } \\
\text { of lots }\end{array}$ & $\begin{array}{l}\text { Average } \\
\text { score }\end{array}$ & $\begin{array}{l}\text { Price } \\
\text { margin }\end{array}$ \\
\hline New York. & 60 & $9 \pi .2$ & $\begin{array}{c}\text { Cents } \\
\text { II I I }\end{array}$ & 122 & 89.8 & $\begin{array}{c}\text { Cents } \\
8.83\end{array}$ \\
\hline Philadelphia. & 80 & 90.8 & II.6 & $2 \mathrm{I}$ & 90.7 & 9.02 \\
\hline Chicago. . & I6I & 89.6 & 6. I & 68 & 88.7 & $4 \cdot 7$ \\
\hline St. Paul and Minneapolis.. & 230 & $89 \cdot 3$ & $5 \cdot 18$ & 37 & 89.7 & 5.06 \\
\hline
\end{tabular}

The production of American butter is not uniform in quantity during the year, for that reason it becomes necessary to store some of the butter that is produced at the time when the production is the largest. About three-quarters of the holdings in the cold storage warehouses are stored during the months of June and July. Bell and Franklin ' (Fig. 26) found that the cold storage ware houses contained the most butter in September, after which it was reduced until it contained the least in May.

It has become possible by storing butter to stabilize the prices somewhat, moreover, it provides a supply in the season when the production is below the demand. Storing of butter will naturally increase the cost of marketing as it involves special expenses such as storage charges, interest on the investment, insurance, and shrinkage.

. U. S. Dep. of Agriculture, Bul. 709, 1918. 
COST OF MARKETING DAIRY PRODUCTS

COLD STORAGE HOLDINGS

OF

CREA IERY BUI IER

Complled from the reports of the assoclated warehouses. Based on the average holdings of the years 1907 to 1916 inclusive.

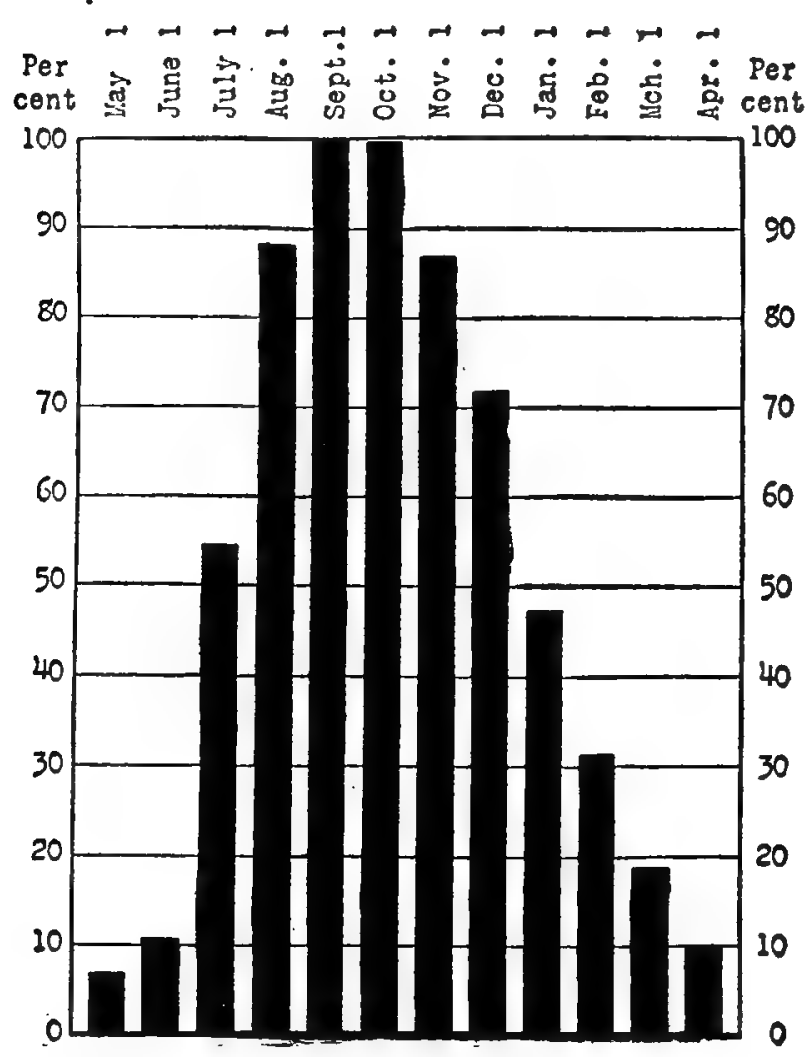

FIG. 26. 


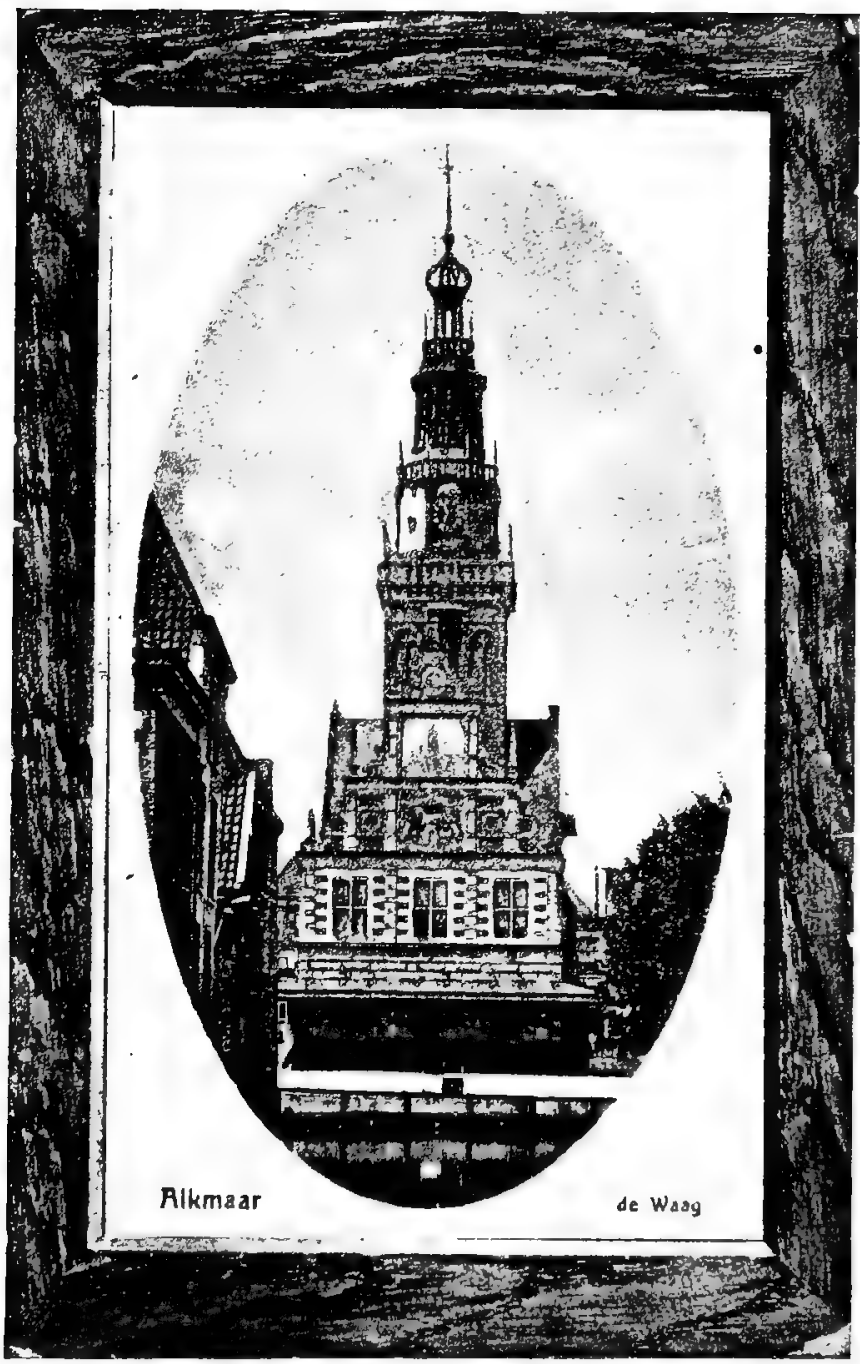

FIG. 27. - Public weigh-house, Alkmar, Holland. 


\section{B. COST OF MARKETING CHEESE}

It is thought that the middleman can be traced further back in the marketing of cheese than in the marketing of any other dairy product. It was through the efforts of the middlemen that Holland cheese became a noted food product in all parts of the world centuries ago. A Dane, Otto Lemwigh, wrote in I79I ${ }^{1}$ that in Holland cheese was considered as one of their most important products of commerce and that it was being sold at fabulous prices in all parts of the world. The public weigh-house used for weighing the cheese sold on the market at Alkmaar, Holland, was built in 1582 . The Alkmaar cheese market in Holland is one of the oldest and to-day the most important cheese market in that country. It is held weekly each Friday forenoon. The cheese is brought in by farmers and manufacturers and is spread out on the big market square. The cheese dealers appear and the buying begins. The cheese is bought mostly by dealers who remove it to their warehouses fro.n which it is shipped to all parts of the world.

The cheese industry in this country has been confined to a comparatively small territory. Wisconsin claims at present to be manufacturing close to 50 per cent of the total amount produced in the United States. ${ }^{2}$ In accordance with Taylor, Schoenfeld, and Wehrwein ${ }^{3}$ there were in I912 eight dairy boards in Wisconsin. Part of the Wisconsin cheese is offered for sale on the board, but the greater portion of the cheese manufactured in the United States is sold on contracts which are more or less binding. Often the dealers find it necessary to keep a number of traveling men in the field buying up the cheese from the manufacturers, a limited amount of cheese being sold on a commission basis.

Cheese is generally handled by three middlemen and the transportation company. The cost of marketing Wisconsin cheese is as follows: The dealer charges from $3 / 4$ to I I/ 2 cents

1 Professor Bernhard Boeggild in "Maelkeribruget" i Fremmede Lande, I897.

2 Wisconsin Bulletin 251, by Hibbard and Hobson, r9r5.

3 Wisconsin Bulletin 231, 1913. 
per pound, the wholesale grocer from $1 / 4$ to 3 cents and the retail grocers from 3 to 5 cents per pound, and the transportation company obtains from $\mathrm{I} / 4$ to $2 \mathrm{I} / 2$ cents per pound.

Hibbard and Hobson ${ }^{2}$ estimate that the farmer receives about half of the money paid by consumers for cheese. The other half of the consumers' price is divided among the middlemen, the retailer getting about as much as the others. The amount of money obtained by the middlemen should not be considered entirely as profit. The various operations in the dealers' warehouse cannot be carried on for less than $1 / 4$ cent per pound. The dealer pays the freight, paraffins the cheese, which costs about $\mathbf{I} / 8$ cent per pound, puts it into the car to be shipped, pays office expenses, insurance, interest, etc., and storage if the cheese has to be stored, which usually costs $\mathrm{I} / 8$ cent per pound for a month or less and from $3 / 8$ to $\mathrm{I} / 2$ cent per pound for three months and up to six months. The dealers estimate that they should realize on the average $5 / 8$ cent on all the cheese they sell (direct and stored) to come out even.

The expense of storing more or less of the cheese cannot be eliminated, as the proportion of cheese made to that sold in each month of the year varies greatly. Figs. 28 and $29^{1}$ illustrate the difference between production and shipments from Wisconsin during the year rgrr. This situation necessitates the storing of at least part of the cheese manufactured.

\section{COST OF MARKETING ICE CREAM}

Ice cream is usually sold by the manufacturer direct to the retailer. The costs of marketing are therefore quite readily determined, as the middlemen are practically eliminated.

I. Cost of Shipping. - The distance for shipping ice cream is rather limited because the product is perishable and the cost of transportation heavy. A shipping distance of 200 miles may well be considered as the limit, for if shipped any greater distance the cost and the inconvenience of repacking is involved, and the cost of transportation is increased to such an extent

' Bulletin 231, Wisconsin Experiment Station, 1913. 


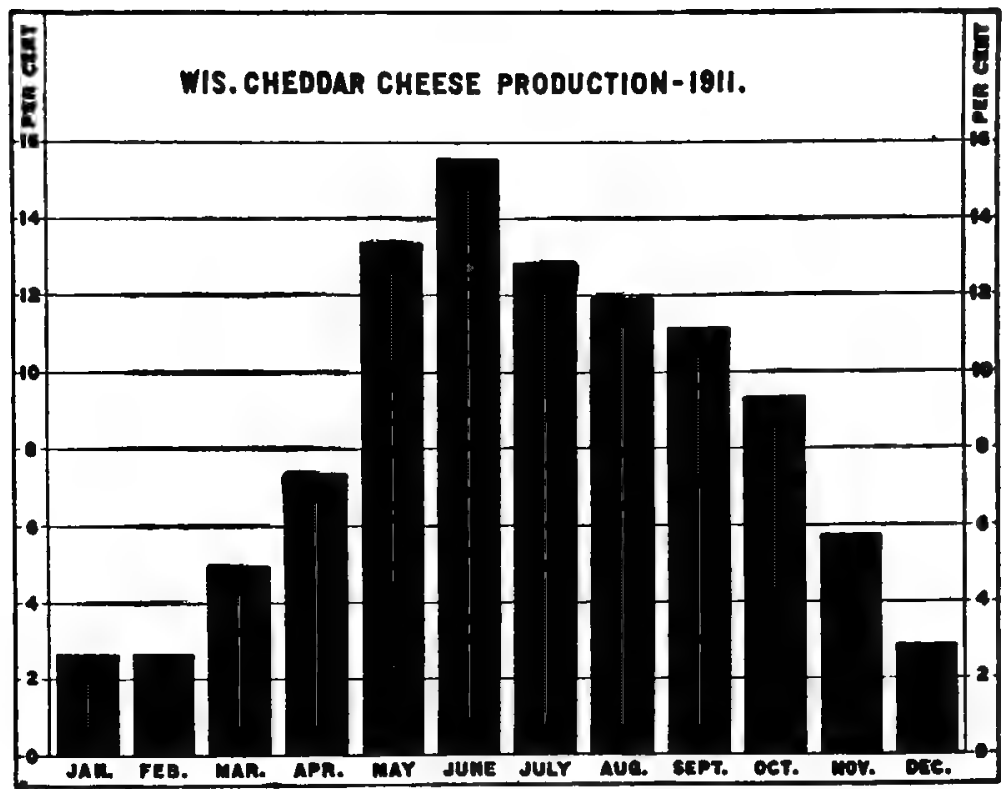

FIG. 28

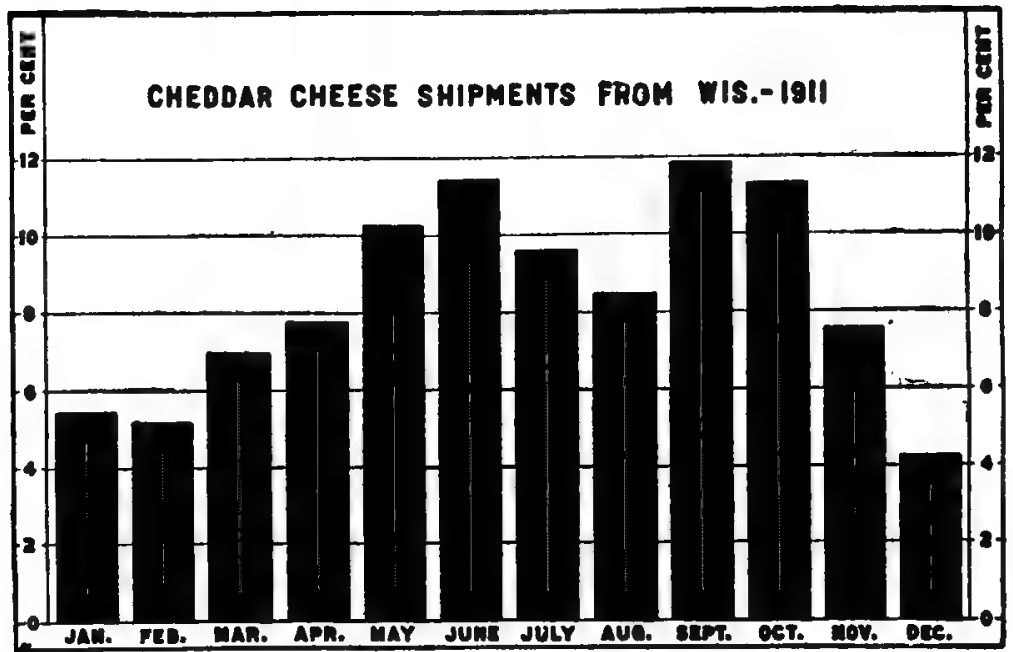

FIG. 29 
that it will not be possible to sell it in competition with the ice cream produced in factories closer by.

The following is the rate of charges made by an express company on five gallons of ice cream on its lines through the state of Iowa in I9i6. To these figures should be added ro or I 5 cents for the return of the empty container.

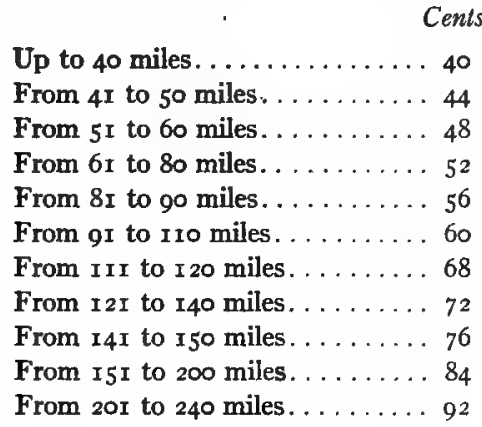

II. Cost of City Delivery. - The cost of city delivery is governed largely by local conditions. Great losses have been sustained by ice cream manufacturers due to an inferior system of city deliveries. Often the city is not properly divided among the various drivers. At times the clerk who makes out the delivery sheet (Form XXVI) is not sufficiently familiar with the city so that he can make out the shortest routing. Some concerns have no definite time for making deliveries, but deliver whenever they have an order and thus several wagons from the same factory may cover the same territory.

Manufacturers engaged in the retail ice cream business usually confine sales to not less than a quart, and the amount ordered is generally delivered by the manufacturer. The cost of making each delivery, including the return of the empty container, often amounts to from Io cents to 15 cents. This additional cost should be added to the price of the first quart, as the following scale of prices will illustrate: $\mathrm{x}$ quart, 60 cents; 2 quarts, $\$ 1.00 ; 3$ quarts, $\$ 1.40 ; 4$ quarts, $\$ 1.80$. 
III. Cost of Re-icing. - The system of re-icing ice cream for the retail dealers was started by some of the larger manufacturers about I904. The object was to systematize thoroughly the method of delivery. A wagon loaded with ice cream, crushed ice, and salt would call at the dealers once or twice daily, delivering ice cream and re-icing cream which was still on hand at the retailer's store. The arguments in favor of this system were, first, the customers would take a larger quantity of ice cream at a time, and as a result special deliveries would be eliminated; second, it would tend to create greater satisfaction among the retail dealers, as they would not have to sustain any loss due to melted ice cream, and to them there was no expense for re-icing. These advantages were soon lost sight of when comparing them with the numerous disadvantages to the manufacturer. First, the retail dealers were willing that the manufacturers should re-ice their cream, but they also demanded that they furnish them with an ice cream cabinet large enough so they could take care of a greater quantity of ice cream - the manufacturers complied with their request; second, some of the smaller dealers would not take ice cream each time when the delivery wagon appeared, but they were always ready to have their ice cream re-iced; the manufacturer had to treat the small dealer the same as the larger dealers. Third, the cost of such a delivery was greatly increased, as it required a heavy team and two men to do the same amount of delivering as was formerly done by a light one-horse delivery and one man. There are places where re-icing may be done to advantage. It has been the general experience, however, that it is a system which is better not introduced unless extra charges are made. It was found by most who tried it that such a business did not return a very satisfactory profit. Some have perhaps correctly considered that this system has resulted in discrimination against the larger purchasers. This is true, inasmuch as the manufacturer operating on this system is often spending on the purchaser of smaller quantities the profit which he makes from the heavier purchaser. This objection does not hold true, however, if the manufacturer charges extra for re-icing. 
IV. Overhead Expenses. - The overhead sales expenses differ greatly in the various ice cream plants and it is impossible to give any figure which would be fair to all. The overhead expenses in the ice cream plant should be carefully looked after perhaps more so in the ice cream plant than in any other dairy establishment.

\section{COST OF MARKETING MILK AND CREAM}

I. Selling Milk and Cream at Retail. - By retail sales is understood sales made directly to the consumers. The principal factors to consider in determining the selling value of milk are:

Purchase cost of milk

Processing and bottling cost

Distributing cost

Loss due to shrinkage and waste at the milk plant

Loss on surplus milk

Loss on bad accounts

Office expenses

Advertising

Interest on investment

Deprecjation

Miscellaneous expenses

The cost of these various items differ greatly in the various milk plants. Such differences may be due to greater or less ability on the part of the manager, size of the city, size of the plant, the relation of investment to size of business, etc.

I. Purchase Cost of Milk. - By purchase cost of milk is understood the cost of milk to the distributor, including the transportation cost to the distributing plant. This cost may fluctuate with the butter market. Some dealers pay the same price during the entire year, while it is perhaps the most common practice for the distributor to have a yearly contract with the producer whereby the latter obtains a price for the year which will change at certain predetermined intervals, so the price paid will to some extent conform to the current butter market. 
2. Processing and Bottling Cost. - This includes cost of putting the milk in shape for marketing, such as clarifying, pasteurizing, cooling, bottling, etc. This cost has been variously estimated at from 0.3 cent to r.o cent per quart.

The labor cost in filling and capping the bottles (Table XXII)1 is determined for 107 plants in six cities and shows that 839 bottles were capped per man per hour; the labor cost per hundred bottles being 2.4 cents; varying from 0.9 to 8.0 cent.

\section{TABLE XXII}

Labor Cost for Fulling and Capping Milk Bottles

\begin{tabular}{|c|c|c|c|c|}
\hline Cily & No. plants & Labor cosis & Variation & $\begin{array}{l}\text { No. bottles } \\
\text { per man } \\
\text { per hour }\end{array}$ \\
\hline Philadelphia. . & 25 & $\begin{array}{c}\text { Cents } \\
\text { I. } 8\end{array}$ & $\begin{array}{c}\text { Cents } \\
0.9 \text { to } 5 \cdot 3\end{array}$ & 1,086 \\
\hline New York... & 3 & $2 . I$ & I. 9 to 3.3 & 964 \\
\hline Pittsburgh. . & 8 & 2.2 & I. 5 to 6.3 & 937 \\
\hline Baltimore. & 16 & 2.1 & I. 3 to 6.7 & 739 \\
\hline Boston..... & 32 & 3.1 & 1.9 to 8.0 & 725 \\
\hline Washington. & 23 & $3 \cdot 3$ & I. 8 to 5.5 & 571 \\
\hline
\end{tabular}

The value of most modern and up-to-date machinery as well as the most efficient operation of such machinery is illustrated by Table XXIII. ${ }^{2}$ This table furthermore emphasizes the fact that the efficiency of the operators as well as the proper num-

1 Milk plant letter No. 20, Dept. of Agriculture, B. A. I., October, Igr 5.

According to figures in Table XXII the average costs in Boston and Washington were considerably higher than in the other cities, but in the latter city a larger proportion of the smaller and less efficient plants were taken into consideration while in the former city 26 of the plants supplying data were capping by hand, with an average labor cost of 4.5 cents per 100 bottles, varying from 2.1 cents to 8.o cents. Higher wages were also reported in that city than in some of the others, thus making the labor cost high in proportion to the number of bottles filled per man per hour. In Philadelphia, New York, and Baltimore a larger proportion of the plants considered were using automatic machines than in the other cities.

2 Milk plant letter No. 25, Dep. of Agriculture, B. A. I. October, I915. 
ber of employees engaged at the work materially influences the economic efficiency.

TABLE XXIII

Table Showing Tme Required for Finling and Capping

\begin{tabular}{r|r|r}
\hline Type of machine & $\begin{array}{r}\text { Boltles filled and } \\
\text { capped per hour }\end{array}$ & $\begin{array}{c}\text { Botlles filled and } \\
\text { capped per man } \\
\text { per hour }\end{array}$ \\
\hline 1. Large, automatic machine, filling & & \\
and capping a full case at a time & $\mathrm{I}, 933$ to 8,622 & 966 to $2, \mathrm{I} 55$ \\
2. Rotary type filler and capper...... & $\mathrm{I}, 350$ to 2,446 & 587 to $\mathrm{I}, 040$ \\
3. Machine filler and capper......... & 750 to 7,760 & 375 to 1,552 \\
4. Hand capping.................... & 350 to $5, \infty 00$ & 238 to $\mathrm{I}, 066$ \\
\hline
\end{tabular}

3. Distributing Cost. - This includes such items as salary of driver and collector, upkeep of horses and wagons, barn expenses, and overhead expenses connected with distribution. This expense has been variously estimated at from 2.0 to 4.0 cents per quart.

4. Loss Due to Shrinkage and Waste at the Milk Plant. - The Department of Agriculture ${ }^{1}$ obtained estimates from 4 I dealers on such losses. These estimates included all losses in handling milk from the time it was shipped and varied from 0.5 to 4 per cent and averaged 2.I 5 per cent of the amount handled by each dealer.

Such losses may be due to leaky cans, inaccuracy in weight or measure, careless handling of milk, insufficient draining of cans, leaky apparatus, losses at the filler, loss from not removing all the milk from the pasteurizer, pipes, pumps, tanks, or other apparatus, evaporation and mechanical loss during the process of clarification, pasteurization, or other processes.

5. Loss on Surplus Milk. - As the demand for sweet milk and cream is not uniform from day to day, and as there is also

I Milk plant letter No. 9, Department of Agriculture, B. A. I., November, 1914. 
slight variation in the daily production of milk, it is evident that it is necessary for market milk establishments to handle a small amount in excess of what can be disposed of at retail. This excess is usually converted into other products, such as butter, cream for ice cream making, or cheese. As there is a good demand for special makes of soft cheese, this has often been made from the surplus milk, and some plants have succeeded in entirely eliminating this particular loss. Prominent milk dealers of Boston estimate the loss due to surplus milk and shrinkage at 0.37 cent per quart. ${ }^{1}$

6. Loss on Bad Accounts. - More accounts are lost when dealing with the consumer direct than when selling to a dealer. Customers leave and neglect to pay and some accounts are so small that it will not pay to collect. To overcome this loss in some places tickets are sold on a cash basis. This system has succeeded in many instances, but has also some failures to its credit. It reduces the bad accounts, but may also have a tendency to reduce the number of customers.

7. Overhead Expenses. - Overhead expenses such as office expenses, insurance, depreciation, advertising, etc., differ greatly in different plants, due to variation in the cost of plant and equipment, office system, efficiency of organization, etc.

8. Total Cost of Marketing. - The datum available on total cost is very limited at this time and it varies greatly in different plants. A dairy school conducting a 500-quart milk route twelve miles in length in the middle Western states reports the cost at 3.5I cents per quart; deliveries were reported not to be made more than three houses from the main route. The milk was not pasteurized.

Milk dealers of Boston report the cost of marketing in that city as follows: ${ }^{2}$

'Hoard's Dairyman.

2 Hoard's Dairyman, July I9, I9I2. 


\section{COUNTry EXPENSES}

Transportation, labor, ice, cans and stopples, can washing
and miscellaneous items...................

$\$ .0102$

\section{CiTy Expenses}

Pasteurizing, washing, and bottling, glass jars, etc. . .... . ००

Salaries of drivers, helpers, foremen, and salesmen...... .0127

Teams expense includes horses, wagons, and harnesses..... , ,0070

Miscellaneous expense, includes bookkeeping, stationery, advertising matter, car fares, telephone calls, and bad

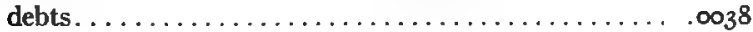

Total city expenses. . . . . . $\ldots \ldots \ldots \ldots \ldots \ldots .033^{8}$

Total expenses, city and country. ............. $\quad .044^{\circ}$

To this must be added shrinkage and loss in carrying sur-

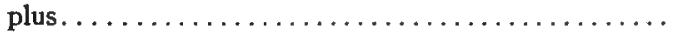

Grand total. ....................

The average price paid in the country, middle zone, from

October I, I9I I, to October 1, I9I 2, is, per quart....

Net cost, per quart milk, delivered to customer, family trade

Percentages of total cost per quart of wholesale and retail from eighty milk distributing plants in Massachusetts are presented in Table XXIV by Cance. ${ }^{1}$ The actual total expenses of milk distribution by the same dealers are presented in Fig. 30 and Fig. 3I. Local conditions greatly influence the cost of marketing milk, which is illustrated by Table XXV. This table was prepared from information furnished by the United States Bureau of Markets of milk prices in various markets of the United States for November, I9r8. The Bureau report is based on reports made to the Bureau of Markets by city health officials, milk dealers, and officers of milk producers' associations,

${ }^{1}$ Bulletịn 173, Mass. Experiment Station, 1917. 

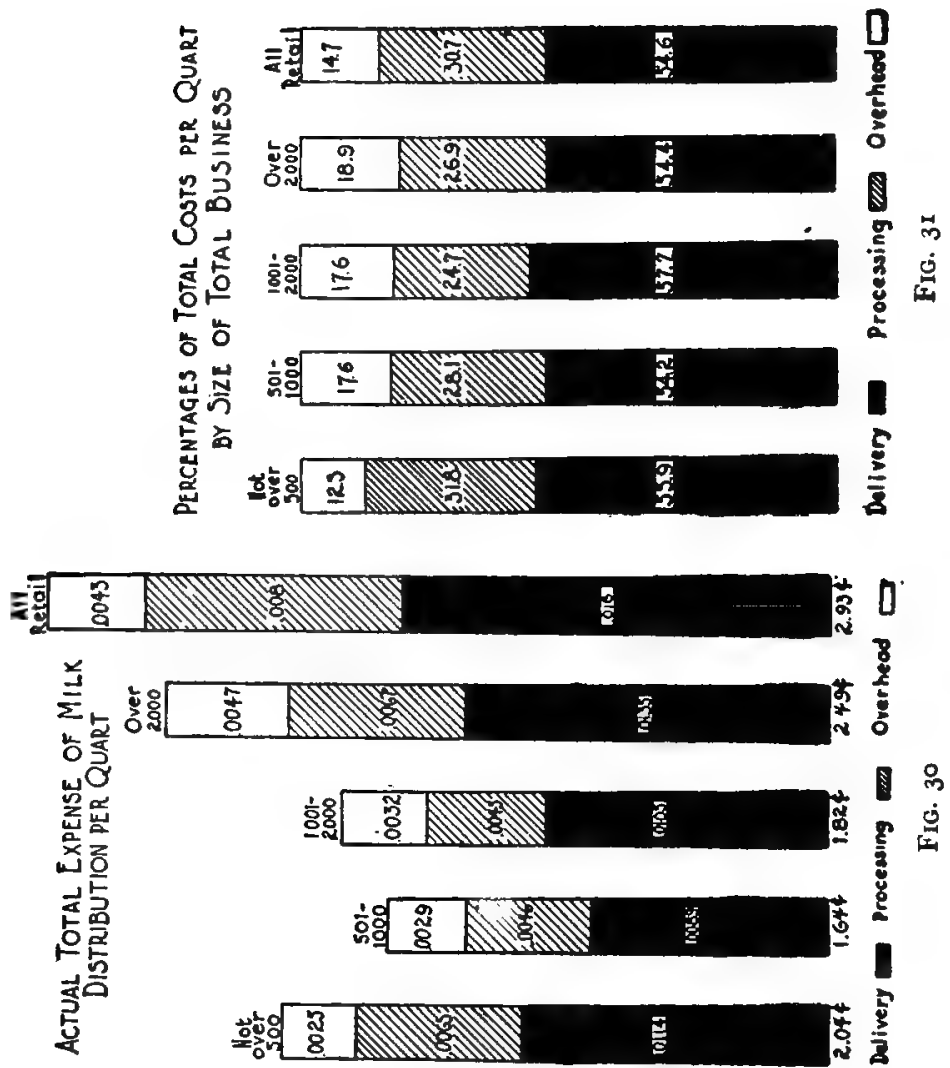
TABLE XXIV

Percentages of Total Cost per Quart of Wholesale and Retall Milk (Eighty Plants), by Size or Character of Business

\begin{tabular}{|c|c|c|c|c|c|c|}
\hline - & $\begin{array}{c}I \\
\text { Under } \\
500 \\
\text { quarls }\end{array}$ & $\begin{array}{c}I I \\
500- \\
I, 000 \\
\text { guarts }\end{array}$ & $\begin{array}{c}I I I \\
\text { I,OOI- } \\
2,000 \\
\text { quarls }\end{array}$ & $\begin{array}{c}I V \\
\text { Over } \\
2, o 00 \\
\text { guarls }\end{array}$ & $\begin{array}{c}V \\
\text { All } \\
\text { retail }\end{array}$ & Average \\
\hline $\begin{array}{r}\text { Number of es- } \\
\text { tablishments }\end{array}$ & 27 & 20 & Io & 3 & 20 & \\
\hline Total cost. . & $\$ 0.0204$ & $\$ 0.0164$ & $\$ 0.0182$ & $\$ 0.0293$ & $\$ 0.0293$ & $\$ 0.0218$ \\
\hline Per cent. . & 100 & 100 & 100 & 100 & 100 & $1 \infty$ \\
\hline $\begin{array}{c}\text { Processing ex- } \\
\text { pense...... }\end{array}$ & $\$ 0.0065$ & $\$ 0.0046$ & $\$ 0.0045$ & $\$ 0.0067$ & $\$ 0.0000$ & $\$ 0.0064$ \\
\hline Per cent. & 31.8 & $28 . I$ & $24 \cdot 7$ & 26.9 & 30.7 & $29 \cdot 3$ \\
\hline $\begin{array}{c}\text { Delivery ex- } \\
\text { pense.... }\end{array}$ & \$o.0II4 & $\$ 0.0089$ & $\$ 0.0105$ & $\$ 0.0135$ & $\$ 0.0160$ & \$ \\
\hline Per cent... & $55 \cdot 9$ & $54 \cdot 2$ & $57 \cdot 7$ & $54 \cdot 2$ & 54.6 & $55 \cdot 7$ \\
\hline $\begin{array}{c}\text { Overhead ex- } \\
\text { pense.... }\end{array}$ & $\$ 0.0025$ & $\$ 0.0029$ & \$o 0032 & $\$ 0.0047$ & $\$ 0.0043$ & $\$ 0.00322$ \\
\hline Per cent. . & I $2 \cdot 3$ & 17.6 & 17.6 & 18.9 & 14.7 & 15.0 \\
\hline $\begin{array}{l}\text { Investment } \\
\text { Per plant.. }\end{array}$ & $\$ 566$ & $\$ 3,325$ & $\$ 5,279$ & $\$ 20,594$ & $\$ 2,277$ & \\
\hline $\begin{array}{l}\text { Per } 1, \infty \infty \\
\text { quarts milk } \\
\text { sold ...... }\end{array}$ & $\$ 430$ & $\$ 1284$ & $\$ 95 I$ & $\$ 1930$ & $\$ 226$ I & \\
\hline
\end{tabular}


TABLE XXV

Table Showing Cost of Handling Milk in American Cities

\begin{tabular}{|c|c|c|c|c|}
\hline $\begin{array}{l}\text { Markets for which } \\
\text { reports were oblained }\end{array}$ & $\begin{array}{c}\text { Prices per } \\
\text { quart paid to } \\
\text { producers for } \\
\text { milk delivered } \\
\text { F.O.B. cily }\end{array}$ & $\begin{array}{c}\text { Prices charged } \\
\text { by dealer per } \\
\text { qualt of milk } \\
\text { delivered to } \\
\text { consumers }\end{array}$ & $\begin{array}{l}\text { Cost for hant- } \\
\text { dling and dis- } \\
\text { tributing one } \\
\text { quart of milk } \\
\text { including } \\
\text { dealers' profll }\end{array}$ & $\begin{array}{l}\text { Per cent of } \\
\text { retail price } \\
\text { paid to the } \\
\text { producers for } \\
\text { milk delipered } \\
\text { F.O. B. cily }\end{array}$ \\
\hline & Cents & Cents & Cents & Cents \\
\hline Los Angeles, Cal. . & $9 \cdot \mathbf{I}$ & I3 & $3 \cdot 9$ & 70.0 \\
\hline San Diego, Cal. . . . . . . . & 10.3 & I6 & $5 \cdot 7$ & $64 \cdot 4$ \\
\hline Denver, Col. . . . . . . . . & $7 \cdot 5$ & 12 & $4 \cdot 5$ & $62 \cdot 5$ \\
\hline Hartford, Conn . . . . . . . & 10.5 & 16 & $5 \cdot 5$ & 65.6 \\
\hline Wilmington, Del. . . . . . & 9.8 & I4 & $4 \cdot 2$ & 70.0 \\
\hline Washington, D. C....... & 10.5 & I 7 & 6.5 & $6 I .8$ \\
\hline Atlanta, Ga........... & 12.5 & 20 & $7 \cdot 5$ & $62 \cdot 5$ \\
\hline Peoria, Ill. . . . . . . . . . & $7 \cdot 9$ & I3 & $5 \cdot I$ & 60.8 \\
\hline Indianapolis, Ind . . . . . . & $7 \cdot 5$ & I3 & $5 \cdot 5$ & $57 \cdot 7$ \\
\hline Des Moines, Iowa . . . . . . & 7.8 & I5 & 7.2 & 52.0 \\
\hline Dubuque, Iowa. . . . . . . & 7.0 & I 2 & 5.0 & $5^{8} \cdot 3$ \\
\hline Kansas City, Kan. . . . . . & 8.7 & I4 & $5 \cdot 3$ & 62.1 \\
\hline Topeka, Kan........... & 7.0 & I4 & 7.0 & 50.0 \\
\hline New Orleans, La........ & $9 \cdot 5$ & I6 & 6.5 & $59 \cdot 4$ \\
\hline Baltimore, Md . . . . . . . . & 10.5 & I 7 & 6.5 & 6 I. 8 \\
\hline Springfield, Mass. . . . . . . & $9 \cdot 75$ & I5 & $5 \cdot 25$ & 65.0 \\
\hline Detroit, Mich. . . . . . . . & $7 \cdot 9$ & I 5 & 7.1 & 52.7 \\
\hline Minneapolis, Minn....... & 8.1 & 13 & $4 \cdot 9$ & $62 \cdot 3$ \\
\hline Kansas City, Mo....... & 9.0 & I 6 & 7.0 & $5^{6.2}$ \\
\hline Butte, Mont........ & $7 \cdot 5$ & I 5 & $7 \cdot 5$ & 50.0 \\
\hline Lincoln, Neb...... . & 8.2 & I4 & 5.8 & $5^{8.6}$ \\
\hline Omaha, Neb...... & 7.0 & I4 & 7.0 & 50.0 \\
\hline New York City.... & $9 \cdot \mathrm{I}$ & I6 & 0.9 & 56.9 \\
\hline Asheville, N. C......... & 8.8 & 16 & $7 \cdot 2$ & 55.0 \\
\hline Oklahoma City, Okla.... . & $7 \cdot 5$ & I5 & $7 \cdot 5$ & 50.0 \\
\hline Cincinnati, Ohio......... & $7 \cdot 5$ & I4 & 6.5 & 53.6 \\
\hline Columbus, Ohio......... & 8.6 & 15 & 6.4 & $57 \cdot 3$ \\
\hline Portland, Ore....... & 8.3 & $\mathrm{I} 4 \cdot 5$ & 6.2 & 57.2 \\
\hline Philadelphia, Pa........ & 9.1 & 14 & $4 \cdot 9$ & 65.0 \\
\hline Providence, R. I. . . . . . . & $9 \cdot 7$ & I6. 5 & 6.8 & $5^{8.8}$ \\
\hline Sioux Falls, S. D . . . . . . & $7 \cdot 5$ & 13 & $5 \cdot 5$ & $57 \cdot 7$ \\
\hline Nashville, Tenn..... & 9.0 & 18 & 9.0 & 50.0 \\
\hline Salt Lake City . . . . . . . . . & $7 \cdot 1$ & 12.5 & $5 \cdot 4$ & 56.8 \\
\hline Richmond, Va.... & 10.0 & I 5 & $5 \cdot 0$ & 66.7 \\
\hline Spokane, Wash... . . & $7 \cdot 9$ & 15 & $7 \cdot I$ & $52 \cdot 7$ \\
\hline Milwaukee, Wis. . . . . . . . & 8.7 & I3 & $4 \cdot 3$ & 66.9 \\
\hline
\end{tabular}


9. Relation of Retail Price to Quantity Sold. - It is considered by milk dealers that one retail wagon should distribute at least 200 quarts daily in order to be operated at a profit. Daily sales of 250 quarts per wagon is considered as a fair average business per driver for a well-established milk plant.

The size of bottles used and the amount delivered to each consumer are important factors in determining the marketing cost. The value of the product handled is still another factor of importance. It is considered that it costs about the same to handle and market one quart of milk and one quart of cream; the profit should therefore be the same in dollars and cents on the same quantity. It is a fact, however, that where there is a loss in handling cream it amounts to more money than the loss incurred in handling the same amount of milk. It also costs a fraction more to deliver a quart of cream than a quart of milk, as the cream customers are usually more scattered than the milk customers and they receive cream in smaller quantities. There should always be a greater margin on the smaller quantity, as the factory labor, office labor, and cost of delivery is the same for a pint of milk as it is for a quart.

The cost of making a delivery of milk and cream should be closely determined and the price charged should be in accordance therewith. The following schedule was adopted by one plant in I9I 6 as a reasonable charge for the various sized deliveries. This schedule might, however, not be suitable to other market milk establishments working under different conditions, but it illustrates the system usually adopted by most milk distributors:

1 gallon milk in bulk . . . . . . . . $\ldots \ldots \$ .28$

1 quart milk in quart bottle. . . . . . . . . 08

1 pint milk................... .05

I gallon 20 per cent cream in quart bottles... I . 20

I quart 20 per cent cream............ . 35

I pint 20 per cent cream............ .20

$1 / 2$ pint 20 per cent cream........... . I2 
II. Selling Sweet Cream and Milk at Wholesale. - As the commercial ice cream business is increasing at a rapid rate, and as the population of the cities is increasing, the demand for sweet cream for ice cream making and for retail purposes is becoming greater and is also more difficult to meet. It is therefore possible for creameries to establish markets for sweet cream and obtain more money therefor than can be obtained by making the cream into butter.

The creameries of the middle West have experienced no difficulty during recent years in obtaining for sweet cream a price of Io cents or more above highest New York quotations for extras F. O. B. their shipping station. Under such conditions, if the quotation of the New York market for extras were 30 cents and sweet cream were sold at 40 cents per pound butter fat and if the cream were made into butter and sold at 30 cents per pound then one pound fat made into butter would be worth $30 X$ $\frac{I 22}{100}=36.6$ cents. Considering that the cost of preparing the cream for marketing it at wholesale is equal to the cost of manufacturing it into butter then a gain of 3.4 cents has been made by marketing the product in the form of cream.

If sweet cream under the same conditions were sold at $5^{\circ}$ cents per pound butter fat as against 40 cents per pound of butter then a pound of fat made into butter would be worth $40 \times \frac{\mathrm{I} 22}{100}=48.8$ cents, or a gain of only I.2 cents would be obtained by selling sweet cream. It is fair to assume that the cost of pasteurization and cooling of the sweet cream to be sold will about equal the cost of manufacturing the butter, as sweet cream should be cooled to within a few degrees of freezing before it is shipped. The method of preparing sweet cream for market is the same as that for preparing sweet cream for ice cream making.

This method of disposing of the butter fat is particularly advantageous to the coöperative creamery. The producers are willing to furnish sweet cream to the creamery if they are 
paid for the extra labor involved. The creameries selling sweet cream seldom experience much difficulty in improving the quality. Even what is bought as sour cream will be much improved. Therefore, we may consider this system as being of much educational value to the creamery and to the producers.

A creamery located in a city may find it profitable to sell milk and cream to big consumers and dealers, such as hotels, restaurants, bakeries, etc. A route for such business was established in a medium-sized city in the middle West, 1915, on which the daily output was as follows:

\begin{tabular}{|c|c|c|c|}
\hline & $\begin{array}{l}\text { Sold } \\
\text { for } \\
\$\end{array}$ & $\begin{array}{c}\text { Purchase } \\
\text { cost } \\
\$\end{array}$ & $\begin{array}{c}\text { Gross } \\
\text { profil } \\
\$\end{array}$ \\
\hline I6 I gals. milk at 20 cents. . . . . . . . & 32.20 & 24.22 & $7 \cdot 98$ \\
\hline I 36 qts. milk at 8 cents . . . . . . . . & ro. 88 & $4 \cdot 95$ & $5 \cdot 93$ \\
\hline 13 pts. milk at 5 cents. . . . . . . . . & .65 & .23 & .42 \\
\hline 32 gals. cream at 70 cents. . . . . . . . & 22.40 & $21 \cdot 32$ & 1.08 \\
\hline 44 qts. cream at 30 cents. . . . . . . . & 13.20 & $7 \cdot 33$ & 5.87 \\
\hline 5 qts. whipping cream at 60 cents..... & $3 . \infty$ & .83 & 2.17 \\
\hline 4 pts. whipping cream at 35 cents..... & 1.40 & $\cdot 33$ & I. .07 \\
\hline 4 half pts. whipping cream at 20 cents. & .80 & .16 & .64 \\
\hline Io qts. lactone at 8 cents. . . . . . . . . & .80 & .38 & .42 \\
\hline 3 gals. B. milk at 16 cents. . . . . . . & .48 & .06 & .42 \\
\hline 8 qts. B. milk at 5 cents........... & .40 & .04 & $\cdot 36$ \\
\hline Total amount of daily sales. & & $\$ 59.85$ & $\$ 26.36$ \\
\hline
\end{tabular}

The purchase cost of the milk was on an average $\$ 1.75$ per hundred pounds delivered at the creamery or market milk plant and the cream about 40 cents per pound of butter fat. The plain cream as sold in the city contained 20 per cent of butter fat and the whipping cream 30 per cent of butter fat. The cost of lactone was about the same as for whole milk and for buttermilk about two cents per gallon.

The proportion of daily expenses to be charged against this route was approximately as follows, not including delivery, 
FACTORY COSTS

Labor in factory and office................. \$ 6.97

Interest on investment, insurance, and depreciation...... I.4O

Power, ice, and water.................... $\quad 2.67$

Miscellaneous expenses, such as loss on surplus milk and cream, loss on bad accounts, stationery, advertising,

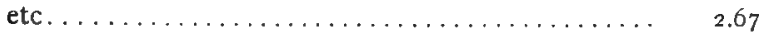

Cost of Delivery

Driver, monthly salary.....................\$60.00

2 horses, feed, and care................... 36.00

Shoeing and repairs, including painting of wagon...... I5.00

Interest and depreciation. ................. I6.00

Monthly cost ............ $\overline{\$ 127.00}$

Daily cost............. \$4.23

Total daily cost ............... $\$ 17.94$

Daily net profit en route $=26.36-\mathrm{r} 7.94=\$ 8.42$.

By studying the above report it is readily discovered that 32 gallons of cream were handled at a loss; I6I gallons of milk were handled at a rather small margin, but it is supposed that these were all sold in cans and were therefore handled with less labor and with less loss. A creamery or a market milk establishment should have a daily report giving complete information about the day's sales. It should preferably be so ruled that the purchase cost and the gross profit can be figured in the office before it reaches the manager's desk. 


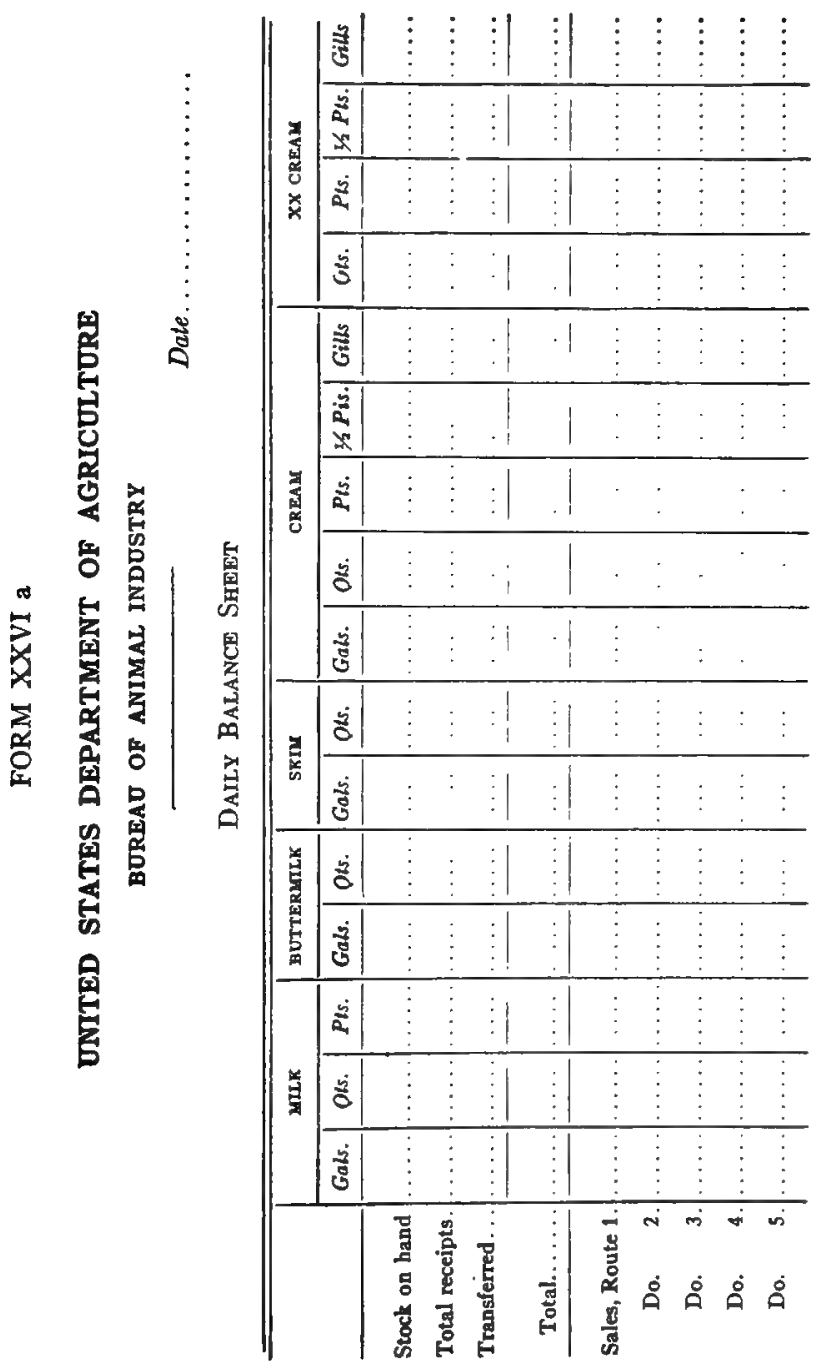




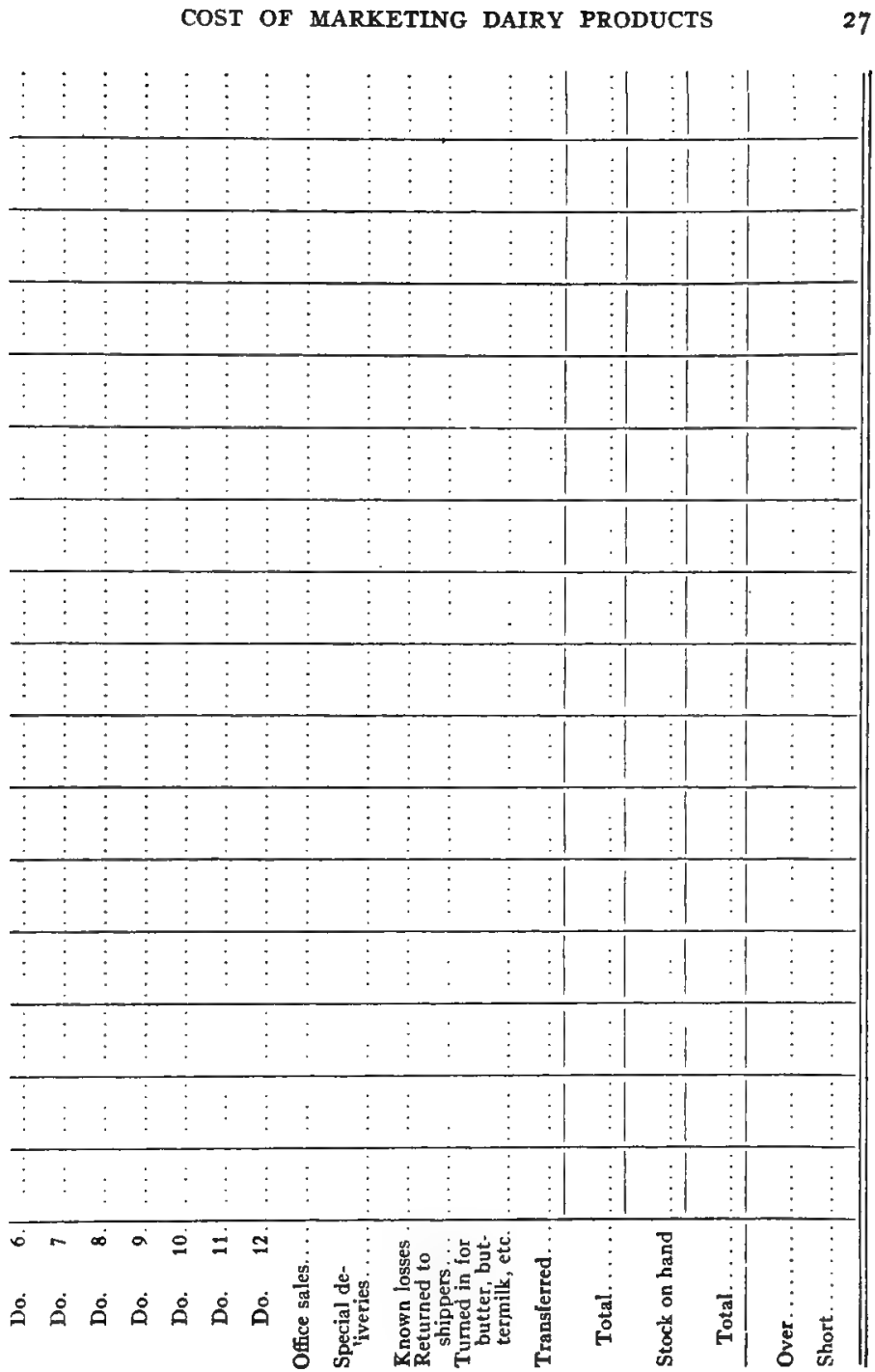




\section{CHAPTER XX}

\section{PREPARING THE BUTTER FOR MARKET}

\section{A. BUTTER PACKAGES}

A Foon offered for sale should possess quality, it should be put up in a neat and attractive package, and it should be of full weight or measure. The quality may not at all times be under absolute control of the manufacturer, as it is largely dependent on the quality of raw material received; but the appearance and weight, however, are under absolute control of the manufacturer. It is a recognized fact that in order to receive prizes at a butter show the package of butter should reach the judges in perfect condition. Therefore the package is usually wrapped in burlap or heavy paper or both. The same appearance of neatness and carefulness which in this case influences the butter judge at a butter show will, to just as great an extent, influence the butter buyer and the consumer. The author knows of a creamery where the manager required that each box of prints be wrapped with heavy paper before shipping. During the summer season the paper would have some insulating value, but the greater value derived from this method lay in the good condition in which this butter arrived at the dealer's store. Some of the merchants were even placing this clean box on the counter as an advertisement for the butter. In some places the ordinary plain butter boxes are returned by the city buyers. Although this saves money to the manufacturer, yet the system should not be encouraged, as the boxes when returned are never clean and even if they are washed their appearance will never be that of a new box. Butter put up in these boxes will suffer in prestige with the dealer. During the summer season butter which cannot be shipped in refrigerator cars should be shipped in refrigerator boxes (Fig. 32). 
I. The Butter Tub. - The butter tub is the most common form of package for American butter. The 60 or 63 pound tub is generally used, although tubs are manufactured of the following sizes, $5 \circ$ pound, 40 pound, 30 pound, 25 pound, 20 pound, and to pound. The larger tubs are held together by five wooden hoops. If the hoops are broken, they should be replaced before the butter is marketed. The cover is fastened to the tub with four tins placed at an equal distance from each

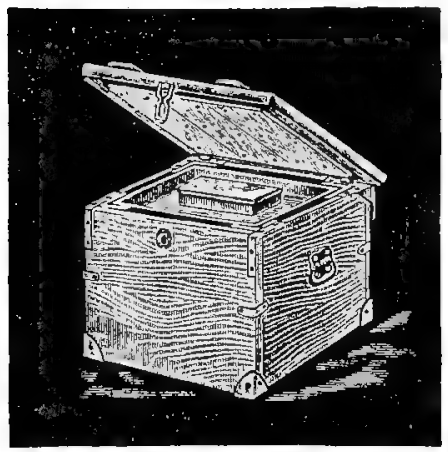

Fig. 32. - A refrigerator butter carrier.

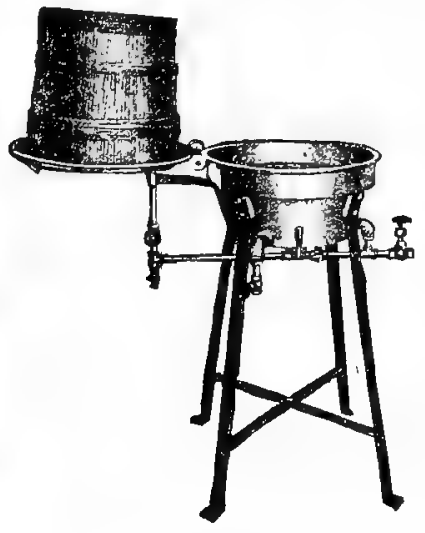

FIG. 33. - A butter tub paraffiner.

other. Clasps should not be used, as they have a cheapening effect on the package. The standard butter tub is manufactured from dry ash wood; spruce is also used, but only for special markets. Although spruce is neater in appearance, it is objected to because it is more expensive and more readily soiled, and if the tub has not been properly prepared, it will impart more of a woody flavor to the butter.

The tub is prepared as follows: the hoops are first tightened and the tub is washed thoroughly both outside and inside with hot water and washing powder. It is then soaked for about two hours so as to prevent leaking. After soaking it is rinsed 
with cold water to remove any sediment which might adhere to it from the water used for soaking. It is now placed over a steam jet for a thorough steaming, immediately after which it is paraffined. For that purpose a paraffiner fitted up with a special steam jet is most convenient.

The liner is next placed in the tub in such a manner that the top thereof will, when folded over the butter, overlap from one-half to one inch. If the tub is not paraffined it should be soaked from eighteen to twenty-four hours in cold water and then rinsed. A couple of pounds of dry salt should be put into it and the tub rolled for the purpose of having an even layer of salt adhere to the inside. The liner is then placed and the butter should be packed before the tub becomes dry or else the salt will fall to the bottom. The salt is added for the purpose of preventing the formation of mold and to facilitate taking the butter from the tub. The surface of the tub after the butter has been packed should be free from holes and should be covered with a cloth circle and with a sprinkle of salt on top. The cover before being placed on the tub should be thoroughly washed and dried.

The paraffining of the butter tub is of advantage, first because it prevents formation of mold, and second because it reduces shrinkage of butter. Mold may readily be prevented without special treatment of the tub. The main factors to consider are that the tubs and liners are stored in a clean and dry place and that the refrigerator is kept dry and free from mold. If liners have been exposed to mold spores they should be boiled in a concentrated salt solution. Rogers 1 found the shrinkage from butter packed in tubs, not paraffined, to be .95 of one per cent. This loss was reduced to .I 7 of one per cent when the tubs had been paraffined.

II. The Australian Butter Box. - The Australian butter box derives its name from the country where it was originally adopted as the standard package. The size of it, inside measure, is 12 X 12 X 12 inches and it holds fifty-six pounds of butter. It is usually made of white spruce. The sides, top, and bot-

${ }_{1}$ Circular 130, B. A. I., Department of Agriculture, 1908. 
tom are made of one piece. This package is used for special orders, particularly for butter shipped to foreign countries. These boxes are prepared for packing in the same manner as the tubs, but the side liners are long enough so that when folded on top they cover the entire surface.

III. Special Square Box. - Special square boxes for solid packed butter are used primarily for butter shipped to the Pacific coast markets. These are made in various sizes as determined by the size of the cutter used. The block of butter when removed from the box should be of such a size that the least amount of butter has to be reprinted. These boxes are used extensively for storage when the butter has to be printed after the storage season.

IV. Earthen Jars. - Earthern jars are used extensively in certain cities for local trade. These have the advantage over many other small packages in that the butter packed in them is less exposed to contamination. There is less shrinkage, and butter packed in them is usually preferred by the housekeeper. These jars are covered with a parchment circle bearing the trade-mark of the manufacturer. The objections to the earthen jar are that they require more labor in the factory, and that they give greater inconvenience in delivering to the dealers. These objections are lessened by the fact that there is practically no loss of moisture with the jars and the cost of the package is less than if cartons were used, as the empty jars are returned.

V. The Bradley Butter Box. - The Bradley butter box is made from spruce with tin bands forming the rim at top and bottom. These boxes are manufactured in sizes from half pound to ten pounds. The boxes for shipment are packed in crates of various sizes.

VI. The Gem Fiber Butter Package. - The Gem fiber butter package is a fiber box lined with parchment. It is much similar in shape to the Bradley box and is packed in crates of various sizes.

VII. The Butter Barrel. - The butter barrel is known particularly on the Pacific coast where it is used as a container 
for print butter sold in Alaska. These barrels are of three sizes, full barrels holding 180 pounds in two-pound prints, half barrels holding 96 pounds in two-pound prints, and quarter barrels holding 48 pounds in two-pound prints.

These butter barrels are mostly made of spruce. They have iron hoops. The barrel is prepared similar to the butter tub. It is first washed in hot water and washing powder, then soaked for twelve hours, steamed and paraffined. The barrel is then lined with cheesecloth which is so folded on the bottom and on the side that the cloth forms a bag in which the butter is packed. After the prints, wrapped in parchment, have been packed in the barrel, the cheesecloth is folded on top and tied with a string in a similar manner as that of tying a bag. The barrel is now filled with a concentrated solution of salt brine. This is prepared by adding 35 parts of salt to roo parts of water at ordinary temperature. This is churned for about thirty minutes. The brine thus prepared will contain about 26 per cent salt. After the barrel is partly filled with brine it is headed up and is then completely filled with brine.

Butter thus packed is often held for a year or more before it is placed on the table and often left without refrigeration. The brine preserves the butter reasonably well. Butter made for that purpose should be from high-grade cream, churned at a low degree of acidity, and should contain a low per cent of protein.

VII. Butter Tins. - Butter packed in tins is also marketed on the Pacific coast and sold primarily in Alaska and in the tropical countries. The print wrapped in parchment is placed in a loosely fitting tin. On top of the butter is placed a small square piece of wood large enough so it practically covers the end of the print. The cover is now placed on the tin and fastened in a crimping machine. It is then soldered. This is most readily done by having a felt pad saturated with soldering liquid and a bath with molten solder. The part to be soldered is rubbed on the felt pad and the tin is then dipped in soldering metal. The wood on top of the butter prevents the hot metal from touching the butter during soldering. The cover of the tin has two small holes, through one of them the tin is filled 
with a concentrated brine, after which these holes are also soldered and the package is tested for leakage. It is advisable that the tins be lacquered both on the inside and outside.

IX. The Danish Firkin. - The butter package most popular on the English market is the Danish firkin holding r ro pounds of butter. The firkin is made of beech wood. These firkins are prepared similar to the American tub and lined with parchment paper. The butter is solid packed in the frkin.

X. Butter Print Boxes. - The most common boxes used for prints are of a fifty-pound size made from spruce, poplar, or cottonwood. The inside measure of these boxes is usually $I_{3} \times I_{3} \times 9 \mathrm{I} / 2$ inches. A flat box of 54 pound size has a dimension of $23 \mathrm{I} / 4 \times \mathrm{I}_{4} \mathrm{I} / 2 \times 5 \mathrm{I} / 4$. The latter box is of a neater appearance, but the principal objection is that a greater surface is exposed to the atmosphere and the butter which is to be shipped without refrigeration during the summer season is more exposed to the heat. For local trade and for short shipments a fiber box is very satisfactory and it is cheaper than the wooden box.

\section{B. PACKING THE BUTTER}

I. Solid Packed Butter.--Butter when packed should have enough overweight so it will be of full weight at the time when it reaches the consumer or dealer. A sixty-pound tub of butter, if the butter is of good body, should not shrink to exceed eight ounces in four weeks if kept in a properly cooled refrigerator. If kept at a comparatively high temperature the loss will be greater. If the manager finds that more than eight ounces are deducted for shrinkage by the dealer then the matter should be investigated and the shrinkage may be found to be due to leaky butter, to overheated refrigerator at the creamery, to being overheated while in transit or at the store of the dealer, or to inaccurate weighing either at the creamery or by the dealer. The prepared empty tub with liners should be weighed on a scale that is sensitive to one-half ounce. The weight of the tub is marked on the hoop of the tub in reasonably small figures written with a pencil. The net weight of the butter should be 
stamped below the upper hoops and if eight ounces are allowed for overweight and if the net weight is 62 pounds and 8 ounces, then it is stamped 62 pounds. It is advisable to have all tubs contain the same amount of butter by weight, as by that system the work of taking inventories is facilitated.

II. Print Butter. - Butter prints should be perfect and square in form; butter should not be printed when it is in such a soft condition that the corners of the prints will be rounded. Holes due to imperfect packing should be filled, as their presence does not merely advertise poor workmanship, but will also lessen the keeping qualities of the butter. The usual size of the prints are, one-pound size, $45 / 8 \times 2 \mathrm{I} / 2 \times 2 \mathrm{I} / 2$; half pound size, $45 / 8 \times 2 \mathrm{I} / 2 \times \mathrm{I} \mathrm{I} / 4$. There are various other sizes, but those mentioned are the most common.

When printing butter it is advisable to weigh each print before it is wrapped, as the butter printer, regardless of how carefully it is adjusted, will not print all of the prints the same size, as the weight of the print depends on the condition of the butter both as to body and packing as well as on the adjustment of the butter printer. If a butter print is too small a sufficient amount of butter should be added to the print before it is wrapped. If a print is too heavy the overweight should be removed with a sharp paddle. Scales used for that purpose should be sensitive to ten grains. When starting to print a churning of butter the printer may need readjustment. The empty box for the prints with liners should be weighed and the weight marked with small figures on the box. The weight of the butter wrappers should be known; the weight of the prints without wrappers for a fifty-pound box should be a trifle over fifty pounds; four ounces are considered to be sufficient overweight on a fiftypound box of print butter. Suppose the weight of the box with liners is five pounds, the butter wrappers five ounces, then the gross weight of the butter should be $5+5 / \mathrm{I} 6+50 \mathrm{I} / 4=559 / \mathrm{I} 6$ pounds.

I. The Single Mold. - This is the oldest form of printer known. The disadvantage of this method of printing lies primarily in the imperfect shape of the print, the greater loss of 
moisture in printing, and in the amount of labor required. The shape of the prints, if made by this kind of a mold, will depend upon the condition of the butter; hard butter may be printed into nice shaped prints, but softer butter will always produce a print which is far from perfect in shape.

This printer requires readjustment when changing to butter of different body or of different firmness. By leaving the printer without readjustment it may affect the weight of the prints to the extent of from one to two pounds on fifty pounds of butter.

The cost of printing butter by this system depends naturally on cost of local labor. Two experienced men or women, one printing and the other wrapping, can in ten hours print and wrap from 4,000 to 5,000 prints.

2. The Wire Cutter. - The butter for this form of printer is packed in larger molds or boxes while in a pliable condition. The butter is then placed in a refrigerator for hardening and it is thereafter cut into prints with the wire cutters. Printers representing this method are the Friday, the Challenge, the Jumbo, etc.

This latter method of printing may be considered as the best and most economical. The prints are square and perfect. The butter is packed when in such a condition that the minimum amount of moisture is lost. The wire cutters cause the least possible loss of moisture, and the prints, because the butter is more uniformly packed, will be more uniform in weight. The labor is somewhat reduced, as two men can produce more work by this system.

III. Wrapping the Butter Prints. - In order to protect the butter a special wax paper is often used over the parchment wrapper. The parchment wrapper itself does not afford much protection from the absorption of flavors, but the wax paper does and is of much value in that respect. When properly wrapped around butter the wax paper forms practically an air-tight covering which also prevents the moisture from leaking out and penetrating the carton which is so common when only the parchment wrapper and the carton are used.

The butter carton has come into prominence during recent 
years. This is due primarily to the fact that it adds in appearance of the package, which is a big factor in selling the goods. It also makes a package which is more easily handled by the dealer. It reduces shrinkage and prevents absorption from articles which otherwise might spoil the flavor of the butter. To afford the greatest amount of protection and to remain in a clean and attractive condition such cartons should be paraffined on both sides.

The amount of labor required for wrapping the prints with the second wrapper and placing them in the cartons is equal to about two-thirds of the amount of labor required for printing and wrapping, differing with the different styles of cartons used.

IV. Butter Printing in Large Factories. - In larger factories the cost of printing, wrapping, and placing the butter in cartons may be materially reduced by the installation of more expensive machinery for printing, wrapping, and placing the butter in cartons. 


\section{CHAPTER XXI}

\section{ADVERTISING DAIRY PRODUCTS}

Advertising is everywhere recognized as a valuable business force. It offers an efficient, economical way of reaching the public, educating it to the merits of a commodity, stimulating, redirecting, or creating buying desires and finally developing and effecting sales. It is used in every field of industry and trade and for many unique purposes outside of these fields. It is employed for every phase of the marketing task, from disarming public criticism or creating good will to securing orders. How generally advertising is recognized for its usefulness may be gathered from the fact that something like a billion dollars is annually invested in it by the business men of the United States alone.

Advertising may be employed in the creamery business as well as in any other. There is nothing in the nature of the manufacture and distribution of dairy products to make advertising impracticable or unprofitable. On the contrary, some of the outstanding successes in advertising are in this field. Several brands of condensed milk have gained national reputation and captured national markets with the aid of advertising. Several brands of butter are familiar to housewives in a large portion of the United States because of advertising and many brands have gained sectional prominence. One selling campaign, in which advertising played a large part, increased butter sales from 450,000 pounds to $7,000,000$ pounds in five years. Several brands of cheese have been established in wide favor through advertising, while many special advertised brands of ice cream command the markets in various cities and their adjoining territories.

In the creamery business, advertising serves several purposes, all of which have to do with marketing either directly or in- 
directly. Some creameries may not find it desirable to use advertising for all of their purposes; some may prefer to sell their entire output on the commission market, and therefore they may not need advertising to aid them in marketing. But such concerns may find advertising valuable for gaining new patrons or holding the old, for example, and maintaining good will

\section{THE PURPOSES OF ADVERTISING}

I. Advertising to Aid Promotion. - When a creamery business is in the organization stage, or is being enlarged, or for any other reason needs promotion, advertising may be used to put the business properly before the people who are to be interested as stockholders, or patrons. It may be used to create a favorable community attitude and secure the confidence of business men, bankers, and farmers. It may be used to enlarge the list of patrons in new or old territory. It must not be understood that advertising can take the place of effective personal solicitation in these matters, but it can pave the way for personal work and support it.

More or less advertising space may be advantageously bought for these purposes. Local newspapers will, as a matter of news and also of community pride and welfare, give considerable space to the promotion of a sound creamery proposition, but they should not be expected to donate all the space that may be required to promote the business phases of the project, because advertising space is the most important commodity they have to sell. Moreover, their coöperation will be more thorough if they are made to feel that benefits are mutual.

Promotion advertising ought to be written conservatively; it should be hopeful or optimistic, but not over-enthusiastic nor too generous in its promises of returns. It should keep well within what may be accomplished and seek to establish confidence.

II. Advertising for Prestige and Good Will. - Prestige and good will are not secured ordinarily except through years of satisfactory dealing with the public. Yet they may be devel- 
oped rapidly by advertising. Through advertising, a business may be made familiar to the trade or to consumers in months where otherwise it might take years. If the good points of a creamery business, its fair dealing and the excellence of its butter, cheese, or ice cream are again and again put before buyers in an interesting, skillful way, they will soon come to believe what they read and the result will be strong prestige and a valuable good will. Too often a creamery goes on year after year doing business honestly and manufacturing a high-class product without its constituents realizing it or thinking very much about it, because it doesn't advertise these facts and thus emphasize them. The result is that its prestige and good will grow slowly. Advertising to build good will must be done skillfully and it must, of course, have back of it honest methods and a high-quality product.

III. Advertising to Establish a Trade-Mark. - If a creamery can make the people in its trade territory think not merely of "butter" when they think of buying butter, but of its special brand of butter, it has accomplished something that counts much toward success. This close association of a trade name and product cannot be established in any other way as quickly or as effectively as through advertising. It may be possible, of course, to bring it about through many years of selling without sepcial advertising, but no business can afford to wait long enough to do it in that way. By constantly associating the product and the trade name in newspapers, on billboards, on window cards, in circulars and booklets, the two are fixed together in the minds of buyers in very quick time. This result is worth much to the manufacturer and will of itself justify the investment of money in advertising.

IV. Advertising to Educate. - The education of the public as to the value of a particular creamery commodity is necessary to interest them in buying that commodity. That is true whether it is butter, which they have'long been accustomed to buying, or whether it is specially prepared market milk or ice cream, which are not so well known to them. It takes a good deal of persuasion to stir people out of an old, deep rut of buying. 
That is especially true of dairy products. For example, to most folks butter is merely butter and milk is merely milk and ice cream is merely ice cream. They cannot be induced to buy skillfully prepared products, insured as to wholesomeness and high food value, without first having been educated to believe that it is worth while to buy such products and pay more for them than for ordinary butter, milk, or ice cream. If the public are to buy high-quality butter, they must be told how high-quality butter is made, how its flavor is secured, how it is packed and protected against contamination, how it excels in food value, and how it provides certain elements for human growth and health. Not until they understand these things can the public be discriminating.

If a creamery plans to manufacture and sell ice cream, it must in many communities create a new demand for it; it must convince many housewives that ice cream when properly made is not merely a confection, but a substantial food, and that they are not indulging in a luxury in buying it and serving it, but that they are making an economical addition to the bill of fare.

If a creamery takes up cheese production, it likewise has an educational task on its hands to make its constituency understand that cheese is one of the most economical of foods as well as one of the most appetizing. The patrons of most creameries do not know this and consequently cannot be expected to buy enough cheese to make its manufacture profitable without first being educated to the buying point.

This education is best accomplished through advertising. Of course, it might be carried on through personal salesmanship, or by letting folks find out the value of these products for themselves, but the one method would be too expensive and the other too slow. Advertising has well been termed "the natural and effective business missionary." It furnishes a way of educating the public quickly and at comparatively small expense. Nowhere are its services more needed to-day than in the dairy business generally, where so many conditions and circumstances have conspired against its proper growth and expansion. 


\section{SPEND YOUR MONEY WISELY When You Buy Food Divide $\mathbf{\$ 1 0 . 0 0}$ As Follows for Best Results:}

Milk and Its Products (Butter, Ice Cream and Cheese) \$4.40

Tegetables and Fruits

$\$ 1.70$

Bread and Ceréals $\$ 1.30$

Vleat and Fish $\$ 1.20$

Eggs 60 cents

50 cents

Sugat 30 cents

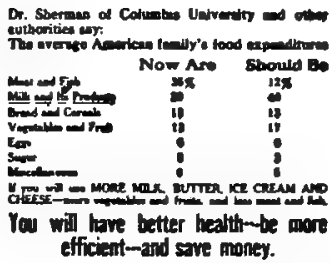

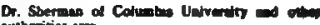

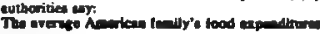

Now Are storlde Be

miter

mant

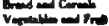

Eor

30

Henem

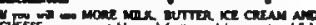

Vor efficient-and save money.

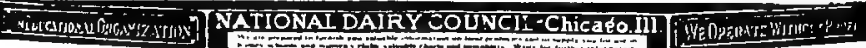

FIG. 34

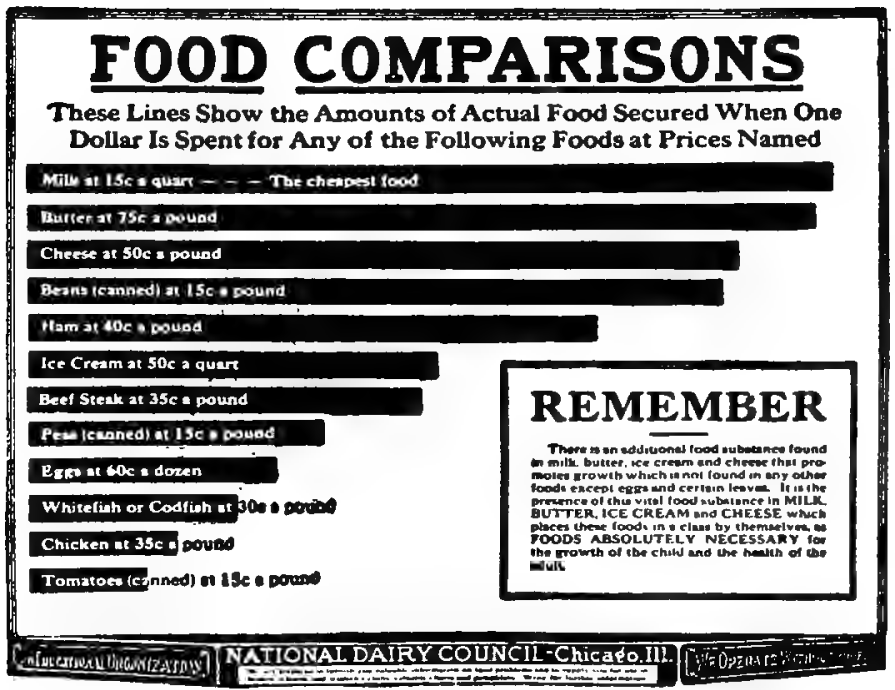

FIs. 35. - Advertising the food value of dairy products. 
V. Advertising to Back Up the Selling Force. - Every well-managed business seeks to give the fullest support and coöperation to its selling force, whether it be its own salesmen and solicitors or jobbers or retailers who handle the goods. Advertising provides an effective and economical means for providing that support and coöperation. It may be sent out ahead of the salesman or the retailer to prepare the way for him. If a creamery takes up the manufacture of cheese, advertising may be used to inform the retail merchant concerning its plans and products. Then when its salesman calls on the merchant he finds he is saved from putting a lot of valuable time into simple explanations because the advertising has taken care of that; he needs to concern himself only with the real business of a 'salesman and get the order. Likewise, advertising may be used to acquaint the buying public with the product and arouse its desire for it, thereby saving the retail merchant much valuable time in making explanations to introduce the new product. Advertising will do this preliminary educational work much more economically than the salesman or merchant can. Moreover, both a selling force and retail distributors will work more enthusiastically for a product that is being promoted skillfully through advertising.

Advertising for Direct Sales. - Some lines of business which distribute direct to customers find advertising a satisfactory means of bringing about sales. Frequently a creamery is so situated that it is best for it to build up direct distribution. It may not economically maintain a soliciting force to make houseto-house calls and it must then rely upon advertising to reach the public. Then advertising must combine many of the purposes heretofore named; it must be educational, it must help to establish a trade-mark, it must help to create good will, it must present selling arguments and stimulate action.

VI. "Policy " Advertising. - "Policy" advertising is a name given to advertising bought not so much for the direct object of increasing business as to secure or maintain the good will of influential individuals or groups. It includes much of the advertising in society programs, menus, hotel registers, and like 
mediums. Usually it is sound business not to advertise except when there is reason to believe it will bring returns, yet often "policy" advertising seems unavoidable. It should be reduced to a minimum. Many times it is better policy to make gifts outright and maintain advertising on a sales-promotion-getting basis.

\section{ESSENTIALS IN CREAMERY ADVERTISING}

Before a creamery can make satisfactory use of advertising, its business must meet several requirements. It must have a product worth advertising and which lends itself to advertising; that product should be put up in distinctive and convenient packages, if possible, bearing a trade-mark or brand name; there must be a definite appropriation for advertising; there must be a complete selling and advertising plan, worked out to the last step by which the product reaches the consumer; the advertising must be in charge of some one who will give it intelligent attention; and finally, honest goods, honest methods, and thorough service.

I. The Product. - Successful advertising demands first of all a product that lends itself to advertising. The product must have quality, of course, but it must have something more than that; it must also have individuality. That is, it must be different from the common run of such products.

If the product is "just butter," for example, no different from the great mass of ordinary creamery butter, than advertising is not likely to aid very much in marketing it; that kind of butter is probably best sold on the commission market. It lacks good talking points and advertising must have talking points. It isn't worth the extra price that advertising should get for it. But if a creamery manufactures butter of uniform high quality, into which an efficient butter maker has put enough brains, skill, and individuality to make it different, then advertising will help to find a special market for it at special prices.

II. The Package. - In dairy manufacturing, the package becomes so closely a part of the product itself that it is usually 
dealt with from the manufacturing standpoint. It is used because it must be used; a container is necessary. It is generally made as cheaply as it can be made and still serve its purpose, which is to insure the delivery of the product to the consumer in convenient form and quantity and without loss of quality or danger of contamination. Its cost is usually charged in the cost of manufacture.

Yet the package may be more than a mere container; it may also be a valuable aid to selling and one of the important factors in advertising. When properly designed and used, the package does not merely supply a necessity; it also furnishes an opportunity-an opportunity to give the goods additional favorable publicity. At the time of buying, the package is the one thing that strikes the eye of the buyer. It needs, therefore, to be considered from the selling and advertising standpoint as well as from the manufacturing standpoint.

If the package is to be something of an advertisement in itself, it must fulfill certain requirements: First, it must have attention value. Through its design and color and the printed matter on it, it should strike the eye of the consumer and get his notice when he buys it or when he sees it on display; the product will then mean more to him and he will be more likely to ask for it another time. Too many creamery packages fail to make any impression because they are commonplace and do not stand out; they are not different. Second, it must have interest value. After a package has secured attention, it must arouse favorable interest; the consumer must also like it. The package must be attractive; it must please the eye through its good design, through its well-arranged printed matter, through proper use of colors; its appearance must be in harmony with the product, suggesting a clean, wholesome, good-tasting product. Third, it must have individuality. A package should be designed and printed so that it will not be mistaken for any other. It should identify the product it contains so that the consumer who likes it will be able to remember it easily and make certain that some other product will not be pushed off on to him, A great majority of 
creamery packages are too much alike. Fourth, it should carry the trade-mark. At every opportunity the trade-mark or trade name should be used in advertising a product. There is no better opportunity than in such close association with the product as is possible on the creamery package.

A trade-mark serves two fundamental purposes. It identifies a product or distinguishes it from similar products of other manufacturers and it provides the purchaser with an easy way of recollecting it when he again needs that kind of a product. Both of these purposes must be attained by every manufacturer to establish a permanent market for his goods and they cannot be attained readily without a trade-mark. In addition, the trade-mark serves a third important purpose: it gives continuity and repetitious valuc to advertising. When the trademark is used in every advertisement, in a more or less conspicuous way, it links each advertisement with every other and makes them a unit; when it is not used, each advertisement stands alone and gets very little aid from advertisements that have gone before.

To fulfill its purposes, a trade name should meet certain requirements. First, it must be distinctive or different. Then it will be more readily remembered and be less likely to be confused with other trade-marks. Second, it must be legible and easily read or taken in by the eye. Words or geometrical figures that are worked into intricate designs are often so difficult to see clearly that no effort is made to remember them. Third, it must be brief or simple. If a word or words, the briefer the better for conveniently storing it in the memory and recalling it. If a figure, the less there is to it the better for the same reason. Fourth, if it is a word or words, it should have a pleasing sound and be easily spoken. Fifth, it should be suggestive of the product and be readily understood. Sixth, it should be applicable, if possible, to all the products of the creamery. If one trade-mark is used for all products, then the advertising done for each will help all the others; the good reputation of one will be extended to the others, which is highly desirable. Seventh, it should be valid. It should be possible to defend the 
trade-mark chosen against all infringement. That may not be so important to the smaller creamery with merely local trade, but it is highly important to the larger concern. Eighth, it should be permanent. It costs too much to establish a trademark to abandon it for a new one.

Trade-marks are made up mainly of materials which have

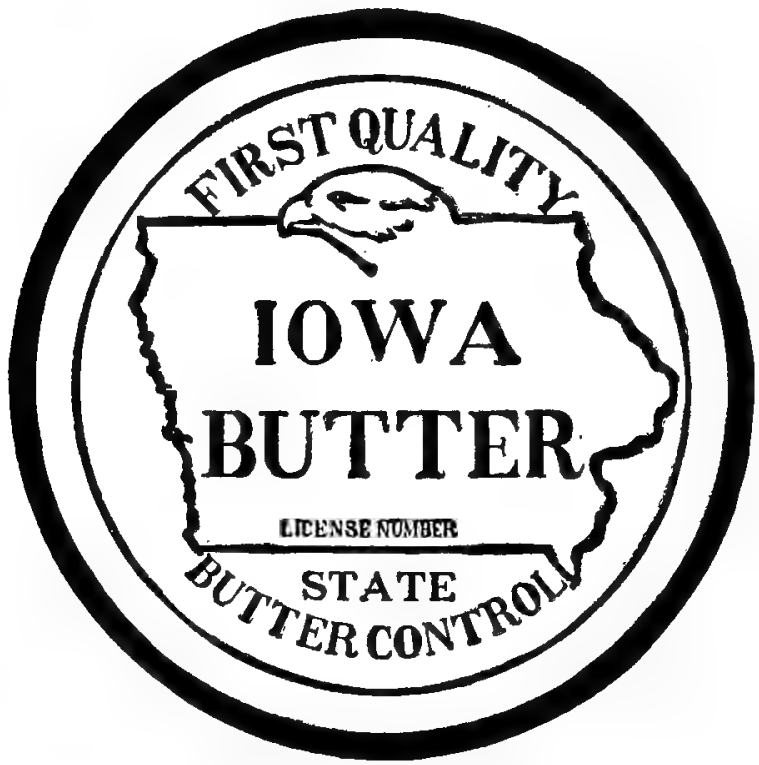

FIG. 36. - A well designed trade mark.

been classified in four groups: Pictures, words, syllables, or disconnected groups of letters.

Careful tests indicate that pictures rank first as to the ease with which they are recognized and the accuracy with which they are recalled; forms second, words third, and syllables fourth. While pictures have this advantage in tests, yet they are not satisfactorily reproduced in all advertising matter and on all packages. Moreover, their satisfactory reproduction 
involves greater expense in art work and printing. Names or words are perhaps most widely used because they lend themselves nicely to many uses; moreover, experience shows that they are readily established in public favor within a short time.

A trade-mark may be established in either one of two ways, by registration or by adoption and use. Registration is the most certain way to guarantee exclusive right to a trade-mark and registration is quite easily secured through application to the United States Patent Office (provided it is to be used in interstate trade). By adopting a trade-mark and using it continuously exclusive right thereto may be established, but the task of defending that right is more difficult than in the case of a registered trade-mark. ${ }^{1}$

If it is proposed to make extensive use of a trade-mark or trade name, a legal specialist on this subject should be consulted about the name or design to make sure that it can be properly protected. In place of such special advice, this general statement as to trade-marks' validity may be of assistance:

"Generally speaking, a trade-mark to be valid must not be the name of a person, name of a place, descriptive of the goods or of the quality of the goods, or old in the class into which the goods fall on which the mark is to be used, according to the arbitrary classification of the Patent Office." - W. A. Knight, trade-mark specialist in Judicious Advertising, Dec., I9I I.

In recent years there has been a marked trend toward the coined or invented word or trade name. They are more likely to be valid, they are usually strong in attention value, and if they are suggestive they are excellent. Sometimes, however, they are not very easily remembered.

III. A Definite Appropriation. - Advertising is best carried on if a definite sum of money is set aside for a year, or a selling season or a campaign. That is true whether a business can afford to invest only $\$ 200$ a year in advertising or $\$ 20,000$. Moreover, it is best to prepare a budget which divides the

1 Complete information on trade-mark registration will be furnished on request by the United States Patent Office in Washington; the fee for registration is \$1o. 
appropriation among the different kinds of advertising to be used. Without a definite appropriation, advertising is likely to go on in a haphazard way, without continued purpose, without enthusiasm. Without an appropriation, the man in charge of the advertising cannot be certain that he can afford to do this or that thing. With an appropriation for a year, advertising may be planned for a year; each step may be taken with satisfaction because money has been set aside for it, and when the total appropriation is kept in mind it is easily determined whether a particular advertising outlay is reasonable or not.

The amount of money that should be set aside for advertising by any creamery business can be best determined by the manager after a careful study of the special circumstances and trade conditions of his business. Even then he cannot be very certain as to the percentage of his gross sales he should set aside for advertising until he has tried out an annual appropriation or two, and studied the results of his advertising expenditure.

A few general principles may guide in determining an appropriation. Advertising should always pay for itself and in addition return a profit, either through increased sales, more economical selling or strengthened good will or some other valuable thing, and the appropriation should not be so large that such a return is not reasonably probable. A new business requires a larger percentage of gross sales for advertising than an old-established business. If it is intended to increase production and secure larger sales in old territory or new, the appropriation must be larger than if it is intended merely to hold an established trade. If competition is keen, the appropriation percentage will have to be larger than if there is no competition. Generally, it is best to appropriate conservatively until experience proves what is a sound basis of appropriation for a particular business.

The appropriation set aside for a year's advertising is usually a certain percentage of the gross sales of the preceding year. Creameries doing a wholesale business appropriate all the way from 0.I of one per cent of their gross sales to r per cent. Creameries doing a retail business necessarily appropriate a larger percentage, often as much as 5 per cent of gross sales. 
It is convenient to keep a special account for advertising rather than charge expenditures for this purpose to the general expense account.

IV. A Definite Plan. - As important as an appropriation is a plan for the year's or season's advertising. There should first be an objective. It is essential to make a careful study of the marketing problems of the business to learn how advertising may help to deal with them. Perhaps the trade needs to be educated as to quality; or, maybe a trade name or brand needs to be popularized; or, possibly it needs to be interested in a product it has not used extensively previously. Then these needs should become the aims of the year's advertising. Next there should be a determination of the general arguments or appeals that are to be made through advertising to accomplish these objectives. Then it is important that there be a careful study of the buying public to which the arguments or appeals are to be presented so that they may be presented most effectively. Who are the people for whom the advertisements are to be written; what are their financial circumstances; what are their prejudices and likes; what and how do they think - these and other questions like them must be asked and answered. Following that, the plan must determine what advertising mediums shall be used - newspapers, circular letters, exhibits, street-car cards, billboards, booklets, etc., and how much of the appropriation shall be devoted to each. Finally, the advertisements and the letters and the signs, etc., must be prepared to fit the plan, and they should be prepared well in advance of their use so that they may be carefully written and revised, put into type, and perhaps again revised in proof. In the best managed campaigns every item of advertising is prepared arıd approved before a single item is published.

That sort of planning demands much thought and hard work, but it pays. It puts brains and energy into advertising. It lifts advertising out of uncertainty into certainty. To plan is always the intelligent thing to do. Without planning advertising is bound to be unintelligent, and unprofitable as well. 
V. An Advertising Manager. - If a business is to make use of advertising, some one connected with that business ought to assume the duties of an advertising manager. In the smaller creamery those duties are likely to fall upon a man who is already overloaded with work, but even that man should find some time to give special thought and attention to advertising, if the business is to make use of advertising. He will find not a little pleasure in it. He should put a good book or two on advertising on his own shelves and borrow what his public library has to offer him; he should read some magazine that deals with advertising and marketing problems; he should study good advertisements, not only of other concerns in his line of business, but in other lines, and through his study discover what it is that makes their advertising effective; he should file examples of advertising that are likely to be helpful to him so that when he writes his own advertising he may have the help of good models. He should interest himself in the local advertising club, if there is one, and cultivate the acquaintance of men in the newspaper and business fields who are experienced in advertising. Circumstances may not permit the part-time advertising manager to do all of these things, but he should do as many as possible. After all, the success of a business depends very largely on its selling end, and advertising is an important factor in selling.

\section{MEDIUMS FOR CREAMERY ADVERTISING}

I. Newspapers and Magazines. - In any campaign to promote creamery product sales, the largest part of the appropriation is likely to be invested in space in newspapers and other publications. Through them it is possible to reach the buying public quickly, conveniently, and economically. Frequently, a well-established newspaper in a smaller city will go into 75 per cent of the homes of the city. In one such middle Western city the one daily newspaper enters 3,500 out of 4,000 homes. It sells its space at 50 cents an inch (having also a large outside circulation). For $\$ 5$, a selling message can be sent into those 
3,500 homes at much less cost then through any other medium. Granting that this space may not be as effective as a circular letter, for example, the advantage in lower cost is still heavily in favor of the newspaper space. For that reason, from 65 to 75 per cent of the total expenditures for advertising in the United States is for newspaper and magazine space.

The value of any newspaper or magazine in advertising creamery business depends upon several things:

First, it depends upon the way in which the circulation fits the creamery's trade territory. If a creamery has the problem of reaching the people of its home city, then that local newspaper with the largest list of home subscribers is likely to be most effective, even though the others may have a greater total of subscribers in the city and outside. If the problem is to increase ice cream sales in half a dozen nearby towns and cities, then best results are likely to be secured by selecting a newspaper of good local circulation in each of the towns. Some one newspaper of general circulation may have many subscribers in each of the six towns, but it likely has also a considerable circulation in twenty or thirty other towns which has little value to the ice cream manufacturer; the money he puts into that circulation outside of his trade territory is largely wasted. Newspapers and magazines of interstate or national circulation are not valuable to the creamery with a business that is more or less localized.

Second, the advertising value of a newspaper depends upon whether it reaches the kind of people a creamery wants to reach. To promote the sales of high-quality butter a newspaper with a smaller but select list of subscribers may bring better returns than a newspaper with a larger list which includes a big percentage of people who are not prospective customers. That newspaper in a community which reaches the housewives is likely to be best for creamery and other food products.

Third, the advertising value of a newspaper depends upon whether it regularly carries much high-class advertising. If one publication carries more business announcements in its advertising columns than another, it is quite certain that house- 
wives will-read its advertising columns more thoroughly and its space value is correspondingly larger.

The price of advertising space in newspapers varies directly according to circulation. In publications of smaller circulation it is sold by the column inch, which is a space one column wide and one inch deep. In publications of larger circulations it is sold by the agate line, of. which it takes fourteen to make a column inch. There is no uniform basis for prices, although the charge for space in publications of larger circulations may often be approximated by figuring it at one-third of a cent per agate line per thousand of circulation. Weekly newspapers of from $I, 000$ to 2,500 circulation have rates ranging from I 5 to 20 cents per inch, and of from 2,500 to 4,000 , from I 7 I/ 2 to 25 cents; sometimes there is an additional charge of 5 or 6 cents per inch for composition. Dailies charge all the way from one-seventh of a cent to one-fourth of a cent per agate line per thousand circulation. Cost of illustration and other special features is borne by the advertiser.

II. Signs and Billboards. - These forms of advertising fit well into many creamery sales campaigns. They do not permit of the presentation of much argumentative or educational matter, but they are especially effective in giving emphasis and repetition to trade-marks or trade names. When attractively designed and printed or painted and well placed, they catch the eye of large numbers. Attractive smaller signs placed in retail stores where creamery products are for sale get the attention of the customer right at the time that he is in a buying mood and are valuable for that reason. Signs and billboards are used in nearly all extensive advertising campaigns. The preparation of attractive show cards or signs is quite expensive, however, and for that reason they are not always available for smaller concerns. This objection may be met in part by purchasing stock cards from large lithographing and printing houses on condition of the right to exclusive use of them in a limited territory. Show cards are usually accepted and used by the retail dealer handling a product as a desirable coöperation of the manufacturer in promoting sales. Billboard 
space is usually best purchased through local or general billboard or outdoor advertising companies which assume full responsibility for painting or posting and upkeep. Electric signs are very attractive, but the expense of erecting and maintaining them is large.

III. Street Railway Cards. - Where city trade is sought for creamery products, the street-car card is valuable. From 80 to 90 per cent of all adults in a city ride in its street cars and they therefore have almost a perfect circulation. They are quite certain to be seen by all who ride, if they are well designed and printed; they are read with little effort at a time when there is leisure for reading them; every card has a fair chance to be read, and finally, they are usually the last advertisement seen by a shopper bound cityward on a buying expedition. They are especially valuable for emphasizing and repeating the trade name and the main selling points of an article. Street-car space is usually controlled by some large company that operates independently of the street railway company. Most of the car space in the United States and Canada is controlled by a single corporation. Through the controlling corporation attractive cards may be bought at a moderate price. The rates are fairly uniform and range from 40 to 50 cents per II $X 21$ card per month.

IV. Circular Letters and Mailing Cards. - For an intimate presentation of a product to prospective customers, circular letters serve a purpose that no other medium can serve. That is especially true if the letters are well written and skillfully printed and carefully mailed. They are not suitable for general or indiscriminate circulation. To send letters to all the housewives of a trade territory would be too expensive for most products. But when through newspaper or magazine advertising, or through the coöperation of retail dealers or salesmen or satisfied customers, special lists of interested persons are secured, they may be circularized to advantage and at reasonable cost. General advertising brings the prospects, while the special advertising of the letter goes far toward convincing them. Through modern letter printing and addressing machines 
letters that have every semblance of being specially written to each individual are now prepared at moderate cost. Letter printing shops are found in most cities. Costs will vary with the quality of the work, approximating 2 or 3 cents per letter where a thousand or more are ordered, not including postage. Cheap, unattractive circular letters are rarely a good investment. Mailing cards printed on attractive paper, sometimes in colors and with illustrations, are useful in calling attention to special propositions. They have good attention value and may be given deep interest value also.

V. Booklets. - These serve much the same purpose as the circular letter. They are for "follow-up" use mainly and permit a more complete presentation of the merits of a product than is possible in other mediums. A booklet for a creamery business may well deal with the processes of manufacture in a popular way with emphasis on quality of materials, food values, and care in making and handling the product. Illustrations are of especial value in a booklet, especially those that tell a story that is to the point. Booklets are circulated in much the same way as letters and to much the same lists. They may also be distributed in the package or through retail dealers. Costs vary greatly with the character of the book and its make-up, but there is possible a booklet for every business, well within the limits of its advertising appropriation.

VI. Novelties. - This heading includes many special forms of advertising, such as calenders, blotters, special display cards, gift articles, and the like. Their value varies. The calendar, if attractive enough, may prove to be an all-the-year reminder in office or home. Blotters, if sent regularly once or twice a month and each attractively printed with a newsy message of business interest, are a good reminder to have on a customer's desk. Gift novelties, like penholders, pencils, fans, drinking cups, canes, etc., carrying the business name of the donor, have some value, but not always a value equal to their cost. They are usually distributed under circumstances that make the distribution wasteful. If novelty advertising is purchased, it ought to be carefully purchased and as carefully distributed. 
VII. Exhibits and Demonstrations. - Food products are often excellently advertised through exhibits and demonstrations, particularly at pure food shows and in retail grocery stores. Such advertising, however, must always be linked up with other advertising and it is quite likely to be expensive. Smaller creameries are not likely to find it profitable to adopt this medium, except when special circumstances favor it. Exhibits and demonstrations take much time and usually require special men and women employees to set them up and conduct them.

VIII. Programs, Directories, etc. - Programs and directory advertising is of uncertain value. There ought to be a special reason for buying advertising space in such publications; most frequently that reason is "policy." However, there is likely to be profit in theater program advertising of ice cream, which is usually in demand at the close of a performance, and perhaps of other dairy products. Theater curtains have similar value probably even more, because they are more certain to get attention.

IX. The Creamery Itself. - Although the creamery itself is primarily a manufacturing plant, it is also its own best advertisement. If it is well located, attractively built, neatly kept, it will get attention from many passers-by, arouse their interest, and help to convince them of the merit of the creamery's products. As far as practicable, a creamery should keep a welcome sign out and even hold open house from time to time when visitors will be given special attention and perhaps a sampling of some new product or some old product made differently. Also, the manager of the plant will not find it amiss if on proper occasion he discusses pure food, or conservation, from his business standpoint, before public or semi-public gatherings.

\section{PLANNING AND WRITING THE ADVERTISEMENT}

Because three-fourths of the advertising prepared for a creamery business is likely to be prepared for a newspaper or other publication, the planning and writing of advertising will 
be discussed from that standpoint. However, what is said specifically from that standpoint may be applied generally to other forms of advertising.

I. Fundamental Considerations. - An advertisement, if it is a real advertisement, is written to secure favorable action upon some proposition of the advertiser, usually to induce a purchase - to sell something. It is essential that this be always kept in mind by the writer of advertisements.

It follows, then, that the writer of an advertisement must have a definite objective, the selling of a commodity, and a thorough understanding of that objective or commodity; also, he must understand how men and women may best be appealed to and influenced, and finally, he needs to know something about the advertising tools by which they may be influenced.

II. Understand the Commodity. - It may seem superfluous to advise a creamery man to understand his product thoroughly before he undertakes to write an advertisement to sell it, yet this is true: It is one thing for him to understand it for himself and another to understand it so that he may make its merits clear to others. We often know things that we cannot readily explain. The writer of butter advertising, for example, should think over the merits of his butter, discover how and why it is different from and better than the common run of butter, and then write out brief, pointed statements covering these facts. Then he will know his butter definitely, not indefinitely; he will have a clear, not a hazy, understanding of it; he will have his talking and selling points - the material out of which an advertisement may be "built."

III. Understand the Buying Public. - A good salesman never approaches a prospective customer without first learning all he can about him. A good "ad" writer likewise seeks to know as much as he can about the people to whom his advertisement is addressed, for his is a selling task also. What are their likes and dislikes? What are their circumstances, financially and otherwise? What emphasis do they put on quality or on price? What is their interest in considerations of food and health? Through these and many other questions create a 
picture in the mind's eye of the people for whom the advertisement is intended and ability to reach them will be increased. A good deal of psychology is involved in this step. In fact, advertising, like other kinds of salesmanship, has much to do with psychology and successful salesmen are good psychologists, either consciously or unconsciously.

IV. Essential Steps in Advertising Appeal. - A successful advertisement accomplishes four things in reaching and influencing the buying public: It gets attention; it arouses interest; it convinces, and it secures action. In other words, it makes people look, like, learn, and buy. The ad writer needs to keep these essentials in mind when he plans and writes his advertisement and to strive definitely to make it effective with respect to all of them.

Attention, depends (a) upon the extent to which counterattractions are eliminated or lessened - the less other advertising competes with an advertisement and the more it is set off by itself, the more likely it is to get attention; (b) upon contrast, which is secured by making an advertisement different from those around it - most ad writers learn what other advertisers are doing and then do something else; (c) upon the impression it makes on the eye and then on the feelings; $(d)$ upon the readiness with which it is understood in a single glance.

Interest, which must develop out of attention if the advertisement is to do more than merely catch the eye for an instant, depends (a) upon the appearance of the advertisement and its surroundings - it must be inviting to the reader; $(b)$ upon the promptness with which it may be understood - the reader should be able to gather quickly its most important message; (c) upon the way in which the reader is set to thinking about the things advertised - there must be a quick suggestion that the advertisement is worth his while for some reason or other.

Conviction depends upon successful appeal to reason or to desire.

Action is secured through direct or indirect suggestion or demand. 
V. The Materials and Tools of Advertising. - To "build" an advertisement and give it these four essentials qualities, the ad writer uses space, type and borders, illustrations and language. They may be called the materials and tools of advertising.

All four "materials and tools" are employed as follows to give attention value to an advertisement:

Space. I. By using as large space as the appropriation permits. Large space gets attention because it is large; it lessens the counter-attraction of other advertisements; it permits of larger headlines, display type and illustrations, and better typographical effects. Experience shows that it is more profitable to use a given amount of space for a few large advertisements than many small ones. However, the value of frequency must not be overlooked.

2. By securing space in the best positions. This is more important with smaller advertisements. Nearness to live reading matter of the right kind is essential; space in the upper half of a page is usually better than in the lower half.

3. By varying the form of space used to secure contrast. When most advertisements are square or nearly square, the long, single column advertisement has marked attention value. An oval or circle effect likewise secures contrast.

4. By providing plenty of white space within the advertisement itself; an open arrangement is desirable, and a crowded space undesirable.

5. By putting important head or key lines into type that is large and which is easily read (display). All capitals are not as legible as capitals and small letters (caps and lower case). Headline type measuring $\mathrm{r} / \mathrm{ro}$ to $\mathrm{I} / 20$ of the height of the advertisement is considered effective. Avoid the use of too many lines of large type (over display), for all emphasis is no emphasis, but merely confusion.

6. By selecting borders that catch the eye by setting off the advertisement and making it different, but which do not attract too much attention to themselves. Usually large advertisers design special borders and have them engraved. 
7. By using illustrations that are different and which may be understood readily and which print clearly. Illustrations have large attention value.

8. By introducing unusual arrangements and forms of type and illustrations, ovals, circles, triangles, etc. But retain simplicity.

Interest value is given to an advertisement by the skillful use of type and border, illustrations and language, as follows:

Type and Borders. I. By making the typography (use of type and borders) pleasing. Type and border should harmonize with each other and type should harmonize with the subjectmatter of the advertisement - for food products suggesting daintiness and purity. Adhere to simplicity, avoid overcrowding and involved designs and backgrounds. Keep plenty of white space within the ad. Maintain balance and symmetry. In short, make the appearance of the advertisement inviting to the eye and interest will follow.

2. By using legible type that the eye may read with least effort. Interest will not develop when reading is difficult.

3. By using illustrations which are clear, which are in good taste, which really illustrate and which present a story that is readily understood. Let them show processes and portray arguments and stir human desires. Such illustrations give great interest value, save many words, and furnish short cuts to understanding.

4. By use of headlines that carry the important, vital fact of the advertisement's story - its best news. Headlines are first to be read; their impression must be favorable; they must deepen attention into interest. Headlines must be brief, lively, interesting, not more than four or five words, and be taken in readily by the eye in a single glance.

5. By use of appeals and arguments in the body of the advertisement that are clear cut, straight to the point, and full of news about the product, making the reader think favorably of it. But what is written should be as brief as possible.

6. By making the advertisements timely and thus linking 
them up with other things already in the popular mind or in popular favor.

Words. - Conviction and action are secured through the use of words almost wholly:

I. By carefully planned appeal to the reason. The arguments in favor of the product should be carefully listed and arranged and then expressed forcibly and briefly, keeping in mind the reader, his way of thinking and his motives of action.

2. By skillful play upon desires and feelings through language, suggesting appetizing tastes, pleasing flavors, and healthful effects of good products. The reading of the advertisement should leave the readers with a desire for the product and an inclination to go buy.

3. By definitely suggesting or commanding action. After interest and conviction have been secured, the ad writer may in so many words say do this or do that.

Type is made in an endless number of styles, but most composing rooms have only a limited variety. This is no handicap, however, providing the few are desirable from the standpoint of good taste, legibility, and attractiveness. Type sizes vary according to the "point" system, a point being equivalent to one seventy-second part of an inch (approximately). The sizes are named according to the measurement of points between the topmost part of a capital letter and the lowest part of such a letter as "g," for example. If that measurement is I 2 points, the type size is "I 2 point." The smallest size in common use is 6 point; the largest, 72 point. Type lines are measured on the same basis, but with the pica, which equals 12 points, as the unit. Newspaper columns commonly measure I3 picas wide, although at present there is a trend toward a standard I 2 I/ 2 pica column. Type is said to be "leaded" when thin metal strips (leads) are inserted between lines to make more white space and increase legibility. In the body matter of advertising, I4 point, I 2 point, Io point, 8 point, and 6 point are most commonly used, especially the first three. On the average, matter set in 14 point will run about ro words to the square inch, set solid (without leads); I2 point, solid, 14 words and 
leaded, I I words; Io point, solid, 20 words, and leaded, I6 words. It is convenient to have in a scrapbook samples of the various sizes and styles of type that are available in the newspaper composing rooms that handle the advertising prepared.

Illustrations for newspaper use are of two kinds, half tones and zinc etchings, both made by photographic processes. Half tones are most often made from photographs, from water-color drawings (wash drawings) in black, brown, or white. They may also be made from oil paintings and direct from smaller objects themselves. A half tone may be identified by the many small dots and squares which change the solid black or white surfaces into "tones" of black or white. These dots are introduced in the engraving process by photographing the original through a screen of fine lines, ranging from 65 per inch to 200 per inch. The screen is varied for different printing uses, and is coarse for rough uneven paper and fine for smoothly surfaced paper. Half tones are designated according to the screen used; for printing on newspapers printed on an ordinary print paper from stereotyped plates, 65 or sometimes 80 line or screen is most satisfactory; for newspapers printed direct from type and engravings on smoother paper, as fine as roo line may be used; for booklets and catalogs as fine as I 20 or I 33 line may be used. Photographic copy for half tones should be clear and sharp. An engraving may be made larger or smaller than the original copy, to fit the advertising space desired.

Zinc etchings are made from pen and ink line drawings. They contain no dots, not being made through a screen. They will print well on any kind of paper and in any kind of a press. They present only one difficulty, the expense of getting good original drawings.

Language is the main reliance of advertising and the ad writer must know both what to say and how to say it. To know what to say he needs. to understand his product; to know how to say it he needs to know the people to whom he is writing his advertisement and how words may be used to interest and convince them.

What to say will depend a good deal upon the kind of an 
appeal that is to be made in the advertisement, whether to the reason ("reason why" advertisement) or to the feelings ("human interest " advertisement). For a "reason why" advertisement, hard facts as to quality, food values, process of manufacture, price, and the like are needed. For the "human interest" advertisement, such features of the product as its pleasing taste, its cleanliness, its healthfulness, its sweet odors, its appetizing appearance, its agreeable associations in use, and so on make the best material. For most advertisements some of each kind of facts or material will be required, for most advertisements combine "reason why" and human interest. Always the limits of the space available in advertising must be kept in mind and the facts or material subjected to what the newspaper man calls the "boiling down" process to eliminate everything that is not absolutely essential and helpful.

How to present the talking points will depend in a measure upon the kind of people who are to be reached by the advertisement. What is written for women must be set forth in terms that they best understand and which catch their interest; it needs to be expressed in words that are familiar in women's activities. Likewise, what is written for men, or for rural people or for city people, needs to be expressed in terms that suit. But certain rules apply to all advertisement writings: Be brief, because the reader hasn't time for long discussion and the advertisement hasn't space for it. Be clear, because what is written will be read more or less hurriedly and must be correspondingly easy to understand. Be simple; avoid big words and high-sounding phrases; plain, everyday words are best; steer clear of the over-use of adjectives. Be forceful when it is essential to hammer home facts; straight talk from the shoulder is most effective. Be interesting; put life into every sentence. Make sentences short and paragraphs likewise; avoid every impression of long-windedness. Be fair and moderate in statement; do not claim too much, for people are suspicious of wholesale claims. Be honest; that is always the best policy.

VI. Writing the Advertisement. - Every writer of advertisement works out his own plan of procedure sooner or later, 
so what is offered here is merely suggestive. However, it is substantially the plan followed by one successful ad writer.

I. Fix a purpose for the advertisement. Don't set out with merely a hazy notion of what is to be accomplished; have a clear-cut understanding on that score, or else the advertisement is not likely to interest or convince any one. Whether it is to sell something at once, or create good will for a product, or to educate the public to its merits, or something else, determine the purpose definitely.

2. Determine the mode of appeal. Settle whether it is to be to reason, to human interest or to both. Your ad writing will be done more or less aimlessly unless you take this step.

3. Select your talking points. Make a list of all the points that may be urged in making your appeal. Study them carefully to make sure that they are worth while; cut out all that are weak; combine some; rearrange them in order, according to interest or importance, or logical sequence.

4. Determine how much space is to be used. Unless the ad writer knows whether he is to have 6 inches double column space or 5 inches single column or a half page, he cannot prepare his copy correctly.

5. Outline this space on paper and locate the typographical features of the advertisement. If an illustration is to be used, sketch its exact outlines in the available space, or better, paste a proof of it on the location that is best. Sketch out a location for the trade-mark or trade name. Determine how much space the headline should occupy and where. Then outline the space that the body or text of the advertisement is to occupy and estimate how many words of matter can be put into that space. Your complete sketch should give you a good idea of what your advertisement will look like in print.

6. Write the copy to fit the space. Sometimes the headlines may be written first, sometimes last. Choose the newsiest or most important feature of your talking points, or the feature with most attention-getting power, for your key line. Put it into the fewest possible number of words. Write it and rewrite it to make sure that it is effective. Write the text of the adver- 
tisement from the list of talking points prepared earlier. Then study the result carefully, make careful criticisms, estimate its probable effect on the reader, and then rewrite. Two or three rewritings are none too many for a worth-while advertisement. This writing and rewriting should, of course, be done on separate sheets of paper; the final result may be numbered to indicate its location in the outline of the advertisement.

7. Secure the coöperation of the printer to get into type the kind of an advertisement you have planned. The printer can help make or mar the ad writer's work. Arrange for proofs so that you may be assured that the advertisement you planned is really worked out in type. Better pay extra for the privilege of tearing down and rebuilding than to have an unsatisfactory advertisement go into circulation.

VII. An Advertising Scrapbook — Such a book, filled with clippings of advertising material, will prove invaluable to the ad writer. It should contain examples of different uses of typography to get attention and interest, of different methods of using illustrations, of effective key lines, of well-written arguments or descriptions or other appeals, of various type faces and type sizes, short articles bearing on advertising, clipped from trade or advertising journals, and such other matter as may prove useful. 


\section{CHAPTER XXII \\ BUSINESS CORRESPONDENCE}

Business is annually transacted between firms and individuals who have never come in personal contact with each other. They have become acquainted and started a business relation with each other entirely through correspondence. A business house writes frequently to its customers and may possibly write from twenty to a hundred letters for each time its representatives have the opportunity of calling in person. It is therefore evident that the letter is one of the big factors in business. It is of as great importance, or even greater, that a business letter be considered as a credit to the institution where it originated as that a call be made by the proper representative. The latter will make only a short call and should the impression he made be unfavorable, the effect therefrom may gradually die away and be forgotten. The letter, however, becomes the property of the one to whom it was addressed and if it creates an unfavorable impression it reflects on the firm even more forcefully and will continue to convey the same impression at least as long as it remains in the possession of its recipient. Such a letter may not merely prevent an immediate sale, but sales for a period of years.

\section{A. THE APPEARANCE OF LETTER}

I. Stationery. - The stationery selected by a firm should at least not be out of harmony with the business of the company. A dairy firm should select paper of good quality. It cannot any more afford to write letters on poor, cheap-appearing stationery - than it can afford to send its salesman out in cheap and shabby clothing. 
The color of stationery should be given attention. A white color is always safe; other colors should be selected with caution. A dealer in whole milk, cream, or butter would prefer a color significant of a product that is rich and of high quality. A cream color might be a very suggestive color for a dairyman to select. However, a cream color should not be confused with an orange color or even a lemon color; it should be more delicate. Unless a satisfactory color can be obtained it would seem safer to stay by the white.

Business stationery should bear the name and full address of the firm or individual. Other information which may properly be used in a letterhead includes the names of firm officers, telephone numbers, cable address, and capital stock of the firm. Manufacturers often add an illustration of the plant. This is usually for the purpose of impressing the recipient with the magnitude of their business and thereby also make the impression of reliability. A building should never be used for the letterhead by a firm occupying only a small part thereof unless the building bears the name of the firm using it. The space on side margins of the paper should not be used for printed matter. Engraved or lithographic stationery is to be preferred to printed. But if printed stationery is used it should be of high class. A letterhead should never be used for second sheet, but a blank sheet of the same size and of the same paper stock as the first sheet.

II. Color of Ink. - Black is the safest color to use; however, other colors such as blue, green, etc., are used more or less. Blue was formerly much favored for typewritten letters, but black ink is gradually taking the place of all others. Various colored inks, even red, have been used by writers of letters for signatures, but also for that purpose the black ink is most satisfactory.

III. The Envelope. - The envelope should be of same paper stock as the letter paper. It should have the return address in the upper left-hand corner. The address should be plainly and neatly written. This is of particular importance when the letter is written to an individual or to a smaller firm 
where the owner or manager opens the letters himself. The size of the regular commercial envelope is about $33 / 4$ inches $X$ $6 \mathrm{I} / 2$ inches.

The open-faced envelope is used quite extensively for mailing bills, thereby saving the labor of addressing the envelope. It may be very useful for such purposes even though many are opposed to receiving a letter, the outside appearance of which indicates that a bill is contained within. This is particularly true in reference to individuals and it is the safer policy not to adopt the open-faced envelope for other purposes than for mailing statements and bills to firms. The open-faced envelope is not well suited for business correspondence, as it necessitates the folding of the paper in a very inconvenient and inattractive way. Moreover, as the outside appearance is against such a letter, it will not receive as hearty a welcome as will a letter appearing in more attractive clothing.

IV. Proper Proportioning of Letter on Sheet. - The letter should be so written that it is properly proportioned on the sheet; that is, the white margin at the bottom should be practically the same as the white margin at the top or a little wider. Likewise, the margin at the two sides of the letter should be the same and the right-hand margin should be made as regular as possible. The body of the letter should also be divided into short paragraphs, as that makes the letter more readable and more pleasing to the eye.

V. Folding the Letter. - In folding the letter two folds are considered, the long and the short fold, to conform with the size of envelope used. The long fold is used for the long envelope and the short fold for the short or regular size commercial envelope. When using the long fold the sheet is folded twice, the upper part of the letter overlapping; the letter thus folded will open most conveniently to the one who reads it. When adopting the short fold the first fold is made from the bottom of the sheet leaving a top margin of about one inch. This is for the purpose of having the name of the firm in plain view of the reader before the sheet has been fully unfolded, but it also makes the unfolding of the letter easier to the one who 
opens the mail. The second and third folds should be made about equal and should be neatly done.

VI. Letter Mailed to the Consumer. - A dairy carrying on a retail business will often send letters to individual homes in the city. Such letters may be sent merely for advertising purposes, but the lady of the house will usually receive them and the appearance of the letter should therefore be such that it will appeal to her. A letter written on business stationery would not receive her attention. If such letters are written on high-grade stationery similar to that used for social correspondence they will be more appreciated. Such stationery may be absolutely plain. If desirable to have the return address on the envelope then it may be placed in the upper left-hand corner of the front or preferably on the back of the envelope. The type should be small and the printing most neatly done.

\section{B. PARTS OF A LETTER}

A business letter is made up of the following parts.

The Heading.

The Introduction.

The Salutation.

The Body of the Letter.

The Complimentary Close.

The Signature.

I. The Heading. - The heading is first to be considered and includes the name of the place from which the letter was sent and the date of writing. If necessary the street and room number may also be given. The heading is placed at the upper right-hand corner immediately below the letterhead. Some place it nearer the center. In a social letter it is often reserved until last.

II. The Introduction. - The introduction or inside address is composed of the name of the person or firm to whom the letter is written, street number, city and state. It is placed at the beginning of the communication or, if in the social form, at 
the lower left-hand corner of the sheet and then includes only name and address. The latter style may be considered as the stronger. The reader is able to get into the subject-matter of the letter without any loss of time, which appeals to the busy man.

A business letter intended for a business firm should always be addressed to the firm itself and not to an individual member or to some employee of the firm. When it is addressed to an individual it becomes a personal letter and if the person to whom it is addressed is absent for some time the letter may be left until he returns, whereas it would receive prompt attention if addressed to the firm. If the writer desires that his letter be brought to the attention of some certain person of the firm, then the inside address may call for the attention of that particular person as follows:

$$
\begin{aligned}
& \text { The - Creamery Co., } \\
& 720-\text { Ave. } \\
& \text { Attention of Mr. J. C. Smith. }
\end{aligned}
$$

III. The Salutation. - The salutation depends much upon the subject-matter of the letter, the rank of the person to whom it is written, and the acquaintance of the parties concerned. If writing to individuals, a business letter starts with "Dear Sir" or "Dear Madam " and with "Gentlemen" if writing to a firm. The form, "My Dear Sir," is often used in business and may be considered very good, however, the former is the safer to use. All words in the salutation may be capitalized. Some writers, however, capitalize only the first word. The salutation is followed by a colon.

The more personal form of salutation, as in "Mr. Brown" or "Dear Mr. Brown," appeals to many people. It makes the reader of the letter feel as if there is a more intimate relation between him and the writer and that form is often preferable, especially so if the two persons are acquainted.

IV. The Body of the Letter. - The body of the letter may begin upon the same line as the salutation or, as is most frequently done, on the next line below. The body of the letter is 
that part which contains the real thought and substance. It is only that business letter which is full of good thoughts and ideas that is worth while writing. The other kind may just as well not be written, for it gains no friends, creates no new business, and may even be a business loser. It is well, especially for the beginner, to study each letter before delivering it to the mail. Single out the strong parts of the letter as well as the weak parts and the entirely superfluous parts. Such analysis may often reveal the fact that the letter is of no value and should be rewritten.

A letter which answers the purpose for which it is intended must present the thought which the writer wants to convey in such a way that the reader takes an interest therein and feels that the writer is telling something that is of value to know. It is therefore to the writer's interest first to make clear to himself how best to present his subject so that it will appeal to the reader and appear of interest to him.

The very first sentence of the letter should arouse interest, but often the beginning of a letter is the weaker part. It should never begin with " $I$ " or "we " as "We are pleased to inform you that we will be in a position to manufacture all kinds of fancy ice creams beginning May ist and we most earnestly solicit your patronage, etc." This information might be of some interest to a party owning a financial interest in this particular ice cream factory, but not to a customer and even less to the one who has never purchased ice cream from that factory. The writer should endeavor to place himself in the background and the one addressed in the foreground. It would appeal more to a woman if it could be shown to her that this letter were written entirely for her benefit. A letter such as the following comes nearer meeting this requirement.

"Dear Madam: You always desire to have for your parties an ice cream which is somewhat different from that served by your neighbors. If you consider that we can assist you in this matter then we should be glad to have you call us over the phone at any time. We are just equipping our factory for 
taking care of special orders and shall endeavor to keep the quality of our product up to your expectation."

A letter is often started as follows: "We have your favor of the fifth inst., etc.," or "Relying to your favor of August 6th, etc." Such may be satisfactory for a certain kind of correspondence when it serves as a connecting link between this and a letter just received, but for a selling letter such a beginning is rather weak. The letter becomes stronger if beginning at once with the subject-matter; at the close of the letter the statement may be made, "This is in reply to your favor of August 6th."

A letter should be simple and clear so the meaning thereof is readily understood by the reader. Long words should be avoided, short Anglo-Saxon words are always the most emphatic. Technical words and terms should never be used unless a technical subject is treated and the letter is written to some one who is technically trained.

Good tact and judgment are essentials in business correspondence. A letter that answers its purpose should always make the reader feel somewhat more friendly toward the writer or the firm from which it came. A letter which cannot accomplish that is either of no value or it may prove to be injurious. The following letter is one of the latter type.

"Dear Sir: We have your favor of recent date asking for a subscription for the erection of your new lodge hall.

"We hardly consider that we should be called upon by your members for a donation, as the members of our firm all belong to the Greenview Lodge and help to pay for the upkeep of same; however, we like to see you meet with success and inclose herewith ten dollars as our donation.

$$
\text { "Yours truly" }
$$

The writer of the above letter should first have decided in his own mind as to whether or not the cause was a worthy one, whether or not he could afford to make a donation, and possibly also the advertising value of such a donation. If he decided to make the donation he should endeavor to go on record as a 
willing and cheerful giver instead of critizicing the organization for calling for support. As the letter now reads the re- . ceivers of the donation are made to feel that they would rather have been without his support. The letter might have been written in such a spirit that it would have been appreciated as much as the donation it contained, and the friendly feeling thus created be of much value even from a business point of view.

More objectionable, however, are letters that contain sarcasm or unfriendly remarks. At times a correspondent will receive such a letter and will possibly take pleasure in using similar terms for reply, but if these matters are given due consideration it is readily understood that such a letter is always injurious to a business concern as well as to an individual. It is therefore a safe policy for any correspondent to keep letters written in an angry mood on his desk until the following day. They should then be reread and analyzed and should be rewritten if they will not tend toward creating a more friendly feeling between the writer and the addressee. It should always be borne in mind that there is nothing which will humiliate the writer of a sarcastic letter more than to receive a kind and friendly letter in return.

The volume of business and character of business done by the firm to whom the letter is addressed and even more the individuality of the one who acts on the letter, if such is known, should be important guides for the writer. It at times appeals to the reader if his name is embodied in the letter, as "We believe you are aware, Mr. Smith, that our firm appreciates your business very much, etc." The busy man wants a short letter full of facts and information. The one who receives but few letters will often take time to read a long letter and enjoy it. It is the safest policy, however, to make a business letter brief without sacrificing any of the essentials.

Often a direct question is asked in a letter. It is convenient to the writer to receive the reply to the question on the same letter and a request should be made when closing the letter asking a reply be made on the back of the letter. 
V. The Complimentary Close. - The complimentary close mostly adopted by the American business men is either "Yours truly" or "Yours respectfully." The first word of the complimentary close should be capitalized and it should be written on the line below the last one of the body of the letter.

VI. The Signature. - The signature should be written plainly so it may readily be read. It should preferably be written in black ink.

\section{THE FORM LETTER}

The form letter is often used by the creamery manager for the purpose of furnishing general information to patrons or customers. It is commonly used to acknowledge receipt of a shipment from a new patron. Such a letter will also furnish information in reference to the company's system of paying and other information as may be desired by the patron. Many general questions are asked which may be answered to greater or less extent through form letters.

For selling goods or purchasing cream the form letter has been an important factor. A series of letters is prepared, one supposed to follow the other at proper intervals. Such letters should be prepared systematically, gradually bringing the receiver up to the point when his desire to do business with the firm becomes strong enough so it leads him to action. Whenever a reply has been received to one of the letters the form letter has answered its purpose and a personal letter should follow.

When using the form letter it is taken for granted that the same desires exist in the minds of all and that the same arguments will appeal to all alike. A form letter that sells and buys goods must contain good arguments presented in an interesting way. When writing a form letter it is well to have several written and to test them out by mailing a certain number of each and noting the per cent of replies obtained from each.

A form letter should not merely contain strong arguments, but it should also be neatly written and properly signed so it 
will not have the appearance of a form letter, for it is the personal touch given to a letter that makes it valuable and of interest to the one who reads it.

Records of form letters are most readily kept on cards filed away in alphabetical order in a special file. When a reply has been received to one of the form letters the corresponding card will be removed to another file and should this person later become a customer the card will be filed among the cards of active customers.

\section{FILING OF CORRESPONDENCE}

A creamery handling a comparatively small amount of mail may conveniently use a small filing case in which the correspondence is filed alphabetically. This system, however, becomes impossible in a larger business, and the vertical drawer files then become the most useful. The letters are filed away in folders of standard size, $93 / 8 \times$ II $7 / 8$ inches with $3 / 4$ inch projecting tabs. The letters may be filed in alphabetical order, geographically, or numerically. The alphabetical order may be considered as being the simplest. This is, however, less convenient for some of the other departments, such as the sales and credit departments, for which the geographical system of filing has its advantages. The letter folders may be filed in numerical order, but if that system is employed then an index reference card file will be required. The cards of such a file are placed alphabetically or geographically and refer to number of folder.

Business correspondence should be transferred about once a year. For transfer files cheap vertical files may be used and the correspondence should be filed away in them so as to correspond to the general system of the office. 


\section{CHAPTER XXIII}

\section{CREDITS AND COLLECTIONS}

\section{A. THE CREDIT MAN}

THE concern selling goods on the credit system to other concerns or to individuals should be in a position to form an opinion of, or to obtain reliable information as to, the responsibility of the purchasers in question. Such information is supplied to the sales department by the credit man. It matters not whether the firm has a separately established credit department, the credit man may be the creamery manager who, as in a small plant, may also be the butter maker, but a credit man must necessarily be there. If he is omitted, the business concern must in safety confine its sales only to cash sales.

The ability of the man who is to pass on credits is a big factor in the successful operation of any large business. In general business is based upon credit; only few concerns can pay cash for all purchases. Therefore a credit man who can safely allow credit to 99 per cent of the people entitled thereto will be of greater value to his firm than the one who is allowing credit to only 95 per cent.

The credit man should have a knowledge of the general financial conditions and of the factors affecting such conditions. If a labor strike is started in a certain locality he should be able to determine the effect of such a strike on the responsibility of firms in that locality with which he may be doing business. Depression will always follow a crop failure, therefore in a district where a crop failure has been experienced it may be advisable to take special precautions and decrease the amount of credit allowed, whereas more liberal credit may be allowed in sections where the crops have been exceptionally good.

Full information should be obtained in reference to the 
financial responsibility of all prospective customers before the salesman makes any attempt to sell them goods. The retail merchant should carefully watch the changing about of people in his community and should investigate the responsibility of newcomers without delay.

\section{B. FACTS UPON WHICH THE CREDIT MAN BASES HIS JUDGMENT}

I. Commercial Agencies' Reports. - The Bradstreet and Dun agencies are considered the most important sources from which to receive credit information. For a stipulated subscription fee a firm can secure the reports which come in book form. These give the ratings of all established business firms and the amount of capital stock that would serve as a fair estimate for credit. They furthermore give their ratings as first, second, and third class. A firm obtaining a first rating should be a good risk if the credit is based on the stated amount of capital stock. The one obtaining a second rating is supposed to be of less responsibility, is often known to be slow at paying bills. The one obtaining a third rating cannot as a rule be considered to be a subject deserving of extensive credit.

In addition to this report these agencies are also at all times ready to furnish confidential information to their subscribers concerning more recently established firms not reported in their regular report or about firms reported but on which a more complete report may be desired. For such confidential reports or for part of them a small charge is made.

Local credit interchange bureaus are found in nearly all cities and are known by various names. Such are often associated with a national association. These organizations are all formed for the purpose of interchanging credit infornıtion. If a member of such an association desires to obtain information with reference to a certain firm, then he merely turns in a request for information to the bureau and usually within a day's time a report is furnished to the inquiring member as well as to the members who furnished the information. This report 
usually states the number of merchants furnishing the information, amount due to such merchants, amount past due, etc. In addition thereto is also furnished opinions of members in reference to whether the firm in question is considered to be prompt pay, medium pay, slow pay, poor pay, or if buying on cash basis.

Members of credit bureaus at times agree not to force a collection from a firm which is financially embarrassed but to report the condition of such a firm immediately to the secretary of the bureau who in that capacity acts as a representative of all members doing business with said firm. Members interested send a certified statement to the secretary, who will collect the money or as much thereof as possible, which amount is prorated among such creditors.

The Credit Men's Association is an organization found in nearly all cities. The membership is usually composed of one representative from each wholesale house of the city. This organization may or may not be associated with a national association. The members meet at more or less frequent intervals for the purpose of exchanging information in regard to their experience with various creditors.

Retail Men's Credit Associations are found in nearly all cities and in most towns and may or may not be associated with national organizations. The members of these associations are the retail merchants or their representatives. They organize for the purpose of obtaining reliable credit information; some such associations also collect accounts for their members, and some publish a book once a year with a key to each individual's rating.

There are a number of other sources through which credit information may be obtained. Some private concerns furnish information and often the bankers are referred to for credit information. The latter, however, are often opposed to furnishing such and whenever they do it is done as a matter of accommodation.

II. The Firm's Own Records. - Records of the firm's former dealings with the merchant who applies for credit offer another important source of information. It will not be safe, 
however, for a firm to allow such a record to be the only source of information upon which to determine his worthiness for credit, if such information is not recent.

III. Reports of Other Merchants. - This information is obtained by securing from the applicant the names of other firms from which he is buying goods. The credit man after obtaining such information writes to the credit men of these firms for their opinion in regard to the responsibility of the party in question.

IV. Financial Statement of Firm Represented by the Applicant. - Any firm or individual asking for extensive credit should be willing to present a financial statement. Such statement should be signed by the proper official or party in order that it may be of real value. This statement is one of the more valuable parts of the credit information, as it sets forth the financial condition of the concern. Such a signed statement when received is filed together with other credit information in reference to the applicant.

V. Financial Responsibility of the Individuals of the Firm. - If a corporation, this may not be of much value, as the liability of the individual is limited. It is, however, of much value when it concerns a copartnership, as in such any one of the partners can be held liable to the full extent of the indebtedness.

VI. Character of the Individuals that Own and Operate the Firm's Business. - An honest man with limited means is always a better credit risk than one who is dishonest, even though the latter may be in possession of unlimited means. The one who is honest and in possession of sufficient determination and a strong moral character will always be able to demand the limit of credit, whereas the one who lacks either of these qualifications will be considered with a certain degree of suspicion.

VII. Business Experience and Ability of the Applicant. The person or persons responsible for the outcome of the business should have experience in that particular business. If such persons have been successful previously in a similar line of 
business it is reasonable to suppose that they should again be able to meet with success. It is also well to note if those responsible for the business give it their personal attention and if they looked pleased or worried. A business manager who looks worried should be watched carefully if credit is extended to him.

VIII. Appearance of the Business. - A creamery doing business with retail firms should have representatives call on the retailers at various times. When making such calls the representative should be able to make a fair report to the credit man of the firm in reference to the appearance of the business. Such a report should furnish the following information:

Amount of stock kept in the retail store. If there has been an increase or a decrease since the former time when the representative called. The kind of stock kept, whether or not it is composed of staple or unstaple articles. The retail dealer who is dealing in such goods as can readily be turned into cash is always a safer man for credit than the one who is handling products of a less staple nature.

The amount of business transacted should also be considered, as well as whether such business is done on a credit or cash basis. If on credit it is well to consider the responsibility of the class of people to whom credit is extended as well as the frequency and method of making collections.

\section{OFFICE RECORDS OF CREDIT INFORMATION}

I. Filing of Credit Information. - Credit information obtained through various sources should be so filed that it may be available when needed. It is most convenient to have a letter folder for each person or firm on which credit information has been secured and all information obtained is filed in this folder. The folders may be filed geographically and alphabetically as in the system recommended for filing under salesmanship. The geographical system of filing is most serviceable, as it thereby becomes more convenient for the salesman when looking up information as to the responsibility of merchants in a certain 
territory. It is also possible that a certain territory may suffer, due to crop failures, labor strikes, or similar causes. It therefore becomes necessary for the credit man to make a thorough study and investigation of the firms so affected, and then the geographical system becomes the most useful as well as the safest.

II. Credit Information for the Salesman. - The salesman should always be supplied with the most recent credit information about his customers. Such is most conveniently kept by him on cards filed away in a suitable, compact case. It may be convenient for him to divide his territory into different sections each having a separate file and thus making it unnecessary to carry a more bulky card file.

III. Credit Information for the Order Clerk. - The order clerk is also supplied with credit information to the extent that he knows whether to allow credit or to demand cash for goods sold. If the creamery is doing both a city and an out-of-town business then it may be most convenient to have two card files, one for city customers and the other for out-of-town customers. It is most convenient that such credit cards be filed alphabetically. All the information of value to the order clerk is the correct name and address of firm, nature of business, credit or cash. If credit, the amount of credit should be stated; if cash should be demanded before the goods are delivered then C. O. D. may be marked across the face of the card. It is advisable that this credit file be kept as complete as possible, containing not merely information pertaining to present customers, but also to such as may become customers within the near future. It is always pleasing to a new customer to obtain credit without having to make application therefor. 
FORM XXVII

The Order Clerk's Credit Care

Name of Firm. .

Street Address

City or Town.

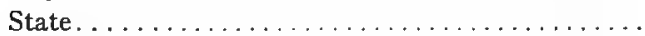

Nature of Business......................

Credit or C. O. D . . . . . . . . . . . . . . .

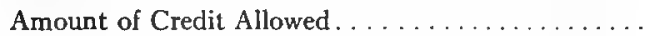

Date................................

The ledger contains the most recent and most reliable credit information available. It is convenient, especially in a larger business, to have the amount of credit allowed marked on the ledger leaf in such a way that the meaning thereof may not be understood by any except the regular office employees. It has the advantage that if a firm should take more credit than it is entitled to, then the bookkeeper can at once call the attention of the credit man thereto.

\section{COLLECTIONS}

A business firm will establish its own terms on which its goods are to be sold. Such terms should be fair to the buyer as well as to the seller. The terms should also be fully explained to the customers in order to eliminate all misunderstandings. After the terms have once been established the firm should enforce them to the best of its ability. An organization that is always collecting its accounts on a definite, prearranged time will have less difficulty in obtaining prompt payments than a firm making its collections at irregular intervals. By being prompt in making collections the debtor involuntarily comes to realize that it is just as important that the account is paid on time as it is that he receives the goods on time.

I. Frequency of Making Collections. - The frequency of collecting bills is governed to some extent by the adopted customs of other merchants; however, such customs may in part be ignored. It is customary in most cities to collect weekly for 
butter and cheese sold in the home city or town, whereas for butter or cheese shipped out collections are often made every other week. Butter and cheese are retailed mostly through the grocery stores. Such business may be considered to be fairly permanent and accompanied by less risk on account of uncollectible accounts. Ice cream is to a greater extent sold to retailers whose business is of a less permanent character. Several will remain in business for only one season or even less. They may also in general be considered as a class of business men not worthy of as much credit as the retail grocer, and therefore it is the usual custom to sell to many of them for cash and it is seldom that more than one week's credit is allowed, regardless of whether the sales are local or not. The manufacturer of ice cream is justified in collecting promptly, as ice cream is a commodity which is sold by the retailer for cash within twelve or forty-eight hours after it has been received. Where milk is sold at retail on the ticket system it is often sold on a cash basis or up to a month's credit may be allowed.

II. Delinquent Customers. - Delinquent customers may be divided into four classes, "careless, chronically slow, temporarily hard up, and insolvent." The careless customer may become prompt by insisting on receiving prompt pay. It is advisable when presenting a statement to a customer that it shows plainly the balance (Form XXIII), as this will continually remind the customer of his delinquency. The credit man is continually making comparisons between the figures of the amount carried over and that indicating his purchases not yet past due. The merchant who always carries a past due balance is less desirable as a customer unless he becomes more prompt in meeting his obligations and it is the duty of the credit man to cause such a customer to become prompt without thereby losing his business. The one who is careless about paying his bills is also apt to be careless in many other respects and cannot very often be considered a safe risk. The one who is chronically slow may be very careful about his business affairs, is often a good moneymaker, but one who will rather receive money than pay it out. The customer who is temporarily hard up often deserves the 
leniency of the merchant who sells him goods. By being properly supported by the creditors such a debtor will usually be able to readjust his financial affairs so that he in time will be able to pay his creditors in full. The insolvent debtor is the one whose property will not pay his liabilities. A firm may actually be insolvent long before it becomes an acknowledged fact and accounts may be collected. Payments will become suspended after it becomes an acknowledged fact that the debtor is insolvent.

III. The Collector. - The collector is an important assistant to the credit man. He should always pay strict attention to the appearance of the business of his firm's debtors and should therefore have a fair understanding of the value of goods. If the debtor is not ready to pay the bill when presented, then the collector should in a judicial manner secure information as to the exact time when payment may be expected. The collector will then make the necessary memorandum and this should be followed up by his calling on the debtor on the particular day, and if possible a definite hour, when the payment of the bill has been promised. Should the debtor fail to pay this time it should be expected that he will present a satisfactory reason for his delinquency.

IV. Collecting by Correspondence. - It is of greatest importance that statements be rendered at regular and definite times. If two weeks' credit is allowed then statements should be mailed every two weeks, leaving on the same mail each time. It should be definitely agreed upon between creditor and debtor that remittance should be forthcoming within a certain number of days after the date of statement. If the statement is dated on Monday of the week, most creameries will expect remittance not later than Friday of the same week. If remittance is not received by that time another statement should be mailed the following morning. If remittance is not received within a reasonable time after the second statement, then a third statement may be rendered, bearing a footnote calling the debtor's attention to the delinquency of the account and advising him that unless paid within a certain time a sight draft 
will be sent through his bank. Such a footnote may be placed by using a rubber stamp and may be worded as follows: "If remittance is not received before - then we take it for granted that you prefer to have us draw on you for the amount." If remittance does not follow, a sight draft should be made out at the time specified. This is turned in to the bank for collection. It is preferable that a sight draft be made out through the bank at which the debtor has his deposit, as the debtor will be less liable to give an evasive answer. If a sight draft is not honored, a good heart-to-heart letter will often bring about the desired result, but if not, it may be necessary to resort to other means for making the collection. Possibly a local attorney or some collecting agency may be most successful in bringing about a speedy settlement.

V. Collecting Agencies. - Collecting agencies are established in some cities for the purpose of collecting accounts. Such agencies are mostly employed by the retail dealers. Some are organized in connection with their associations such as have been mentioned in connection with Retail Men's Credit Association. Others are private concerns. Some retail merchants will turn all their accounts over to such agencies for collection. The claims made in favor of collecting agencies are that they make the collections at less cost than is possible if made by the individual merchants, and that they are better trained as collectors and as a result less money is lost due to bad accounts. Arguments against this system of collecting may be based on the ground that if he adopts it then he will not be in as close touch with his customers and that the collector is not working directly under the merchant for whom he collects and may therefore adopt means for collecting which would not be approved by the seller. Furthermore some customers are opposed to having a collector employed by a collecting age $\epsilon_{1}$ cy call, as such are often known to be employed for collecting bad debts.

For collecting bad accounts a local collecting agency will often prove to be very efficient. Local attorneys may also be employed to advantage. They are usually willing to collect on a percentage basis. 
YI. Selling on Sight Drafts or Time Drafts. - This practice may not be followed entirely because of fear that the one receiving the goods will not be able to pay therefor. However, it is the safe system by which to ship goods to persons or firms that are not able to satisfy the shipper as to their financial responsibility. The smaller creameries are often, when shipping butter or cheese to commission merchants, making out sight drafts for part value and at times when the butter has been contracted for at a definite price the shipper will draw a sight draft for part or at times for the total value of the products shipped. By this method the creamery is receiving cash for its products and will require less money for carrying on its business.

The sight draft when used for such a purpose is attached to the bill of lading and is forwarded through the local bank to the bank on which it is drawn, this bank being located in the city to which the goods are being shipped. The sight draft is presented to the consignee for payment who on payment thereof receives the bill of lading for goods covered by draft.

Some shippers, especially shippers of carload lots, make all collections on time drafts. These are similar to the sight drafts except that they are not payable on sight but payable in five, ten, or fifteen days or may be made out for any time agreed upon between the shipper and the consignee. Such a draft is sent through the bank in a similar manner as the sight draft, but when presented by the bank to the consignee the draft is accepted by the consignee who in return receives the bill of lading. When accepting a time draft the word "accepted" is written across the face of the draft and signed by an officer of the firm accepting the draft. The banker who holds the draft will present it to she consignee for collection the day it becomes due. 
FORM XXVII-A

\section{A Bank Draft}

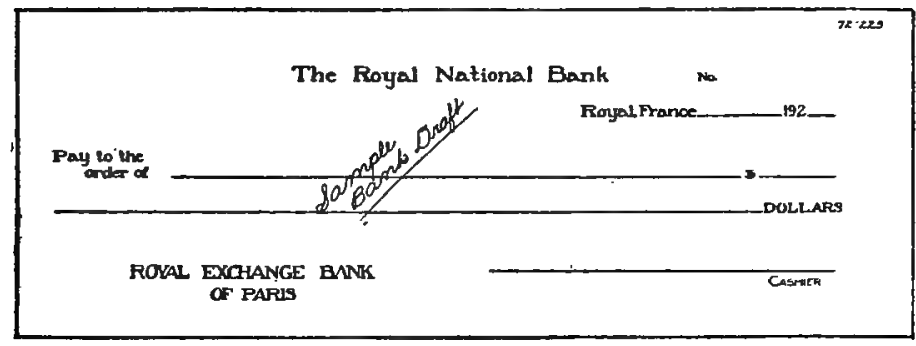

FORM XXVIII

\section{Sight Drafts}
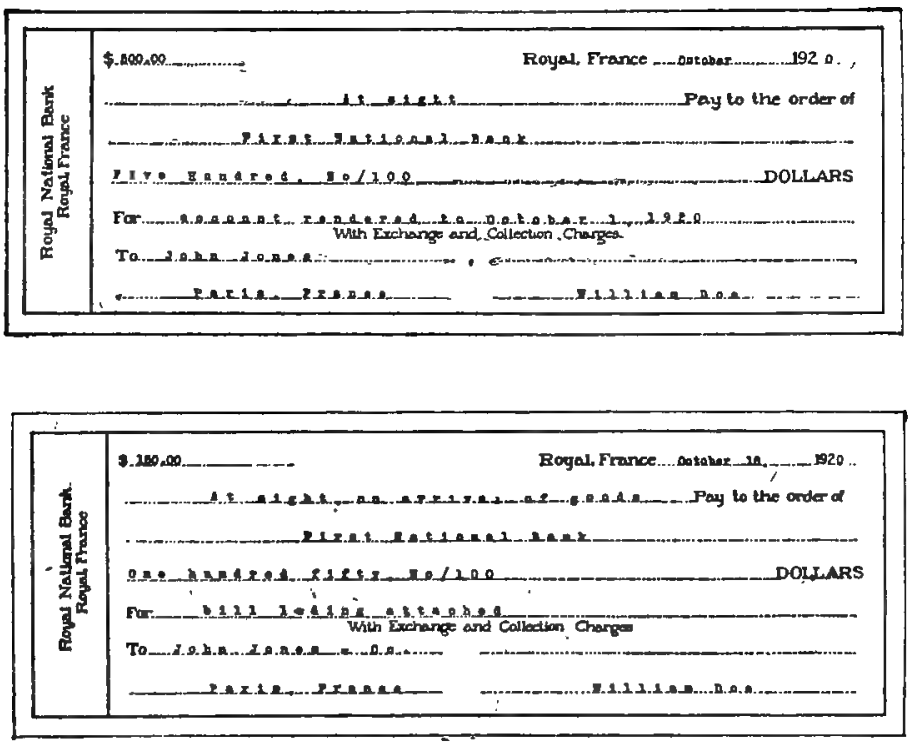
FORM XXIX

A Time Dratt

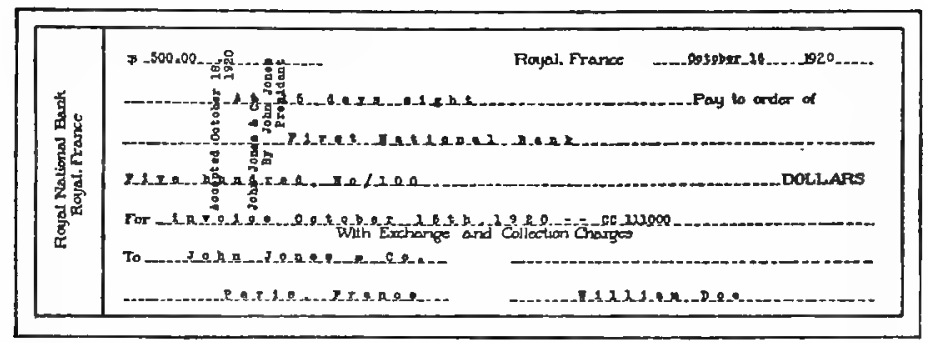

There are four kinds of drafts - "bank drafts," " on demand drafts," "sight drafts," and "time drafts." A "bank draft" is drawn by one bank on another. An "on demand draft" is drawn on one person by another and is payable as soon as presented. A "sight draft" is drawn on one person by another; in some states it is payable immediately upon presentation, and thus becomes an "on demand draft," but in other states it becomes payable three days after it has been accepted by the person on whom it is drawn. We speak of one, two, three, four, or five day sight drafts; then one, two, three, four, or five days respectively will be added to the three days of grace. If it is written for more than five days it is considered to be a time draft. The first three kinds of drafts are considered by the bookkeeper as belonging to the cash account, whereas the time drafts are considered as bills receivable or bills payable.

VII. Shipping Goods C. O. D. - The C. O. D. (Cash on Delivery) system is made use of for smaller shipments, such as when cream or butter is shipped to firms to which credit is not extended. By this system the transportation company makes collection for the shipper before goods are delivered and the shipper will either receive the money or have the goods returned. 


\section{CHAPTER XXIV \\ CREAMERY BOOKKEEPING ।}

\section{A. DEFINITION AND GENERAL INFORMATION}

BOOKKEEPING is the science of making a systematic record of business transactions. By a business transaction is understood an exchange of values.

I. Systems of Bookkeeping. - The systems adopted by the various firms differ greatly so as to meet the needs of the various concerns. There are two general systems known in bookkeeping which include all; these are "Single Entry" and Double Entry Systems."

1. The Single Entry System. - By single entry is understood an entry to only one account. This may be a credit or a charge. Only personal accounts are affected by this system and the books will show no balance and consequently no profit or loss.

2. The Double Entry System. - By double entry is understood an entry that is made twice. If a credit is made to one account a corresponding debit is made to some other account. By this system the ledger is kept in balance perpetually.

II. The Ledger. - The ledger is conveniently divided into two parts: first, the general ledger; second, the debit ledger.

I. The general ledger is a book which contains a summary of all of a firm's business transactions. It shows its resources and liabilities.

1 It is suggested that students familiarize themselves with "Accounting Records for Country Creameries," by Nahstoll, Bulletin No. 559, U. S. Department of Agriculture. 
FORM XXX

DEBIT LFDGer

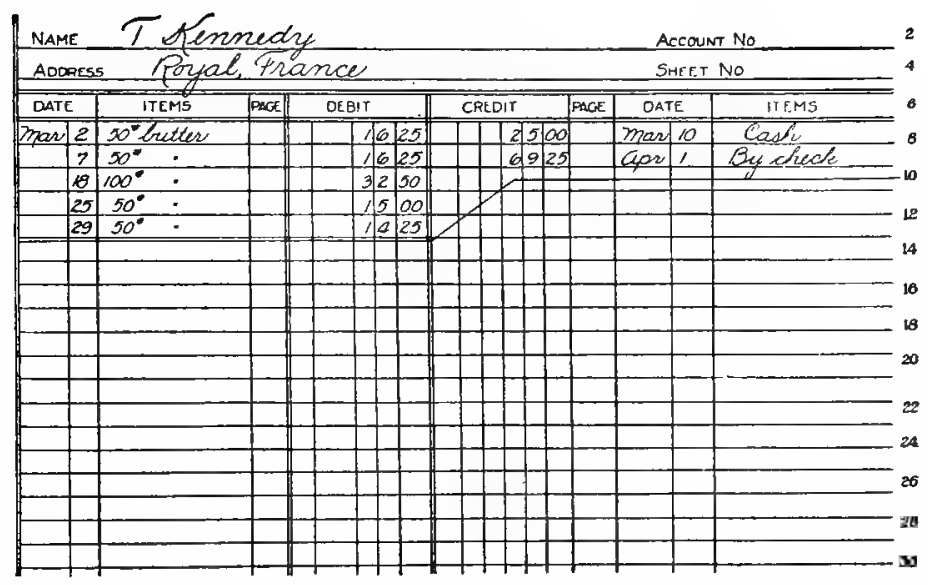

2. The debit ledger, also known as the dealer's ledger, deals with personal accounts; it contains all accounts with the firm's customers.

The left-hand side of the ledger is known as the debit and the right-hand side as the credit side. The principal rules in posting to the ledger are first "debit what we receive" and second "credit what we give."

When the credit side of an account in a ledger is the greater, then the amount by which the credit exceeds the debit is either a liability or a gain. When the debit side of the ledger is greater, then the difference is a resource or a loss.

A personal account is an account with a person, firm, or corporation.

A resource is anything of value belonging to the firm. A liability is anything that is owed, such as a personal account, bills payable, notes payable, etc.

III. The Cashbook. - The cashbook is a book in which is recorded a detailed record of all cash transactions. The left- 


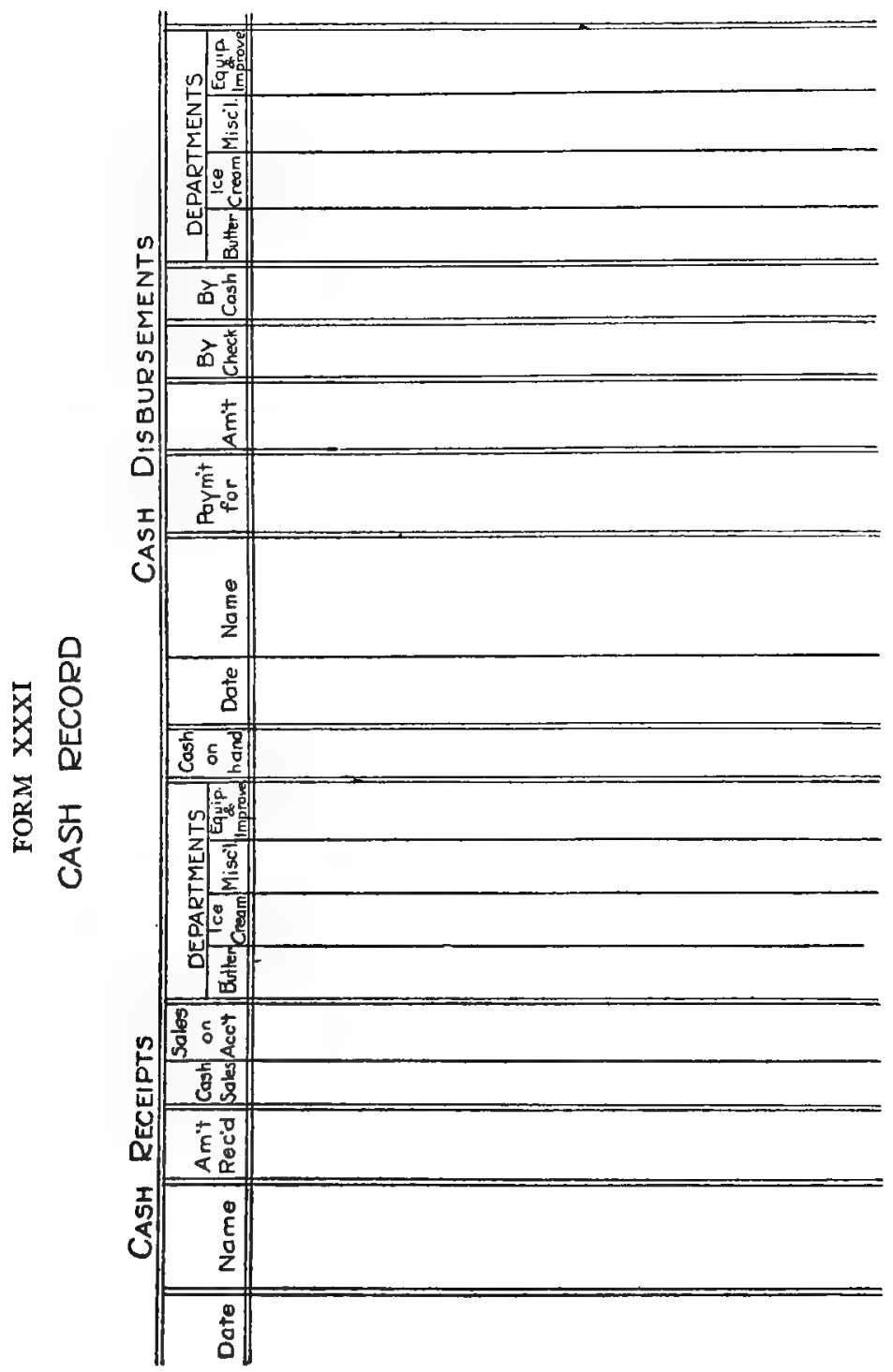


hand side of the cashbook is the debit side on which is recorded cash received. The right-hand side is the credit side on which is recorded cash paid out. All receipts and disbursements may be entered in detail in the cashbook; however, that system may not be practical to the average creamery. A complete record should be made in detail of all receipts. Cash sales for the day may be entered as one item. By adhering to the system outlined in the following it becomes possible to materially reduce the number of entries to be made in the cashbook.

A petty cash record may conveniently be kept in many dairy establishments where small sums of money are paid out daily in the form of cash. By that system a check should be drawn crediting cash and debiting petty cash.

IV. The Check Register. - The check register is a record of all checks issued. Checks should be drawn for all money paid out, and the check register should therefore check with the purchase record. No itemized record needs to be made of the milk and cream pay roll, but one entry should be made daily of the total amount paid for milk and cream. The check register should also at all times show the bank balance. The stub of the check book may be satisfactorily used, thus eliminating a special form of check register.

\section{B. RECORD OF PURCHASES}

I. Milk and Cream Purchases. - Milk received at a whole milk creamery is recorded on a blank known as "the milk receiving record." It is not transferred to any other form of record before payment is made, when it may be transferred to the general purchase record as one single item of milk purchased for the period. Creameries receiving cream are forced to keep more detailed records as each separate lot of cream is tested and the butter fat calculated. Cream collected on routes may be recorded on a driver's report blank (Form IX, p. II8). The entire load of cream collected by a driver is at the creamery recorded on the daily cream receiving record (Form VIII, p. II3), and a special route checking record (Form 


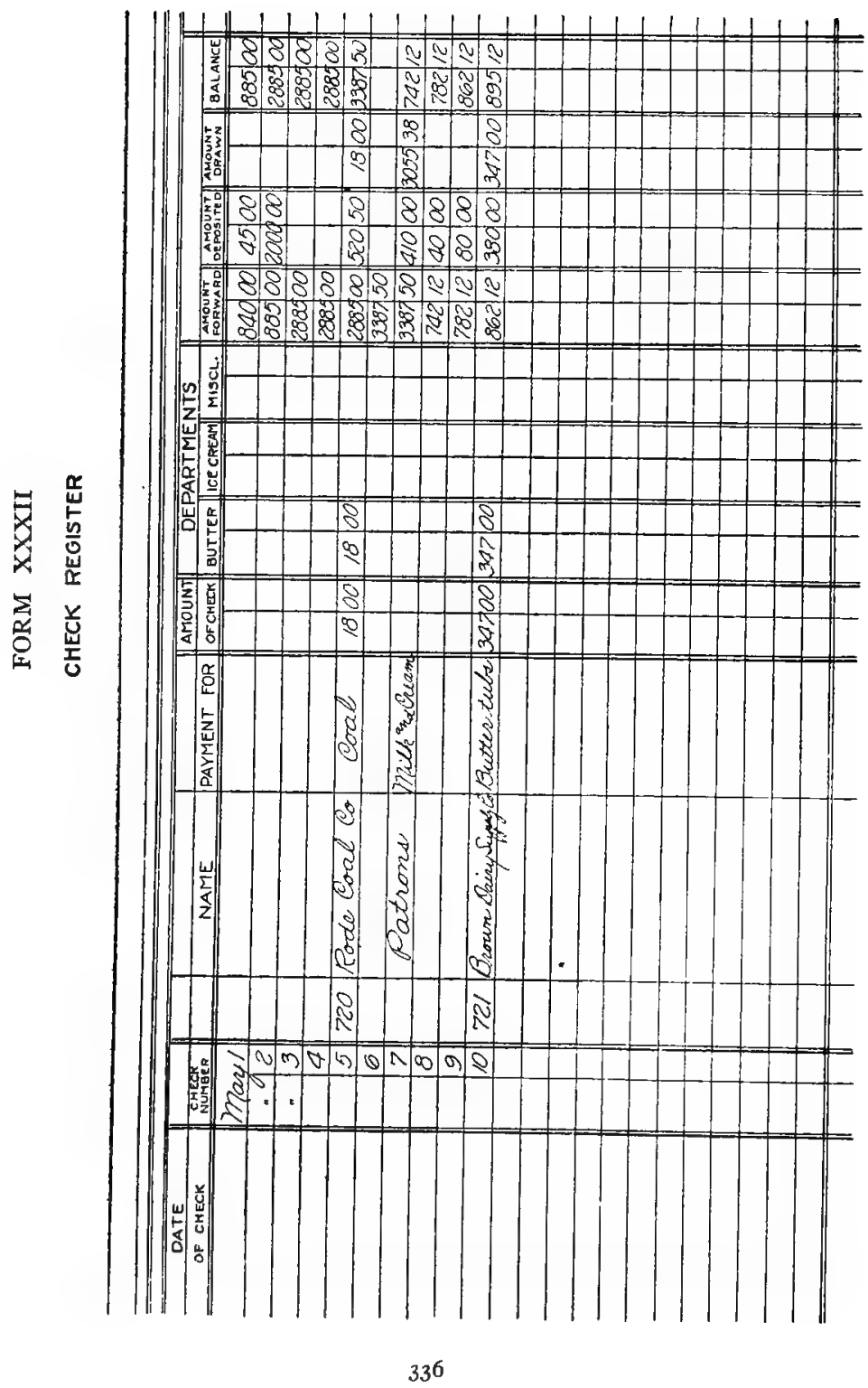


$\mathrm{X}$, p. IIg), is kept of losses or gains sustained from each route operated.

The accounts of the individual patrons are daily transferred from the cream receiving record and from the driver's reports to the patrons' statements. These are often attached to the check blanks and are filed alphabetically in a loose-leaf binder. When time for making remittance, the statement with check properly made out is delivered to the patron. A duplicate (a plain sheet of cheap paper may be used for this purpose) is kept for reference and filed alphabetically and divided numerically in accordance with date of payment.

FORM XXXIII

\section{Patrons Statement and Check}

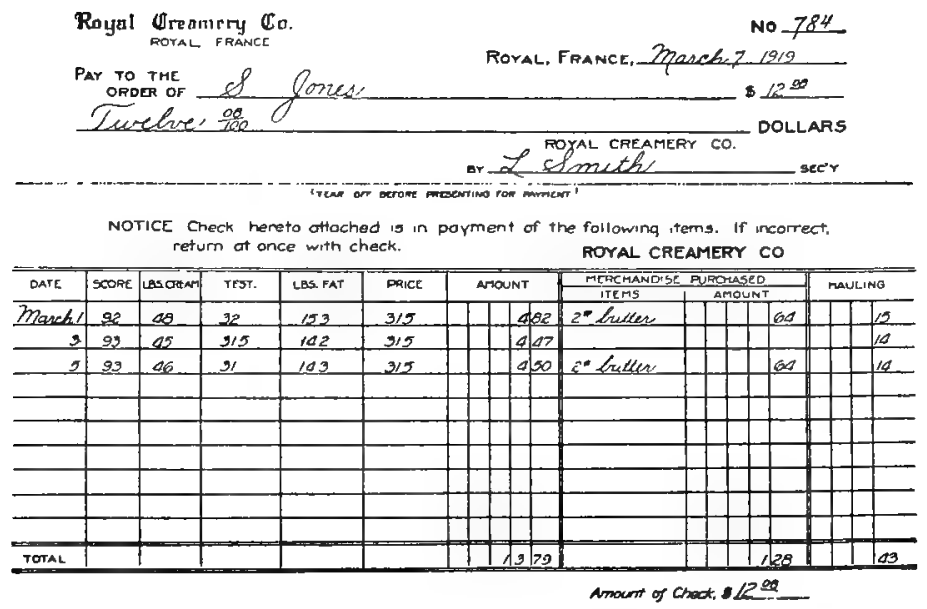

Labor is saved by having statement and check attached, as it becomes necessary to write the name of a patron only once, whereas, if separate, the name should be on the statement, on the check, and on the check register. Furthermore it should be noted on the check register the item for which the check was 


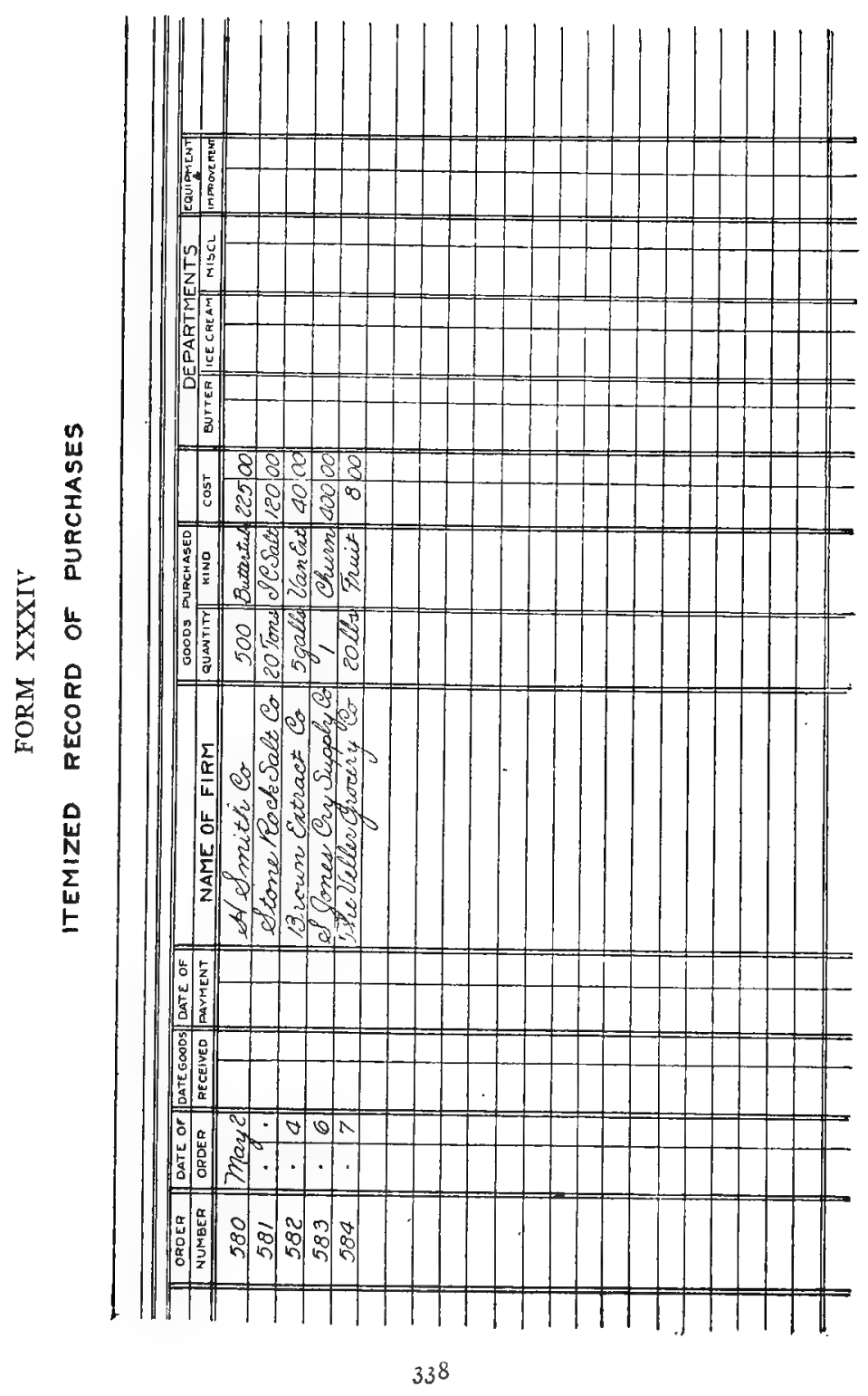


issued. That information is by this system contained on the duplicate.

As will be noted, the statement (Form XXXIII) also answers the purpose of a patron's ledger, and the bookkeeping is thus materially facilitated and it assures prompt payment for merchandise purchased by the creamery patrons.

II. Forms of Purchase Records. - The purchase record may for the sake of convenience be divided into two forms, one containing an itemized record of purchases and the other a summary of daily purchases.

An itemized record of purchases is kept so the one who is in charge of purchases may be enabled to know when orders for goods were placed, when such goods were received, and when paid for. Such a record is convenient to refer to at various times and particularly when closing the books at the end of each month. A glance at this report will give information as to whether the goods inventoried at the close of the month have been paid for.

The monthly purchase record furnishes a record of all purchases made during the month including all items which have been paid, such as labor, insurance, interest, depreciation, etc.

Entries may be made on the monthly purchase record whenever payments are made, or not later than the last day of the month for all goods, labor, etc., received during the month.

III. Record of Depreciation. - Depreciation and similar items, the amounts of which are paid back to the firm, may be treated the same as any account payable and a check issued, payable to the firm by which issed. This amount, as in case of depreciation, is credited to the plant and equipment account and charged against the expense accounts of the departments. The advantage in issuing a check for the amount is that the amount of checks issued should equal the total amount of the purchase record.

The general ledger should always contain a complete record of depreciations. Consider, for example, the equipment account; the cost of the equipment should be entered on the debit 
$34^{\circ}$ MANAGEMENT OF DAIRY PLANTS

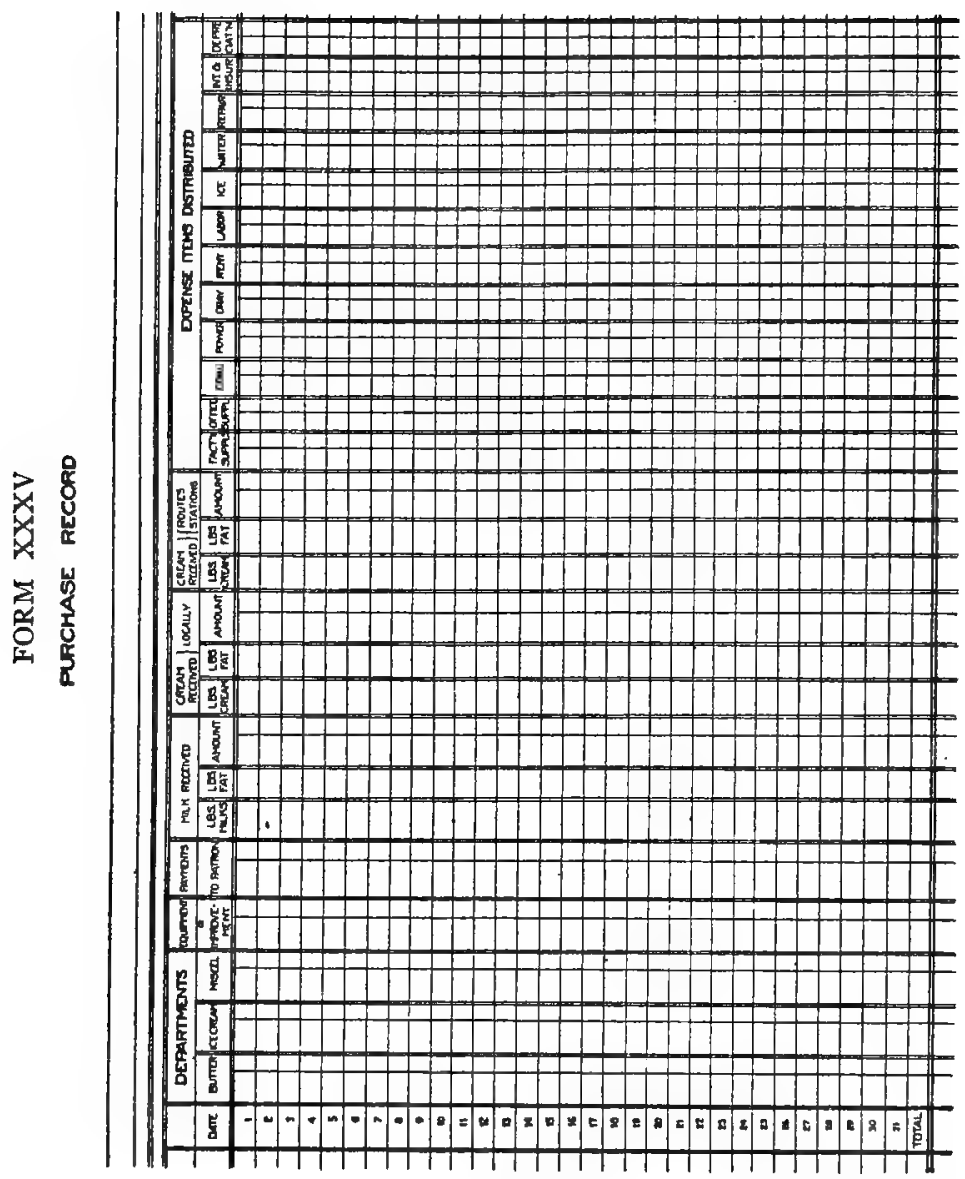


side of the ledger while the amount depreciated is entered on the credit side. Suppose the value of the equipment January Ist is $\$ 3, \infty 0$ and that a depreciation of $\$ 50$ per month is allowed; then the equipment will at the close of the year show a value of $\$ 2,400$, provided no new equipment was added during the year. If equipment to the amount of $\$ 300$ was added, then the equipment account will show a value of $\$ 2,700$. The amount depreciated should represent the actual loss due to wear, breakage, etc.

A creamery operating routes with its own teams and wagons should keep a similar ledger account of the horses, wagons, and harness. If several departments are operated by the same creamery, such as ice cream, butter, and cheese departments, then a separate ledger account should be kept of the equipment for each separate department. If the creamery owns its own building, a building account should be carried, etc. The object is that the record should always be complete enough so that the management at all times will have a correct idea of the assets and liabilities of the enterprise.

\section{RECORD OF SALES}

A complete monthly record should be kept of all sales. Such record should be complete enough to furnish information about cash and credit sales, sales to patrons, and consignments.

I. Cash Sales. - Such are sales for which cash is received upon the delivery of the goods. The only record necessary to keep of such sales is the original sales ticket (Form XXI, p. 239) and a total of the day's cash sales is recorded on the sales record.

II. Credit Sales. - Credit sales are recorded on the same forms as cash sales; in addition thereto an entry of each personal credit sale is made to the debit ledger (Form XXX). After the daily entries have been made to the debit ledger the sum of the entries for the day should be taken and should check with the total credit sales as recorded on the sales record.

III. Sales to Patrons. - Although these are credit sales they are recorded separately as, instead of being entered on the debit 
ledger, they are entered on Form XXXIII and remittance for such sales are made when the amount is being deducted from amount due the patron for milk or cream. A ticket such as Form XXIV is usually presented for such sales instead of the general sales ticket.

IV. Consignments. - Goods disposed of on consignment may cause some confusion as the remittance is made later and there is usually some shrinkage in weight from the time the butter leaves the creamery until it is sold. The price is also likely to change. The writer has found it most satisfactory to make a sales ticket for such shipment the same as for butter sold locally, figuring actual weight the day of shipping and calculating the value on the same basis as that of butter sold to local merchants. This entry is made on the sales record. Another entry is made thereon when remittance has been received. This record is of value to the creamery, also for the reason that if the creamery is losing too much on butter sold on commission, it may be advisable to establish local markets for the entire output.

\section{RECORD OF INVENTORY}

I. Monthly Record of Inventory. - If the monthly sales constitute the sales of the product manufactured from the monthly receipts of raw material, no more nor less, and if the material on the purchase record includes such purchases as are made only for the month's business, then the difference between the total monthly sales as recorded on the sales record and the total monthly purchases as recorded on the purchase record equals profit or loss. This method, however, is impracticable in business and therefore it will be necessary to consider the monthly inventory when making out a report of monthly profit and loss.

The monthly record of inventory is furthermore of value for the following reasons:

I. For determining the amount of supplies used during the month.

2. As a guide for placing orders for supplies. 


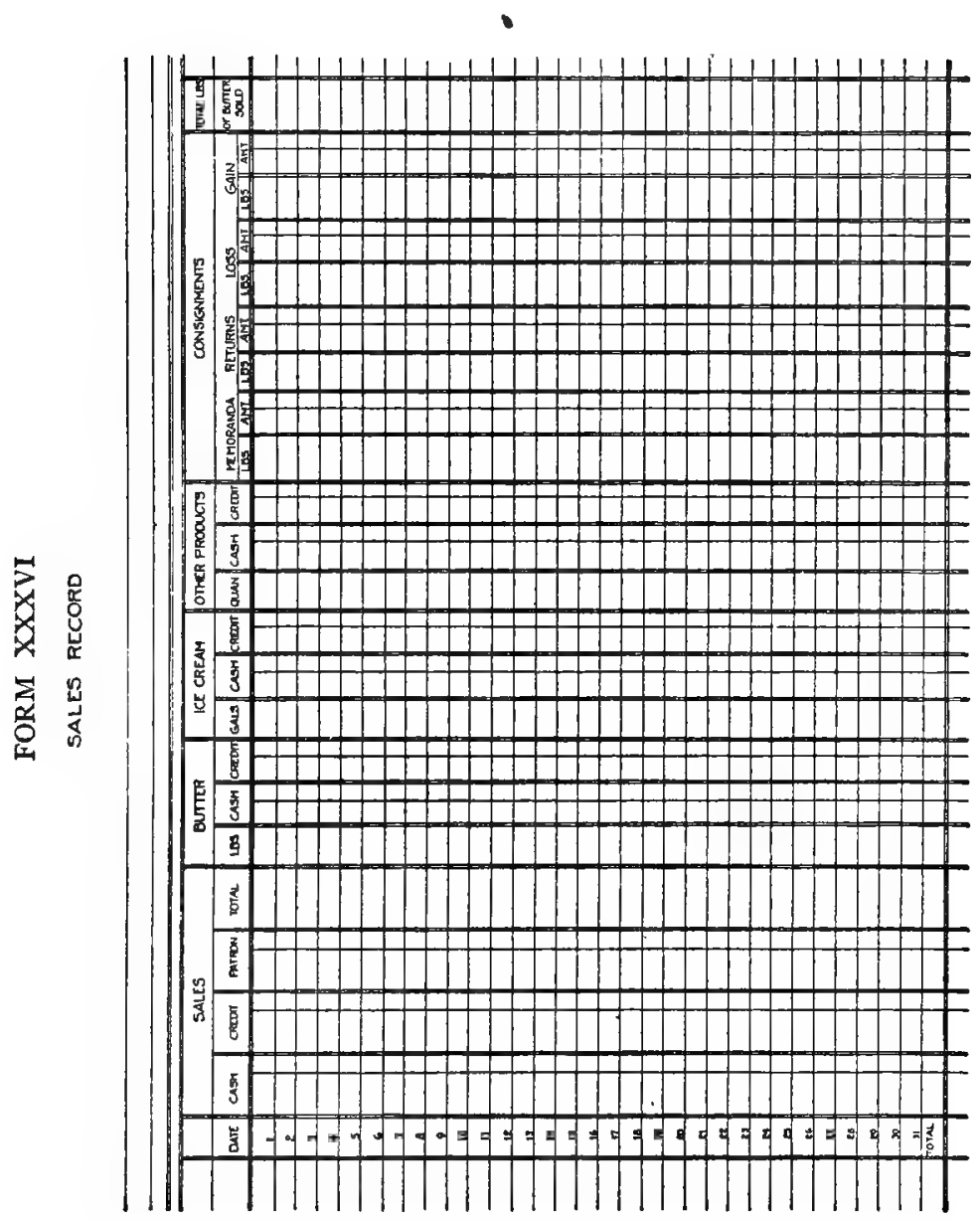


3. As a record in case of fire loss.

4. As a check record on waste of supplies.

FORM XXXVII

BUTTER DEPARTMENT

INVENTORY - MONTH OF MAY

\begin{tabular}{|c|c|c|c|c|c|c|}
\hline \multirow{2}{*}{ I lem } & \multicolumn{2}{|c|}{ On hand May $I$} & \multicolumn{2}{|c|}{ Purchased } & \multicolumn{2}{|c|}{ On hand $J$ une $I$} \\
\hline & A mount & Value & A mount & Value & A mount & Value \\
\hline $\begin{array}{l}\text { Butter tul } \\
\text { Butter bo } \\
\text { Tub liners }\end{array}$ & $\begin{array}{r}152 \\
20\end{array}$ & $\begin{array}{r}76.00 \\
5.60\end{array}$ & $\begin{array}{l}300 \\
200\end{array}$ & $\begin{array}{r}150.00 \\
56.00\end{array}$ & $\begin{array}{l}147 \\
152\end{array}$ & $\begin{array}{l}73.50 \\
42.56\end{array}$ \\
\hline Box & $\begin{array}{l}200 \\
150\end{array}$ & $\begin{array}{r}11.20 \\
1.50\end{array}$ & $\begin{array}{r}1,000 \\
400\end{array}$ & $\begin{array}{r}56.00 \\
4.00\end{array}$ & $\begin{array}{l}920 \\
450\end{array}$ & $\begin{array}{r}51.52 \\
4.50\end{array}$ \\
\hline Butte & 1,000 & 1.56 & 10,000 & 15.60 & 6,500 & 10.14 \\
\hline Butter colo & 10 gals. & 40.00 & & & $73 / 4$ pals. & 1.00 \\
\hline $\begin{array}{l}\text { Salt... } \\
\text { Thermo }\end{array}$ & 24 bbls. & $\begin{array}{l}16.00 \\
24.00\end{array}$ & 10 bbls. & 40.00 & $21^{81 / 2}$ bhls. & $\begin{array}{l}34.00 \\
21.00\end{array}$ \\
\hline Can bru & & 2.00 & 12 & 6.00 & 12 & 6.00 \\
\hline $\begin{array}{l}\text { Floor_brus\} } \\
\text { Acid_... }\end{array}$ & 1 & $\begin{array}{r}.65 \\
1.20\end{array}$ & ${ }_{5}^{6}$ gals. & $\begin{array}{l}3.90 \\
3.00\end{array}$ & $\mathbf{5}$ & $\begin{array}{l}325 \\
0.60\end{array}$ \\
\hline Separat & $61 / 2$ gals. & 6.50 & & & $21 / 2$ & 2.50 \\
\hline Engin & 4 gals. & 1.80 & & & $41 / 2$ gals. & 2.02 \\
\hline $\begin{array}{l}\text { Tub tir } \\
\text { Washin }\end{array}$ & 1,000 & $\begin{array}{r}2.50 \\
70.00\end{array}$ & 5,000 & 12.50 & 4,750 & $\begin{array}{l}11.87 \\
49.00\end{array}$ \\
\hline & & & & & & \\
\hline Total & & 260.51 & & 347 & & 343.46 \\
\hline $\begin{array}{l}\text { Coal on } \\
\text { Butter or }\end{array}$ & $\begin{array}{l}11 / 2 \text { tons } \\
4,078 \mathrm{lbs} .\end{array}$ & $\begin{array}{r}6.00 \\
2,854.60\end{array}$ & 18 & & $47,121^{6}$ lbs. & $\begin{array}{r}24.00 \\
2,827.20\end{array}$ \\
\hline Cota & & 2860 & & & & \\
\hline
\end{tabular}

The manufactured products, such as butter and ice cream, may or may not be included on the monthly record of inventory, but if not included then record of such products should be found on a daily inventory record.

II. Daily Record of Inventory. - This record is primarily of value for checking the stock of manufactured goods as well as stock of raw material on hand. Such reports should be available for the manager daily and may be in form of a card as Forms XXXVIII and XXXIX, or on a large record sheet combined with a daily manufacturing report as Form $\mathrm{XL}$. 


\begin{tabular}{l|l|l|l|l|l|l|l} 
& \multicolumn{7}{c}{ FORM XXXVIII } \\
& \multicolumn{7}{c}{ STOCK RECORO } \\
\hline & Butter & Misc Butter & Croom & Milk & Chose & lee Chear & Miscl. \\
\hline Inventory & & & & & & & \\
\hline Monufoctured & & & & & & & \\
\hline Received & & & & & & & \\
\hline Goins & & & & & & & \\
\hline Tronsferred & & & & & & & \\
\hline Totol & & & & & & & \\
\hline Tronsferred & & & & & & & \\
\hline Sold & & & & & & & \\
\hline Loss & & & & & & & \\
\hline Inventor & & & & & & & \\
\hline & & & & & & & \\
\hline & & & & & & & \\
\hline & & & & & & & \\
\hline
\end{tabular}

Form XXXVIII is a general form which may be used for the entire stock in the various departments while Form XXXIX is a department inventory record; the latter containing a record of the manufactured product as well as of milk and cream handled for the manufacture of ice cream.

The inventory recorded as last item on Form XXXVIII is the inventory taken of the goods in the stock room. If this inventory does not tally with the theoretical inventory then there is a gain or a loss in the stock on hand and such gain or loss is recorded on report.

\section{E. PROFIT AND LOSS}

I. Monthly Report. - The creamery business is of such a nature that it is difficult to estimate profit or loss daily; the prices are changeable, so is the margin of profit, operating expenses, losses, etc. Therefore a complete report of profit or loss should be available monthly. Larger plants are even known to estimate the profit or loss for the month at the beginning of the month. This estimate is then at the close of the month checked against the monthly report. An estimate is readily prepared of 


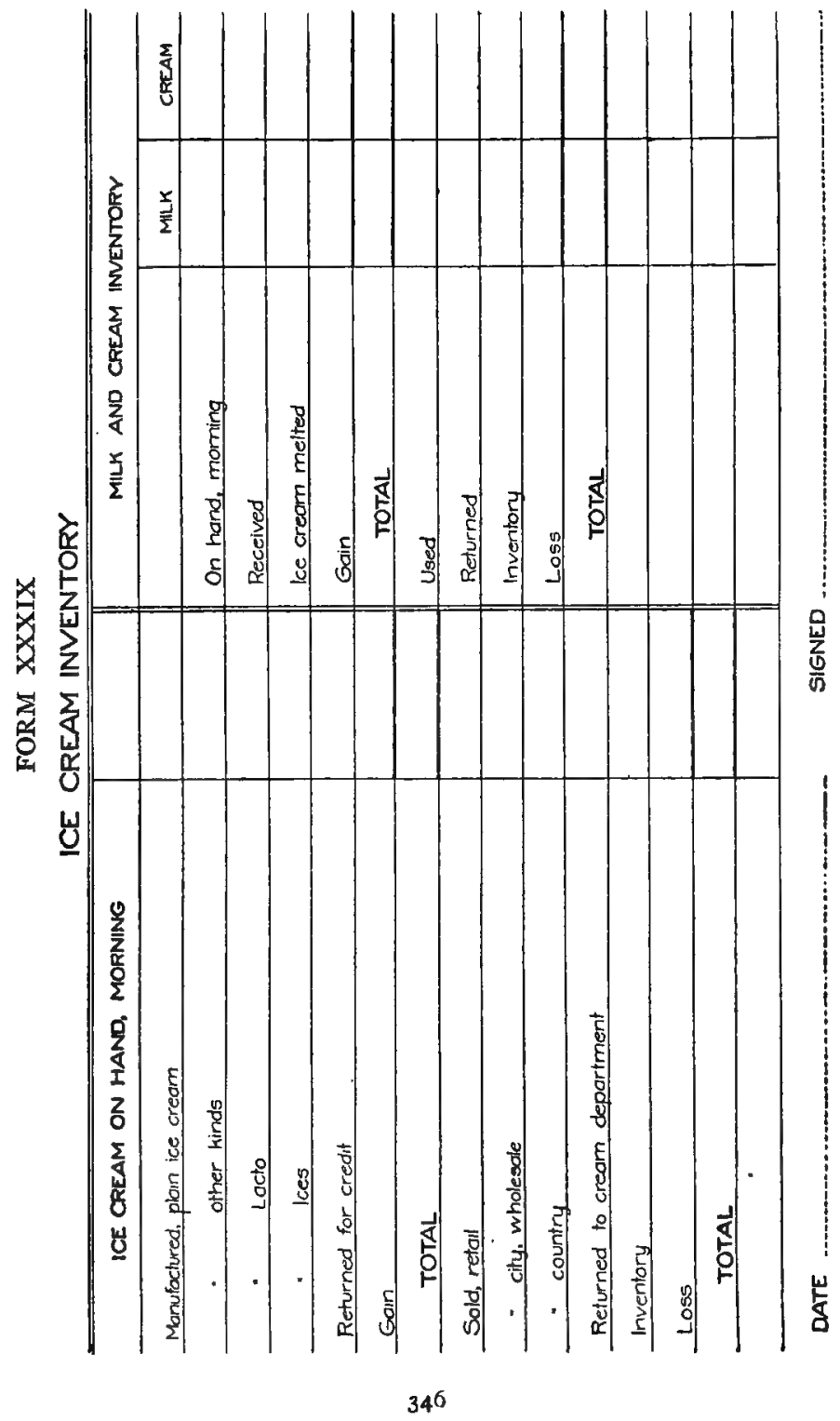




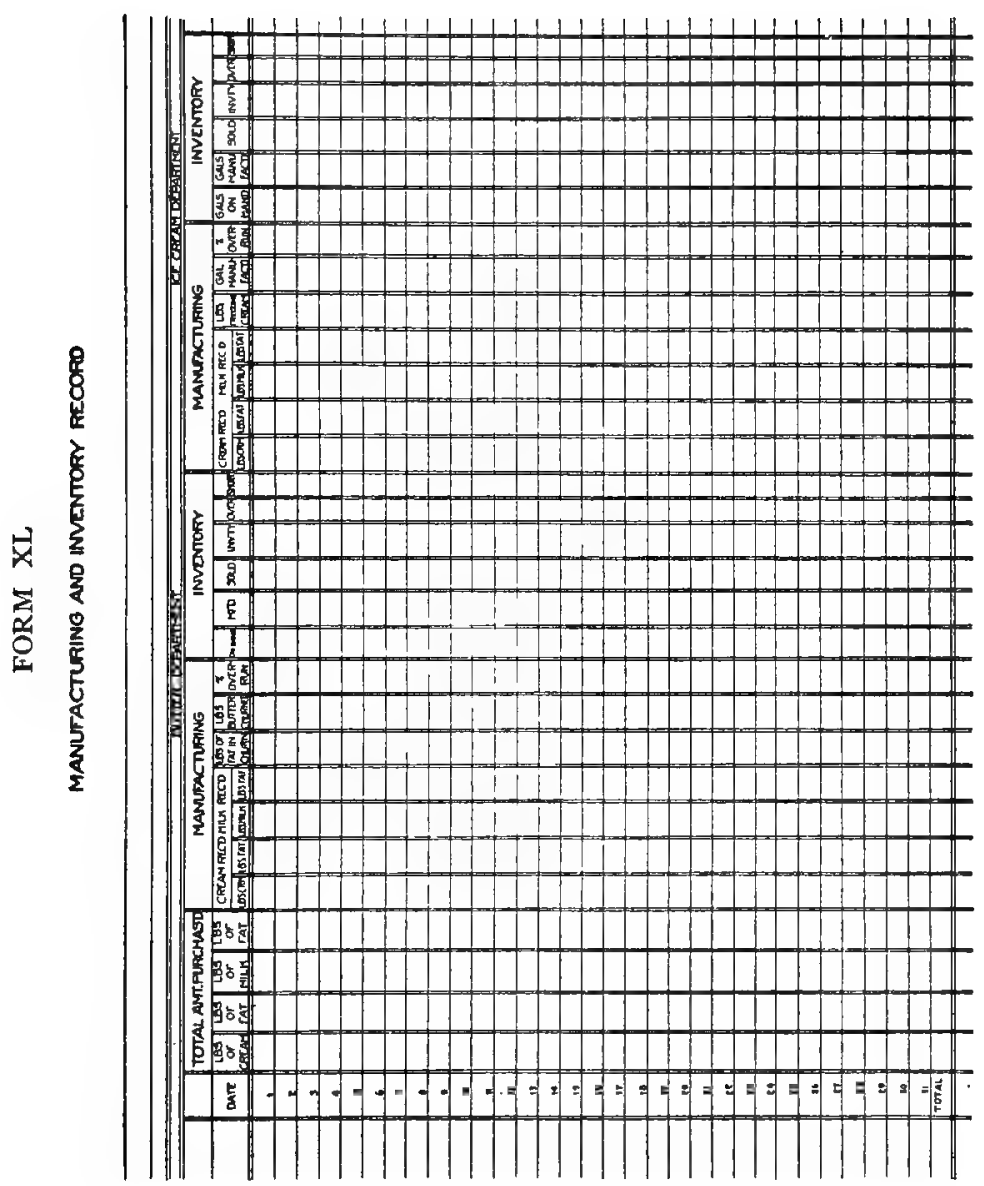


the coming month's business by comparing expenses, output, etc., with that of the corresponding month of previous years. This is a valuable method for guarding against losses, and it is known that large companies have made good returns by adopting this system.

Records from which the figures are obtained for the profit and loss report are the purchase record, the sales record, and the monthly inventory record.

$$
\begin{gathered}
\text { FORM XLI } \\
\text { Statement of Profit and Loss for May } \\
\text { Bulter }
\end{gathered}
$$

Butter sales, 18,718 lbs . . . . . . . . . . . .\$1 1,979.52

Buttermilk sales. . . . . . . . . . . . . . . 4 I..

Steam sold to ice cream department. . . . . . . . 20.00

Butter on hand, June Ist, 4,7 2 lbs......... 2,827.20

Coal on hand . . . . . . . . $24.0 \ldots \ldots \ldots \ldots \ldots$

Factory supplies on hand. . . . . . . . . 343.46

Office supplies on hand . . . . $24.5^{\circ}$

Dr.

$\$$ I $5,259.68$

Butter on hand, May rst, 4,078 lbs. . . . . . . . \$ 2,854.60

Coal on hand, " $" \ldots \ldots \ldots \ldots \ldots \ldots \ldots \ldots .6 . \infty$

Factory supplies on hand, May ist. . . . . . 260.51

Office supplies on hand " $" \ldots \ldots \ldots \ldots \ldots$ I8.00

Milk and cream purchased . . . . . . . . . . . . II,I95.14

Factory supplies purchased . . . . . . . . . 347.00

Office " $"$ " $\ldots \ldots \ldots \ldots \ldots \ldots \ldots$ I0.

Coal purchased . . . . . . . . $7 \ldots \ldots \ldots \ldots \ldots$

Power $" \ldots \ldots \ldots \ldots \ldots \ldots \ldots \ldots \ldots \ldots \ldots$

Drayage . . . . . . . . . $\ldots \ldots \ldots \ldots \ldots \ldots \ldots . \ldots \ldots$

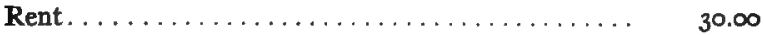

Labor . . . . . . . . . . . . . . . . . . . $\quad 200.00$

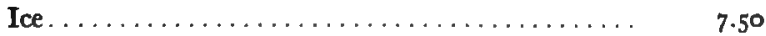

Repairs. . . . . . . . . . . . . . . . . . $\quad$ I5.00

Interest and insurance. . . . . . . .

Depreciation..................... 30.00

Loss on consignments. . . . . . . . . . . . . 46.48

Profit for May . .................... II 2.95 
FORM XLII

\section{Ice Cream}

\begin{tabular}{|c|c|c|}
\hline & $C r$. & . \\
\hline$\ldots \ldots \ldots \ldots \ldots \ldots$ & $2,421 . \infty$ & \\
\hline Ice cream on hand, June ist $\ldots \ldots \ldots \ldots \ldots$ & 108.00 & \\
\hline Milk and cream on hand, June ist........... & $85 . \infty 0$ & \\
\hline upplies on hand, June ist. . . . . . . . . . . . & $260 . \infty 0$ & \\
\hline & Dr. & \\
\hline Ice cream on hand, May Ist $\ldots \ldots \ldots \ldots \ldots \ldots \$$ & 63.00 & \\
\hline Milk and cream on hand, May Ist............ & 76.00 & \\
\hline Supplies on hand, May Ist. . ............... & 40.76 & \\
\hline Milk and cream purchased. . . . . . . . . . . . & I,619.80 & \\
\hline Factory supplies purchased $\ldots \ldots \ldots \ldots \ldots \ldots$ & 284.24 & \\
\hline 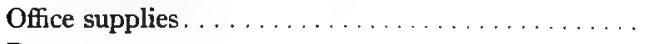 & $15 . \infty$ & \\
\hline Power . . . . . . . . . . . . . . . . . . & $10 . \infty 0$ & \\
\hline Drayage . . . . . . & 60.00 & \\
\hline 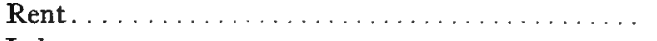 & 15.00 & \\
\hline Labor. . . . . . . . . . & 150.00 & \\
\hline Ice. $\ldots \ldots \ldots \ldots \ldots \ldots \ldots \ldots \ldots$ & IOI.20 & \\
\hline Repairs. . & $10 . \infty 0$ & \\
\hline Insurance and interest. $\ldots \ldots \ldots \ldots \ldots \ldots \ldots$ & 10.20 & \\
\hline Depreciation...$\ldots \ldots \ldots \ldots \ldots \ldots \ldots \ldots \ldots$ & 25.00 & \\
\hline Steam from butter department $\ldots \ldots \ldots \ldots \ldots \ldots$ & $20 . \infty 0$ & \\
\hline Profit for May $\ldots \ldots \ldots \ldots \ldots \ldots \ldots$ & 373.80 & \\
\hline
\end{tabular}

The total monthly profit or loss should be entered in the general ledger, which will serve as a permanent record. A separate ledger leaf is used for each year. The monthly profit and loss report, the same as other important records, should be filed so it may be available for future reference. For this purpose a loose-leaf binder is most satisfactory.

II. Financial Statement. - The financial statement is a summary of the firm's resources and liabilities and as such it shows the financial condition of the firm. The monthly statement of profit and loss should be checked against the financial statement. The monthly statement may be considered correct 
if the resources of the firm show an increase above the liabilities equal to the monthly profit.

\section{FORM XLIII}

\section{Financial Statement June ist}

\section{Resources}

Plant and equipment. . . . . . . . . . . . . \$15,1 20.00

Butter on hand . . . . . . . . . . . . . . . . . 2,827.20

Ice cream on hand .................... 108.00

Milk and cream on hand .................. 85.00

Coal on hand ....................... $\quad 24.00$

Supplies on hand, butter department......... $\quad 367.96$

" " " ice cream " ......... 260.00

Accounts receivable. . . . . . . . . . . . . . 3,295.02

Bank balance...................... $\quad 669.77$

Money on hand in office............... $\quad 52.15$

$-\$ 22,855.60$

\section{Liabilities}

Capital stock. .......................\$15,000.00

Due patrons for milk and cream........... 660.50

Bills payable...................... $\quad 370.67$

Notes payable................... $5,000.00$

Undivided profit previous to May ............ 1,29г.20

Profit for May....................... $\quad 486.75$

At the close of the year, plant, fixtures, etc., should be revalued, uncollectible accounts and notes should be charged off, and the new year should be begun with figures representing the actual value of the resources. 


\section{INDEX}

Absorption refrigeration, 8I

Acidity of cream, ror, 210

Active custumers, 233, 237

Active patrons, I06

Advertising, 26, 28I

advertising manager, 294

appropriation for advertising, $29 \mathrm{I}$

booklets, 298

circular latters, 297

creamery, 299

essentials, 287,301

exhibits, 299

mailing cards, 297

medium for advertising, 294

newspapers and magazines, 294

novelties, 298

planning and writing, 293, 299, 306

"policy" advertising, 286

programs, 299

purposes of advertising, 282

scrapbook, 306

signs and billboards, 296

street railway cards, 297

tools of advertising, 302

Aging creams, 220

Air lift, $\mathrm{x} 6 \mathrm{r}$

Ammonia, 68, 69, 78

Ammonia condenser, $70,76,78$ atmospheric condenser, 78 double-pipe condenser, 78

Ammonia compressor, 70, 72 double acting, 75,76 single acting, 75
Application blank, 84, 85

Articles of incorporation, 14, 19

Artificial cream, 209

Artificial extracts, 214

Asphalt, 28, 30

Australian butter box, 274

Bacteria in cream, $21 \mathrm{I}$

Bacteria in ice cream, 218

Bad accounts, 26I

Bank draft, 329, 33I

Banking facilities, 6

Bell trap, 4I

Berries, 215

Bills, 127

Bill boards, 296

Blackberries, 215

Boiler, I38, I57, I64

Boiler losses, I34

Bonds, 9I, I66

Bookkeeping, 332

cashbook, 333

check register, 335

depreciation, 339

financial statement, $35^{\circ}$

inventory, 342

ledger, 332, 337, 339

patron's statement, 337

profit and loss, 345

purchase record, 335

sales record, 34I

systems, 332

Booklets, 298

Bottling cost, 260, 264 
Bourbon vanilla bean, 21 2

Bradley box, 275

Bradstreet agency, 320

Branded butter, 250

Brick, 3I, 33, 34, 53

Brine method of refrigeration, 70

Brine table, 72, 73

British thermal unit, 50

Broker, 199, 235

Building, 5, 8, 33, 120, 164, 232, 299

chimney, 35

floor, 9

foundation, 31, 36

frame building, 3 I

location, 8, 9

painting, 37

roof, 36

ventilation, 38

walls, 9, 3I, 5I

windows, 9, 53

Butter, 236, 245, 250, 272

Butter barrel, 275

Butter box, 272

Butter fat, 170, 181, 185

Butter grades, 246, 249

Butter maker, 90, 93, 95

Butter printer, 278

Butter tins, 276

Butter tub, 273

Buying supplies, 123

contract, 125

cash discount, 126

By-laws, I6, I9

Cans, II2, II5, 164

Capital stock, 17, 19, 22

Carbonic acid, 68

Card records, 106, 237

Cash book, 333

Cash sales, 34I
Cash system, 103, 261

Catch basin, $4^{2}$

Cement, 30

Cement block, 3I, 34

Cement floor, 28

Certificate of stock, 18

Cesspool, 43

Checking routes, II7, 243

Check register, 335, 336

Checks, 103, 237

Cheese, 231, 236, 253

Cherries, 215, 217

Chimney, 35

Chocolate, 217

Chocolate sirup, 218

Cinders, 56

Circular letter, 238, 297, 317

City delivery, 256

Clearance, 80

Coal, 13I

Cocoa, $2 \mathrm{I} 7$

C. O. D. sales, $33 \mathrm{I}$

Collecting agencies, 328

Collections, 325,327

Collector, 327

Commercial agencies, 320

Commission merchants, 235

Commission sales, 235, 242, 342

Common stock, I 7

Competition, 4, 5

Composite samples, II 7, Igr

Composition of butter, 170

Condensed steam, 144

Conduction of heat, 50

Convection of heat, 49

Coolers, I48, 156

Cooling, 447

Cooling tank, 72

Cooling water, 148

Coöperative creamery, 5, 7, 18, 165 advantages, $2 \mathrm{I}$ 
Coöperative capital stock, I9 dividends, I9 membership, 20

Coöperative cream hauling, II4 Coöperative cream selling, I 22

Coöperative selling agency, 236

Copartnership, II dissolution, I3 formation, II liabilities, I 2 partners, 12

Cork, 56

Corporation, 14 advantages, 14 capital stock, I7 certificate of stock, 18 liabilities, I 7 officers, 16

Correspondence, 309, 327

body of letter, 313

filing, 318

form letter, 3I 7

parts of letter, $3 \mathrm{I} 2$

stationery, 309

Cost

advertising, 292, 294

bottling milk, 259, 264

buttermaking, 3, 198, 247

cooling, 147

delivery, 256, 260, 264, 266

electric power, I4I

fruit sirups, 216,217

gasoline for power, 140

homogenization, 209

ice, $8 \mathrm{r}, 223$

ice cream making, 203, 22I, 222

kerosene for power, $14 \mathrm{I}$

labor, 95, 96, 148, 20I, 222, 259, 269

lemon extract, 214
Cost of marketing butter, 199, 200 , 234,245

marketing cheese, 253

marketing ice cream, 254

marketing milk and cream, 258, $26 \mathrm{I}, 267$

mechanical refrigeration, 80

overhead expenses, 26I, 264

pasteurization, 143,149

power, 223

printing butter, 279

roofs, 36

routes, II4, 234

raw material, $203,258,265$

re-icing ice cream, 257

salt, 223

simple sirup, 218

shipping ice cream, 254

steam, I3I, I4O, I43

vanilla, 2 I 2

water, 158,162

Cream, 102, II6, 204, 210, 220,

234, $25^{8}$

Cream buyer, 122

Creamery construction, 24

Cream-receiving station, 5, I 20

Credit information, 320,323

Credit man, 3 I9

Credit men's ass'n, 32 I

Creditors, I3

Credit sales, 34I

Curd in butter, 180

Daily records, 107, 113, 202, 270

Danish firkin, 277

Day-wage, 92

Dead air space, 34, 54

Debts, I 2

Delinquent custumers, 326

Demonstrations, 299

Density of water, I45 
Depreciation, 164, 339

Direct expansion, 70

Directors, 16, 19, 90, 91, 236

Discontinued custumers, 237

Discontinued patrons, 106, 107

Distributing milk, 260, 264

Dividends, I7, 19, 22

Dormant partner, 12

Dosing chamber, 44, 46

Double acting compressor, 75,76

Double entry, 332

Drafts, 329

Dun Agency, 320

Earthern jars, 275

Electric power, 14I

Employees, 84, 90

Envelope, 310

Equipment, 123,148

Exclusive agency, 234

Exhaust steam, 135, I38

Exhibits, 299

Expansion coil, 70

Expansion valve, 70, 78

Factory school, 88

Feed water, I35

Feed water heater, 138

Filing, 106, т27, 318

Fillers for ice cream, 218

Filter bed, 44, 46

Financial statement, 322, 349

Fire brick, 35

Fire clay, 35

Firing, 138

Flavoring extracts, 2II

lemon, 213

orange, 214

vanilla, 2 I I

Flavors in cream, Ior

Floor plan, 9, 24
Floor, 28, 35, 60

asphalt, 30

cement, 28

plank, 30

stone and tile, 30

Follow-up system, I04

Food value of dairy products, 183

Foot pound, 134

Foundation, 31, 36

Freezing ice cream, 220

Friction head, I59

Fruit, 215

Fuel, I31, I32

Gasoline, I40

Gasoline engine, 140

Gelatin, 218

Gem fiber box, 275

Glymol, I94

Good will, 164,282

Grading cream, I00, 102

Gravity-brine refrigeration, 62

Half tone, 305

Hauler, 94, II 5, II 6

Hauler's report, II 8

Heat, 133

Hollow tile, 31, 33, 34

Homogenization, 208

Horse power, 134, 157

Ice, $62,64,81$, II 7

Ice bunker, 58

Ice cream, 203, 23I, 234, 254

Ice cream containers, 221

Ice cream freezers, 72

Ice house, 58, 60, 63, 64, 67

Ices, 214

Illustrations, 303, 305

Incorporators, 15

Ink, 310 
Insulated ice house, 60

Insulation, 49

construction, 54

material, 5I

piping, 140

Insurance, 165

employers' liability insurance, $\mathrm{I} 66$

fidelity insurance, 166

fire insurance, 166

Interest, 165

Inventory, I28, 342

Invoices, I 27, 240

Jobber, 199, 200, 235

Joint-stock co., 2I, I65

capital, 22

dividends, 22

stockholders, 23

Kerosene, I4I

Kerosene engine, I4I

Kilowatt, I4I

Labor, 84, 20I, 222

cost of labor for pasteurization, 148

day-wage, 92

distributing cost of labor, 96

hiring the employees, 84

non-productive labor, $92,96,97$

organization of labor, 89

piecework, 93

premium and percentage, 93

productive labor, 92, 95

prompt pay, 94

reducing cost of labor; 95

surety bond, 9 I

time keeping, 95

training the employee, 87

Latent heat of fusion, 5I

Latent heat of vaporization, 69
Laundry, I

Liabilities, 12, 13, 17, 333, 350

Lintels, 35

Lith, 58

Losses

bad accounts, 261

boiler, I34, I40

butter, I96, 243

butter fat, II 7, I8I, I85, I86, 195

butter milk, 185

equipment, 224

heat, I33, I34, 135

ice, 64,66

ice cream, 22I, 224

mechanical losses in butter making, 186,188

pasteurization, 152

power, I34

refrigeration, $54,64,80$

salt, 176

samples, 190

skim milk, I8I

surplus milk, 260

testing, I89, 192

waste at milk plant, 260

water, 159

weighing, 188, 190

Loyalty, 89

Magazines, 294

Mailing cards, 297

Manager, 10, 90, 9I, 229, 232, 236

Manufacturing costs, see "Costs."

Manufacturing records, 202, 222, 347

Maps, 104, 233

Marketing, 226, 23r commission sales, 235

coöperative selling agency, 236

local markets, 5, 232

municipal milk plant, 237 
Marketing records, 237

Mechanical losses of butter fat, 18 I, 195

Mechanical refrigeration, 68 absorption system, 8I compression system, 69

Mexican vanilla bean, $2 \mathrm{II}, 2 \mathrm{I} 3$

Milk, 23, 23I, 234, 236, 237, 258

Mineral wool, 56

Minor, I2

Moisture control, I76

Moisture in butter, I $7 \mathbf{I}$

Molding ice cream, 221

Mortar, 30

Motors, 142

Natural refrigeration, 58

Newspapers and advertising, 294

Nominal partner, 12

Nonproductive labor, 92, 96

Novelties, 298

Officers, 16,19

Oil trap, 138

Oleomargarine, 249

Orange extract, 214

Order clerk, 324

Originality in business, 87

Ostensible partner, 12

Overhead expenses, 258, 26r, 264

Overrun, I68

butter overrun, $168,183,186,195$

ice cream overrun, 204, 218

per cent overrun, 169,218

value of overrun, I 70

Package, 272, 288

Painting, 37 enamel paint, 37

priming, 37

Parafiner, 273
Pasteurization, 143, 210

cost, 149

flash method, I46, I49

holding method, $146, I_{50}$

Pasteurizers, I5O, 156

efficiency, 152

purchasing a pasteurizer, ${ }^{15} 6$

Patrons, 22, 103, 337

active, I06

discontinued, ro6

prospective, 106

Patron's sales ticket, 242, 34I

Patron's statement, 337

Peach, 2I5

Percentage system for labor, 93

Perpetual succession, 15

Piecework, 93

Pineapple, 215

Pine wood, 52

Piping for refrigerator, 72

Piston pump, I6I

Plastering, 35

"Policy" advertising, 286

Potassium chromate, 179

Power, I3I, 209

electric power, $14 \mathrm{r}$

gasoline power, 140

kerosene power, I4I

steam power, I3I, I4O

Preferred stock, 17

Premium system for labor, 93

Preparing butter tubs, 274

Print butter, 278, 280

Process butter, 249

Productive labor, 92, 95

Profit and loss report, 348

Programs, 299

Promotion, 282

Proprietary plant, 4, 5, 7

Prospective custumers, 233, 237

Prospective patrons, Io6 
Purrhase of milk and cream, Ioo, Roof, pitched roof, 37

335

coöperative cream selling, I 22

coöperative hauling, 114

cost, $25^{8}$

cream buyer, 122

cream route, I14, II9

cream station, 120

follow-up system, ro4

grading, 100

individual delivery, 108

records, 338

shipping, Io9

Quality, 100, 287

Quick assets, 5

Radiation of heat, 49

Railroad facilities, 8

Raspberry, 215

Raw material, 2, 21, 22, 203

Real estate, I6

Receiving record, 126

Refrigeration, 49

cost, 80

insulation, 49

mechanical refrigeration, 68

natural refrigeration, 58

Refrigerator, 59, 64

Refrigerator butter carrier, 273

Regenerator, 148

Rent, 163

Repairs, 165

Resources, 333, 35०

Retailer, 199, 200, 232, 247

Retail sales, 222, 223, 232, 247, 258, 264,265

Richness of cream, roz

Roof, 36

flat roof, 36

gravel roof, 36 prepared roofing, 36

tin roof, 36

Rotary pump, I6I

Routes, 105, II4

Route sheet, 244

Rural business, 7

Salesman, 226, 233, 286, 324

Salesmanship, 226

Sales record, 239, 34 I, 343

Sales ticket, 239, 24I 242

Salt control, I76

Salt in butter, 174

Salt test, $\mathrm{I} 78$

Sandstone, 53

Sanitation, 8

Sawdust, 54

Scales, 188

Score card for cream, roI

Seals, I6, I10

Septic tank, 8, 44

Sewage disposal, 40

catch basin, 42

cess pool, 43

septic tank, 44

sewer system, 40

sewer traps, 4I

Shavings, 54

Shipping cream, 109, I 2I

Shipping ice cream, 224, 254

Shipping-tags, I10, 225

Shrinkage in butter, 196

Sight draft, 6, 329

Signs, 296

Sills, 35

Silver nitrate, 178

Simple sirup, 217,218

Single acting compressor, 75

Single entry, 332

Sinking fund, 20 
Siphon trap, 42

Skim milk, I8I formula for fat loss, 182

Smoke bridging, 35

Solid-packed butter, 277

Special partner, I2

Specific heat, 65

Standardization of cream, 204

Statement, 24I

Stationery, 309

Station report, $\mathrm{r} 20$

Steam, I3I, I33, I43, I44

Steam engine, I40, I64

Stock clerk, I 28

Stockholders, 16, 17, 23

Stock record, 344, 345, 346

Storing butter, 199, 250, $25 \mathrm{I}$

Storing cream, 210

Storing fruit sirup, 215

Strawberry, 2I5, 216

Street-railway cards, 297

Sugar, 2 I I

Sulphuric dioxide, 68

Superintendent, 87, 90, 91

Supplies, I 23, I 27, I 28, 344

Surplus milk, 26I

Sweet butter, 175

Tahiti vanilla bean, 21 2, 213

Testing, 189

artificial extracts, 214

glassware, 189

reading tests, 192
Testing samples, Igo

Time draft, 329

Time keeping, 95

Trade-mark, 250, 283, 289, 290

Transferring correspondence, 318

Treasury stock, 18

Type, 303, 304

Unsalted butter, I 75

Vacancies, I6

Vanilla bean, 2I I

Vanilla extract, 2II preparation, 2I 2 standard, 2I 2

Ventilation, 38

Vestibule, 54

Walls, 9, 3I, 5I, 56, 57, 60

Waste, 260

Water, 158

Watered stock, 18

Water pumps, I60

air lift, $16 \mathrm{I}$

piston pump, I6I

rotary pump, $16 \mathrm{I}$

Wholesale milk, 264, 267

Windows, 9, 53, 62

Working capital, 5, 6

Wrapping butter, 279

Zinc etchings, 305 





